Portland State University

PDXScholar

Fall 11-20-2017

\title{
Analysis of the Acid-Base Balance of Mainstream Tobacco Smoke and its Effect on the Gas/Particle Partitioning of Nicotine
}

Amy Kathleen DeVita-McBride

Portland State University

Follow this and additional works at: https://pdxscholar.library.pdx.edu/open_access_etds

Part of the Chemistry Commons, and the Civil and Environmental Engineering Commons Let us know how access to this document benefits you.

Recommended Citation

DeVita-McBride, Amy Kathleen, "Analysis of the Acid-Base Balance of Mainstream Tobacco Smoke and its Effect on the Gas/Particle Partitioning of Nicotine" (2017). Dissertations and Theses. Paper 4156.

https://doi.org/10.15760/etd.6044

This Thesis is brought to you for free and open access. It has been accepted for inclusion in Dissertations and Theses by an authorized administrator of PDXScholar. Please contact us if we can make this document more accessible: pdxscholar@pdx.edu. 
Analysis of the Acid-Base Balance of Mainstream Tobacco Smoke and its Effect on the Gas/Particle Partitioning of Nicotine

by

Amy Kathleen DeVita-McBride

A thesis submitted in partial fulfillment of the requirements for the degree of

\author{
Master of Science \\ in \\ Civil and Environmental Engineering
}

Thesis Committee:

James F. Pankow, Chair

William Fish

Wentai Luo

Portland State University

2017 


\begin{abstract}
Tobacco smoke particulate matter (PM) is a complex mixture of condensed organic compounds, with about 5 to $10 \%$ water. Its general properties are similar in some respects to that of atmospheric organic aerosol PM and thus provides a useful surrogate when studying atmospheric PM. Due to its ability to undergo acid-base chemistry, nicotine is of particular interest in the tobacco smoke system. The gas/particle partitioning of nicotine depends on the protonation state of nicotine in the particles, so the distribution of nicotine between these phases provides a means of understanding the acid-base balance in the tobacco smoke system. The goal of this work is to develop an acid-base balance for mainstream tobacco smoke that accounts for the extent of protonation of nicotine.
\end{abstract}

Samples of extracted smoke particulate matter from seven brands of cigarettes were analyzed by ion chromatography (IC) and titration by both acid (HCl) and base (lithium phenoxide) for comparison with nicotine data collected by colleagues. IC analysis was used to quantify tracers of known acidic and basic species in tobacco smoke. Anion tracers for acids included: glycolate, acetate, formate, lactate, chloride, nitrite, sulfate, and nitrate. The cation tracers for base were ammonium, sodium, and potassium. The tobacco smoke extracts were also analyzed after acidification by the $\mathrm{HCl}$ titrant for changes in ammonia and organic acid concentrations to determine whether "bound" forms of these compounds were present in the PM. The titration data provided total concentrations of weak acid and bases in the samples. This titration data was compared with the concentrations of the tracers for weak acids and bases (along with the 
quantification of total nicotine by colleagues) to determine whether the IC analyses were accounting for all of the important species. The results of this comparison show that these analyses missed relevant species in the tobacco smoke system.

As tobacco smoke PM is a complex organic mixture, the ability of acid species to protonate nicotine will be different than in aqueous media. The acidic species of interest were assumed to be either strong or weak, with the strong species assumed to be fully ionized after protonation of nicotine. Some portion of the weak acid species could then protonate any available nicotine. An electroneutrality equation (ENE) was developed for the tobacco smoke PM and populated using the IC data and the nicotine data obtained by colleagues. Using this ENE, the extent ionization of the weak acids species $\left(\alpha_{1}{ }^{\mathrm{A}}\right)$ and the net reaction constant for the protonation of nicotine by these weak acids $\left(K^{*}\right)$ was estimated. However, interpretation of the results were complicated by the underrepresentation of the pertinent weak acid species in our IC analyses.

This study concluded that further work is needed to identify the missing weak acid and base species to obtain a better representation of the acid-base balance in tobacco smoke PM and to understand the ability of these weak acid species to protonate nicotine. 


\section{Acknowledgements}

I would like to thank everyone who supported me during this research project. I owe so much to the support and guidance of my advisor James Pankow, without whom this project would not have been possible. I also am very thankful to have had the support of Wentai Luo who always made himself available to any questions that came up during this project. Also a special thanks to Julia DeGagné, from whom I took over this project. It was thanks to her hard work on the front end of the project that things ran smoothly on my end. I also thank Christopher Motti and Benjamin Walker for their help in the data collection. Also thanks to the support of my colleagues Kilsun Kim and Kevin McWhirter. And thanks to my friends and family for their support throughout, especially my parents Carolyn DeVita and Michael McBride. 


\section{Table of Contents}

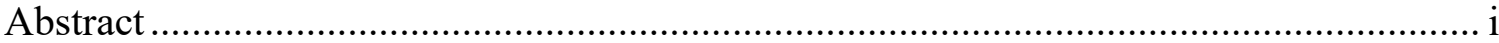

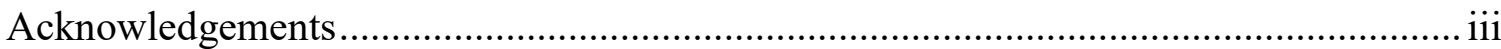

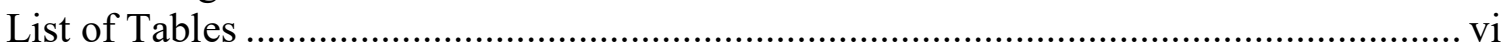

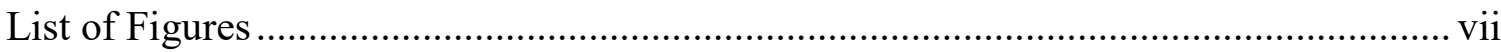

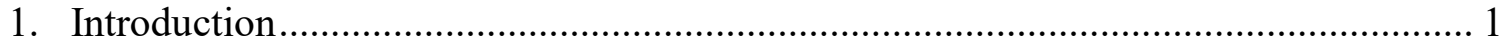

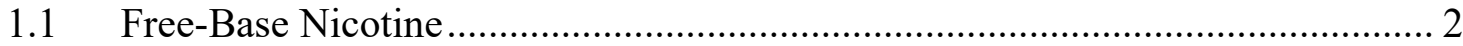

1.2 Moving Away from "Smoke $\mathrm{pH}$ " ................................................................. 4

2. Mainstream Tobacco Smoke Ion and Nicotine Analysis........................................ 9

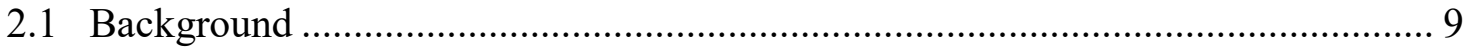

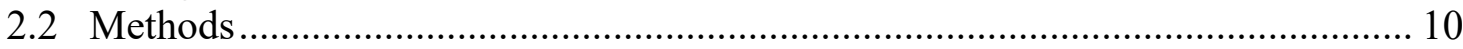

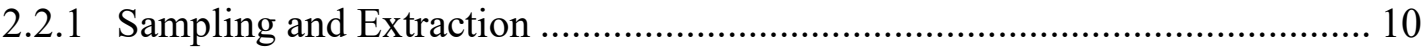

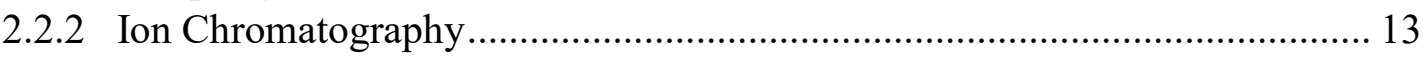

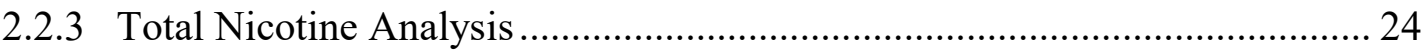

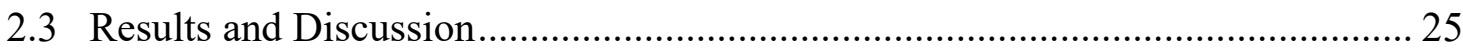

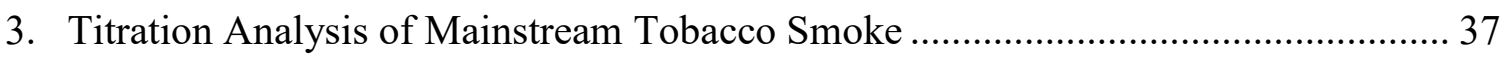

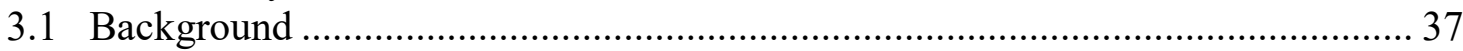

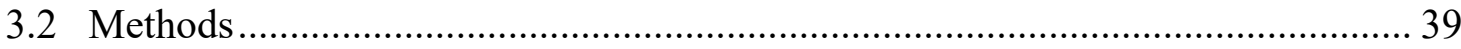

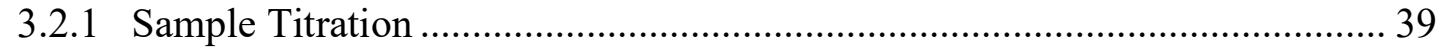

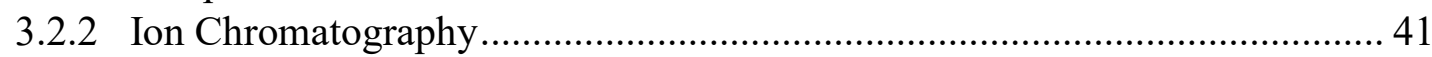

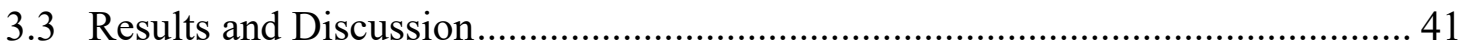

4. The Acid-Base Balance of Mainstream Tobacco Smoke as it Relates to the Percent

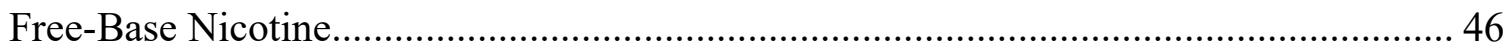

4.1 Background .......................................................................................... 46

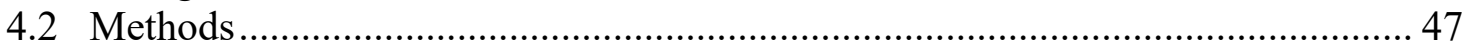

4.2.1 Determination of Free-Base Nicotine ....................................................... 47

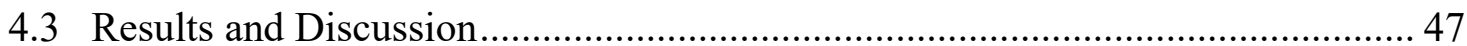

5. The Development of an Electroneutrality Equation (ENE) for Mainstream Tobacco

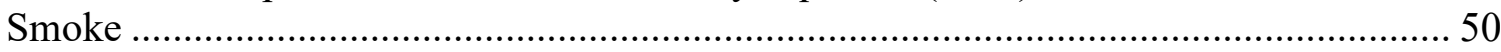

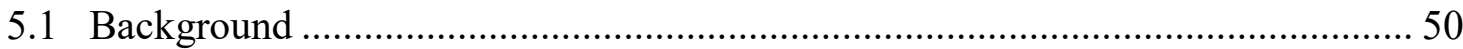

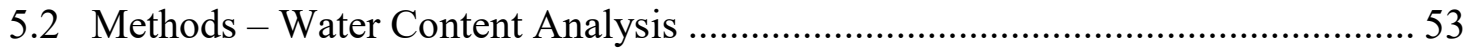

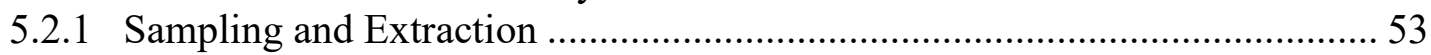

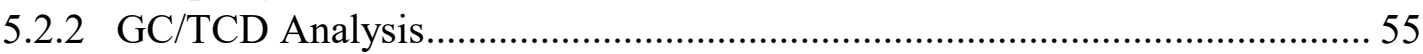

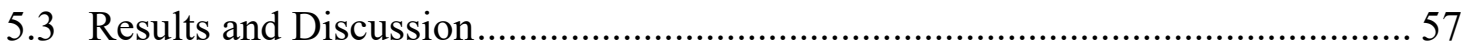

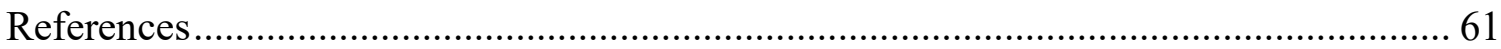

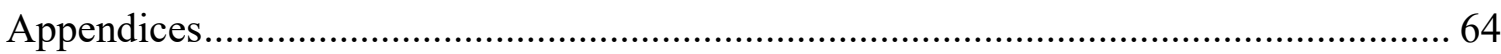

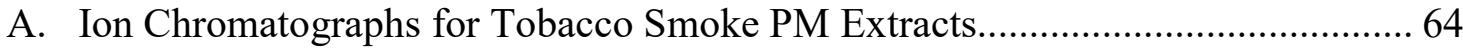

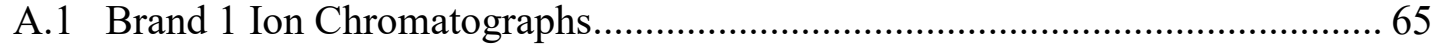

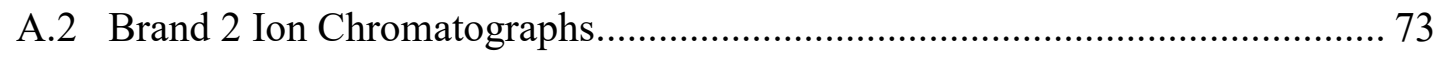

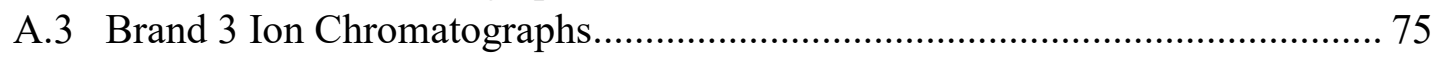

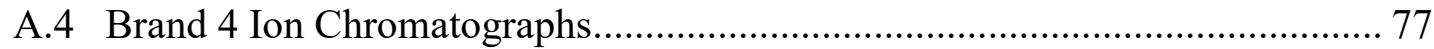




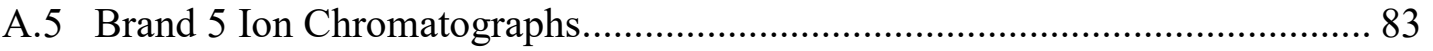

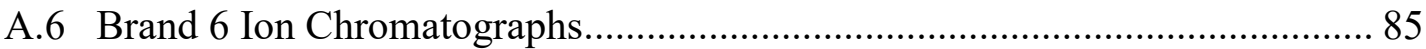

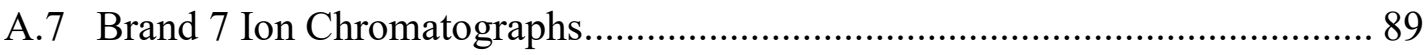

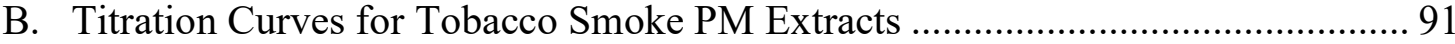

C. Gas Chromatographs for Water Content Analysis ............................................... 98 


\section{List of Tables}

Table 1 Cigarette brands codes (1 through 7) with sampling dates. The same brand sampled multiple times are distinguished with a letter code. Full-rod samples are noted by

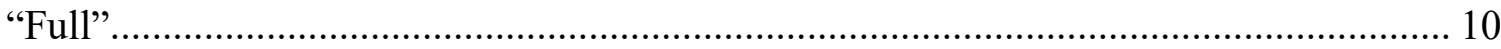

Table 2 Calibration standards' concentrations from anion analysis in February 2016... 19

Table 3 Calibration standards' concentrations from anion analysis in March 2016...... 20

Table 4 Calibration standards' concentrations from anion analysis in October 2016... 20

Table 5 Calibration standards' concentrations from anion analysis in May 2017......... 20

Table 6 Calibration standards' concentrations for cation analysis in March 2016........ 24

Table 7 Calibration standards' concentrations for cation analysis in November 2016. . 24

Table 8 Calibration standards' concentrations for cation analysis in May 2017........... 24

Table 9 Mean number of puffs (minus lighting puff) and wet total particulate matter

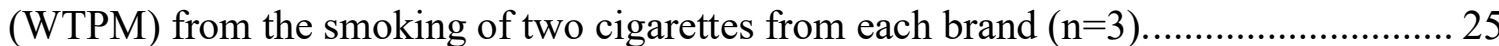

Table 10 Anion concentrations measured in the pre-titration tobacco smoke samples from IC analysis of the 6-puff and full cigarette samples $(\mathrm{n}=3$ for all brands). ............ 26

Table 11 Anion concentrations measured in the post-titration tobacco smoke samples from IC analysis of the 6-puff and full samples $(\mathrm{n}=3$ for all brands). ......................... 27

Table 12 Cation concentrations measured in the pre-titration tobacco smoke samples from IC analysis for 6-puff and full cigarette samples $(\mathrm{n}=3$ for all brands)................. 28 Table 13 Cation concentrations measured in the post-titration tobacco smoke samples from IC analysis for 6-puff and full cigarette samples ( $\mathrm{n}=3$ for all brands)................. 28 Table 14 Total nicotine concentrations for the seven brands of cigarettes studied

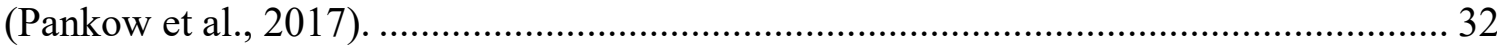

Table 15 Ammonium concentrations pre- and post-titration with $\mathrm{HCl}$ titrant for 6-puff

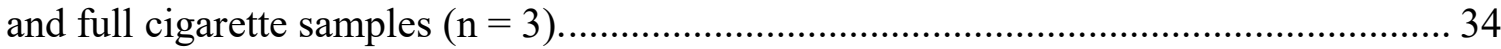
Table 16 Total acids and bases from titrations of tobacco smoke samples for 6-puff and

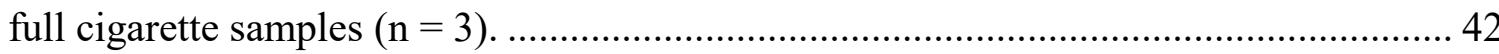

Table 17 Estimated fraction free-base nicotine based on aqueous assumption............. 48 Table 18 Measured fraction nicotine in free-base form for 6-puff samples (Pankow et

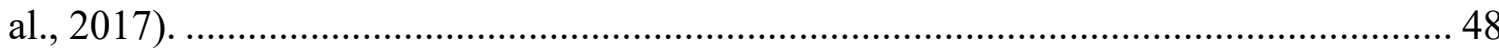

Table 19 Mass fraction water in particulate matter of AT and BR cigarettes. .............. 58 Table 20 Estimation of the fraction of unpronated weak acid $\left(\alpha_{1}{ }^{\mathrm{A}}\right)$ and the net reaction constant for the protonation of nicotine by weak acids $\left(\mathrm{K}^{*}\right)$. 


\section{List of Figures}

Figure 1 Protonation states of nicotine: neutral "free-base" (Nic), monoprotonated

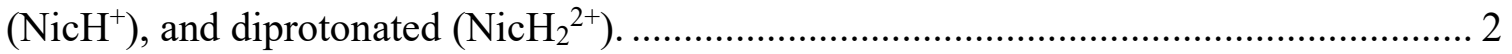

Figure 2 Smoking apparatus for PM collection. ...................................................... 12

Figure 3 Anion standards run using the $1^{\text {st }}$ anion method. .......................................... 15

Figure 4 Anion standards run using the $2^{\text {nd }}$ anion method.......................................... 16

Figure 5 Anion standards run using the $3^{\text {rd }}$ anion method.......................................... 18

Figure 6 Cation standards run using the $1^{\text {st }}$ cation method........................................ 22

Figure 7 Cation standards run using the $2^{\text {nd }}$ cation method.......................................... 23

Figure 8 Total anion concentrations measured in the pre-titration samples. The error bars represent the standard deviation between the three replicates. ................................ 29

Figure 9 Comparison of concentrations for tracers of weak (acetate, lactate, glycolate) and strong (formate, chloride, nitrite, sulfate, nitrate) acids from the anion determination

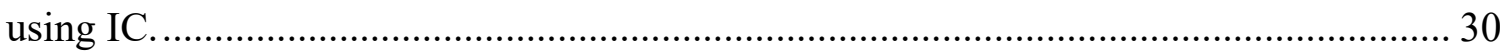

Figure 10 Changes in (a) nitrite and (b) nitrate concentrations pre- and post-titration with $\mathrm{HCl}$. Error bars represent the standard deviation between the three replicates. ...... 31 Figure 11 Total cation concentrations measured in the pre-titration samples. The error bars represent the standard deviation between the three replicates. ................................. 31

Figure 12 Comparison of basic species concentrations across brands. ........................ 33 Figure 13 Ammonium concentrations pre- and post-titration with $\mathrm{HCl}$ titrant. Error bars represent the standard deviation between the replicates $(n=3)$.

Figure 14 Concentrations of strong base tracers (sodium and potassium) and strong acid tracers (chloride and nitrate) for the tobacco smoke samples (pre-titration). Error bars show standard deviation between the replicates ( $\mathrm{n}=3$ for all brands).

Figure 15 Example of a full titration curve (both acid and base-side) of a tobacco smoke extract. 38

Figure 16 Acids and bases measured from the titration of the 6-puff and full-rod samples. Error bars represent the standard deviation between replicates $(n=3)$. 42

Figure 17 Net strong base from titrations of tobacco smoke samples. Error bars represent the standard deviation between replicates $(n=3)$.

Figure 18 Total weak acid concentrations from base-side titrations compared with concentrations of (a) weak acid tracers (acetate, lactate, glycolate), (b) organic acid tracers (acetate, lactate, glycolate, formate), and (c) organic acid tracers plus nitrate for the different brands.

Figure 19 Total weak base concentrations from acid-side titrations compared with total nicotine and ammonium concentrations for the different brands. ................................ 45

Figure 20 Smoking apparatus for PM water content analysis. ..................................... 54

Figure 21 Example GC/TCD chromatograph of tobacco smoke PM extract for water content determination 
Figure 22 Calibration plot for PM water content analysis...................................... 57 


\section{Introduction}

The acid-base chemistry of aerosols can have a significant effect on the equilibrium partitioning of chemical species between the gas and particle phases. The chemistry in the

aerosol phase includes the dissociation of acids, protonation of bases and the formation of salts. This chemistry is very dependent on the on the makeup of the particulate matter (PM), specifically the proportion of organic versus inorganic species. The makeup of this chemical environment impacts the dissociation constants of acids and protonated bases. Under a given set of conditions these dissociation constants along with the $\mathrm{pH}$ of the $\mathrm{PM}$ determines the form of each compound - whether ionized or in their free (neutral) form. Only compounds in neutral form are free to partition into the gas phase.

Like atmospheric organic aerosol PM, tobacco smoke PM is a complex mixture of condensed organic compounds, with a portion of water. For this reason, tobacco smoke is a useful surrogate when studying atmospheric aerosols. Due to its ability to undergo acidbase chemistry, nicotine is of particular interest in the tobacco smoke system. The amount of nicotine in either phase can be easily measured using well-developed techniques and its distribution between the phases provides a means of understanding the acid-base balance in the tobacco smoke system. The tobacco smoke system and nicotine partitioning are also important in their own right due to the implications for public health.

This thesis looks to develop an acid-base balance for mainstream (MS) tobacco smoke through the analysis of acids, bases, ions, and water content to further our understanding of the complex chemistry in tobacco smoke aerosols. 


\subsection{Free-Base Nicotine}

Mainstream cigarette smoke is an aerosol composed of a complex mixture of both organic and inorganic compounds, including nicotine. Nicotine, an alkaloid found naturally in tobacco leaves, has stimulant properties and is known to be an addictive compound. Its bioavailability and speed of delivery in the MS smoke affect the addictiveness of cigarettes. Nicotine is dibasic and thus has three possible forms (or protonation states) (see Figure 1, below): unprotonated or "free-base" (Nic), monoprotonated $\left(\mathrm{NicH}^{+}\right)$, and diprotonated $\left(\mathrm{NicH}_{2}{ }^{2+}\right)$. However, the diprotonated form $\left(\mathrm{p} K_{a}=3.12\right.$ in water) is typically neglected as concentrations are insignificant under typically observed acidities in tobacco smoke PM (Pankow, 2001). As discussed previously, ions are non-volatile and for this reason only the free-base nicotine (Nic) can partition from the particle to the gas phase.
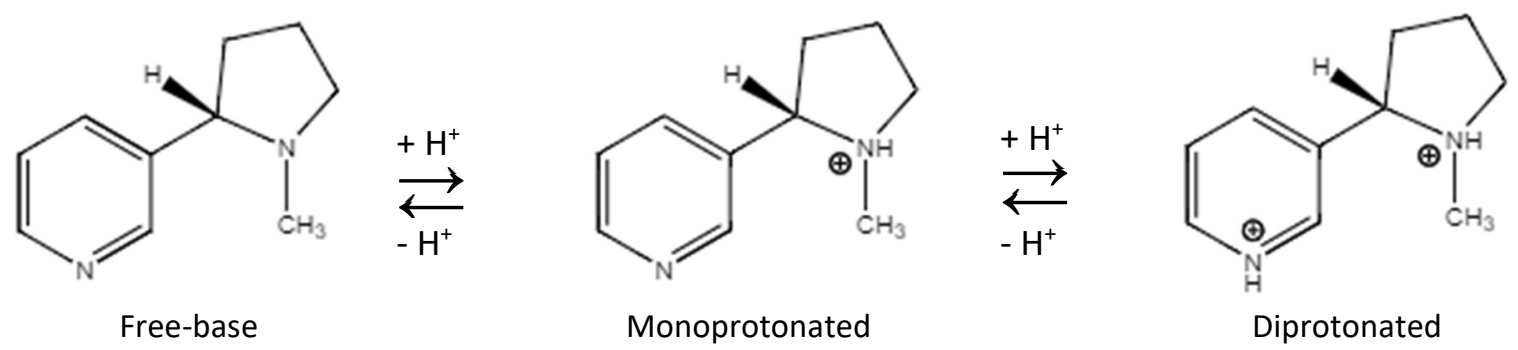

Figure 1 Protonation states of nicotine: neutral "free-base" (Nic), monoprotonated $\left(\mathrm{NicH}^{+}\right)$, and diprotonated $\left(\mathrm{NicH}_{2}{ }^{2+}\right)$.

Studies have shown that the addictive properties of nicotine are dependent on the efficacy of nicotine delivery to the brain (Henningfield and Keenan, 1993). Gas-phase nicotine rapidly deposits in the respiratory tract and only the free-base form of nicotine is 
lipophilic, and so has been argued to be more bioavailable than the monoprotonated form (Tomar and Henningfield, 1997; Watson et al., 2004).

In aqueous solutions, the fraction of free-base, $\alpha_{\mathrm{fb}}$, of the particulate phase nicotine is approximated by,

$$
\alpha_{f b}=\frac{[\mathrm{Nic}]}{[\mathrm{Nic}]+\left[\mathrm{Nic}^{+}\right]}
$$

Equation (1) can also be expressed in relation to the aqueous $\mathrm{pH}$ and the $\mathrm{p} K_{a}$ of nicotine,

$$
\alpha_{f b}=\frac{10^{-\mathrm{p} K a}}{10^{-\mathrm{p} K a+1}-\mathrm{p}}
$$

Where $K_{a}$ is the acidity constant for the dissociation of monoprotonated nicotine to the free-base form $\left(\mathrm{NicH}^{+}=\mathrm{Nic}+\mathrm{H}^{+} ; \mathrm{p} K_{a}=8.02\right.$ in dilute water $)$.

Equations (1) and (2) are derived for aqueous solutions. But based on previous studies tobacco smoke PM is mainly non-aqueous with water content around 5 to $10 \%$ (Chen and Pankow, 2009), thus in the circumstances investigated in this work, these equations do not apply. We must therefore use an alternative approach to determine the extent of protonation of nicotine.

The amount of nicotine in the free-base form depends on the $\mathrm{pH}$ of the PM phase. In the presence of acids with sufficiently low $\mathrm{p} K_{a}$ values, the free-base nicotine will protonate (equation (3)) and the fraction of free-base nicotine decreases. Under sufficient concentrations of these acids, nearly all the nicotine will be protonated. 


$$
\mathrm{Nic}+\mathrm{HA} \rightarrow \mathrm{NicH}^{+}+\mathrm{A}^{-}
$$

In a similar manner, the presence of basic compounds with sufficiency high $\mathrm{p} K_{a}$ values, such as ammonia (Pankow et al., 1997), will drive deprotonation (equation (4)) and increase the fraction of free-base nicotine.

$$
\mathrm{NicH}^{+}+\mathrm{NH}_{3} \rightarrow \mathrm{Nic}+\mathrm{NH}_{4}^{+}
$$

A number of studies have looked at tobacco additives for their ability to alter the $\mathrm{pH}$ of tobacco smoke particulate phase (Steele, 1989; RJ Reynolds, 1991; Henningfield et al., 2004; Lakritz et al., 2014). Among the additives investigated were ammonia, ammonium bicarbonate, ammonium hydroxide, urea, diammonium phosphate (DAP), sodium hydroxide, sodium carbonate, levulinic acid, lactic acid, and nicotine salts of organic acids. These compounds help to control the perceived "harshness" of the MS tobacco

smoke - believed to be related to the amount of free-base nicotine in the smoke - in two ways: (1) by controlling the $\mathrm{pH}$ of the tobacco smoke particulate phase and thus the level of free-base nicotine; (2) the addition of ammonia compounds leads to the formation of flavor compounds via Maillard reactions which may reduce the "harshness" of the smoke when free-base nicotine levels are high (Watson et al., 2015).

\subsection{Moving Away from "Smoke pH"}

As discussed, understanding the acid-base chemistry of smoke PM is key to determining the fraction of nicotine in the free-base form. Many of the preceding studies of MS tobacco smoke's acid-base chemistry have focused on attempts to measure the $\mathrm{pH}$ of the 
tobacco smoke as a means to quantify the acid-base balance. Use of these methods have usually, in effect, assumed that MS tobacco smoke is an aqueous solution with a $\mathrm{pH}$ scaled like that of water. However, as stated above MS tobacco smoke PM is around 90\% organic. While these methods may provide a means to compare the relative acidity/alkalinity of samples collected using the same protocol, it is not an appropriate means of quantifying the acid-base balance of MS tobacco smoke.

In this work, we will instead focus on the composition of MS tobacco smoke PM to develop an acid-base balance. This balance can be accomplished by the development of an electroneutrality equation (ENE) for the tobacco smoke PM. An ENE is used as a "charge balance" of a "neutral" or uncharged solution, with the equating of the net for positively-charged species and the net for negatively-charged species. In tobacco smoke, positively charged species include: $\left[\mathrm{H}^{+}\right]$, protonated weak bases, and cation tracers for strong bases. The negatively-charged species include: $\left[\mathrm{OH}^{-}\right]$, deprotonated weak acids, and anion tracers for strong acids. The following ENE was theorized for tobacco smoke PM (DeGagné, 2016):

$$
\begin{aligned}
& {\left[\mathrm{H}^{+}\right]+\left[\mathrm{K}^{+}\right]+\left[\mathrm{Na}^{+}\right]+\left[\mathrm{NH}_{4}^{+}\right]+\left[\mathrm{NicH}^{+}\right]} \\
& =\left[\mathrm{OH}^{-}\right]+\left[\mathrm{A}^{-}\right]+\left[\mathrm{NO}_{2}{ }^{-}\right]+\left[\mathrm{Cl}^{-}\right]+\left[\mathrm{NO}_{3}{ }^{-}\right]+\left[\mathrm{HCO}_{3}{ }^{-}\right]+2\left[\mathrm{SO}_{4}{ }^{2-}\right]
\end{aligned}
$$

Where $\left[\mathrm{A}^{-}\right]$is the combined concentration of anion tracers for organic acids: acetic, formic, lactic, and glycolic. For weak acid and base species, it is easier to quantify the total concentrations of compounds than the ions. It is assumed that sulfuric acid is strong 
enough that it will fully dissociated to protonate nicotine and, therefore, bisulfate concentrations are negligible. We can rewrite equation (5):

$$
\begin{aligned}
& {\left[\mathrm{H}^{+}\right]+\left[\mathrm{K}^{+}\right]+\left[\mathrm{Na}^{+}\right]+\left[\mathrm{NH}_{4}^{+}\right]+\left(1-\alpha_{1}^{\mathrm{Nic}}\right) \mathrm{Nic}_{\mathrm{T}}} \\
& =\frac{{ }^{c} K_{W}}{\left[\mathrm{H}^{+}\right]}+\alpha_{1}^{\mathrm{A}} \mathrm{A}_{\mathrm{T}}+\alpha_{1}^{\mathrm{F}} \mathrm{F}_{\mathrm{T}}+\alpha_{1}^{\mathrm{L}} \mathrm{L}_{\mathrm{T}}+\alpha_{1}^{\mathrm{G}} \mathrm{G}_{\mathrm{T}}+\left[\mathrm{NO}_{2}^{-}\right]+\left[\mathrm{Cl}^{-}\right] \\
& \quad+\left[\mathrm{NO}_{3}^{-}\right]+{ }^{c} K_{H}^{\mathrm{HCO}_{3}{ }^{c}} K_{1}^{\mathrm{HC}}{ }_{3} \frac{p_{\mathrm{CO}_{2}}}{\left[H^{+}\right]}+2\left[\mathrm{SO}_{4}{ }^{2-}\right]
\end{aligned}
$$

Where $\alpha_{1}$ is the fraction of the acid or unprotonated base in the particulate phase and the subscripts denote the chemical system: Nic = nicotine, $\mathrm{A}=$ acetic acid, $\mathrm{F}=$ formic acid, $\mathrm{L}$ $=$ lactic acid, $\mathrm{G}=$ glycolic acid, and $\mathrm{HCO}_{3}=$ carbonate. ${ }^{c} K_{w}$ is the autoprotolysis constant of tobacco smoke PM, ${ }^{c} K_{H}^{\mathrm{HCO}_{3}}$ is the Henry's gas law constant for carbon dioxide in tobacco smoke PM, ${ }^{c} K_{1}^{\mathrm{HCO}_{3}}$ is the acid dissociation constant for carbonic acid, and $p_{\mathrm{CO}_{2}}$ is the atmospheric pressure of carbon dioxide. The "c" superscript on the $K$ values denotes they are concentration constants (Pankow, 1991) and have been activity corrected for the non-aqueous media.

In order to populate the above ENE, tobacco smoke PM extracts were analyzed using several quantitative methods. Concentrations of the organic acids of interest (acetic, formic, lactic, glycolic), chloride, nitrite, nitrate, ammonium, potassium, and sodium were determined through ion chromatography (IC). Total nicotine numbers were determined using GC/MS analyses by colleagues (Pankow et al., 2017). Titrations using both acid and base titrants provided quantification of the total titratable acid and bases. The results of the IC analysis should correlate well with the titration results if all the 
important acid and base species have been accounted for. This analysis will provide an understanding of the overall acid-base balance in the MS tobacco smoke PM.

The fraction of nicotine in the free-base form should also be reflected by this acid-base balance. If we assume that tobacco smoke PM is an aqueous mixture, predicting the fraction of free-base nicotine is simple. The amount of protonated nicotine should be directly related to the total amount of acid present. Thus, tobacco smoke PM with higher proportion of organic acids - relative to nicotine - will have a lower fraction of free-base nicotine. And it follows that tobacco smoke PM with a lower proportion of organic acids compared to nicotine will have a higher fraction of free-base nicotine.

However, as discussed previously, tobacco smoke PM is not an aqueous solution, and as such, the behavior of species will be different than in water. The extent of ionization of an acid or base species is dependent on their activity coefficient $(\gamma)$ values in the solution of interest. Tobacco smoke PM is considerably less polar than water, so this will have a significant effect on the activity (or relative comfort) of species in the particulate phase compared with an aqueous solution. For example, ammonia $\left(\mathrm{NH}_{3}\right)$ is quite polar and hydrophilic, thus it will be less comfortable in tobacco smoke PM than in water (Chen and Pankow, 2009). In contrast, free-base nicotine (Nic), a neutral organic compound, will be more comfortable in the tobacco smoke PM than in water (Chen and Pankow, 2009). The ionized form of both of these weak bases $\left(\mathrm{NH}_{4}{ }^{+}\right.$and $\left.\mathrm{NicH}^{+}\right)$will be less comfortable in the tobacco smoke PM than in an aqueous solution, but $\mathrm{NicH}^{+}$less so than ammonium as an organic species in a mixture of organic compounds. Due to the 
differences in activities of the species, the tobacco smoke PM will feel more acidic to the ammonia than to nicotine (Chen and Pankow, 2009). Similar effects on the activities will also be observed for the organic acid species in the tobacco smoke PM. In a complex mixture of organics such as tobacco smoke PM, the organic acids may be less acidic than in water. For example, acetic acid has a $\mathrm{p} K_{a}$ of around 4.7 in dilute water but in methanol the acidity constant is five orders of magnitude higher at around 9.7 (Rived et al., 1998; Sarmini and Kenndler, 1999). Due to these confounding issues, it may be that the organic acids are not strong enough in the tobacco smoke PM to protonate the nicotine as we would expect. Thus, the non-aqueous effects on the species activities and acid dissociation constants will result in the fraction of free-base nicotine being different than what might be expected under aqueous conditions.

Previous studies have used volatility-based techniques to measure fraction free-base nicotine in MS tobacco smoke PM (Pankow et al., 2003; Watson et al., 2004; Lauterbach et al., 2010). These studies found a range of $\alpha_{\mathrm{fb}}$ values across cigarette brands: between 0.01 and 0.36 . This variability between brands suggests that the formulation of the cigarette filler materials has a significant impact on the acid-base chemistry of the PM. The following work looks to further investigate this acid-base balance. 


\section{Mainstream Tobacco Smoke Ion and Nicotine Analysis}

\subsection{Background}

Tobacco smoke is a complex mixture consisting of innumerable different constituents. Many previous studies have analyzed acidic and basic compounds present in the smoke PM. Based on the findings of these studies, important organic acids present in tobacco smoke are the following monocarboxylic acids: acetic, formic, lactic and glycolic (Quin and Hobbs, 1958; Lakritz et al., 1969; Sakuma et al., 1983; Nanni et al., 1990; Lagoutte et al., 1994). In aqueous solutions, these are weak acids with $\mathrm{p} K_{a}$ values of $4.75,3.75$, 3.86, and 3.83, respectively. The studies of Nanni et al. (1990) also found chloride, nitrite and nitrate (ion tracers for strong acids) in IC analyses of tobacco smoke PM. For this study, we also analyzed sulfate in the samples. The cation species determined here were also chosen based on previous studies that have found sodium, ammonium, and potassium to be the most prevalent inorganic cations in tobacco smoke aerosols (Sakuma et al., 1984; Nanni et al., 1990). As discussed previously, ammonia is a weak base ( $\mathrm{p} K_{a}=$ 9.25, in water) and sodium and potassium are ion tracers for strong base. The most prevalent base in tobacco smoke is nicotine ( $\mathrm{p} K_{a}=8.02$, in water).

As discussed previously, the intent of this work is to develop an acid-base balance for MS tobacco smoke PM. In an aqueous solution, a charge balance of the anion and cations should provide a good estimate of the extent of protonation of the nicotine. A comparison of the free-base nicotine estimate from the following analysis and the free-base numbers measured by colleagues should allow a good evaluation of the non-aqueous effects on the extent of ionization of the organic species. Ion chromatography was chosen as the best 
means to quantify ionic species as it can provide good separation of the species of interest.

\subsection{Methods}

\subsubsection{Sampling and Extraction}

In this study, seven packs from four different American cigarette brands were studied.

The brands and packs have been assigned code names and will be referred to using these throughout this work. Table 1, below, shows the dates of sampling for the individual packs. All of the cigarettes used in this study were purchased in Portland, Oregon between December 2015 and May 2017. Prior to sampling the cigarettes, packs were kept at ambient temperature. After sampling, the remaining cigarettes were sealed within two plastic zippered bags and stored in laboratory refrigerators for further sampling by colleagues.

Table 1 Cigarette brands codes (1 through 7) with sampling dates. The same brand sampled multiple times are distinguished with a letter code. Full-rod samples are noted by "Full".

\begin{tabular}{ccc}
\hline Brand Code & Sampling Code & Sampling Date \\
\hline & 1A & $02 / 19 / 2016$ \\
1 & 1Full & $03 / 04 / 2016$ \\
& 1B & $10 / 10 / 2016$ \\
& $1 \mathrm{C}$ & $05 / 12 / 2017$ \\
\hline 2 & 2 & $02 / 26 / 2016$ \\
\hline 3 & 3 & $02 / 29 / 2016$ \\
\hline \multirow{2}{*}{4} & 4Full & $03 / 07 / 2016$ \\
& $4 \mathrm{~A}$ & $10 / 12 / 2016$ \\
& $4 \mathrm{~B}$ & $05 / 02 / 2017$ \\
\hline 5 & 5 & $02 / 24 / 2016$ \\
\hline \multirow{2}{*}{6} & 6 Full & $03 / 02 / 2016$ \\
& 6 & $10 / 07 / 2016$ \\
\hline 7 & 7 & $02 / 22 / 2106$ \\
\hline
\end{tabular}


For each sample, two cigarettes were simultaneously lit and the smoke was collected into a Tedlar bag placed in a sealed 4L chamber. The smoking apparatus (Figure 2) consisted of the following components in series: (i) a glass dual cigarette holder (Clear Concepts, Bend, OR); (ii) a 0.25" Teflon Swagelok union (Solon, OH); (iii) a glass/TFE tee stopcock (Swagelok; modified by Clear Concepts, Bend, OR); (iv) a 0.25 ” Teflon Swagelok union; (v) a 1" piece of 0.125" I.D. silicone tubing (Nalgene); (vi) a 1 liter Tedlar gas sampling bag (Supelco, Bellefonte, PA). Teflon tape was wrapped around the filter end of each cigarettes to create a better seal in the cigarette holder. The pump was calibrated to take a $70 \mathrm{~mL}$ puff ( $35 \mathrm{~mL}$ per cigarette) of two-second duration every 60 seconds. Six puffs (the initial lighting puff +5 additional puffs) were collected into the pre-weighed Tedlar bag. After collection, the bag was sealed and set aside to allow the PM to settle onto the walls of the bag. After 20 minutes, the gas was evacuated and the bag was re-weighed to determine the mass of wet total particulate matter (WTPM).

Three of the seven brands which were studied above were also selected for full cigarette studies: 1, 4, and 6. In the 6-puff study described above, the whole cigarette rod was not burned. This full-rod study was aimed at observing any differences in PM chemistry when the entire cigarette rod was burned. The sampling method was the same as described above, aside from the number of puffs from the cigarettes. The number of puffs for smoking of the entire rod varied from 7 to 12 . 

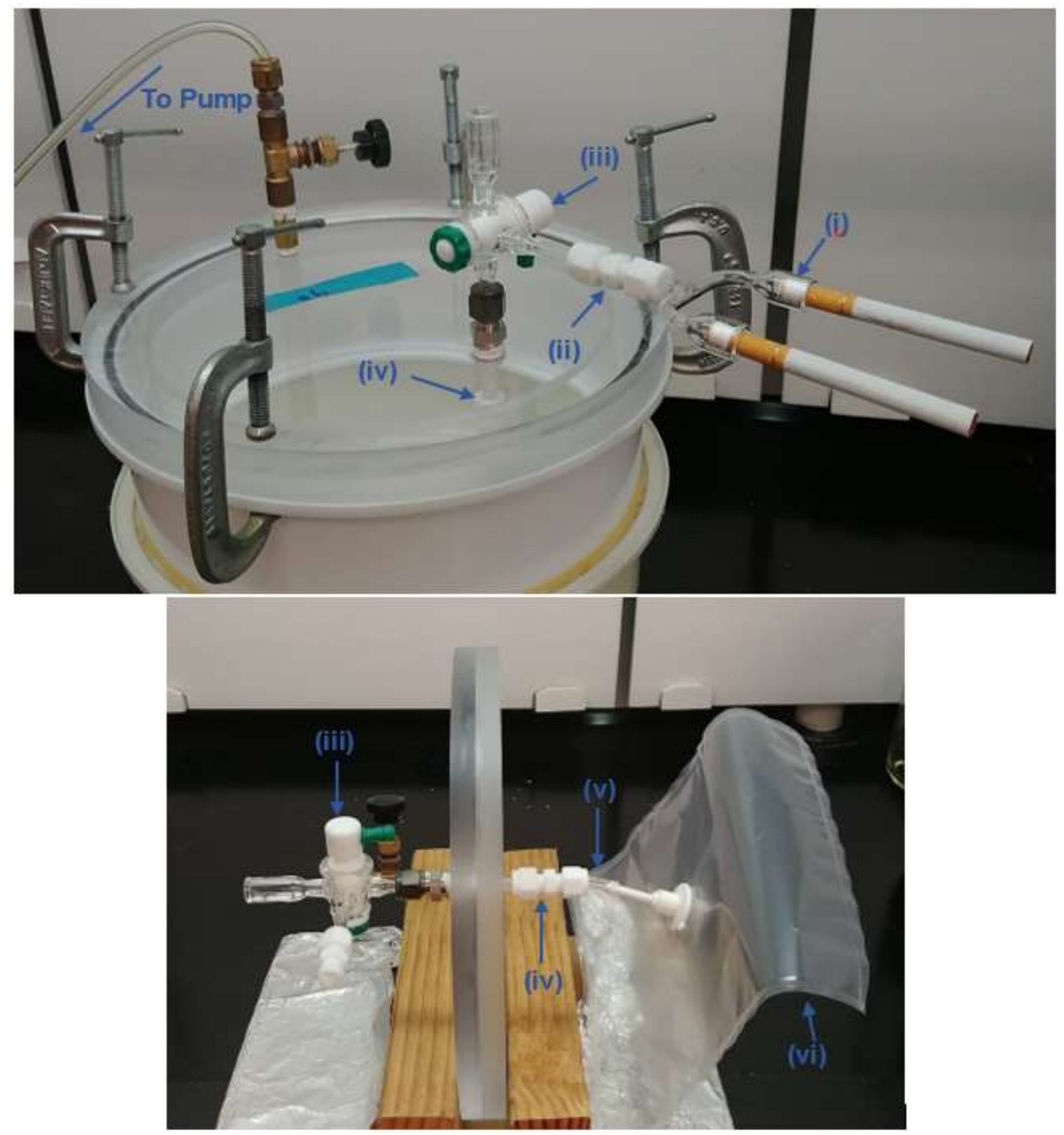

Figure 2 Smoking apparatus for PM collection.

A solution of $98 \%$ isopropanol (>99\% IPA, Sigma Aldrich) with 2\% nanopure water $\left(18.2 \mathrm{M} \Omega \cdot \mathrm{cm}\right.$ at $25^{\circ} \mathrm{C}$, Millipore) was made daily for extraction of the tobacco smoke particulate matter. This solution was degassed and kept under nitrogen gas throughout the day to remove any carbonic acid. Use of an IPA/water solvent ensures that both 
hydrophobic and hydrophilic components of the tobacco smoke PM are dissolved. The fraction of water was included to ensure sufficient levels of water were present in the tobacco smoke extract regardless of the water content of the particulate phase (which varies between brands). To extract the PM, $14 \mathrm{~mL}$ of the $98 \%$ IPA solution was injected into the bag and moved around to ensure thorough contact with the entire bag surface. The bag was then opened and the extract was poured into a clean beaker. Aliquots of the extract were then distributed for further analysis by ion chromatography (below) and titration (see Section 3.2.1, p. 39).

Each day of sampling consisted of three replicates of smoking as described above. In addition, a blank Tedlar bag was injected with $14 \mathrm{~mL}$ of the $98 \%$ IPA solution to be studied in the same manner as the tobacco smoke samples. The results of these studies revealed any background contribution to the acid-base chemistry from the sampling bags. Each of the three tobacco smoke samples and bag blank were titrated (both acid- and base-side) and studied by ion chromatography.

\subsubsection{Ion Chromatography}

Aliquots of the tobacco smoke samples both pre- and post-acidification (see Chapter 3, p. 37) were filtered using $0.2 \mu \mathrm{m}$ pore size PTFE syringe filters (National Scientific, Claremont, CA) and sealed in polypropylene IC sample vials (Dionex, Sunnyvale, CA). All ion analysis was conducted using an ICS-5000 ion chromatography system (Dionex, Sunnyvale, CA). Samples for anion analysis were run on an anion-exchange IC column immediately following sampling. Samples for cation analysis were sealed and stored at 
sub-zero temperatures to be run within 30 days of sampling. All system eluents were made up in nanopure water $\left(18.2 \mathrm{M} \Omega \cdot \mathrm{cm}\right.$ at $25^{\circ} \mathrm{C}$, Millipore $)$ which was degassed by sonication for a minimum of 20 minutes. To remove any dissolved carbon dioxide, the eluent water was also bubbled with nitrogen gas then kept under 5 psi of nitrogen gas. The dissolved carbon dioxide in the eluent contributed to a large carbonate peak not associated with the samples.

A range of calibration standards were run along with samples. Linear calibration curves were developed using the Chromeleon ${ }^{\mathrm{TM}}$ software (Version 7.1, Dionex) and used to determine the concentrations of ions in the samples. The calibration plots for most ions were developed with respect to peak heights, however, in some circumstances, peak area was used. The $\mathrm{R}^{2}$ values for almost all fits was greater than 0.99 .

\subsubsection{Anion-Exchange Ion Chromatography}

Anion samples were run on an IonPac ${ }^{\mathrm{TM}}$ AG15 analytical anion-exchange column (4 x $250 \mathrm{~mm}$, Dionex) with a corresponding guard column (4 x $50 \mathrm{~mm}$, Dionex). The system was run using a potassium hydroxide $(\mathrm{KOH})$ eluent generator cartridge (EGC) (Dionex) with a concentration gradient. The system used an AERS 500 electrolytically selfregenerating suppressor (4 mm, Dionex) with a current of $71 \mathrm{~mA}$. The anion-exchange analysis protocol maintained the detector cell and column compartment at $40{ }^{\circ} \mathrm{C}$ and the suppressor compartment at $35^{\circ} \mathrm{C}$. A sample volume of $25 \mu \mathrm{L}$ was injected into the system running with an eluent flow rate of $0.75 \mathrm{~mL} / \mathrm{min}$. The total run time of the anion analysis was 42 minutes. An equilibrium period of 4 minutes at an eluent concentration 
of $10 \mathrm{mM}$ was added prior to new sample injection. The eluent was maintained at $10 \mathrm{mM}$ for the first 10 minutes of the run. Between 10 and 12.5 minutes, the eluent concentration was increased at a rate of $4.8 \mathrm{mM} / \mathrm{min}$. At 12.5 minutes the eluent concentration was raised to $45 \mathrm{mM}$ and maintained at this concentration for the remainder of the run. This eluent gradient was used for all samples analyzed through 03/07/2016. Examples of the chromatographs obtained using this method are shown in Figure 3, below.

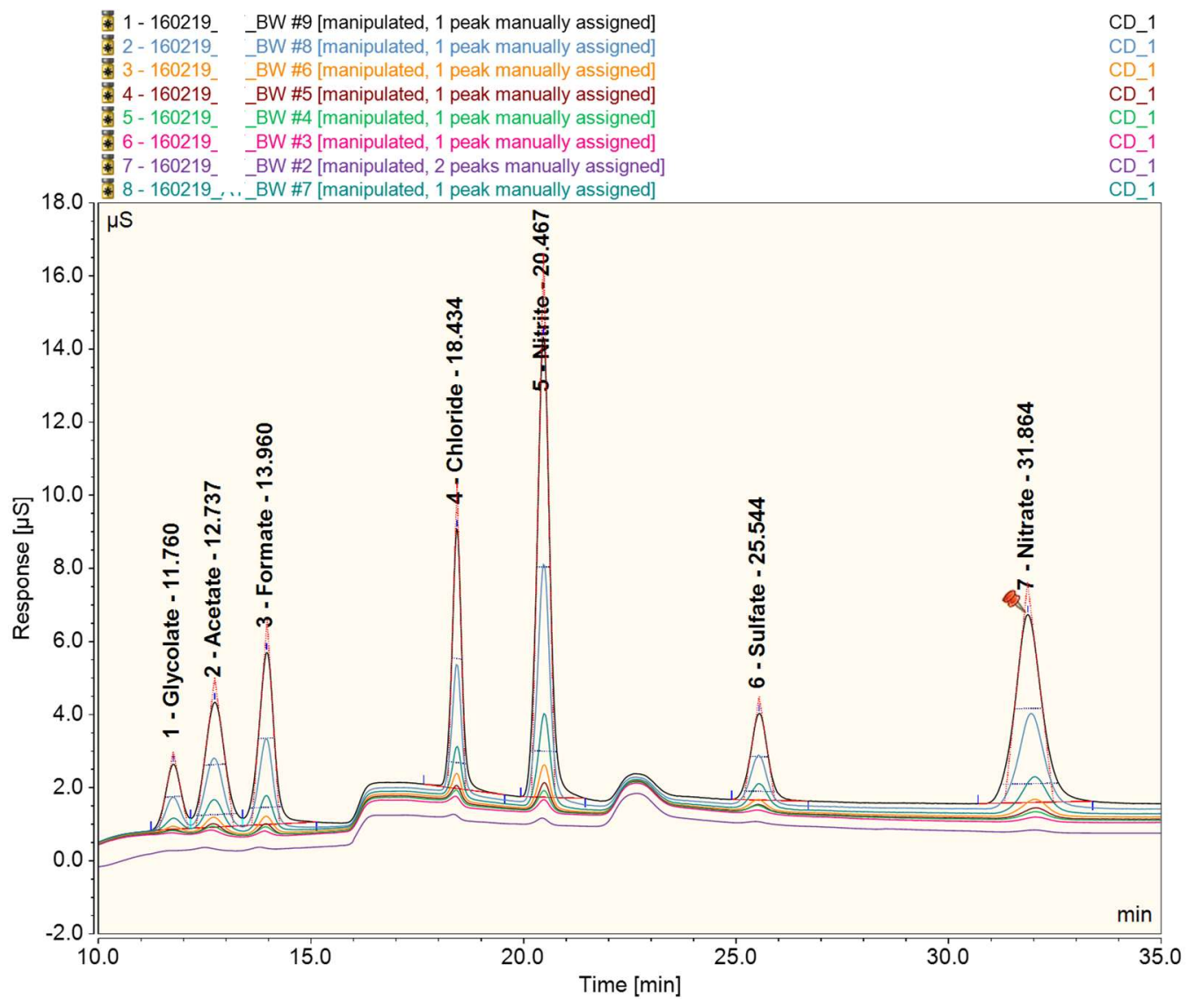

Figure 3 Anion standards run using the $1^{\text {st }}$ anion method.

Upon recommendation of Dionex representatives, the eluent gradient was modified to include the equilibrium period to the end of the run and the total run time was extended to 
45 minutes to allow a longer period for equilibrium between runs. This updated gradient was the same as previous between 0 and 12.5 minutes. The eluent concentration of 45 $\mathrm{mM}$ was maintained between 12.5 and 36 minutes. Between 36 and 38 minutes, the eluent concentration was decreased at a rate of $17.5 \mathrm{mM} / \mathrm{min}$. The concentration was maintained at $10 \mathrm{mM}$ for the remainder of the run. This updated gradient was used for all analysis conducted in October 2016. Examples of the chromatographs obtained using this method are shown in Figure 4, below.

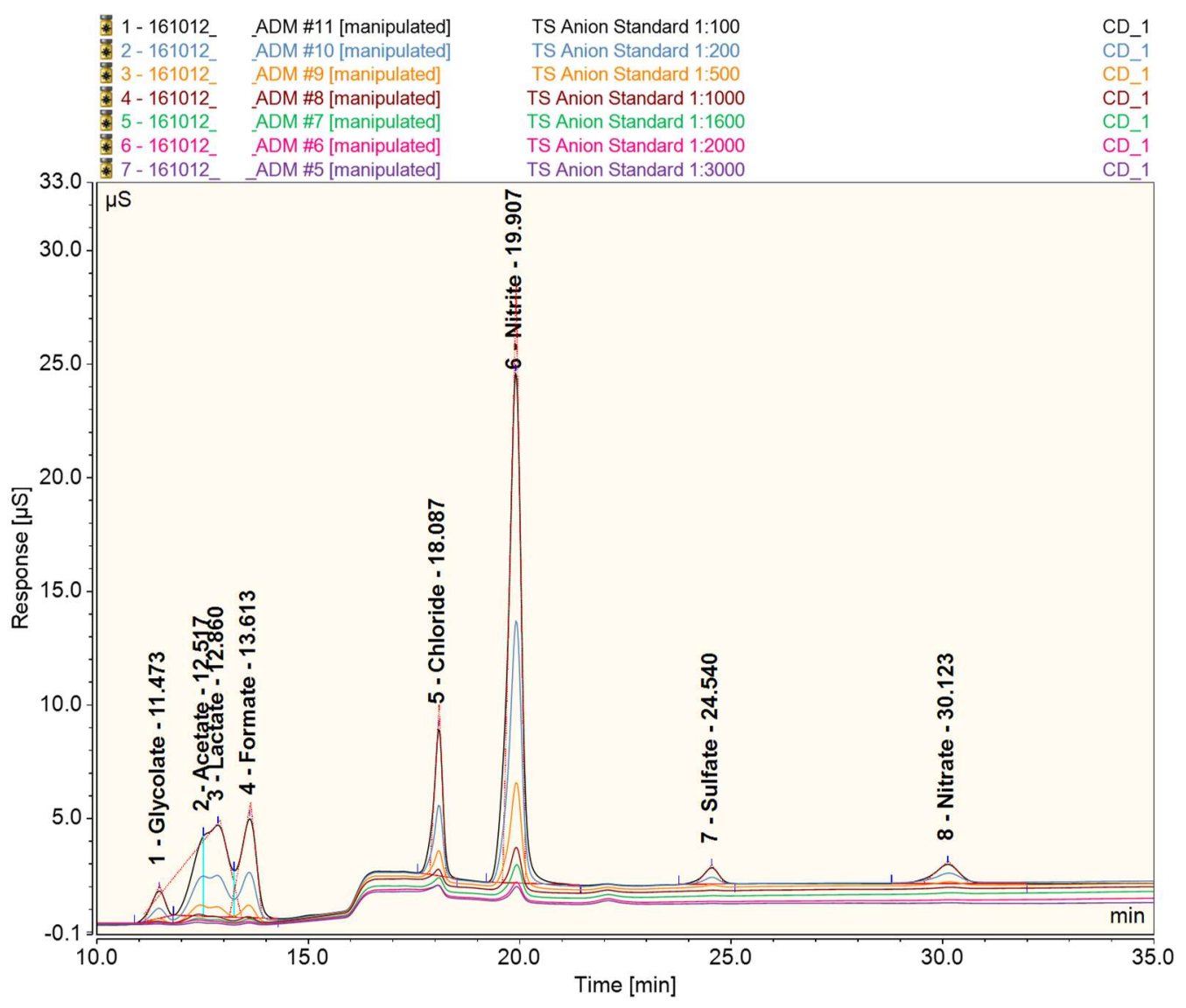

Figure 4 Anion standards run using the $2^{\text {nd }}$ anion method. 
The eluent concentration gradient was further modified to obtain better resolution of the organic acid peaks. These peaks are the first of the target ions to come off the column. To obtain this increased resolution, the initial eluent concentration was decreased and therefore, the total run time had to be extended (57 minutes). All method settings aside from the eluent gradient were maintained. The eluent concentration was maintained at 3 $\mathrm{mM}$ from 0 to 36.5 minutes. At 36.5 minutes, the eluent concentration was increased to $45 \mathrm{mM}$ which was maintained until 53 minutes. At 53 minutes, the eluent concentration was decreased to $3 \mathrm{mM}$ and was maintained at this concentration for the remainder of the run. This updated gradient was used for all anion analysis conducted in May 2017. Examples of the chromatographs obtained using this method are shown in Figure 5, below. 


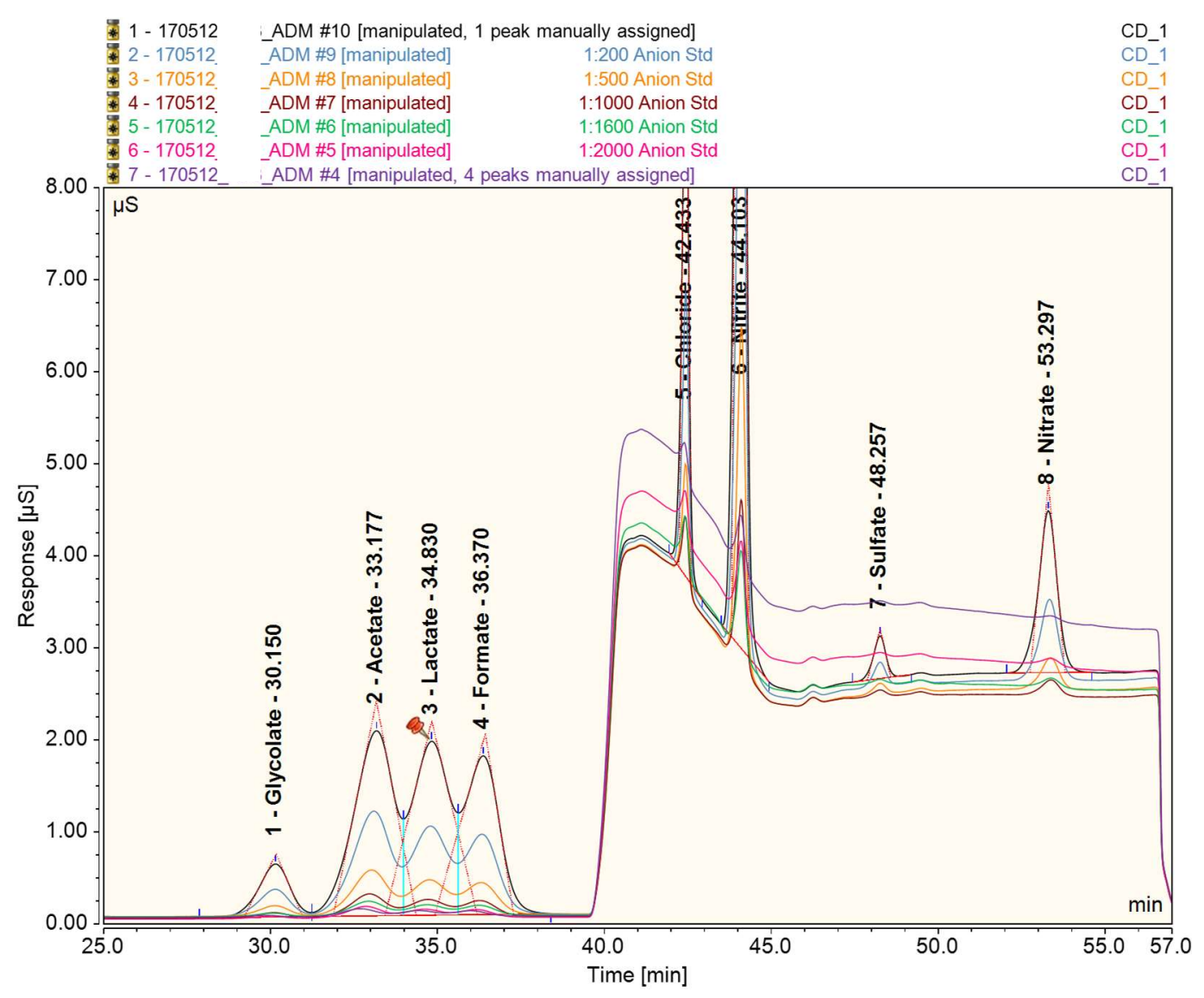

Figure 5 Anion standards run using the $3^{\text {rd }}$ anion method.

For anion determination, an aqueous stock standard solution was made with varying concentrations of the eight, anion species of interest: glycolate, acetate, lactate, formate, chloride, nitrite, sulfate, and nitrate. The concentrations of the target ions were determined based on observed concentration ranges in previous tobacco smoke studies. The concentration in the stock solution was back calculated so that these observed ranges would be covered in dilutions of the stock solution within the calibration range of 1:100 to 1:4000. The stock solution was made from the following ACS reagents: glycolic acid (99\%, Sigma Aldrich), potassium acetate ( $>99.0 \%$, Fisher Scientific), lactic acid (>98\%, MP Biomedicals, Santa Ana, CA), sodium formate (99.4\%, JT Baker), sodium chloride 
( $>99.0 \%$, Sigma Aldrich), potassium nitrite ( $>99.0 \%$, Fisher Scientific), sodium sulfate ( $>99.0 \%$, Sigma Aldrich), and sodium nitrate ( $>98.1 \%$, Mallinckrodt Chemical Works). All salts were stored in a desiccator for at least 1 week prior to use to ensure they were fully dried. $0.2 \%$ chloroform (99.96\%, Cambridge Isotope Laboratory) was added to the anion stock solution to preserve the nitrite and nitrate. Calibration standards were made from dilutions of the stock solution to be made up to $98 \%$ IPA $/ 2 \%$ water solutions.

Standard dilutions between 1:100 and 1:4000 were made from which linear calibration curves were created. Stock solutions were kept in the refrigerator for several weeks in well-sealed glass vials. Calibration standards were diluted fresh daily. The concentrations of the anion calibrations standards for the different periods of this study are shown in Tables 2 through 5 (below).

Table 2 Calibration standards' concentrations from anion analysis in February 2016.

\begin{tabular}{lrrrrrrrrr}
\hline & \multicolumn{10}{c}{ Ion Concentration [mg/L, ppm] } \\
\cline { 2 - 10 } \multicolumn{1}{c}{ Ion } & Stock & $1: 100$ & $1: 200$ & $1: 500$ & $1: 1000$ & $1: 1500$ & $1: 2000$ & $1: 3000$ & $1: 4000$ \\
Solution & Dilution & Dilution & Dilution & Dilution & Dilution & Dilution & Dilution & Dilution \\
\hline Glycolate & 1499 & 14.99 & 7.49 & 3.00 & 1.50 & 1.00 & 0.75 & 0.50 & 0.37 \\
Acetate & 5000 & 50.00 & 25.00 & 10.00 & 5.00 & 3.33 & 2.50 & 1.67 & 1.25 \\
Lactate & 1512 & 15.12 & 7.56 & 3.02 & 1.51 & 1.01 & 0.76 & 0.50 & 0.38 \\
Formate & 2000 & 20.00 & 10.00 & 4.00 & 2.00 & 1.33 & 1.00 & 0.67 & 0.50 \\
Chloride & 1000 & 10.00 & 5.00 & 2.00 & 1.00 & 0.67 & 0.50 & 0.33 & 0.25 \\
Nitrite & 4999 & 49.99 & 25.00 & 10.00 & 5.00 & 3.33 & 2.50 & 1.67 & 1.25 \\
Sulfate & 1000 & 10.00 & 5.00 & 2.00 & 1.00 & 0.67 & 0.50 & 0.33 & 0.25 \\
Nitrate & 2000 & 20.00 & 10.00 & 4.00 & 2.00 & 1.33 & 1.00 & 0.67 & 0.50 \\
\hline
\end{tabular}


Table 3 Calibration standards' concentrations from anion analysis in March 2016

\begin{tabular}{lcrrrrrr}
\hline & \multicolumn{7}{c}{ Ion Concentration [mg/L, ppm] } \\
\cline { 2 - 8 } \multicolumn{1}{c}{ Ion } & Stock & $1: 100$ & $1: 200$ & $1: 500$ & $1: 1000$ & $1: 1500$ & $1: 2000$ \\
\hline Slycolate & 1499 & 14.99 & 7.49 & 3.00 & 1.50 & 1.00 & 0.75 \\
Acetate & 5000 & 50.00 & 25.00 & 10.00 & 5.00 & 3.33 & 2.50 \\
Lactate & 1512 & 15.12 & 7.56 & 3.02 & 1.51 & 1.01 & 0.76 \\
Formate & 2000 & 20.00 & 10.00 & 4.00 & 2.00 & 1.33 & 1.00 \\
Chloride & 1000 & 10.00 & 5.00 & 2.00 & 1.00 & 0.67 & 0.50 \\
Nitrite & 4999 & 49.99 & 25.00 & 10.00 & 5.00 & 3.33 & 2.50 \\
Sulfate & 1000 & 10.00 & 5.00 & 2.00 & 1.00 & 0.67 & 0.50 \\
Nitrate & 2000 & 20.00 & 10.00 & 4.00 & 2.00 & 1.33 & 1.00 \\
\hline
\end{tabular}

Table 4 Calibration standards' concentrations from anion analysis in October 2016.

\begin{tabular}{|c|c|c|c|c|c|c|c|c|}
\hline \multirow[b]{2}{*}{ Ion } & \multicolumn{8}{|c|}{ Ion Concentration [mg/L, ppm] } \\
\hline & $\begin{array}{c}\text { Stock } \\
\text { Solution }\end{array}$ & $\begin{array}{c}1: 100 \\
\text { Dilution }\end{array}$ & $\begin{array}{c}1: 200 \\
\text { Dilution }\end{array}$ & $\begin{array}{c}1: 500 \\
\text { Dilution }\end{array}$ & $\begin{array}{c}1: 1000 \\
\text { Dilution }\end{array}$ & $\begin{array}{c}1: 1600 \\
\text { Dilution }\end{array}$ & $\begin{array}{c}1: 2000 \\
\text { Dilution }\end{array}$ & $\begin{array}{c}1: 3000 \\
\text { Dilution }\end{array}$ \\
\hline Glycolate & 496 & 4.96 & 2.48 & 0.99 & 0.50 & 0.31 & 0.25 & 0.17 \\
\hline Acetate & 1793 & 17.93 & 8.97 & 3.59 & 1.79 & 1.12 & 0.90 & 0.60 \\
\hline Lactate & 2751 & 27.51 & 13.75 & 5.50 & 2.75 & 1.72 & 1.38 & 0.92 \\
\hline Formate & 818 & 8.18 & 4.09 & 1.64 & 0.82 & 0.51 & 0.41 & 0.27 \\
\hline Chloride & 415 & 4.15 & 2.07 & 0.83 & 0.41 & 0.26 & 0.21 & 0.14 \\
\hline Nitrite & 2495 & 24.95 & 12.48 & 4.99 & 2.50 & 1.56 & 1.25 & 0.83 \\
\hline Sulfate & 125 & 1.25 & 0.63 & 0.25 & 0.13 & 0.08 & 0.06 & 0.04 \\
\hline Nitrate & 257 & 2.57 & 1.28 & 0.52 & 0.26 & 0.16 & 0.13 & 0.09 \\
\hline
\end{tabular}

Table 5 Calibration standards' concentrations from anion analysis in May 2017.

\begin{tabular}{lrrrrrrrr}
\hline & \multicolumn{7}{c}{ Ion Concentration $[\mathrm{mg} / \mathrm{L}, \mathrm{ppm}]$} \\
\cline { 2 - 9 } \multicolumn{1}{c}{ Ion } & Stock & $1: 100$ & $1: 200$ & $1: 500$ & $1: 1000$ & $1: 1600$ & $1: 2000$ & $1: 3000$ \\
\hline Glycolate & 441 & 4.411 & 2.205 & 0.882 & 0.441 & 0.276 & 0.221 & 0.147 \\
Acetate & 1803 & 18.030 & 9.015 & 3.606 & 1.803 & 1.127 & 0.901 & 0.601 \\
Lactate & 1999 & 19.993 & 9.997 & 3.999 & 1.999 & 1.250 & 1.000 & 0.666 \\
Formate & 800 & 7.996 & 3.998 & 1.599 & 0.800 & 0.500 & 0.400 & 0.267 \\
Chloride & 399 & 3.985 & 1.993 & 0.797 & 0.399 & 0.249 & 0.199 & 0.133 \\
Nitrite & 2514 & 25.141 & 12.570 & 5.028 & 2.514 & 1.571 & 1.257 & 0.838 \\
Sulfate & 90 & 0.899 & 0.450 & 0.180 & 0.090 & 0.056 & 0.045 & 0.030 \\
Nitrate & 268 & 2.677 & 1.339 & 0.535 & 0.268 & 0.167 & 0.134 & 0.089 \\
\hline
\end{tabular}




\subsubsection{Cation-Exchange Ion Chromatography}

Cation samples were run on an IonPac ${ }^{\mathrm{TM}} \mathrm{CS} 12 \mathrm{~A}$ analytical cation-exchange column $(4 \mathrm{x}$ $250 \mathrm{~mm}$, Dionex) with the corresponding guard column (4 x $50 \mathrm{~mm}$, Dionex). The cation system is run using a methanesulfonic acid (MSA) EGC (Dionex) with an isocratic eluent concentration. The system uses a CERS 500 electrolytically regenerated suppressor (4 $\mathrm{mm}$, Dionex) set at a current of $59 \mathrm{~mA}$. A sample volume of $25 \mu \mathrm{L}$ was injected into the system running at an eluent flow rate of $1.0 \mathrm{~mL} / \mathrm{min}$. The total run time was 15 minutes with a constant eluent concentration of $20 \mathrm{mM}$. No heating was implemented for the cation analysis. This method was used for all samples run through March 2016. Examples of the chromatographs obtained using this method are shown in Figure 6. 


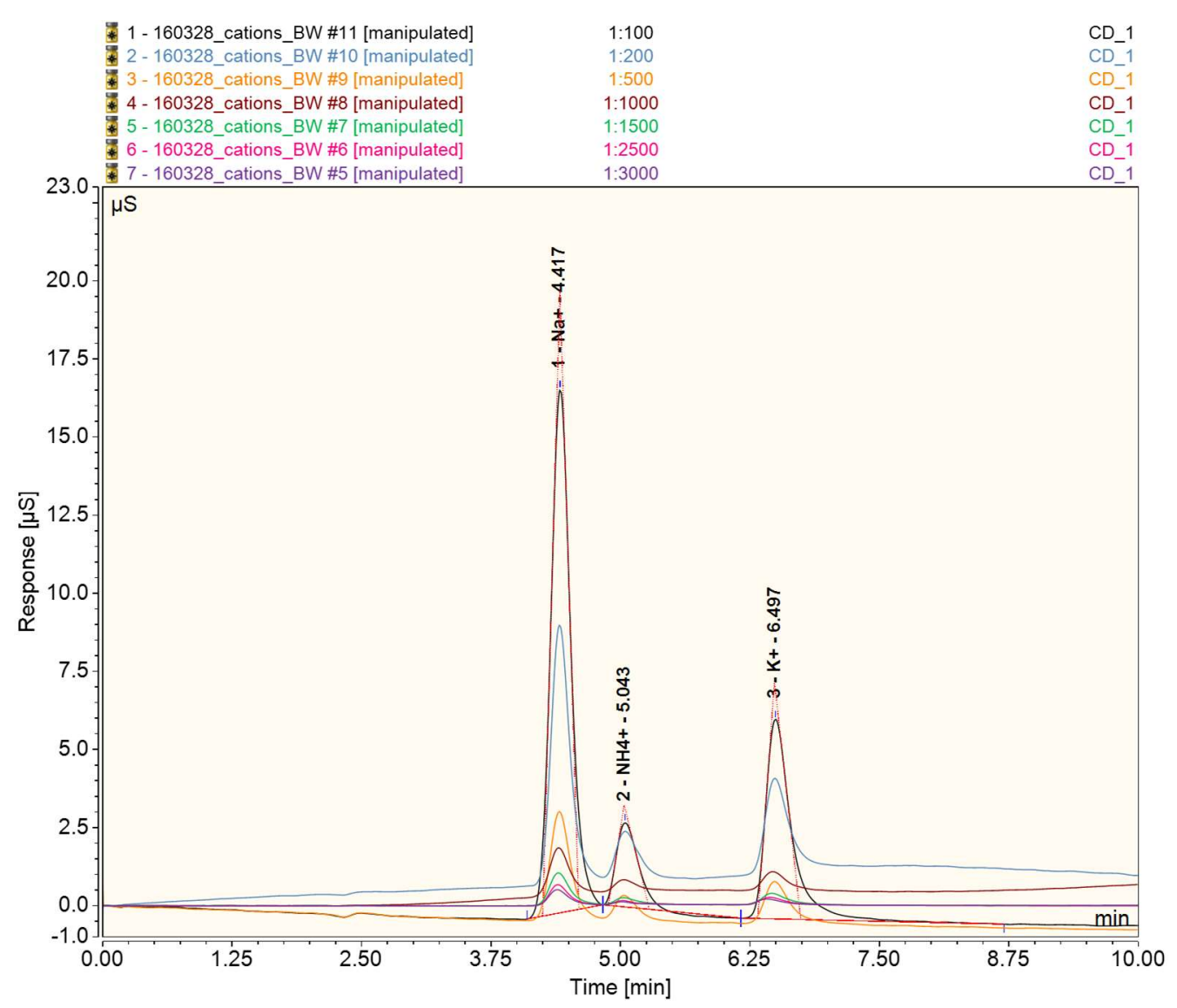

Figure 6 Cation standards run using the $1^{\text {st }}$ cation method.

To improve resolution of the sodium and ammonium peaks, the cation method was modified and the eluent concentration was decreased $(15 \mathrm{mM})$. To accommodate this lower eluent concentration, the total run time was extended to 30 minutes and the suppressor current was decreased to $44 \mathrm{~mA}$. All other settings were maintained as described above. This updated method was used for the analysis of all samples collected in October 2016 and May 2017. Examples of the chromatographs obtained using this method are shown in Figure 7. 


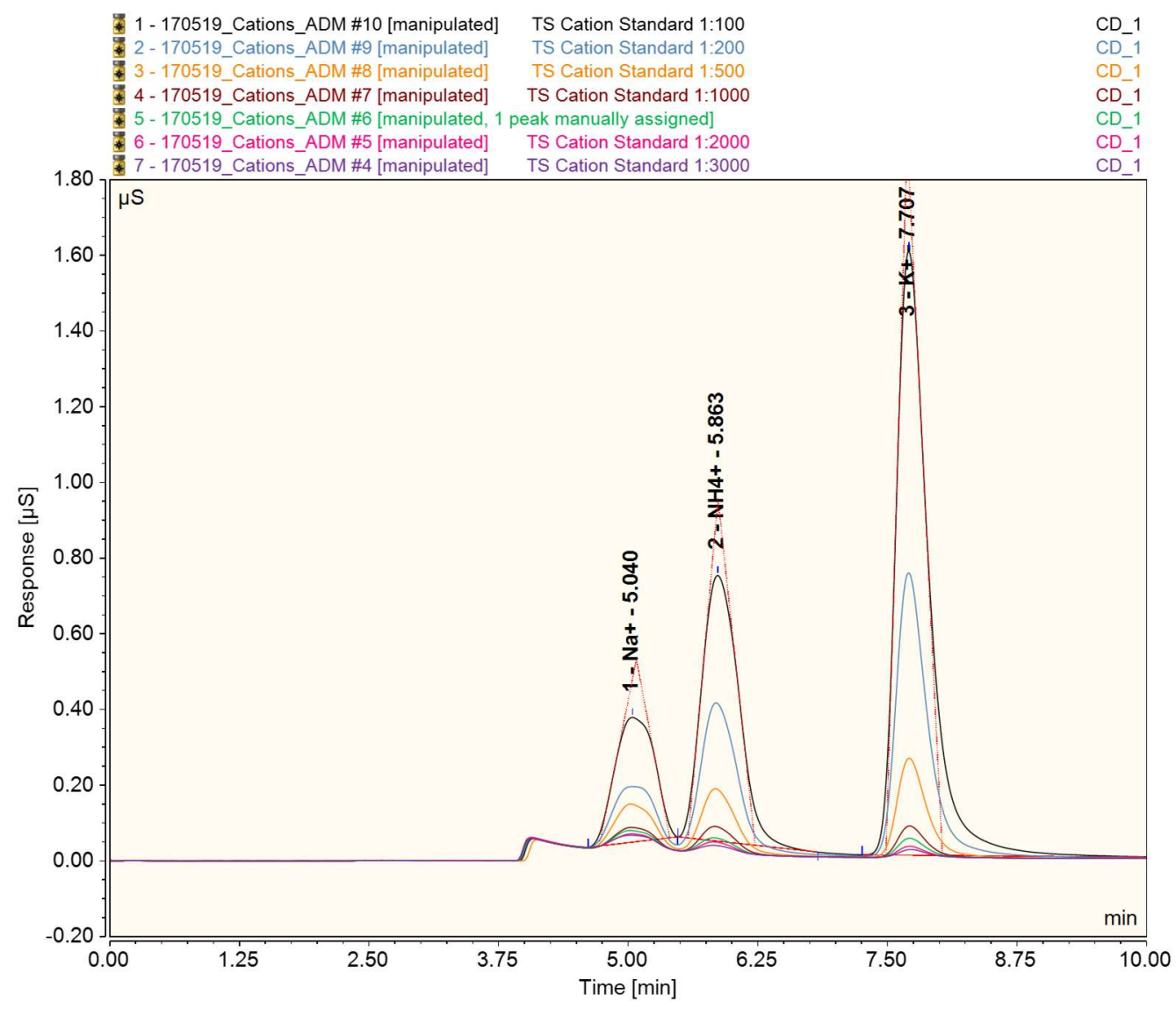

Figure 7 Cation standards run using the $2^{\text {nd }}$ cation method.

As with the anion analysis, an aqueous stock solution was made with concentrations of the three cation species of interest: sodium, ammonium, and potassium. These were found to be the most prevalent anion species based on the findings of previous studies (e.g., Nanni et al, 1990). The concentrations were determined based on observed concentrations from earlier work to obtain a representative calibration curve with dilutions between 1:100 and 1:3000. The stock solution was made from the following ACS reagents: sodium chloride ( $>99.0 \%$, Sigma Aldrich), ammonium chloride $(99.5 \%$, Acros), and potassium chloride ( $>99.0 \%$, Chem Products). All salts were stored in a desiccator for at least one week prior to use. The stock solution was stored in HDPE 
bottles, to avoid contamination from glass. Fresh dilutions for the calibration curve were made daily. The concentrations of the anion calibration standards for the different periods of this study are shown in Tables 6 through 8 (below).

Table 6 Calibration standards' concentrations for cation analysis in March 2016.

\begin{tabular}{lrrrrrrrr}
\hline & \multicolumn{7}{c}{ Ion Concentration [mg/L, ppm] } \\
\cline { 2 - 9 } \multicolumn{1}{c}{ Ion } & Stock & $1: 100$ & $1: 200$ & $1: 500$ & $1: 1000$ & $1: 1500$ & $1: 2000$ & $1: 3000$ \\
Sodium & Solution & Dilution & Dilution & Dilution & Dilution & Dilution & Dilution & Dilution \\
Ammonium & 3007 & 30.066 & 15.033 & 6.013 & 3.007 & 2.013 & 1.203 & 1.002 \\
Potassium & 993 & 9.931 & 4.966 & 1.986 & 0.993 & 0.662 & 0.397 & 0.331 \\
\hline
\end{tabular}

Table 7 Calibration standards' concentrations for cation analysis in November 2016.

\begin{tabular}{lcccccccr}
\hline & \multicolumn{7}{c}{ Ion Concentration [mg/L, ppm] } \\
\cline { 2 - 9 } \multicolumn{1}{c}{ Ion } & Stock & $1: 100$ & $1: 200$ & $1: 500$ & $1: 1000$ & $1: 1500$ & $1: 2000$ & $1: 3000$ \\
Solution & Dilution & Dilution & Dilution & Dilution & Dilution & Dilution & Dilution \\
\hline Ammonium & 101.5 & 1.015 & 0.507 & 0.203 & 0.101 & 0.063 & 0.051 & 0.034 \\
Potassium & 121.7 & 1.217 & 0.609 & 0.243 & 0.122 & 0.076 & 0.061 & 0.041 \\
\hline
\end{tabular}

Table 8 Calibration standards' concentrations for cation analysis in May 2017.

\begin{tabular}{lrrrrrrrr}
\hline & \multicolumn{8}{c}{ Ion Concentration [mg/L, ppm] } \\
\cline { 2 - 9 } \multicolumn{1}{c}{ Ion } & Stock & $1: 100$ & $1: 200$ & $1: 500$ & $1: 1000$ & $1: 1600$ & $1: 2000$ & $1: 3000$ \\
\hline Sodium & 70.8 & 0.708 & 0.354 & 0.142 & 0.071 & 0.044 & 0.035 & 0.024 \\
Ammonium & 120.1 & 1.201 & 0.600 & 0.240 & 0.120 & 0.075 & 0.060 & 0.040 \\
Potassium & 414.3 & 4.143 & 2.072 & 0.829 & 0.414 & 0.259 & 0.207 & 0.138 \\
\hline
\end{tabular}

\subsubsection{Total Nicotine Analysis}

Total nicotine content for 6-puff samples were analyzed by colleagues using GC/MS. The methods and results of this study will be published in future work (Pankow et al., 2017). 


\subsection{Results and Discussion}

The mass of wet total particulate matter (WTPM) collected for the 6-puff study ranged from 2.3 to $22.8 \mathrm{mg}$ across the brands studied (Table 9, below). The WTPM for the three brands studied in the full cigarette study ranged from 10.4 to $24.2 \mathrm{mg}$.

Table 9 Mean number of puffs (minus lighting puff) and wet total particulate matter (WTPM) from the smoking of two cigarettes from each brand $(n=3)$.

\begin{tabular}{lcrll}
\hline \multirow{2}{*}{$\begin{array}{c}\text { Sampling } \\
\text { Code }\end{array}$} & & \multicolumn{2}{c}{ WTPM [mg] } \\
\cline { 3 - 5 } \# of Puffs & Mean & \multicolumn{2}{c}{ Std. Dev. } \\
\hline 1A & 5 & 5.7 & \pm & 0.4 \\
1B & 5 & 5.8 & \pm & 1.9 \\
1C & 5 & 7.4 & \pm & 1.4 \\
2 & 5 & 2.3 & \pm & 0.6 \\
3 & 5 & 5.6 & \pm & 1.6 \\
4A & 5 & 15.4 & \pm & 0.9 \\
4B & 5 & 22.8 & \pm & 0.9 \\
5 & 5 & 4.6 & \pm & 1.2 \\
6 & 5 & 10.4 & \pm & 0.5 \\
7 & 5 & 18.0 & \pm & 1.1 \\
\hline 1Full & 11.7 & 13.7 & \pm & 0.1 \\
4Full & 7.3 & 24.2 & \pm & 1.1 \\
6Full & 8.3 & 19.3 & \pm & 2.0 \\
\hline
\end{tabular}

Sample ion chromatographs for the MS tobacco smoke samples can be found in Appendix A (p. 64). The concentrations of the anions of interest are presented in Tables

10 and 11, below. And the concentrations of the cations of interest are presented in Tables 12 and 13 below. 
Table 10 Anion concentrations measured in the pre-titration tobacco smoke samples from IC analysis of the 6-puff and full cigarette samples ( $\mathrm{n}=3$ for all brands).

\begin{tabular}{|c|c|c|c|c|c|c|c|c|}
\hline \multirow[b]{3}{*}{$\begin{array}{c}\text { Sampling } \\
\text { Code }\end{array}$} & \multicolumn{8}{|c|}{ Anions (neq/mg WTPM) } \\
\hline & \multicolumn{2}{|c|}{ Glycolate } & \multicolumn{2}{|c|}{ Acetate } & \multicolumn{2}{|c|}{ Lactate } & \multicolumn{2}{|c|}{ Formate } \\
\hline & Mean & $\begin{array}{l}\text { Std. } \\
\text { Dev. }\end{array}$ & Mean & $\begin{array}{l}\text { Std. } \\
\text { Dev. }\end{array}$ & Mean & $\begin{array}{l}\text { Std. } \\
\text { Dev. }\end{array}$ & Mean & $\begin{array}{l}\text { Std. } \\
\text { Dev. }\end{array}$ \\
\hline $1 \mathrm{~A}$ & 21.78 & \pm 2.46 & 100.18 & \pm 2.71 & 62.00 & \pm 4.30 & 64.42 & \pm 2.02 \\
\hline 1B & 17.98 & \pm 0.49 & 92.06 & \pm 21.87 & 55.59 & \pm 0.28 & 53.61 & \pm 5.28 \\
\hline $1 \mathrm{C}$ & 40.16 & \pm 2.37 & 160.55 & \pm 4.62 & 55.97 & \pm 3.78 & 79.83 & \pm 2.75 \\
\hline 2 & 8.63 & \pm 2.97 & 40.99 & \pm 19.04 & 106.51 & \pm 24.82 & 34.37 & \pm 9.26 \\
\hline 3 & 12.05 & \pm 1.42 & 72.42 & \pm 6.85 & 94.96 & \pm 19.84 & 48.59 & \pm 7.70 \\
\hline $4 \mathrm{~A}$ & 19.31 & \pm 2.34 & 159.78 & \pm 13.95 & n.a. & \pm n.a. & 69.44 & \pm 5.84 \\
\hline $4 \mathrm{~B}$ & 43.23 & \pm 1.09 & 228.24 & \pm 5.45 & 63.77 & \pm 1.66 & 101.29 & \pm 2.23 \\
\hline 5 & 18.87 & \pm 8.44 & 98.10 & \pm 32.34 & 111.13 & \pm 37.93 & 90.78 & \pm 28.55 \\
\hline 6 & 18.88 & \pm 1.37 & 93.09 & \pm 8.21 & 62.54 & \pm 5.42 & 55.03 & \pm 5.34 \\
\hline 7 & 15.65 & \pm 1.35 & 124.49 & \pm 21.00 & 83.19 & \pm 8.62 & 80.00 & \pm 8.36 \\
\hline 1Full & 12.88 & \pm 1.06 & 165.82 & \pm 20.63 & 72.40 & \pm 6.05 & 72.11 & \pm 4.31 \\
\hline 4Full & 22.13 & \pm 3.95 & 153.22 & \pm 4.34 & 79.00 & \pm 0.88 & 82.93 & \pm 3.29 \\
\hline 6Full & 15.24 & \pm 0.71 & 123.25 & \pm 4.17 & 84.95 & \pm 2.34 & 75.60 & \pm 2.40 \\
\hline
\end{tabular}

\begin{tabular}{|c|c|c|c|c|c|c|c|c|}
\hline \multirow[b]{3}{*}{$\begin{array}{l}\text { Sampling } \\
\text { Code }\end{array}$} & \multicolumn{8}{|c|}{ Anions (neq/mg WTPM) } \\
\hline & \multicolumn{2}{|c|}{ Chloride } & \multicolumn{2}{|c|}{ Nitrite } & \multicolumn{2}{|c|}{ Sulfate } & \multicolumn{2}{|c|}{ Nitrate } \\
\hline & Mean & $\begin{array}{l}\text { Std. } \\
\text { Dev. }\end{array}$ & Mean & $\begin{array}{l}\text { Std. } \\
\text { Dev. }\end{array}$ & Mean & $\begin{array}{l}\text { Std. } \\
\text { Dev. }\end{array}$ & Mean & $\begin{array}{l}\text { Std. } \\
\text { Dev. }\end{array}$ \\
\hline $1 \mathrm{~A}$ & 8.37 & \pm 2.54 & 68.50 & \pm 7.74 & 10.36 & \pm 1.99 & n.d. & \pm n.d. \\
\hline $1 \mathrm{~B}$ & 0.59 & \pm 0.43 & 9.93 & \pm 7.55 & 1.37 & \pm 1.04 & 1.99 & \pm 2.81 \\
\hline $1 \mathrm{C}$ & 6.74 & \pm 0.85 & 34.11 & \pm 1.28 & 1.53 & \pm 0.40 & 5.20 & \pm 2.03 \\
\hline 2 & 23.22 & \pm 6.16 & 204.67 & \pm 73.06 & n.d. & \pm n.d. & n.d. & \pm n.d. \\
\hline 3 & 37.26 & \pm 7.24 & 294.51 & \pm 25.27 & n.d. & \pm n.d. & 5.44 & \pm 1.24 \\
\hline $4 \mathrm{~A}$ & 43.27 & \pm 3.49 & 142.92 & \pm 1.60 & 3.31 & \pm 0.31 & 13.66 & \pm 0.56 \\
\hline $4 \mathrm{~B}$ & 54.63 & \pm 6.33 & 207.54 & \pm 12.16 & 3.56 & \pm 0.37 & 24.32 & \pm 2.09 \\
\hline 5 & 39.95 & \pm 11.37 & 328.86 & \pm 99.44 & n.d. & \pm n.d. & 5.84 & \pm 0.75 \\
\hline 6 & 20.25 & \pm 1.69 & 91.47 & \pm 6.07 & 2.13 & \pm 0.20 & 5.62 & \pm 0.66 \\
\hline 7 & 27.14 & \pm 1.09 & 192.71 & \pm 18.55 & 4.29 & \pm 0.32 & 6.64 & \pm 0.17 \\
\hline 1Full & 5.78 & \pm 1.37 & 98.82 & \pm 15.62 & 2.20 & \pm 0.62 & 3.03 & \pm 2.62 \\
\hline 4Full & 49.39 & \pm 6.97 & 341.75 & \pm 3.43 & 3.13 & \pm 0.17 & 9.77 & \pm 0.27 \\
\hline 6Full & 27.11 & \pm 0.96 & 278.32 & \pm 14.69 & 3.69 & \pm 0.50 & 5.42 & \pm 0.69 \\
\hline
\end{tabular}

*n.a. $=$ information not available. Compound was detected, but unable to quantify the amount.

** n.d. = compound not detected or in concentrations below the detection limit. 
Table 11 Anion concentrations measured in the post-titration tobacco smoke samples from IC analysis of the 6-puff and full samples ( $\mathrm{n}=3$ for all brands).

\begin{tabular}{|c|c|c|c|c|c|c|c|c|c|c|c|c|}
\hline \multirow[b]{3}{*}{$\begin{array}{c}\text { Sampling } \\
\text { Code }\end{array}$} & \multicolumn{12}{|c|}{ Anions (neq/mg WTPM) } \\
\hline & \multicolumn{3}{|c|}{ Glycolate } & \multicolumn{3}{|c|}{ Acetate } & \multicolumn{3}{|c|}{ Lactate } & \multicolumn{3}{|c|}{ Formate } \\
\hline & Mean & & $\begin{array}{l}\text { Std. } \\
\text { Dev. }\end{array}$ & Mean & & $\begin{array}{l}\text { Std. } \\
\text { Dev. }\end{array}$ & Mean & & $\begin{array}{l}\text { Std. } \\
\text { Dev. }\end{array}$ & Mean & & $\begin{array}{l}\text { Std. } \\
\text { Dev. }\end{array}$ \\
\hline $1 \mathrm{~A}$ & 19.47 & \pm & 2.03 & 102.39 & \pm & 8.70 & 68.21 & \pm & 3.84 & 66.03 & \pm & 2.09 \\
\hline 1B & 21.93 & \pm & 3.69 & 94.75 & \pm & 21.51 & 63.80 & \pm & 10.39 & 56.55 & \pm & 3.19 \\
\hline $1 \mathrm{C}$ & 37.30 & \pm & 6.75 & 135.83 & \pm & 19.18 & 32.61 & \pm & 24.03 & 70.90 & \pm & 12.40 \\
\hline 2 & 9.91 & \pm & 2.54 & 36.10 & \pm & 26.04 & 138.37 & \pm & 27.78 & 25.35 & \pm & 5.98 \\
\hline 3 & 11.53 & \pm & 1.86 & 59.55 & \pm & 1.23 & 118.13 & \pm & 30.65 & 43.05 & \pm & 3.80 \\
\hline $4 \mathrm{~A}$ & 20.42 & \pm & 1.56 & 166.35 & \pm & 17.85 & n.a. & \pm & n.a. & 66.17 & \pm & 6.90 \\
\hline 4B & 46.10 & \pm & 0.89 & 250.56 & \pm & 2.14 & 65.10 & \pm & 1.62 & 101.45 & \pm & 1.35 \\
\hline 5 & 10.25 & \pm & 6.66 & 71.71 & \pm & 21.14 & 111.62 & \pm & 31.64 & 79.17 & \pm & 25.51 \\
\hline 6 & 19.18 & \pm & 1.40 & 91.55 & \pm & 6.69 & 59.93 & \pm & 3.54 & 50.04 & \pm & 3.62 \\
\hline 7 & 17.34 & \pm & 1.88 & 116.14 & \pm & 26.14 & 55.10 & \pm & 39.92 & 75.74 & \pm & 9.51 \\
\hline 1Full & 12.60 & \pm & 2.08 & 141.64 & \pm & 22.09 & 67.95 & \pm & 8.28 & 70.90 & \pm & 12.40 \\
\hline 4Full & 15.48 & \pm & 0.58 & 152.82 & \pm & 10.17 & 77.85 & \pm & 4.99 & 78.37 & \pm & 6.65 \\
\hline 6Full & 14.64 & \pm & 0.94 & 120.31 & \pm & 7.01 & 82.58 & \pm & 2.55 & 74.82 & \pm & 1.48 \\
\hline
\end{tabular}

\begin{tabular}{|c|c|c|c|c|c|c|c|c|c|}
\hline \multirow[b]{3}{*}{$\begin{array}{c}\text { Sampling } \\
\text { Code }\end{array}$} & \multicolumn{9}{|c|}{ Anions (neq/mg WTPM) } \\
\hline & \multicolumn{3}{|c|}{ Nitrite } & \multicolumn{3}{|c|}{ Sulfate } & \multicolumn{3}{|c|}{ Nitrate } \\
\hline & Mean & & $\begin{array}{l}\text { Std. } \\
\text { Dev. }\end{array}$ & Mean & & $\begin{array}{l}\text { Std. } \\
\text { Dev. }\end{array}$ & Mean & & $\begin{array}{l}\text { Std. } \\
\text { Dev. }\end{array}$ \\
\hline $1 \mathrm{~A}$ & n.d. & \pm & n.d. & 14.50 & \pm & 3.57 & 26.61 & \pm & 1.08 \\
\hline 1B & 0.27 & \pm & 0.38 & 1.08 & \pm & 0.78 & 14.52 & \pm & 4.68 \\
\hline $1 \mathrm{C}$ & n.d. & \pm & n.d. & 3.25 & \pm & 1.33 & 9.71 & \pm & 1.15 \\
\hline 2 & n.d. & \pm & n.d. & n.d. & \pm & n.d. & 18.79 & \pm & 5.78 \\
\hline 3 & 19.07 & \pm & 17.65 & n.d. & \pm & n.d. & 20.61 & \pm & 3.56 \\
\hline $4 \mathrm{~A}$ & 5.16 & \pm & 0.89 & 3.97 & \pm & 0.19 & 35.73 & \pm & 3.74 \\
\hline 4B & 16.20 & \pm & 1.21 & 4.28 & \pm & 0.26 & 58.38 & \pm & 4.19 \\
\hline 5 & 12.03 & \pm & 3.62 & n.d. & \pm & n.d. & 35.67 & \pm & 11.77 \\
\hline 6 & 10.53 & \pm & 0.55 & 3.36 & \pm & 0.10 & 22.31 & \pm & 2.79 \\
\hline 7 & 24.62 & \pm & 3.48 & 6.93 & \pm & 0.66 & 19.50 & \pm & 1.70 \\
\hline 1Full & 7.25 & \pm & 10.26 & 0.60 & \pm & 0.42 & 6.78 & \pm & 1.42 \\
\hline 4Full & 39.25 & \pm & 0.22 & 5.23 & \pm & 0.13 & 27.19 & \pm & 0.91 \\
\hline 6Full & 19.02 & \pm & 3.48 & 4.94 & \pm & 0.54 & 24.88 & \pm & 0.78 \\
\hline
\end{tabular}


Table 12 Cation concentrations measured in the pre-titration tobacco smoke samples from IC analysis for 6-puff and full cigarette samples ( $\mathrm{n}=3$ for all brands).

\begin{tabular}{|c|c|c|c|c|c|c|c|c|c|}
\hline \multirow{4}{*}{$\begin{array}{c}\text { Sampling } \\
\text { Code }\end{array}$} & \multicolumn{9}{|c|}{ Cations (neq/mg WTPM) } \\
\hline & \multicolumn{3}{|c|}{ Sodium } & \multicolumn{3}{|c|}{ Ammonium } & \multicolumn{3}{|c|}{ Potassium } \\
\hline & & & Std. & & & Std. & & & Std. \\
\hline & Mean & & Dev. & Mean & & Dev. & Mean & & Dev. \\
\hline $1 \mathrm{~A}$ & 0.25 & \pm & 0.36 & 15.37 & \pm & 2.79 & 22.50 & \pm & 2.86 \\
\hline $1 \mathrm{~B}$ & 2.25 & \pm & 0.90 & 8.18 & \pm & 1.67 & 29.40 & \pm & 4.13 \\
\hline $1 \mathrm{C}$ & 0.67 & \pm & 0.91 & 7.91 & \pm & 1.03 & 12.91 & \pm & 1.33 \\
\hline 2 & 5.70 & \pm & 4.10 & 30.50 & \pm & 3.88 & 20.69 & \pm & 4.15 \\
\hline 3 & 11.44 & \pm & 2.50 & 26.38 & \pm & 3.31 & 71.29 & \pm & 17.22 \\
\hline $4 \mathrm{~A}$ & 0.97 & \pm & 0.35 & 20.42 & \pm & 1.80 & 82.53 & \pm & 15.30 \\
\hline $4 B$ & 1.10 & \pm & 0.13 & 23.09 & \pm & 0.38 & 96.30 & \pm & 12.49 \\
\hline 5 & 0.31 & \pm & 0.33 & 21.10 & \pm & 8.75 & 83.34 & \pm & 25.16 \\
\hline 6 & 1.76 & \pm & 0.24 & 17.23 & \pm & 1.60 & 33.64 & \pm & 2.61 \\
\hline 7 & 2.38 & \pm & 0.76 & 19.29 & \pm & 1.94 & 66.60 & \pm & 12.28 \\
\hline 1Full & n.d. & \pm & n.d. & 12.29 & \pm & 2.09 & 14.16 & \pm & 0.72 \\
\hline 4Full & 2.39 & \pm & 0.47 & 21.01 & \pm & 1.28 & 120.37 & \pm & 31.60 \\
\hline 6Full & 1.62 & \pm & 0.39 & 21.98 & \pm & 1.47 & 56.73 & \pm & 4.63 \\
\hline
\end{tabular}

Table 13 Cation concentrations measured in the post-titration tobacco smoke samples from IC analysis for 6-puff and full cigarette samples ( $\mathrm{n}=3$ for all brands).

\begin{tabular}{|c|c|c|c|c|c|c|c|c|c|}
\hline \multirow{4}{*}{$\begin{array}{l}\text { Sampling } \\
\text { Code }\end{array}$} & \multicolumn{9}{|c|}{ Cations (neq/mg WTPM) } \\
\hline & \multicolumn{3}{|c|}{ Sodium } & \multicolumn{3}{|c|}{ Ammonium } & \multicolumn{3}{|c|}{ Potassium } \\
\hline & & & Std. & & & Std. & & & Std. \\
\hline & Mean & & Dev. & Mean & & Dev. & Mean & & Dev. \\
\hline $1 \mathrm{~A}$ & 9.56 & \pm & 2.21 & 60.60 & \pm & 3.88 & 3.65 & \pm & 2.59 \\
\hline $1 \mathrm{~B}$ & 0.83 & \pm & 0.46 & 19.66 & \pm & 7.93 & 4.17 & \pm & 2.36 \\
\hline $1 \mathrm{C}$ & 1.25 & \pm & 0.47 & 17.97 & \pm & 1.16 & 14.29 & \pm & 1.05 \\
\hline 2 & 11.54 & \pm & 9.05 & 48.08 & \pm & 15.74 & 8.75 & \pm & 8.17 \\
\hline 3 & 25.75 & \pm & 9.49 & 59.30 & \pm & 11.99 & 104.51 & \pm & 77.63 \\
\hline $4 \mathrm{~A}$ & 1.64 & \pm & 0.15 & 51.67 & \pm & 2.11 & 73.66 & \pm & 6.50 \\
\hline $4 B$ & 3.13 & \pm & 0.65 & 43.45 & \pm & 2.43 & 92.17 & \pm & 11.43 \\
\hline 5 & 10.38 & \pm & 2.70 & 49.77 & \pm & 14.60 & 44.34 & \pm & 16.71 \\
\hline 6 & 0.80 & \pm & 0.88 & 38.45 & \pm & 0.18 & 27.16 & \pm & 4.75 \\
\hline 7 & 5.61 & \pm & 2.58 & 34.54 & \pm & 3.73 & 69.38 & \pm & 8.84 \\
\hline 1Full & 1.95 & \pm & 1.54 & 11.25 & \pm & 15.91 & 5.33 & \pm & 7.54 \\
\hline 4Full & 4.98 & \pm & 0.45 & 46.48 & \pm & 2.18 & 101.70 & \pm & 27.30 \\
\hline 6Full & 4.67 & \pm & 1.91 & 46.96 & \pm & 0.74 & 42.94 & \pm & 8.12 \\
\hline
\end{tabular}




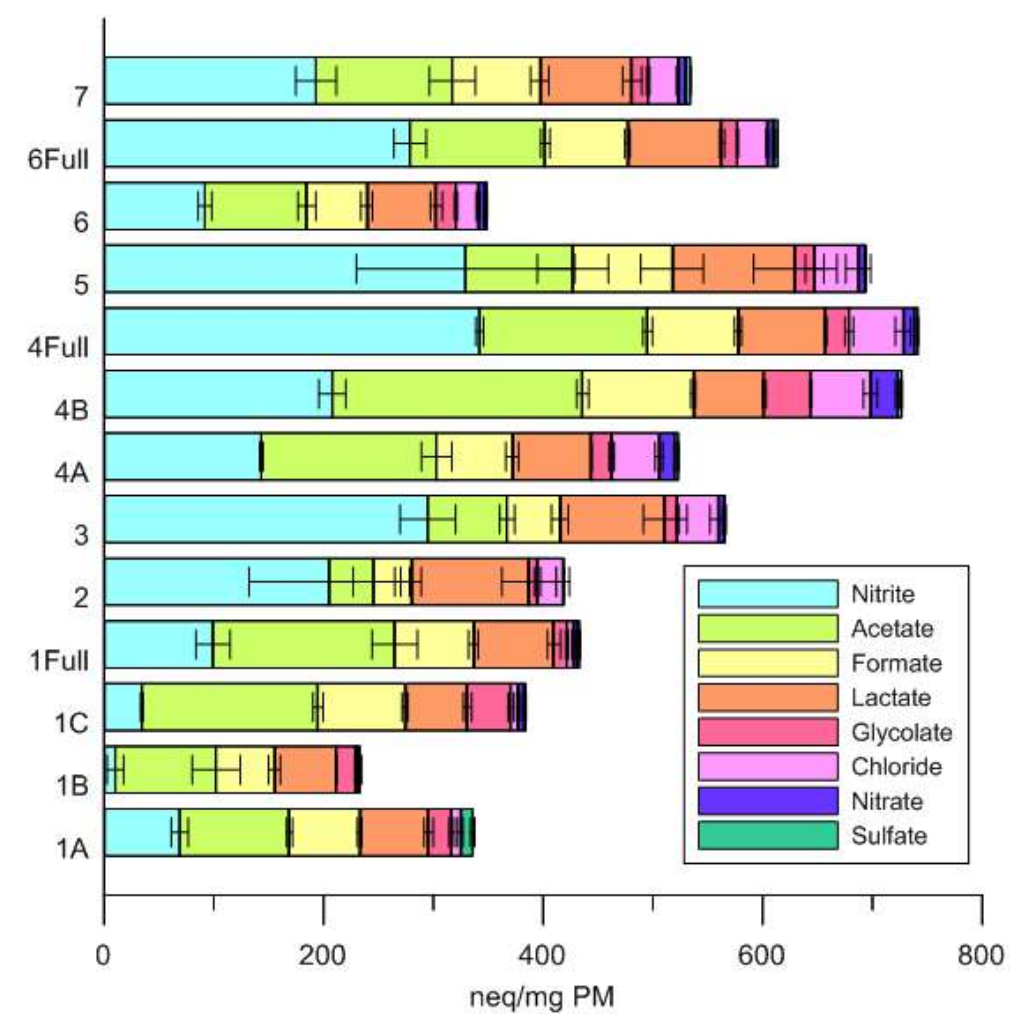

Figure 8 Total anion concentrations measured in the pre-titration samples. The error bars represent the standard deviation between the three replicates.

Nitrite and acetate were the most abundant of the anions (see Figure 8, above) in all brands excluding brand 1, which had the least amount of nitrite among the brands sampled. Sulfate was the least abundant anion studied and was below the detectable limit in the samples of brands 2, 3, and 5. Through comparison of the tracers for the weak acids (acetate, lactate, glycolate) and the tracers for strong acids (formate, chloride, nitrite, sulfate, nitrate) in Figure 9, it can be seen that all of the brands, aside from brand 1, have a larger proportion of strong acid species than weak acid species. Section 5.1 (p. 50) will further expand on this distinction between strong and weak acids in the tobacco smoke PM. 


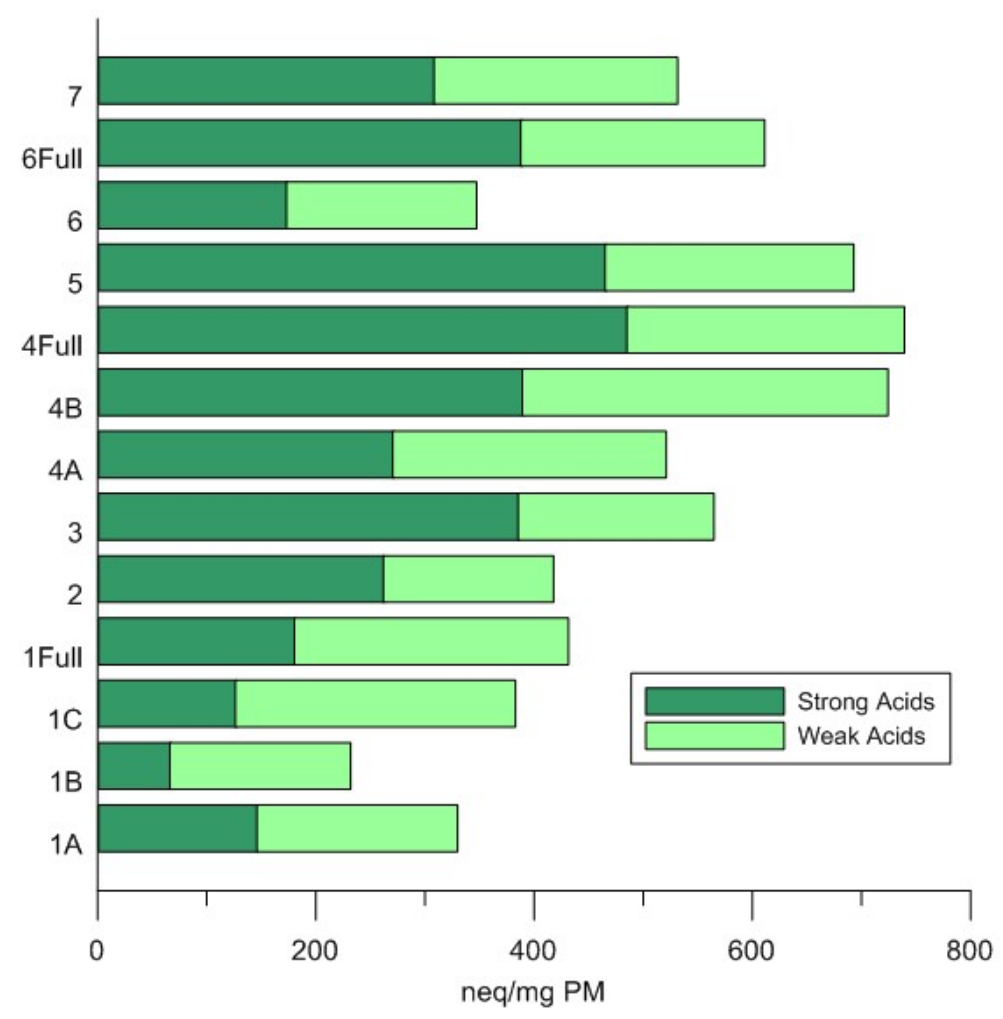

Figure 9 Comparison of concentrations for tracers of weak (acetate, lactate, glycolate) and strong (formate, chloride, nitrite, sulfate, nitrate) acids from the anion determination using IC.

Most of the concentrations of the anions were consistent from the pre- and postacidification. However, the concentrations of nitrite decreased dramatically while the concentration of nitrate increased between the two samples (see Figure 10, below). Most likely, the nitrite is being transformed into nitrate during the titration. 


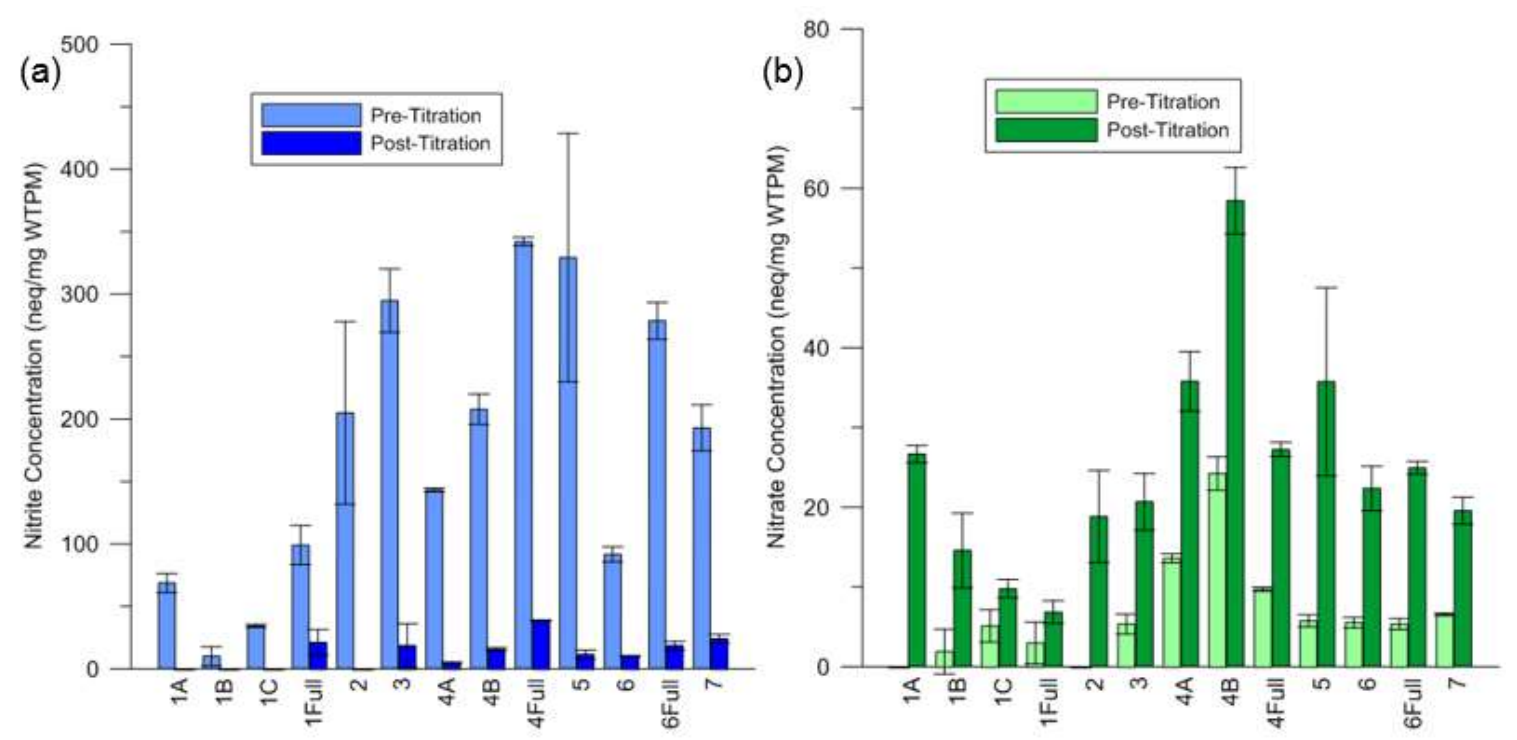

Figure 10 Changes in (a) nitrite and (b) nitrate concentrations pre- and post-titration with $\mathrm{HCl}$. Error bars represent the standard deviation between the three replicates.

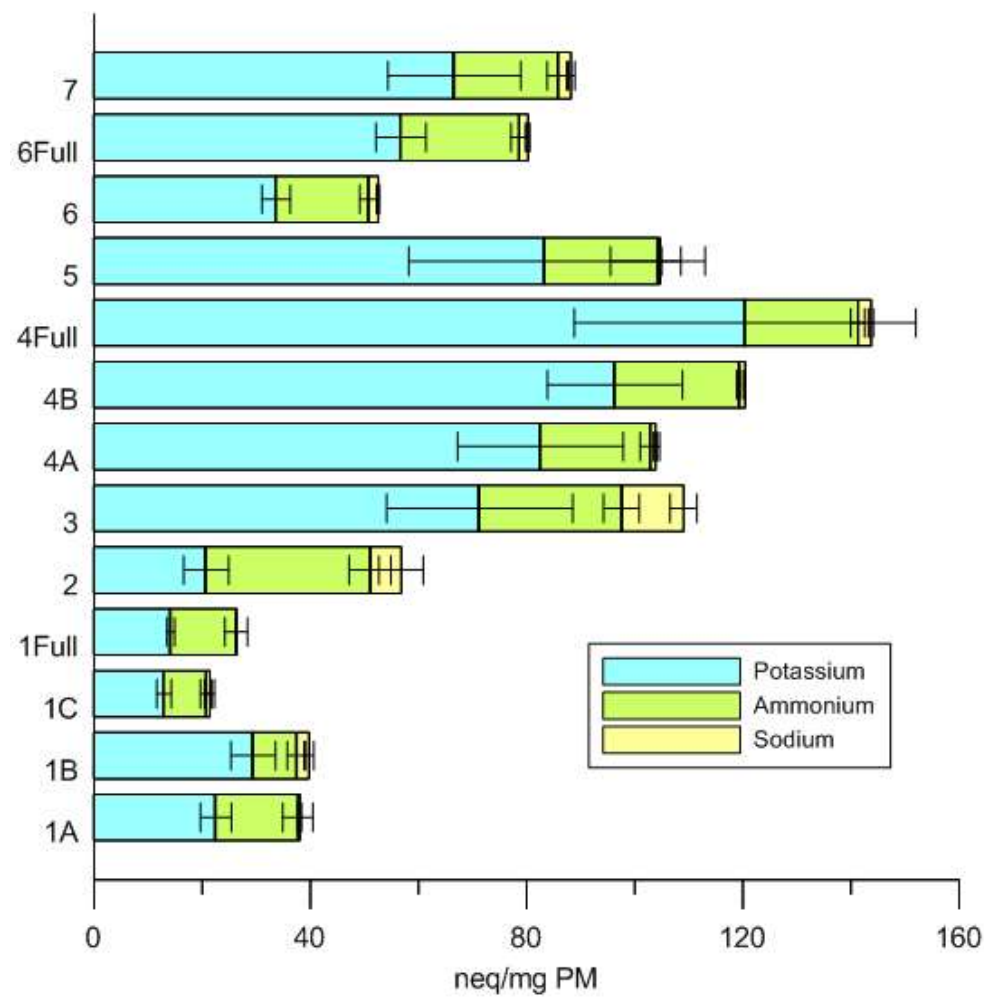

Figure 11 Total cation concentrations measured in the pre-titration samples. The error bars represent the standard deviation between the three replicates. 
Figure 11 (above) provides a comparison of the cation concentrations in the tobacco smoke samples across the various brands. Potassium is the most abundant cation species across all of the brands. The values for total cations by IC were generally much lower than values for total anions by IC. This is due to the most abundant basic species in tobacco smoke PM, nicotine, not being determined through IC analysis. If the total nicotine concentrations determined through GC/MS (see Table 14) are included with the cation data, concentrations of basic species of a similar scale to that of acidic species is observed (see Figure 12).

Table 14 Total nicotine concentrations for the seven brands of cigarettes studied (Pankow et al., 2017).

\begin{tabular}{ccll}
\hline & \multicolumn{2}{c}{$\begin{array}{c}\text { Total Nicotine } \\
{[\text { neq/mg WTPM] }}\end{array}$} \\
\cline { 2 - 3 } Brand & Mean & \multicolumn{1}{c}{ Std. Dev } \\
\hline 1 & 526.9 & \pm & 141.7 \\
2 & 302.3 & \pm & 32.6 \\
3 & 332.6 & \pm & 17.1 \\
4 & 332.7 & \pm & 44.5 \\
5 & 397.6 & \pm & 40.6 \\
6 & 364.6 & \pm & 68.1 \\
7 & 522.5 & \pm & 199.5 \\
\hline
\end{tabular}

The total nicotine levels in can be seen to vary across brands. The lowest nicotine levels were seen in brand $2(302 \pm 33$ neq/mg WTPM $)$ with the highest levels observed in brand $1(527 \pm 142 \mathrm{neq} / \mathrm{mg}$ WTPM$)$. The mean nicotine level across the brands was 397 neq/mg WTPM. These values are within the range observed in previous studies (Chen and Pankow, 2009). 


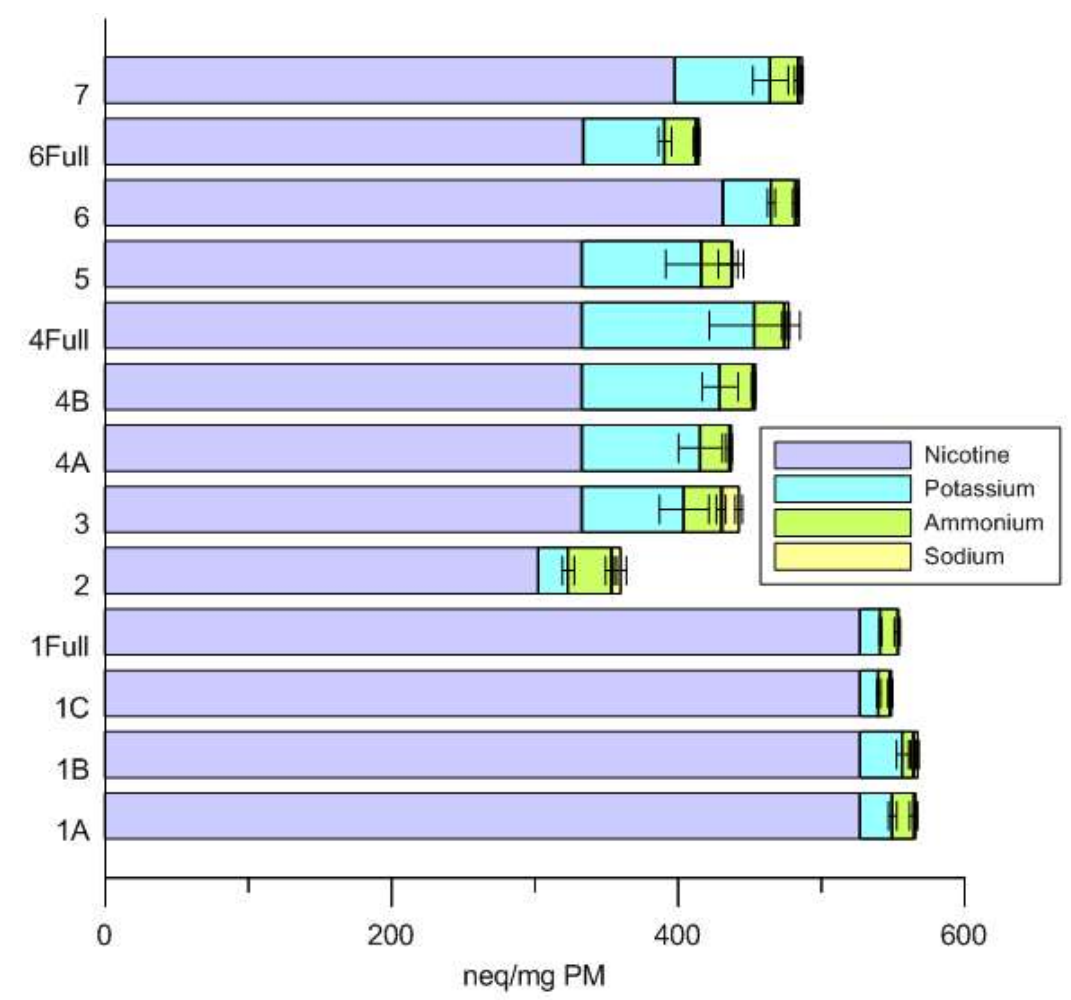

Figure 12 Comparison of basic species concentrations across brands.

From the IC data we can also see the concentration of ammonia in the tobacco smoke extract increased dramatically after the addition of acid to the solution post-titration. As discussed in the introduction, tobacco filler material contains both ammonia and ammonia forming compounds. These compounds can be both species indigenous to the tobacco leaf (e.g., amino acids, proteins) and those added to the tobacco composite (e.g., ammonium bicarbonate, ammonium hydroxide, ammonium sulfide, ammonium phosphate, urea). Some ammonia in tobacco smoke might be bound as amides, and these can release ammonia by hydrolysis:

$$
\mathrm{H}_{2} \mathrm{O}+\mathrm{RCONH}_{2} \rightarrow \mathrm{NH}_{3}+\mathrm{RCOOH}
$$


The results of the IC analysis of ammonia pre- and post-titration (see Table 15 and Figure 13) show that there was a significant portion of ammonia released. The results from this study show that the amount of ammonia in this bound state accounted for between 37 and $75 \%$ of the total ammonia in the tobacco smoke PM, with a mean of $56 \%$. This is consistent with previous studies, which have found that bound ammonia accounts for about two thirds the total ammonia (Nanni et al., 1990; Chen and Pankow, 2009).

Table 15 Ammonium concentrations pre- and post-titration with $\mathrm{HCl}$ titrant for 6-puff and full cigarette samples $(\mathrm{n}=3)$.

\begin{tabular}{|c|c|c|c|c|c|c|c|c|c|}
\hline \multirow{2}{*}{$\begin{array}{l}\text { Samplig } \\
\text { Code }\end{array}$} & \multicolumn{3}{|c|}{$\begin{array}{c}\text { Pre-Titration Ammonium } \\
\text { (Unbound) } \\
\text { [neq/mg PM] }\end{array}$} & \multicolumn{3}{|c|}{$\begin{array}{c}\text { Post-Titration Ammonium } \\
\text { (Bound + Unbound) } \\
{[\text { neq/mg PM] }}\end{array}$} & \multicolumn{3}{|c|}{$\begin{array}{l}\text { Bound Ammonium } \\
{[\text { neq/mg PM] }}\end{array}$} \\
\hline & Mean & & Std. Dev & Mean & & Std. Dev & Mean & & Std. Dev \\
\hline $1 \mathrm{~A}$ & 15.37 & \pm & 2.79 & 60.60 & \pm & 3.88 & 45.23 & \pm & 2.16 \\
\hline 1B & 8.18 & \pm & 1.67 & 19.66 & \pm & 7.93 & 11.48 & \pm & 6.28 \\
\hline $1 \mathrm{C}$ & 7.91 & \pm & 1.03 & 17.97 & \pm & 1.16 & 10.06 & \pm & 2.15 \\
\hline 2 & 30.50 & \pm & 3.88 & 48.08 & \pm & 15.74 & 17.59 & \pm & 14.80 \\
\hline 3 & 26.38 & \pm & 3.31 & 59.30 & \pm & 11.99 & 32.92 & \pm & 8.69 \\
\hline $4 \mathrm{~A}$ & 20.42 & \pm & 1.80 & 51.67 & \pm & 2.11 & 31.25 & \pm & 2.41 \\
\hline 4B & 23.09 & \pm & 0.38 & 43.45 & \pm & 2.43 & 20.36 & \pm & 2.10 \\
\hline 5 & 21.10 & \pm & 8.75 & 49.77 & \pm & 14.60 & 28.68 & \pm & 7.48 \\
\hline 6 & 17.23 & \pm & 1.60 & 38.45 & \pm & 0.18 & 21.22 & \pm & 1.61 \\
\hline 7 & 19.29 & \pm & 1.94 & 34.54 & \pm & 3.73 & 15.25 & \pm & 1.78 \\
\hline 1Full* & 12.29 & \pm & 2.09 & 33.75 & \pm & n.a. & 21.46 & \pm & n.a. \\
\hline 4Full & 21.01 & \pm & 1.28 & 46.48 & \pm & 2.18 & 25.47 & \pm & 1.60 \\
\hline 6Full & 21.98 & \pm & 1.47 & 46.96 & \pm & 0.74 & 24.98 & \pm & 0.85 \\
\hline
\end{tabular}




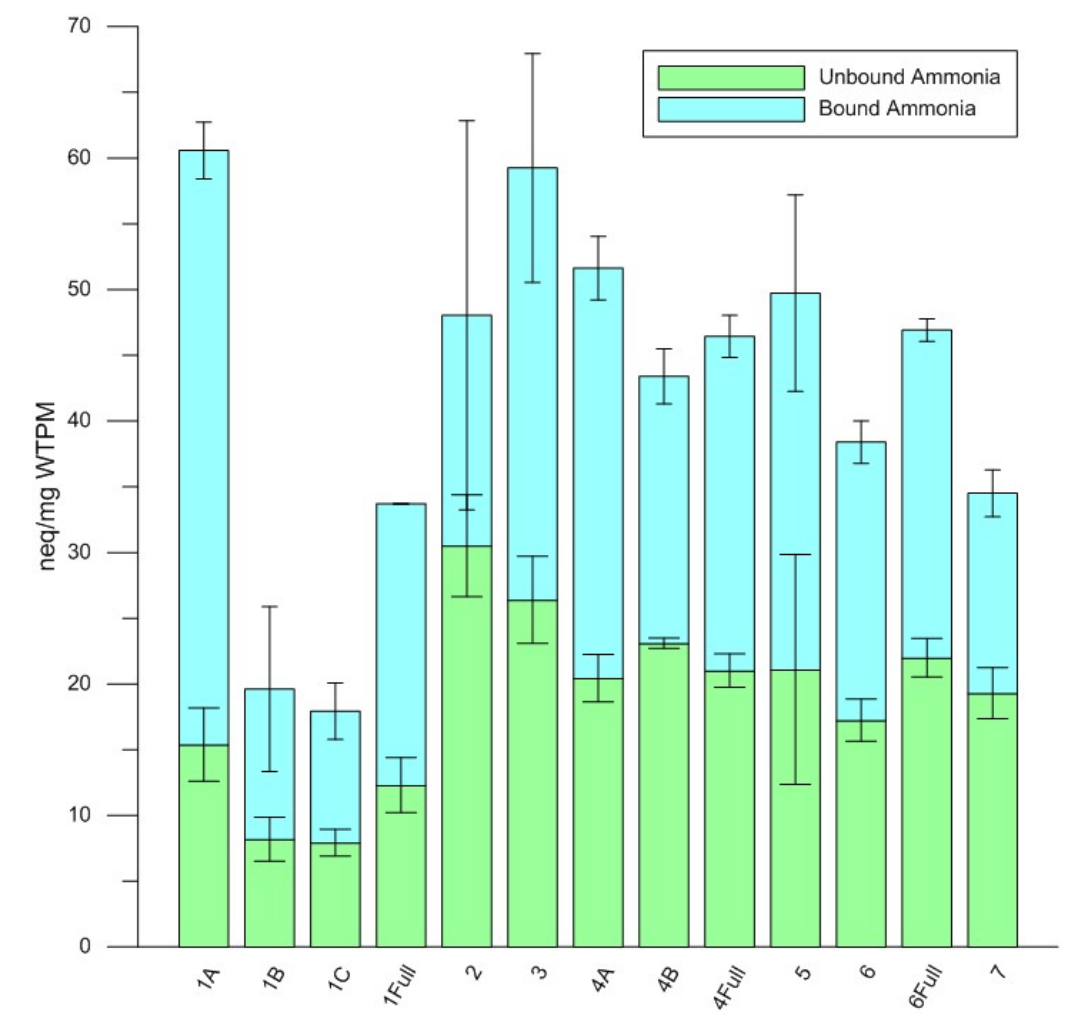

Figure 13 Ammonium concentrations pre- and post-titration with $\mathrm{HCl}$ titrant. Error bars represent the standard deviation between the replicates $(n=3)$.

Analysis of the strong acid and strong base tracers (chloride + nitrate and sodium + potassium, respectively) show that all the brands have a higher proportion of strong base tracers than strong acid (Figure 14, below). Brand 1 had the lowest levels while brand 4 had the highest. Potassium was significantly more abundant across the brands than sodium. Chloride was more abundant than nitrate across all brands. 


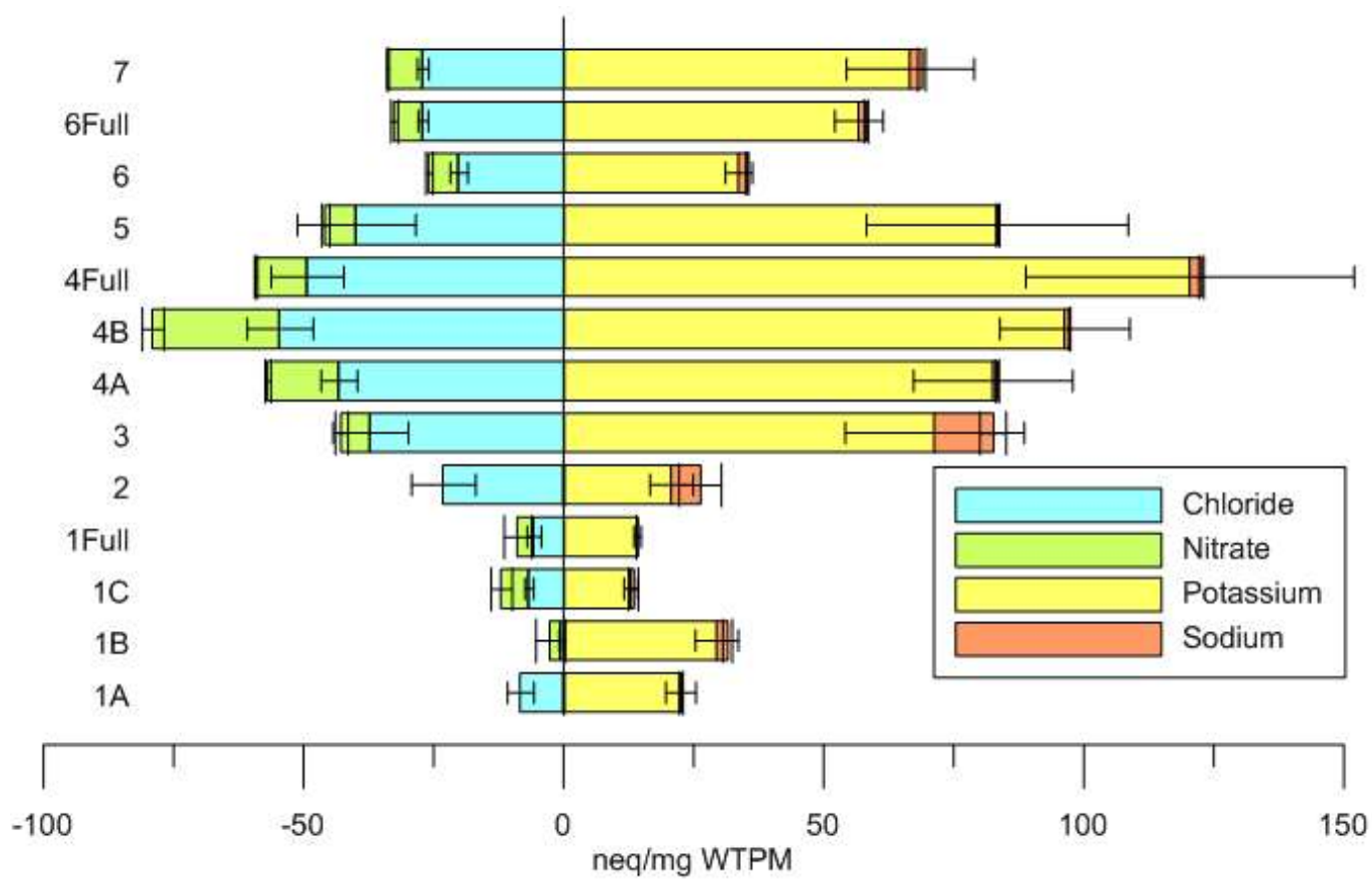

Figure 14 Concentrations of strong base tracers (sodium and potassium) and strong acid tracers (chloride and nitrate) for the tobacco smoke samples (pre-titration). Error bars show standard deviation between the replicates ( $\mathrm{n}=3$ for all brands). 


\section{Titration Analysis of Mainstream Tobacco Smoke}

\subsection{Background}

As discussed previously, this work is looking to develop an acid-base balance for MS tobacco smoke PM. Samples of the tobacco smoke extracts were titrated to confirm that all the major titratable acids and bases are being identified using the analysis method described in Chapter 2.

From these titrations we can obtain the relative acid-base content of the different cigarette brands. The amounts of titratiable acids and bases is based on the equivalence points (EPs) of the titration curves (see Figure 15, below) located at the maxima of the first derivative of the electrode potential. For the titrations of the cigarette samples, there are three, clearly distinguishable EPs. EP1 is the leftmost equivalence point and represents the point at which the organic acids and nicotine are mostly protonated in the forms $\mathrm{RCOOH}$ and $\mathrm{NicH}^{+}$, respectively. Under the view that an organic acid does not strongly protonate nicotine in IPA (see below), EP2 (the middle equivalence point) represents the point at which the organic acids are mostly protonated $(\mathrm{RCOOH})$ and the nicotine is mostly unprotonated (Nic). The third equivalence point, EP3, is the point at which both the organic acids and nicotine are mostly unprotonated ( $\mathrm{RCOO}^{-}$and Nic, respectively).

As previously stated, organic acids are less acidic in organic solvents than in aqueous solutions. Work by DeGagné (2016) showed by ${ }^{1}$ HNMR the nicotine in a 1:1 mixture with acetic acid in 95\% IPA remained mostly unprotonated. That work provided evidence 
that in a solution of IPA, the organic acids are not strong enough to fully protonate nicotine at the second equivalence point.

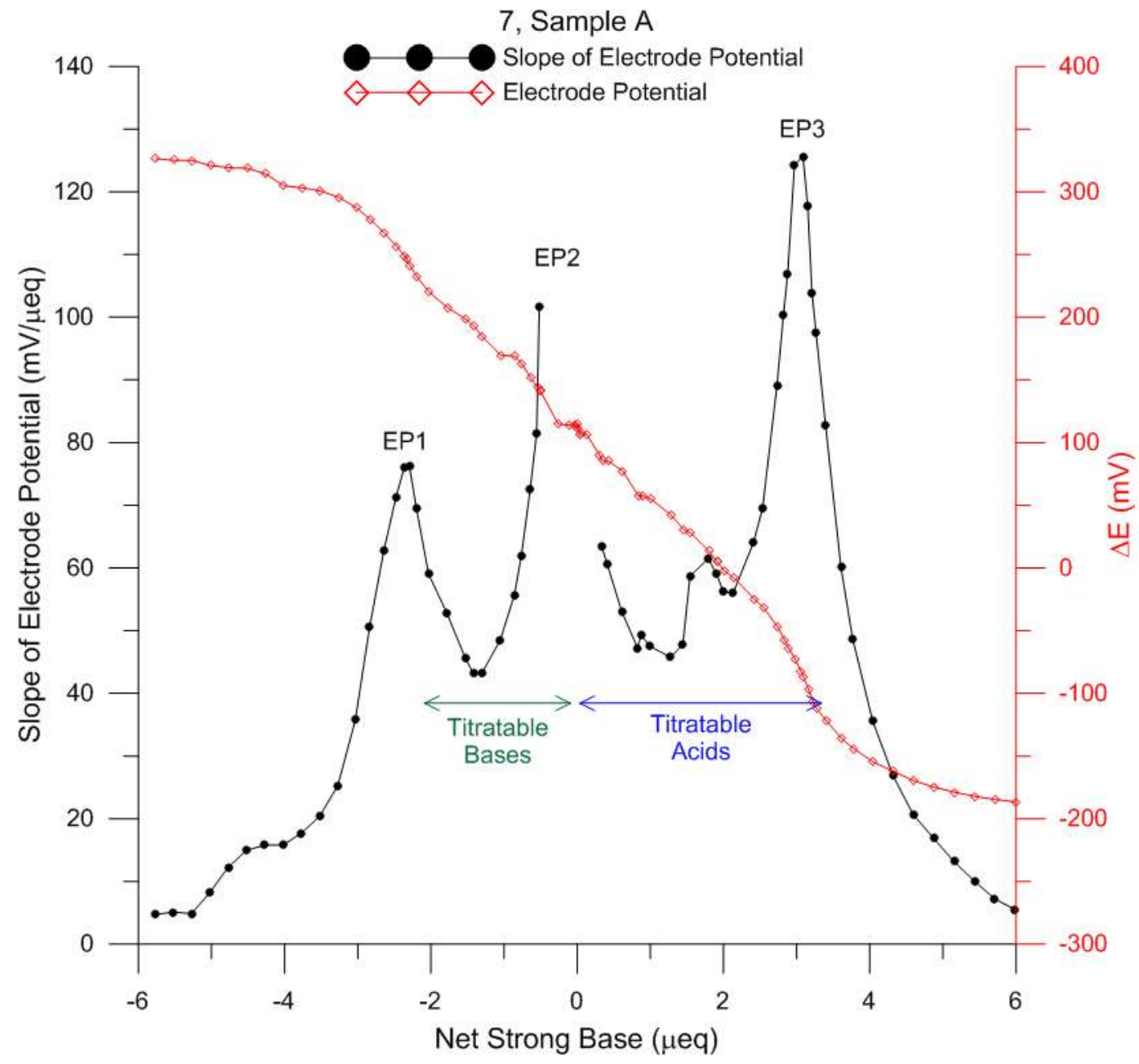

Figure 15 Example of a full titration curve (both acid and base-side) of a tobacco smoke extract.

The total titratable weak acids, $A_{T}$, is given by:

$$
A_{T}=\mathrm{NSB}_{\mathrm{EP} 3}-\mathrm{NSB}_{\mathrm{EP} 2}
$$


Where $\mathrm{NSB}_{\mathrm{EP} 3}$ is the net strong base that has been added at the third equivalence point (EP3) and $\mathrm{NSB}_{\mathrm{EP} 2}$ is the net strong base that has been added at the second equivalence point (EP2). The value of 0 pertains to the starting solution for the titration, at which point no strong acid or base has been added. All units are in equivalents strong base, with addition of strong acid expressed as negative net strong base. The total titratable weak bases, $B_{T}$, is given by:

$$
B_{T}=-\left(\mathrm{NSB}_{\mathrm{EP} 1}-\mathrm{NSB}_{\mathrm{EP} 2}\right)
$$

Where NSBEP1 is the net strong base that has been added at the first equivalence point (EP1).

\subsection{Methods}

\subsubsection{Sample Titration}

Two $3 \mathrm{~mL}$ aliquots of each sample of tobacco smoke extract were set aside for the acidside and base-side titrations. After extraction, each of the $3 \mathrm{~mL}$ samples was titrated with a total of $2.0 \mathrm{~mL}$ of $5 \mathrm{mN}$ titrant in increments ranging from 5.0 to $50 \mu \mathrm{L}$ using a T-50 automatic titrator (Mettler Toledo, Columbus, $\mathrm{OH}$ ). The acid titrant was a $5 \mathrm{mN}$ solution of hydrochloric acid (prepared from 0.1 N, Fisher Scientific), prepared in 95\% IPA $/ 5 \%$ nanopure water. The base titrant was a nominal $5 \mathrm{mN}$ solution of lithium phenoxide (prepared from $1 \mathrm{~N}$ in THF, Sigma Aldrich, calibrated with $\mathrm{HCl}$ as discussed below), prepared in $99.5 \% \mathrm{IPA} / 0.5 \%$ THF. Lithium phenoxide was selected as the base-side titrant for its ability to titrate organic acids without titrating phenols. Phenols are known to be common components of tobacco smoke PM (Lakritz et al., 1969; Sakuma et al., 
1983) and titration using a stronger base, such as sodium hydroxide, would have let to deprotonation of these compounds. The exact concentration of lithium phenoxide was determined against $\mathrm{HCl}$ and was found to be on average $5.35 \mathrm{mN}( \pm 0.18 \mathrm{mN})$.

The electrode potential $(\Delta \mathrm{E})$ of the sample solutions was measured between additions of titrant with glass combination electrode (InLab ${ }$ Ultra-Micro, Mettler Toledo). The internal reference electrolyte was Friscolyt-B ${ }^{\circledR}$ (Mettler Toledo). The electrode was stored in a $3 \mathrm{M}$ solution of potassium chloride ( $\mathrm{pH} \sim 5.5$, Aqua Solutions, Jasper, GA). The $\mathrm{mV}$ response of the electrode was examined daily as a $\mathrm{QC}$ check using $\mathrm{pH} 4.0$ and 10.0 aqueous buffer solutions (Fisher Scientific); $\mathrm{mV}$ readings were only used in this work. The parameters of the automatic titrator were selected to accommodate the slower response of organic solutions (DeGagné, 2016). A change in electrode potential of less than $0.5 \mathrm{mV}$ over a 10 second period was required before the recording of the data point by the titrator software. The targeted change in electrode potential per addition was 10.0 $\mathrm{mV}$. The equivalence points (EPs) were identified by a slope change in the titration curve of $200 \mathrm{mV} / \mathrm{mL}$ for the acid titration and $150 \mathrm{mV} / \mathrm{mL}$ for the base titration. To avoid titration of carbonic acid, from carbon dioxide from the ambient air, the base-side titrations proceeded immediately following extraction of the tobacco smoke samples. The base-side titrations were conducted under nitrogen gas to prevent carbon dioxide from dissolving in the solution during titration. The concentrations ( $\mathrm{v} / \mathrm{v})$ of IPA for the posttitration samples were $96.8 \%$ for the acid-side and $98.6 \%$ for the base-side. 
The first and third equivalence points (EP1 and EP3) were automatically located by the LabX ${ }^{\circledR}$ titrator software (Version 5, Mettler-Toledo). However, due to the location of the second equivalence point (usually near the interface of the acid- and base-side titrations), it was necessary estimate EP2 manually. For this, the Gran technique (explained in Pankow, 1991) was employed.

\subsubsection{Ion Chromatography}

The acidified aliquots from the acid-side titration were run using IC in the same method as described in Section 2.2.2 (p. 13). The results of which were presented previously in Tables 11 and 13 .

\subsection{Results and Discussion}

All acid and base concentrations are reported in units of equivalents per weight of wet total particulate matter (WTPM). This was done to enable better comparisons of results across the different brands. Table 16 and Figure 16, below, show the results of the total titratable acids and total titratable bases for the MS tobacco smoke extracts. The results show that, aside from brand 1, all the brands had negative net base (see Figure 17).

Among the brands, the results show that brands 4 and 6 have the most negative net base. 
Table 16 Total acids and bases from titrations of tobacco smoke samples for 6-puff and full cigarette samples $(n=3)$.

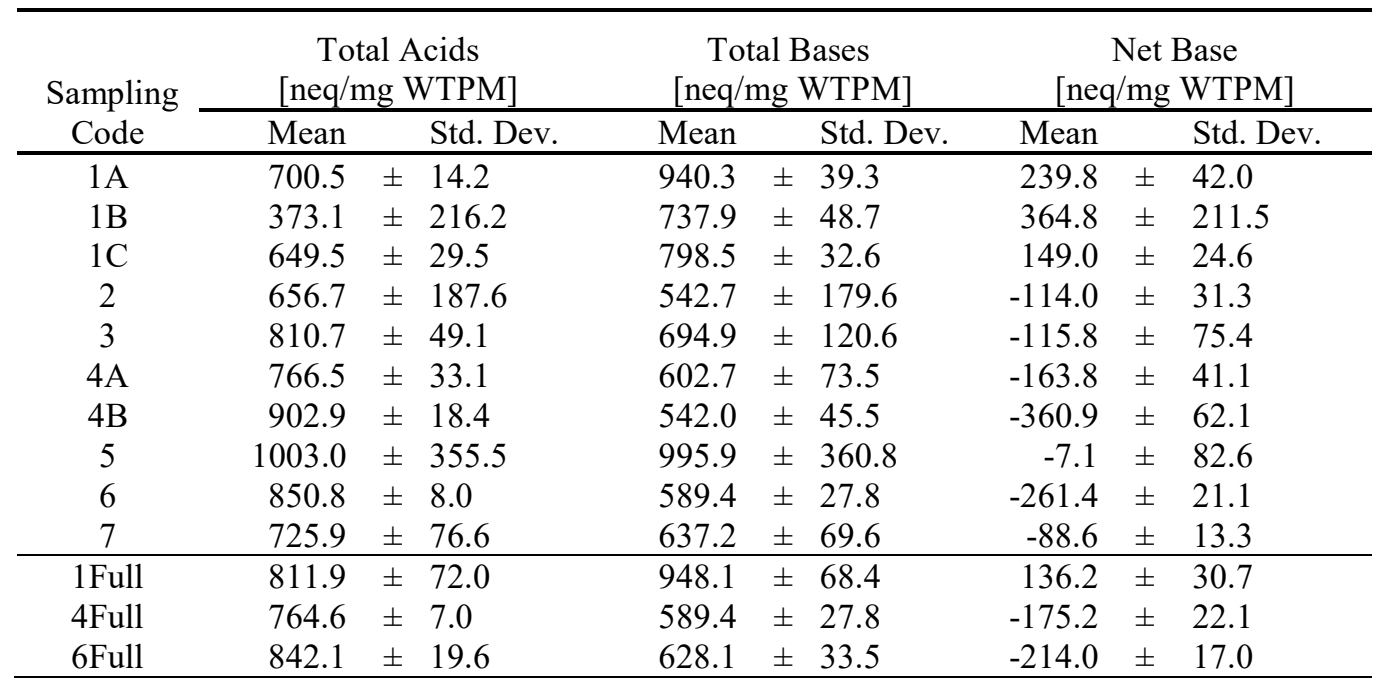

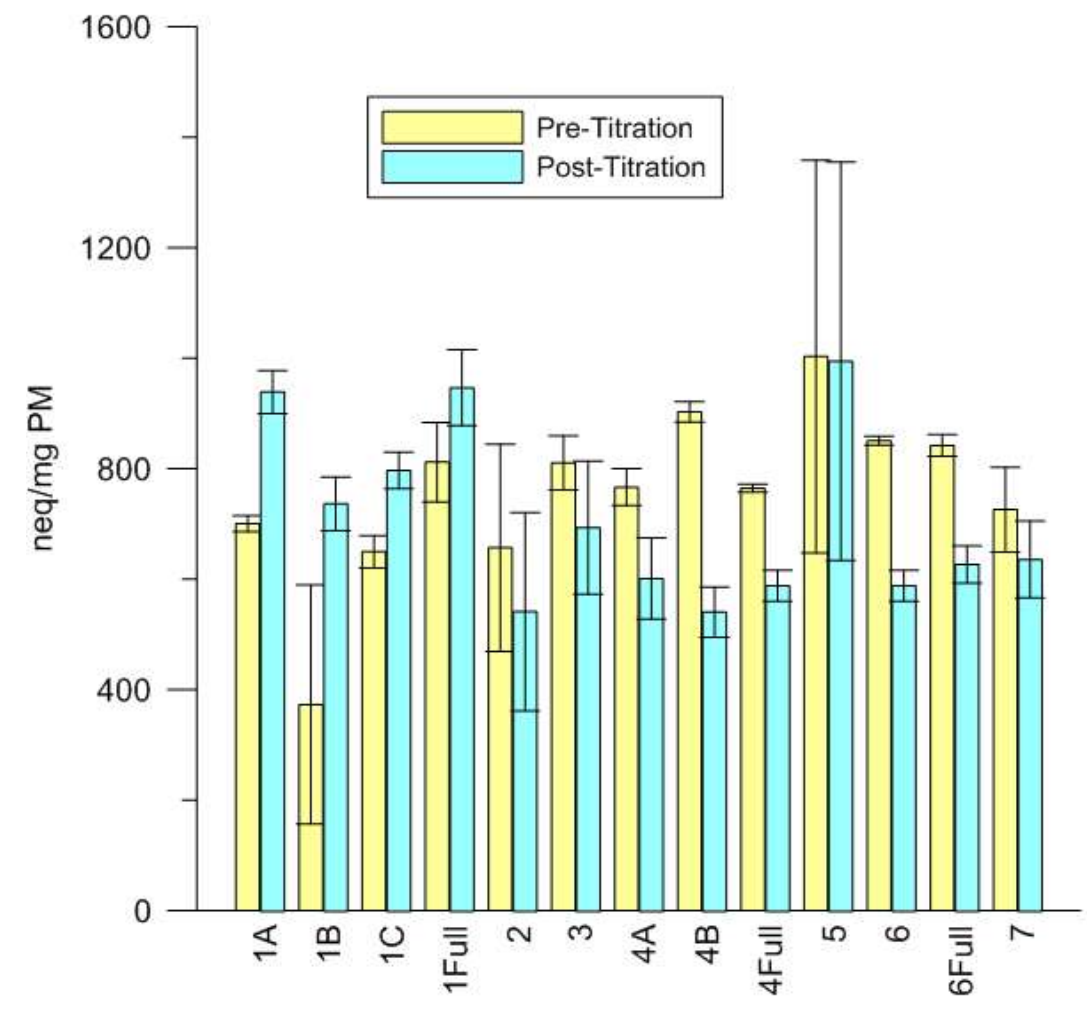

Figure 16 Acids and bases measured from the titration of the 6-puff and full-rod samples. Error bars represent the standard deviation between replicates $(n=3)$. 


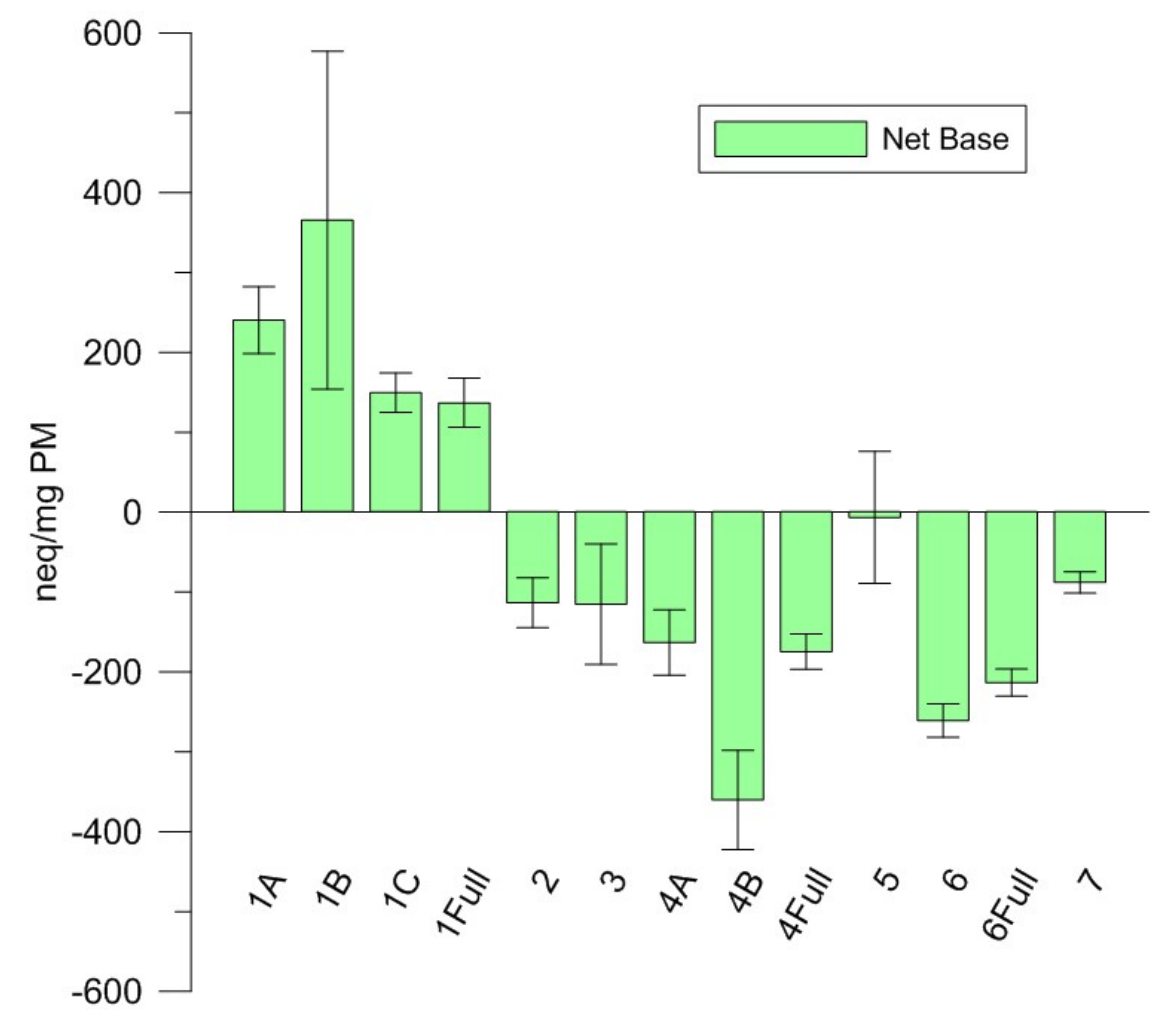

Figure 17 Net strong base from titrations of tobacco smoke samples. Error bars represent the standard deviation between replicates $(n=3)$.

Figure 18, below, shows the comparison of the total titratable acids found with the analysis of anionic species for each of the tobacco smoke sample extracts. Figure 18 provides three different comparisons depending on the species we consider "weak acids". Figure 18a, shows a comparison of only acetic, lactic, and glycolic acids. From this comparison, a significant portion of the weak acids are remaining to be identified. If we include formic acid as a "weak acid" (Figure 18b) the balance between identified and unidentified acids is improved. And by inclusion of nitrous acid (Figure 18c) we see further improvement. If we include all of these compounds (acetic, lactic, glycolic, formic and nitric acid), most of the acidic species are identified through the ion analysis. 
However, for some brands a relevant portion of the total weak acids remain unaccounted for using the IC data.

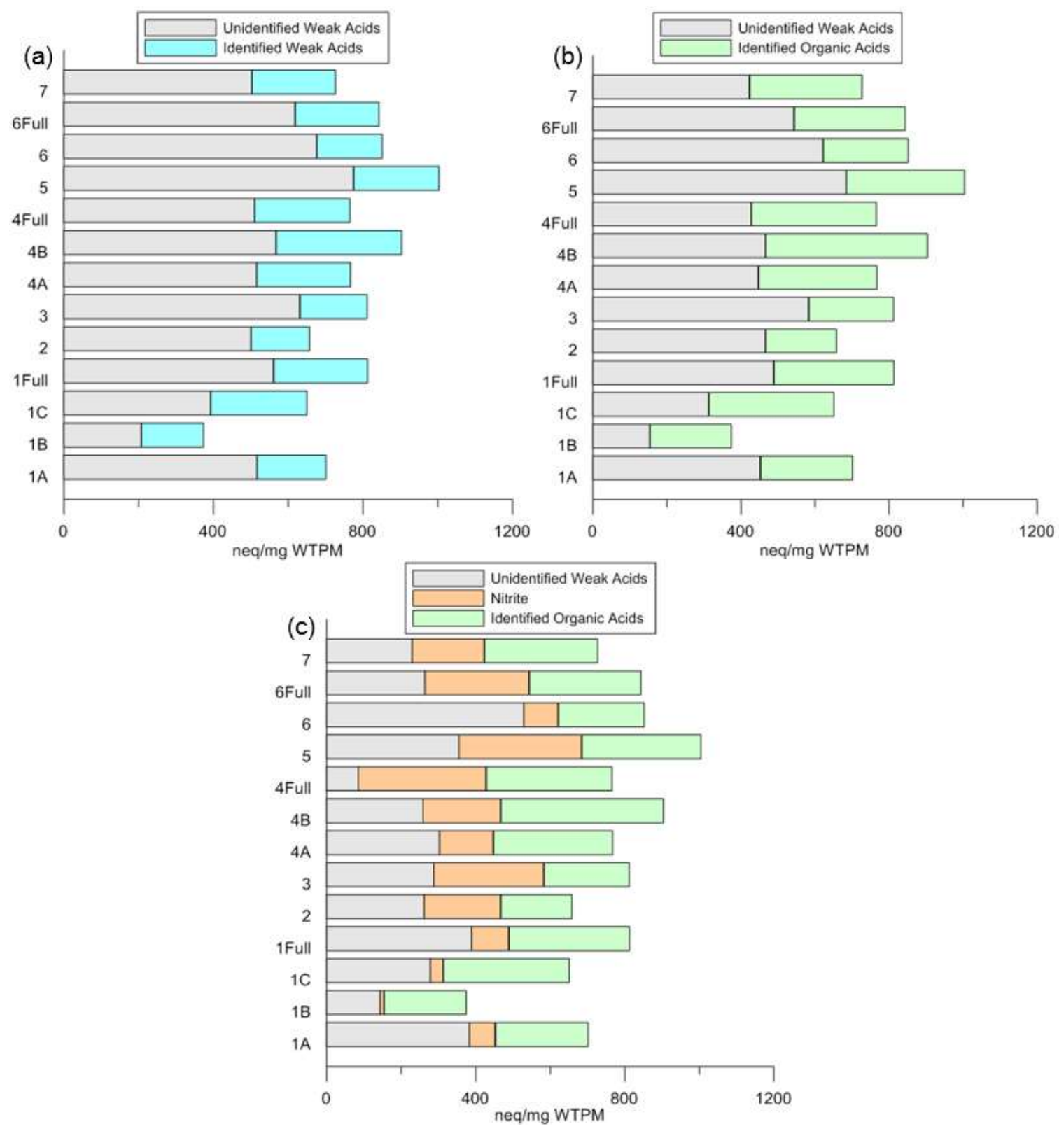

Figure 18 Total weak acid concentrations from base-side titrations compared with concentrations of (a) weak acid tracers (acetate, lactate, glycolate), (b) organic acid tracers (acetate, lactate, glycolate, formate), and (c) organic acid tracers plus nitrate for the different brands. 
When we conduct this same comparison with the weak base species and the total titratable bases (Figure 19, below), it can be seen that likewise not all of the titratable bases are being accounted for in the IC analysis. However, aside from brand 5, a majority of the basic species are being accounted for.

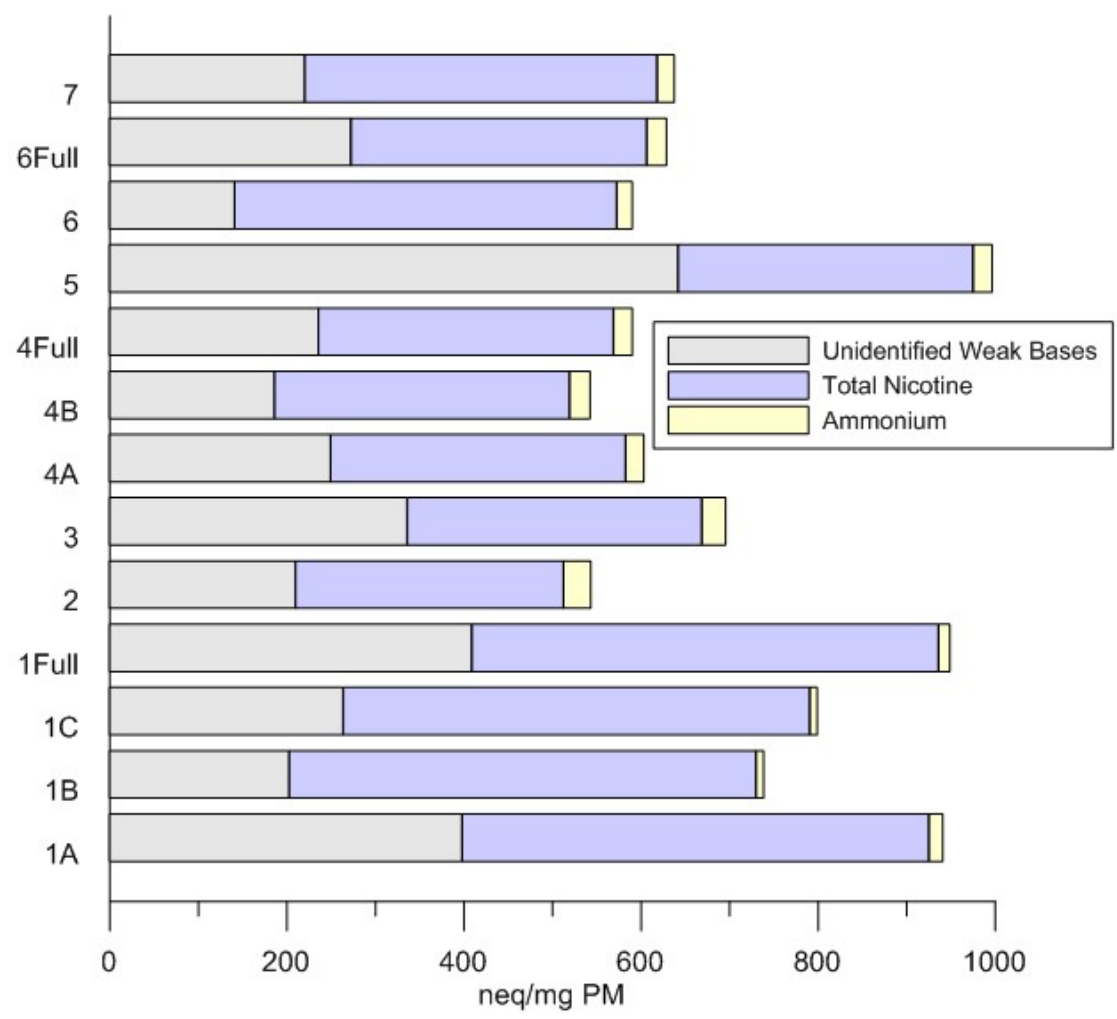

Figure 19 Total weak base concentrations from acid-side titrations compared with total nicotine and ammonium concentrations for the different brands. 


\section{The Acid-Base Balance of Mainstream Tobacco Smoke as it Relates to the Percent Free-Base Nicotine}

\subsection{Background}

As discussed previously, the relative acid-base balance of the tobacco smoke PM will affect the protonation state of the nicotine. In an aqueous solution, if there is an excess of organic acids present they will protonate most of the nicotine to $\mathrm{NicH}^{+}$. As ions are nonvolatile, all of the protonated nicotine will remain in the liquid phase. In contrast, if there is an excess of weak base (e.g., ammonia) significant nicotine will remain in the free-base form and be free to volatilize into the gas phase.

In an aqueous solution, the amount of nicotine protonated should be proportionate to the amount of acid that is in excess. Using the concentration of total nicotine, total cations, and total anions, we can develop an estimate of the concentration of free-base nicotine:

$$
[\mathrm{Nic}]=\mathrm{Nic}_{(\mathrm{T})}+[\text { Cations }]-[\text { Anions }]
$$

We can then determine the fraction of free-base nicotine, $\alpha_{\mathrm{fb}}$,

$$
\alpha_{f b}=\frac{[\mathrm{Nic}]}{\mathrm{Ni}(\mathrm{T})}
$$

However, tobacco smoke PM is not an aqueous solution and species will behave differently in this complex mixture of organics than in water. The effects of the nonaqueous environment on the ability of the organic acids to protonate nicotine is unknown. Using the results of the IC and titrations analyses and the total and free-base nicotine 
analyses undertaken by colleagues, we can get a sense of the degree of the impact of these non-aqueous effects.

\subsection{Methods}

\subsubsection{Determination of Free-Base Nicotine}

Free-base nicotine numbers for 6-puff samples were determined by colleagues using solid-phase microextraction (SPME) and GC/MS analysis (Pankow et al., 2017). Comparison of the volatile nicotine concentration with the total nicotine numbers (see Table 14, p. 32) yielded estimates of the fraction free-base nicotine, $\alpha_{\mathrm{fb}}$.

\subsection{Results and Discussion}

The results of free-base nicotine estimates based on the aqueous assumption (Table 17) described above suggest that, because most of the samples have an excess of acidic species (compared to basic) (see Figure 17, p. 43), all of the nicotine in the tobacco smoke will be protonated. We can see that the aqueous assumption does not hold true when we compare these free-base numbers with the results of Pankow et al. (2017). These measured values (Table 18) show that all of the brands have a measurable amount of free-base nicotine, despite the fact that the titration and IC analysis shows that most of these brands have a greater amount of acidic compounds than basic. 
Table 17 Estimated fraction free-base nicotine based on aqueous assumption.

\begin{tabular}{cc}
\hline Sampling Code & $\alpha_{\mathrm{fb}}$ \\
\hline 1A & 0.41 \\
1B & 0.59 \\
1C & 0.30 \\
2 & 0.00 \\
3 & 0.00 \\
$4 \mathrm{~A}$ & 0.00 \\
4B & 0.00 \\
5 & 0.00 \\
6 & 0.00 \\
7 & 0.00 \\
\hline
\end{tabular}

Table 18 Measured fraction nicotine in free-base form for 6-puff samples (Pankow et al., 2017).

\begin{tabular}{cccl}
\hline & \multicolumn{3}{c}{$\alpha_{\mathrm{fb}}$} \\
\cline { 2 - 4 } Brand & Mean & \multicolumn{2}{c}{ Std. Dev } \\
\hline 1 & 0.335 & \pm & 0.081 \\
2 & 0.063 & \pm & 0.005 \\
3 & 0.041 & \pm & 0.009 \\
4 & 0.051 & \pm & 0.037 \\
5 & 0.050 & \pm & 0.010 \\
6 & 0.055 & \pm & 0.009 \\
7 & 0.085 & \pm & 0.032 \\
\hline
\end{tabular}

The estimated $\alpha_{\mathrm{fb}}$ values for brand 1 are reasonable given the range of the measured values (although the value estimated on 10/10/16 is much higher than the other two days). However, while the aqueous assumption led to estimations of zero free-base nicotine for the other brands, the calculated values show that between 4.1 and $8.5 \%$ freebase nicotine is present in these samples.

This discrepancy lends support to the idea that in a majority organic mixture, such as MS tobacco smoke PM, acids are less acidic and as such may not be able to protonate the nicotine to the extent that one would expect from an aqueous assumption. While there may be an excess of acidic species, it may be that the lack of water in the tobacco smoke 
prevents full protonation of the nicotine and some of this nicotine will remain in the neutral, free-base form and be free to volatilize. 


\section{The Development of an Electroneutrality Equation (ENE) for Mainstream Tobacco Smoke}

\subsection{Background}

In order to simplify our thinking of the ENE for the tobacco smoke system it will be helpful to make some assumptions about the relative strength of the acids. We can think of them in two groups: "strong-enough" and weak acids. The "strong-enough" acids are those which are able to fully protonate nicotine and are stronger relative to the weak acids. In our system, tracers for these acids are sulfate, chloride, nitrate, nitrite and formate. We might assume that these acids will by $100 \%$ ionized by protonation of available nicotine. Any nicotine remaining after protonation by the stronger acids, will be available for protonation by the weak acids. The weak acids are all of the organic acids, excluding formic. Formic acid is considered essentially inorganic for these purposes as it has no carbon-carbon bonds.

If we do a sum of all the strong acids $\left(C_{A}\right)$

$$
C_{A}=\left[\mathrm{CHOO}^{-}\right]+\left[\mathrm{Cl}^{-}\right]+\left[\mathrm{NO}_{2}^{-}\right]+\left[\mathrm{NO}_{3}^{-}\right]+2\left[\mathrm{SO}_{4}^{2-}\right]
$$

and all the strong bases $\left(C_{B}\right)$,

$$
C_{B}=\left[\mathrm{Na}^{+}\right]+\left[\mathrm{K}^{+}\right]
$$

We can combine equations (12) and (13) to obtain an expression for net strong acid $\left(C_{A}-\right.$ $\left.C_{B}\right)$ 
$C_{A}-C_{B}=\left[\mathrm{CHOO}^{-}\right]+\left[\mathrm{Cl}^{-}\right]+\left[\mathrm{NO}_{2}^{-}\right]+\left[\mathrm{NO}_{3}^{-}\right]+2\left[\mathrm{SO}_{4}^{2-}\right]-\left[\mathrm{Na}^{+}\right]-\left[\mathrm{K}^{+}\right]$

We can now write an ENE for the system,

$$
\begin{aligned}
& {\left[\mathrm{NicH}^{+}\right]+\left[\mathrm{NH}_{4}^{+}\right]=C_{A}-C_{B}+\left[\mathrm{A}^{-}\right]} \\
& {\left[\mathrm{NicH}^{+}\right]+\left[\mathrm{NH}_{4}^{+}\right]+\left[\mathrm{Na}^{+}\right]+\left[\mathrm{K}^{+}\right]} \\
& \quad=\left[\mathrm{CHOO}^{-}\right]+\left[\mathrm{Cl}^{-}\right]+\left[\mathrm{NO}_{2}^{-}\right]+\left[\mathrm{NO}_{3}^{-}\right]+2\left[\mathrm{SO}_{4}^{2-}\right]+\left[A^{-}\right]
\end{aligned}
$$

Comparing this ENE with that presented in equation (5) (p. 5), you can see we have neglected $\left[\mathrm{H}^{+}\right],\left[\mathrm{OH}^{-}\right]$, and $\left[\mathrm{HCO}_{3}^{-}\right]$. We will assume that ammonia is basic enough in our system to be completely protonated, thus all ammonia will be in the form of $\mathrm{NH}_{4}{ }^{+}$. Also, as stated previously, for this analysis, formic acid is no longer combined with the other organic acids in the $\mathrm{A}^{-}$term.

We can rewrite equation (15) in terms of the $\alpha$ values for both nicotine and weak acids, as the extent of protonation for both species is unknown.

$$
\alpha_{0}^{\mathrm{Nic}} \mathrm{Nic}_{\mathrm{T}}+\left[\mathrm{NH}_{4}^{+}\right]=C_{A}-C_{B}+\alpha_{1}^{\mathrm{A}} \mathrm{A}_{\mathrm{T}}
$$

Where $\alpha_{0}{ }^{\mathrm{Nic}}$ is the fraction of protonated nicotine $\left(\mathrm{NicH}^{+}\right)$and is equal to $1-\alpha_{1}{ }^{\mathrm{Nic}}=1-\alpha_{\mathrm{fb}}$. $\alpha_{1}{ }^{\mathrm{A}}$ is the fraction of deprotonated acids. The above equation is now in a form where all values are known besides $\alpha_{1}^{\mathrm{A}}$. We can rearrange equation (16) to solve for this unknown quantity,

$$
\alpha_{1}^{A}=1 / A_{T}\left(\alpha_{0}^{N i c} \mathrm{Nic}_{\mathrm{T}}+\left[\mathrm{NH}_{4}^{+}\right]-\left(C_{A}+C_{B}\right)\right)
$$


If we assume that all species other than the weak acids and nicotine are fully ionized, then we are left with two reactions with unknown $K_{a}$ values. The first being the deprotonation of organic acids,

$$
\mathrm{HA}=\mathrm{A}^{-}+\mathrm{H}^{+} \quad\left(K_{a}^{A}\right)
$$

And the second being the protonation of nicotine,

$$
\mathrm{Nic}+\mathrm{H}^{+}=\mathrm{NicH}^{+} \quad\left(1 / K_{a}^{N i c}\right)
$$

Since we are interested in the extent of protonation of nicotine by weak acids, we can take the sum of these two reactions,

$$
\mathrm{Nic}+\mathrm{HA}=\mathrm{NicH}^{+}+A^{-} \quad\left(K^{*}\right)
$$

We can write the net reaction constant for the reaction as,

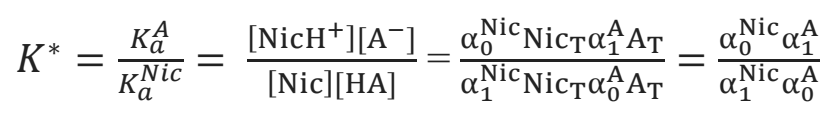

Subsisting known quantities into equation (21) leads to,

$$
K^{*}=\frac{\left(1-\alpha_{\mathrm{fb}}\right) \alpha_{1}^{\mathrm{A}}}{\alpha_{\mathrm{fb}}\left(1-\alpha_{1}^{\mathrm{A}}\right)}
$$

Equation (22) provides a means of estimating the net reaction constant $\left(K^{*}\right)$ for the protonation of nicotine by weak acids in MS tobacco smoke PM. 
The next step in this analysis is to create a fit of these $K^{*}$ values to measured water content data for MS tobacco smoke. This fit would be useful for predictions of the extent of protonation given compositional information. We expect that the $K^{*}$ values will increase with water content as this will allow the organic acid species a greater ionization potential and increase their ability to protonate the nicotine.

\subsection{Methods - Water Content Analysis}

\subsubsection{Sampling and Extraction}

Two cigarettes brands were chosen to study for their water content. Knowing that water content affects the protonation state of nicotine, the brands were chosen based on their percent free-base nicotine numbers. Of the cigarettes studied, brand 1were found to have the highest freebase nicotine levels and brand 4 were found to be on the lower end of the spectra (Table 18, p. 48). Thus, these two brands were selected to provide a representative range of water content numbers.

As with the previously described experimental setup, two cigarettes were smoked simultaneously. However, for study of water content the particulate matter was collected on Cambridge filter pads (CFP) as the Tedlar bags were found to have too much variability in their water content. The experimental setup was thus altered as shown in Figure 20, below. The dual cigarette holder (Clear Concepts, Bend, OR) was inserted directly to the Teflon filter holder containing a dried CFP (Borgwaldt KC). 


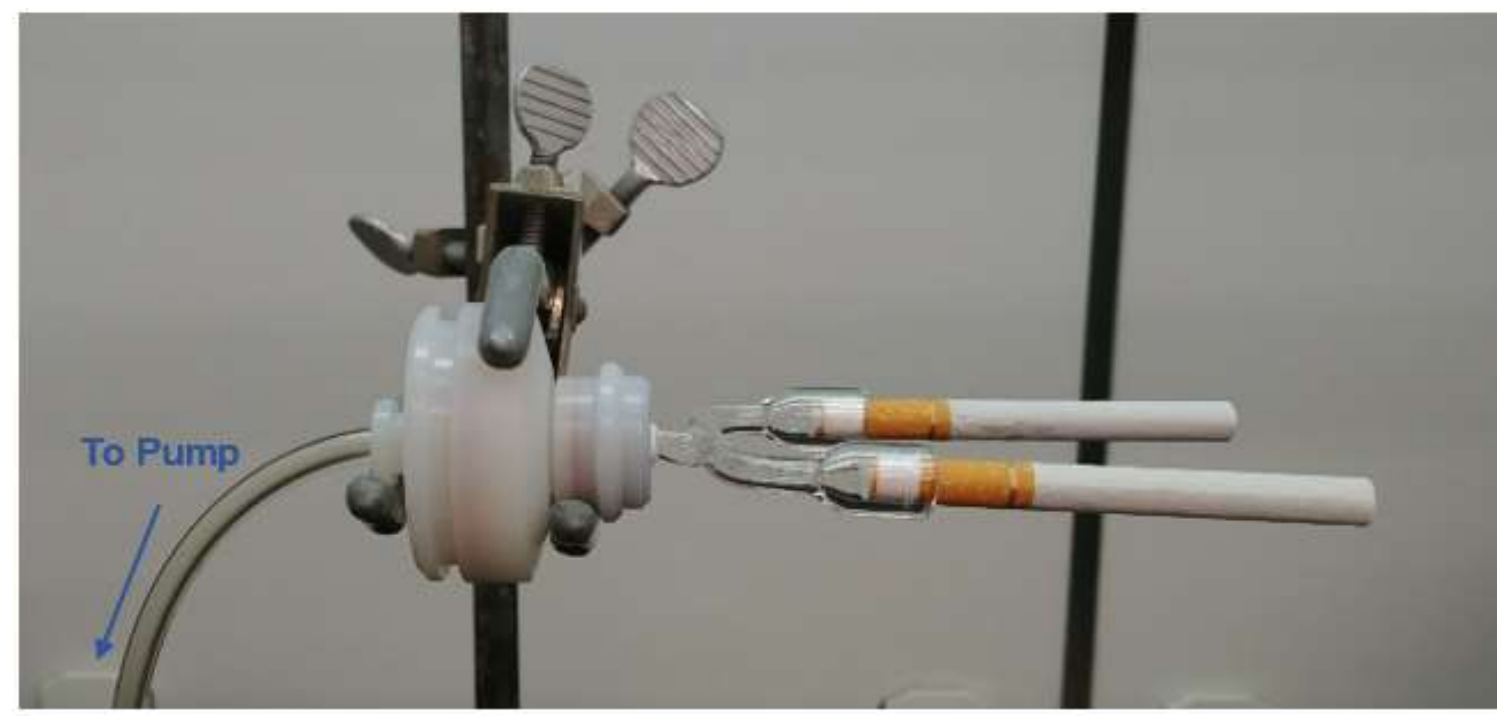

Figure 20 Smoking apparatus for PM water content analysis.

All materials used for the sample collection were dried in a 60 to $70^{\circ} \mathrm{C}$ oven for a minimum of 24 hours prior to use. The smoking protocol was the same as previously described: $70 \mathrm{~mL}$ puff volumes of two-second duration every 60 seconds with a total of six puffs collected, including the lighting puff. The filter holder sat for 10 minutes before the filter pad was removed and weighed. The difference between the initial filter weight and final weight was used to calculate the total mass of PM. The filter pad was then inserted into a dry VOA vial containing $5 \mathrm{~mL}$ of dry IPA. The IPA $(>99.9 \%$, Fisher Scientific) was dried using sodium sulfate ( $>99.0$, Sigma-Aldrich). The filter was fully submerged in the dry IPA and sonicated for 30 seconds to ensure full transfer of water from the filter pad to the IPA. The CFP sat in the IPA for approximately 1 hour before sample aliquots were transferred to GC vials. To control for residual water content on the filter pads, dry filter pads were also placed directly into VOA vials containing $5 \mathrm{~mL}$ of dry IPA and processed in the same way as those with PM. 


\subsubsection{GC/TCD Analysis}

The water content of the isopropanol extracts was determined by gas chromatography (GC) (7890B, Agilent Technologies) employing a thermal conductivity detector (TCD). With the GC injector set at $150^{\circ} \mathrm{C}, 1 \mu \mathrm{L}$ of sample was injected with a 5 to 1 split. A guard column (30 m x $0.53 \mathrm{~mm}$ ID fused silica, Restek, Bellefonte, PA) was installed to protect the column from a buildup of non-volatile and low-volatility, tobacco smoke compounds. The GC column (30 m x $0.53 \mathrm{~mm}$ x $20 \mu \mathrm{m}$, Rt ${ }^{\circledR}$-U-Bond; Restek, Bellefonte, PA) was operated under isothermal conditions at $150{ }^{\circ} \mathrm{C}$ with a carrier gas (helium) flow of $5 \mathrm{~mL} / \mathrm{min}$. The thermal conductivity detector was set at $250{ }^{\circ} \mathrm{C}$ and the reference flow and makeup flow were 12 and $5 \mathrm{~mL} / \mathrm{min}$, respectively (both helium). The liner was replaced frequently due to the low injection temperature and the resulting buildup of non-volatile tobacco smoke compounds. After the injection of approximately 100 tobacco smoke samples, the guard column was disconnected from the Rt巴-U-Bond column and baked to remove non-volatile residuals from the tobacco smoke samples.

Standards with water contents varying between $0.01 \%$ to $0.10 \%$ water by volume $(0.10$ to $1.00 \mathrm{mg} \mathrm{H}_{2} \mathrm{O} / \mathrm{mL}$ ) in water-free IPA were prepared from a stock solution of $5.0 \%$ water in dry IPA. As with the sample collection, all materials and glassware used in preparation of the standards were dried in the oven or rinsed thoroughly with dry IPA to ensure no additional sources of water were introduced to the standards. 


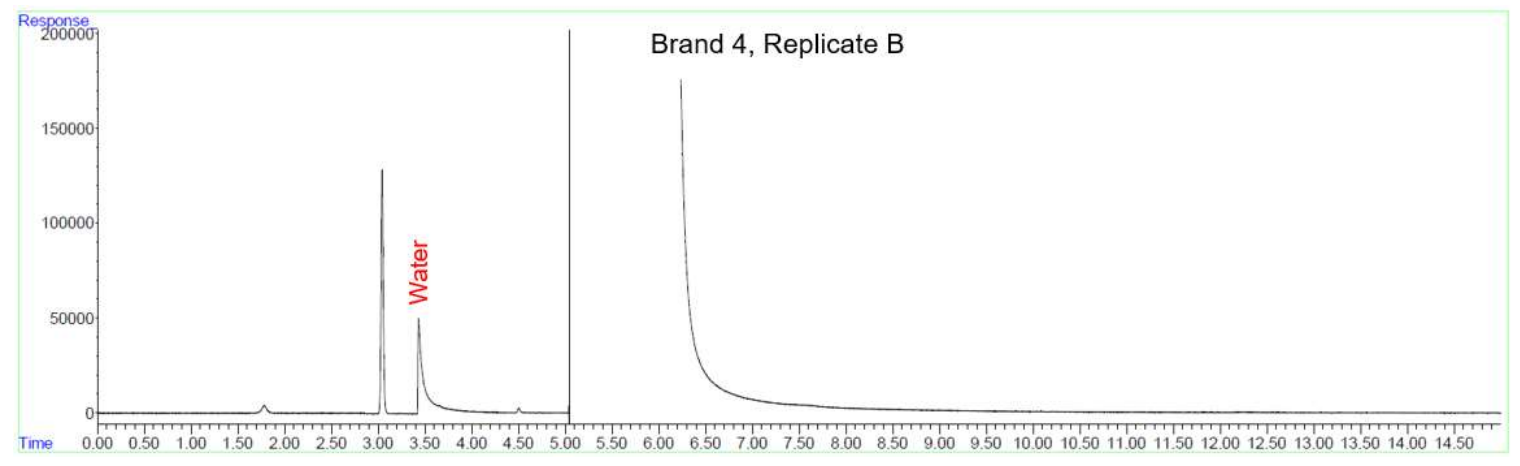

Figure 21 Example GC/TCD chromatograph of tobacco smoke PM extract for water content determination.

Due to the irregular shape of the water peak (see Figure 21 and Appendix C, p. 98), peak height was chosen to evaluate the peaks over area. Peak heights from the water-free IPA blanks were subtracted from the peak heights of all the samples and calibration standards. The data for the calibration standards were then used to create a calibration curve (see Figure 22, below). It was found that a second order polynomial was the best fit for the calibration standards. This fit was then used to find the water content of the samples based on their peak heights. The water content of the two blank samples was then subtracted from the tobacco smoke samples, to account for any water associated with the dry filter pads. 


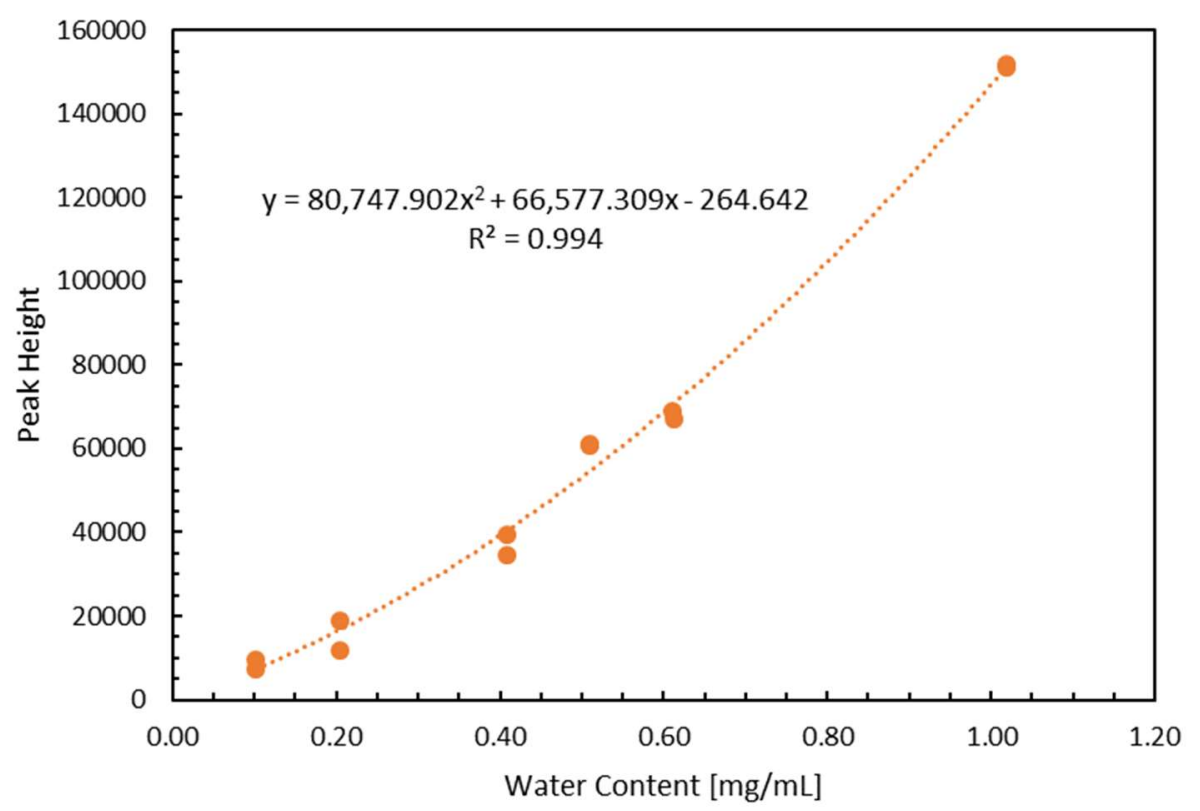

Figure 22 Calibration plot for PM water content analysis.

\subsection{Results and Discussion}

The results of the water content analysis can be seen in Table 19, below. The results show that brand 1 cigarettes have a lower water content than the brand 4, $0.043 \pm 0.007$ versus $0.114 \pm 0.022$, respectively. This is consistent with the initial reasoning for choosing these two brands. As the water content increases, the weak acids are better able to protonate the nicotine and the fraction of free-base will decrease. 
Table 19 Mass fraction water in particulate matter of AT and BR cigarettes.

\begin{tabular}{clcc}
\hline \multirow{2}{*}{ Brand } & \multicolumn{1}{c}{ Replicate } & $\begin{array}{c}\text { TPM } \\
(\mathrm{mg})\end{array}$ & $\begin{array}{c}\text { Mass Water Fraction in } \\
\mathrm{PM}, f_{w}{ }^{P M}(\mathrm{mg} / \mathrm{mg})\end{array}$ \\
\hline \multirow{3}{*}{1} & A & 8.2 & 0.036 \\
& C & 8.1 & 0.043 \\
& D & 9.8 & 0.050 \\
\cline { 2 - 4 } & Average & 8.7 & 0.043 \\
& Std. Deviation & 1.0 & \pm 0.007 \\
\hline \multirow{3}{*}{4} & B & 11.3 & 0.089 \\
& C & 13.7 & 0.141 \\
& D & 17.7 & 0.105 \\
& E & 13.3 & 0.121 \\
\cline { 2 - 4 } & Average & 14.0 & 0.114 \\
& Std. Deviation & 2.7 & \pm 0.022 \\
\hline
\end{tabular}

*Note: Brand 1, replicate B and brand 4, replicated A were excluded from this analysis as they were found to be statistically different from the other replicates.

Following the calculations outlined in Section 5.1, the fraction of unprotonated weak acid $\left(\alpha_{1}^{A}\right)$ and the net reaction constant for the protonation of nicotine by these weak acid species $\left(K^{*}\right)$ were calculated using equations (17) and (22), respectively (Table 20, below).

Table 20 Estimation of the fraction of unpronated weak acid $\left(\alpha_{1}{ }^{\mathrm{A}}\right)$ and the net reaction constant for the protonation of nicotine by weak acids $\left(K^{*}\right)$.

\begin{tabular}{ccc}
\hline Sampling Code & $\alpha_{1}{ }^{\mathrm{A}}$ & $K^{*}$ \\
\hline 1A & 1.29 & -8.89 \\
1B & 1.95 & -4.08 \\
1C & 0.95 & 39.28 \\
2 & 0.50 & 14.68 \\
3 & 0.24 & 7.22 \\
4A & 0.82 & 86.28 \\
4B & 0.13 & 2.90 \\
5 & 0.08 & 1.55 \\
6 & 1.27 & -75.39 \\
7 & 1.14 & -85.31 \\
\hline
\end{tabular}

The calculated values for $\alpha_{1}{ }^{\mathrm{A}}$ range from 0.08 to 1.95. The presence of values $>1$ are a signal that there was a problem with the calculation method. Because some of the $\alpha_{1}{ }^{\mathrm{A}}$ 
values were greater than one, this resulted in the calculations of the associated $K^{*}$ values to be negative. Obviously, there were issues with the fit of this data, as the $\alpha_{1}{ }^{\mathrm{A}}$ values were forced to be greater than 1 by equation (17) to account for the protonation of the nicotine species indicated by the free-base nicotine numbers.

One of the most likely sources of error would be the underrepresentation of the organic acid species from the IC analysis. As discussed in Section 3.3 (p. 41), a comparison of the titration results showed a significant portion of the titratable acids were not being quantified in the IC analysis. It is known that tobacco smoke is an incredibly complex mixture containing some 200 carboxylic acids species. Commonly identified acids that might be attributing to this missing segment include: succinic, oxalic, levulinic, propionic, maleic, malonic, butyric, valeric, and quinic (Shumacher et al., 1977; Sakuma et al., 1983; Lu et al., 2003; Borgerding and Klus, 2005; Moldoveanu, 2012). Additionally, the ENE neglects the contribution of polyprotic acids (such as succinic and citric).

In order to improve this fit, further investigation into the origin of these errors is needed. The anion chromatographs for the tobacco smoke samples contain unidentified peaks. If these peaks can be identified and the species quantified, it may go a ways to fill in the gaps of the missing acid species.

Also future work is needed to quantify the water content of the remaining cigarette brands that were not studied in this thesis. This would allow a fit with the $K^{*}$ data to be 
created to allow for prediction of nicotine protonation based on composition. As is, the two points presented in this work are not sufficient to make any significant claims as to the relationship between the $K^{*}$ values and the fraction water content in the tobacco smoke PM. 


\section{References}

Borgerding, M., Klus, H., 2005. Analysis of complex mixtures - Cigarette smoke. Exp. Toxicol. Pathol. 57, Supplement 1, 43-73. doi:10.1016/j.etp.2005.05.010

Chen, C., Pankow, J.F., 2009. Gas/particle partitioning of two acid-base active compounds in mainstream tobacco smoke: nicotine and ammonia. J. Agric. Food Chem. 57, 2678-2690. doi:10.1021/jf803018x

DeGagne, J.L., 2016. Acid-Base Equilibria in Organic-Solvent/Water Mixtures and Their Relevance to Gas/Particle Partitioning in the Atmosphere and in Tobacco Smoke.

Henningfield, J.E., Keenan, R.M., 1993. Nicotine delivery kinetics and abuse liability. J. Consult. Clin. Psychol. 61, 743-750.

doi:http://dx.doi.org.proxy.lib.pdx.edu/10.1037/0022-006X.61.5.743

Henningfield, J.E., Pankow, J.F., Garrett, B.E., 2004. Ammonia and other chemical base tobacco additives and cigarette nicotine delivery: Issues and research needs. Nicotine Tob. Res. 6, 199-205. doi:10.1080/1462220042000202472

Lagoutte, D., Lombard, G., Nisseron, S., Papet, M.P., Saint-Jalm, Y., 1994.

Determination of organic acids in cigarette smoke by high-performance liquid chromatography and capillary electrophoresis. J. Chromatogr. A 684, 251-257. doi:10.1016/0021-9673(94)00593-1

Lakritz, L., Stedman, R.L., Strange, E.D., 2014. Composition studies on tobacco XXXLX: changes in smoke composition and filtration by artificial alteration of smoke pH: formic and acetic acids and volatile phenols. Contrib. Tob. Res. 5, 104108. doi:10.2478/cttr-2013-0224

Lauterbach, J.H., Bao, M., Joza, P.J., Rickert, W.S., 2010. Free-base nicotine in tobacco products. Part I. Determination of free-base nicotine in the particulate phase of mainstream cigarette smoke and the relevance of these findings to product design parameters. Regul. Toxicol. Pharmacol. 58, 45-63. doi:10.1016/j.yrtph.2010.05.007

Lu, X., Cai, J., Kong, H., Wu, M., Hua, R., Zhao, M., Liu, J., Xu, G., 2003. Analysis of cigarette smoke condensates by comprehensive two-dimensional gas

chromatography/time-of-flight mass spectrometry I. Acidic fraction. Anal. Chem. 75, 4441-4451. doi:10.1021/ac0264224

Moldoveanu, S., 2012. Analysis of quinic acid and of myo-inositol in tobacco.

BeitrageZur Tab. Int. Contrib. Tob. Res. 25, 498-506. 
Nanni, E.J., Lovette, M.E., Hicks, R.D., Fowler, K.W., Borgerding, M.F., 1990. Separation and quantitation of monovalent anionic and cationic species in mainstream cigarette smoke aerosols by high-performance ion chromatography. J. Chromatogr. Sci. 28, 432-436. doi:10.1093/chromsci/28.8.432

Pankow, J.F., 1991. Aquatic Chemistry Concepts. CRC Press.

Pankow, J.F., 2001. A consideration of the role of gas/particle partitioning in the deposition of nicotine and other tobacco smoke compounds in the respiratory tract. Chem. Res. Toxicol. 14, 1465-1481. doi:10.1021/tx0100901

Pankow, J.F., Mader, B.T., Isabelle, L.M., Luo, W., Pavlick, A., Liang, C., 1997. Conversion of nicotine in tobacco smoke to its volatile and available free-base form through the action of gaseous ammonia. Environ. Sci. Technol. 31, 2428-2433. doi:10.1021/es970402f

Pankow, J.F., Tavakoli, A.D., Luo, W., Isabelle, L.M., 2003. Percent free base nicotine in the tobacco smoke particulate matter of selected commercial and reference cigarettes. Chem. Res. Toxicol. 16, 1014-1018. doi:10.1021/tx0340596

Pankow, J.F., Motti, C., Luo, W., 2017. Unpublished work.

Quin, L.D., Hobbs, M.E., 1958. Analysis of nonvolatile acids in cigarette smoke by gas chromatography of their methyl esters. Anal. Chem. 30, 1400-1405. doi:10.1021/ac60140a032

Rived, F., Rosés, M. and Bosch, E., 1998. Dissociation constants of neutral and charged acids in methyl alcohol. The acid strength resolution. Anal. Chim. Acta 374, 309-324.

RJ Reynolds, 1991. Levulinic Acid. RJ Reynolds. Truth Tobacco Industry Documents. https://industrydocuments.library.ucsf.edu/tobacco/docs/rymk0089

Sakuma, H., Kusama, M., Munakata, S., Ohsumi, T. and Sugawara, S., 1983. The distribution of cigarette smoke components between mainstream and sidestream smoke: I. Acidic components. Beiträge zur Tabakforschung/Contributions to Tobacco Research 12, 63-71.

Sakuma, H., Kusama, M., Yamaguchi, K., Matsuki, T. and Sugawara, S., 1984. The distribution of cigarette smoke components between mainstream and sidestream smoke: II. Bases. Beiträge zur Tabakforschung/Contributions to Tobacco Research 12, 199-209.

Sarmini, K. and Kenndler, E., 1999. Ionization constants of weak acids and bases in organic solvents. J. Biochem. Biophys. Methods 38, 123-137. 
Schumacher, J.N., Green, C.R., Best, F.W., Newell, M.P., 1977. Smoke composition. An extensive investigation of the water-soluble portion of cigarette smoke. J. Agric. Food Chem. 25, 310-320. doi:10.1021/jf60210a003

Steele, R., 1989. Chemical Evaluation of Levulinic Acid.RJ Reynolds. Truth Tobacco Industry Documents.

https://industrydocuments.library.ucsf.edu/tobacco/docs/rsbd0095

Tomar, S.L., Henningfield, J.E., 1997. Review of the evidence that $\mathrm{pH}$ is a determinant of nicotine dosage from oral use of smokeless tobacco. Tob. Control 6, 219-225. doi:10.1136/tc.6.3.219

Watson, C.H., Trommel, J.S., Ashley, D.L., 2004. Solid-phase microextraction-based approach to determine free-base nicotine in trapped mainstream cigarette smoke total particulate matter. J. Agric. Food Chem. 52, 7240-7245. doi:10.1021/jf049455o

Watson, C.V., Valentin-Blasini, L., Damian, M., Watson, C.H., 2015. Method for the determination of ammonium in cigarette tobacco using ion chromatography. Regul. Toxicol. Pharmacol. 72, 266-270. doi:10.1016/j.yrtph.2015.04.019 


\section{Appendices}

\section{A. Ion Chromatographs for Tobacco Smoke PM Extracts}

Ion chromatographs for both pre- and post-titration with $\mathrm{HCl}$ for all brands studied are presented in this appendix. It can be noted that the both the cation and anion methods were modified during this study, as described in Section 2.2 .2 (p. 13). Table 1 (p. 10) can be referenced for testing dates to check the method used. The identity of peaks were confirmed by spiking of the tobacco smoke extracts with the anion and cation standards.

The order of the anion peaks is as follows: glycolate, acetate, lactate, formate, chloride, nitrite, sulfate, and nitrate. It should be noted that the sharp increase in the response after the organic anions elute, is due to an increase in the eluent concentration. This sharp increase in eluent concentration was necessary to elute the inorganic species and decrease the total run time for the samples

The order of cation peaks is as follows: sodium, ammonium, and potassium. In many of the post-acidification samples, a lithium peak is observed prior to the sodium. The source of the lithium is likely from glassware used in the titration. There is also a potential the acidification resulted in the release of lithium from compounds in the tobacco smoke extracts.

Note that each figure displays three overlapping chromatographs, one for each replicate (denoted as A, B, C in the legend above the plot). 


\section{A.1 Brand 1 Ion Chromatographs}

\section{A.1.1 Brand 1, Sampling Code 1A}

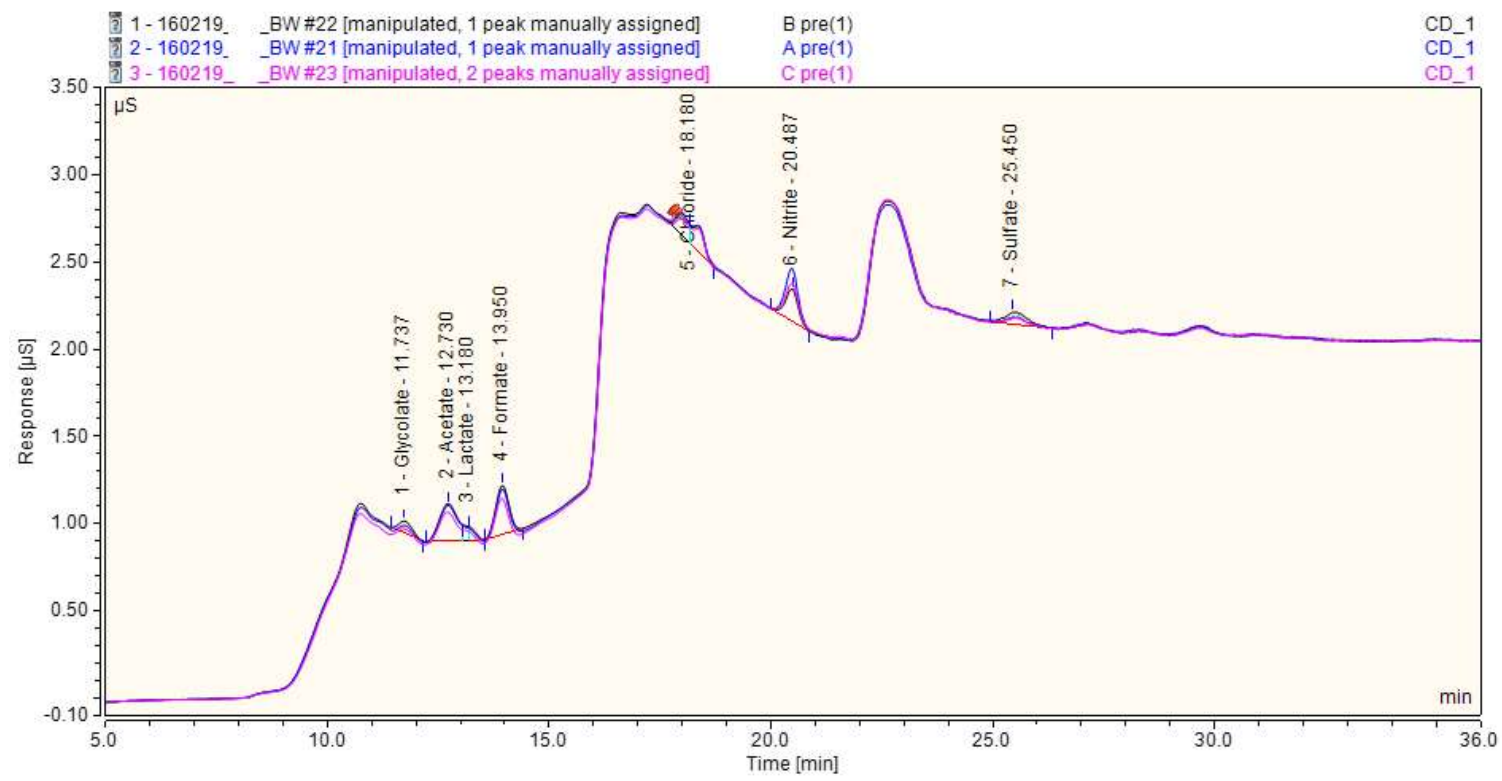

Figure A.1 Anion chromatographs for 1A, pre-titration.

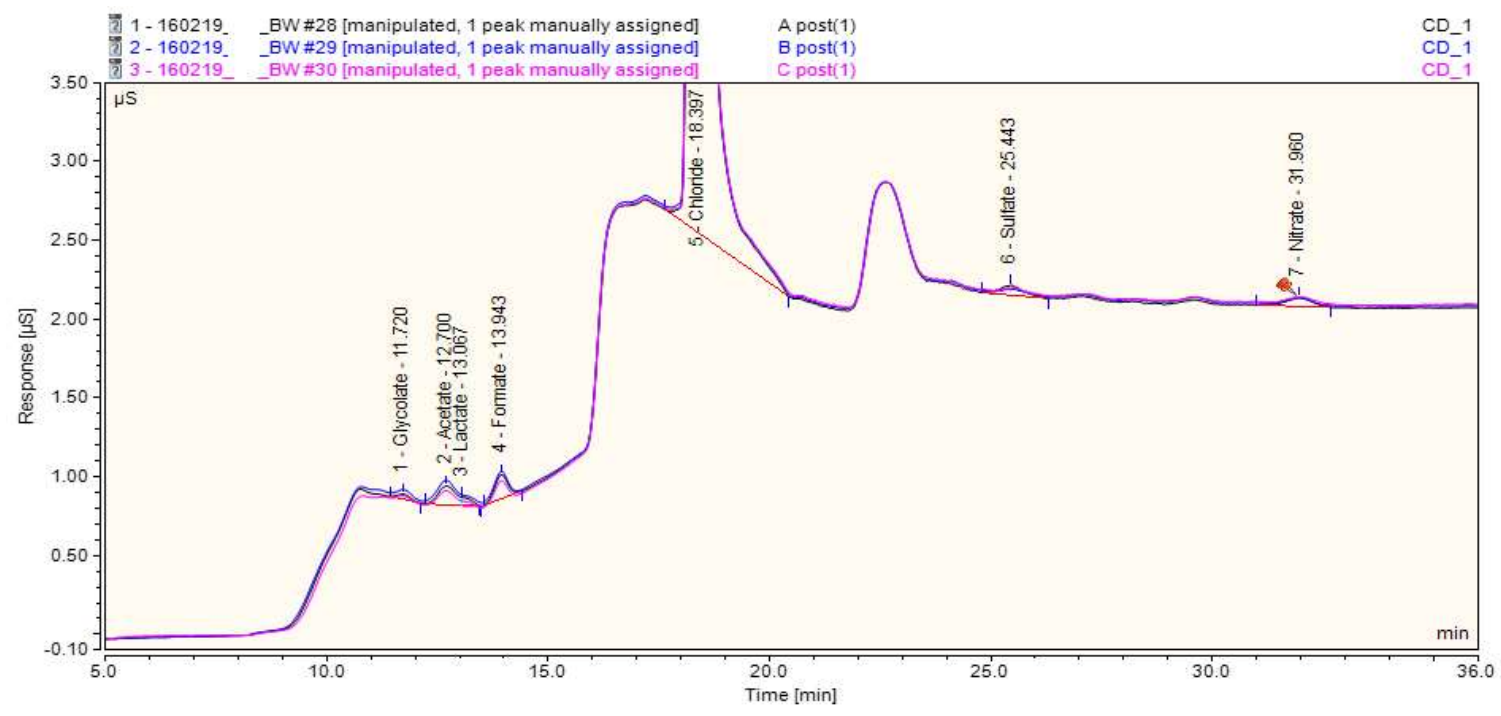

Figure A.2 Anion chromatographs for 1A, post-titration. 


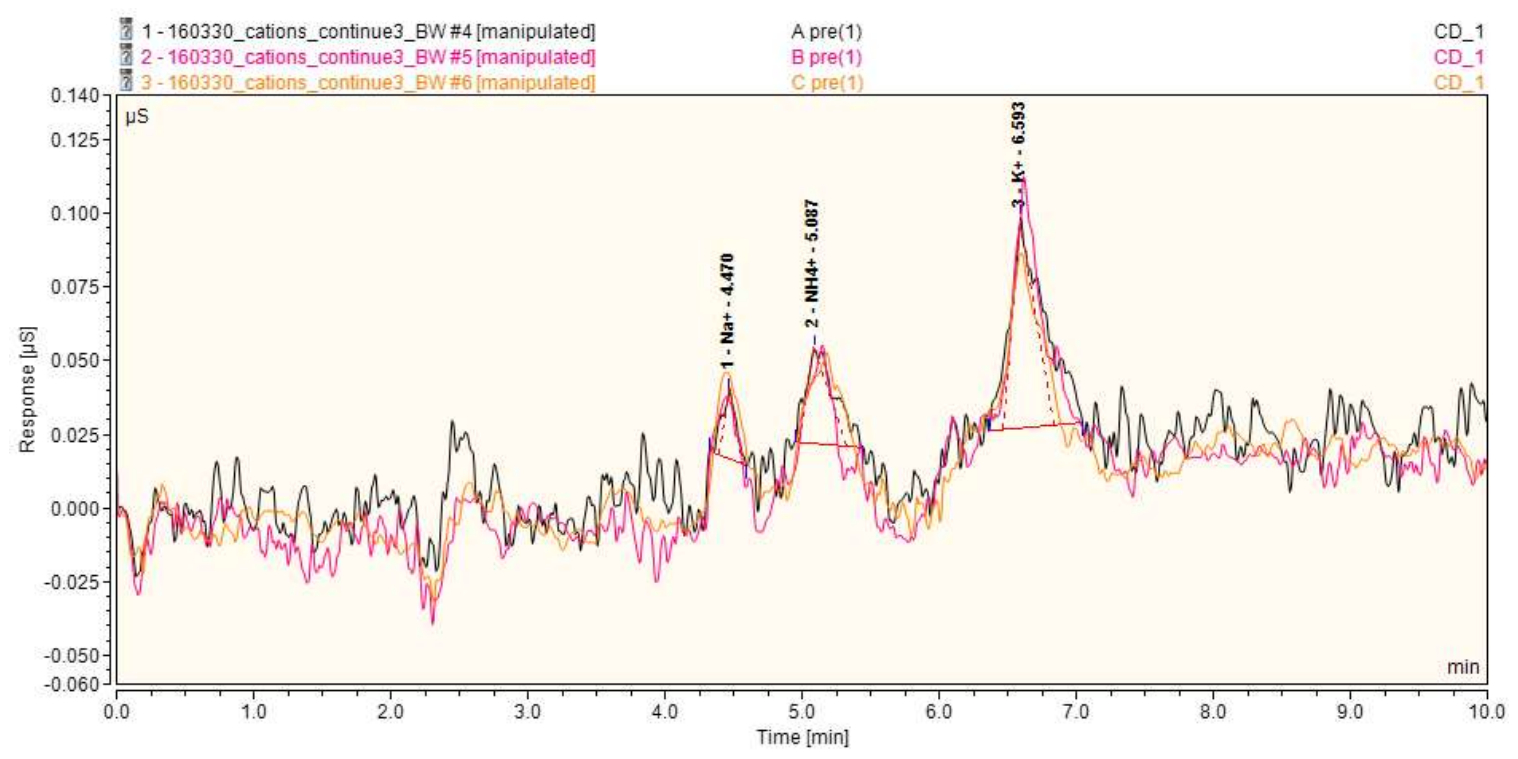

Figure A.3 Cation chromatographs for 1A, pre-titration.

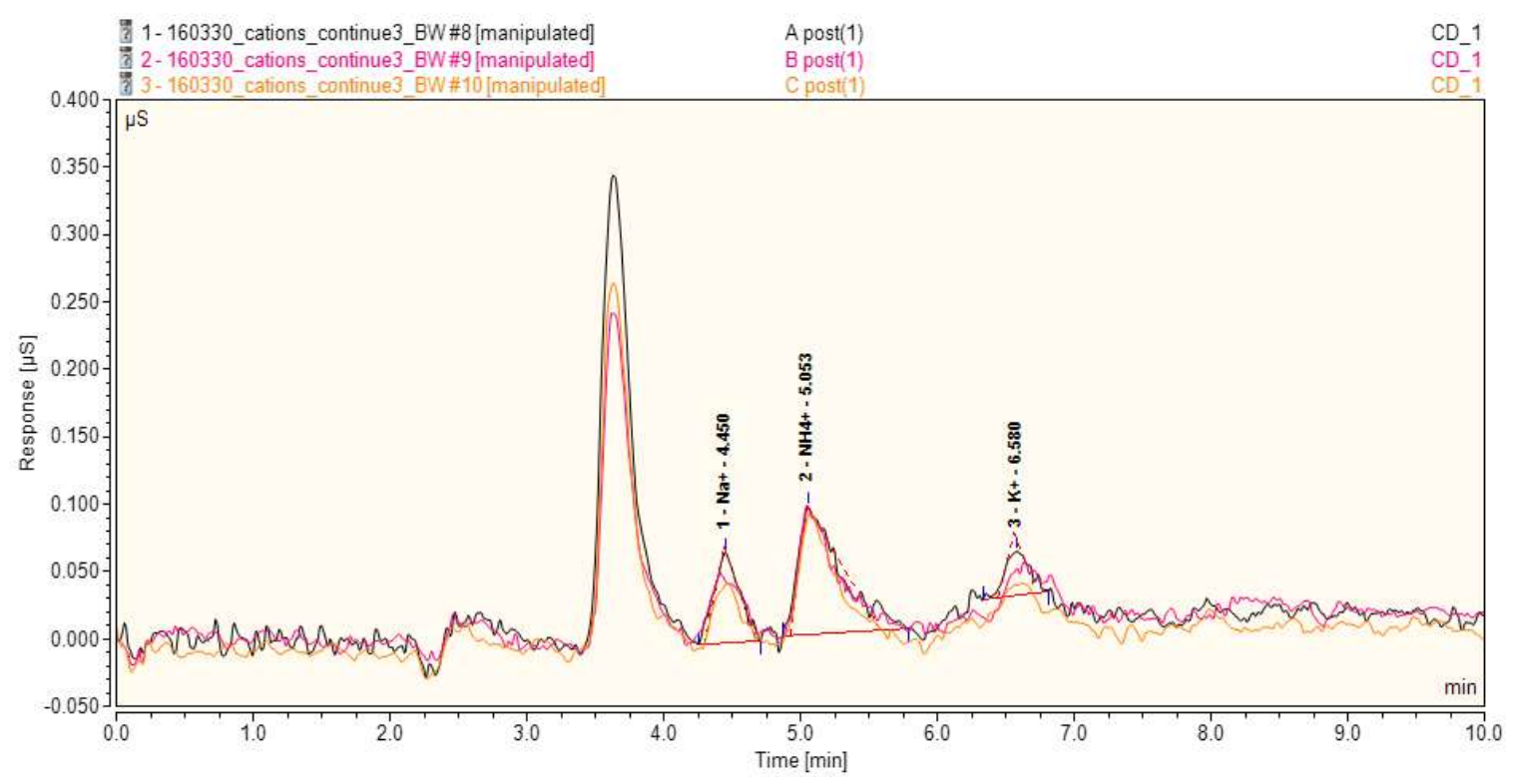

Figure A.4 Cation chromatographs for 1A, post-titration. 


\section{A.1.2 Brand 1, Sampling Code 1B}

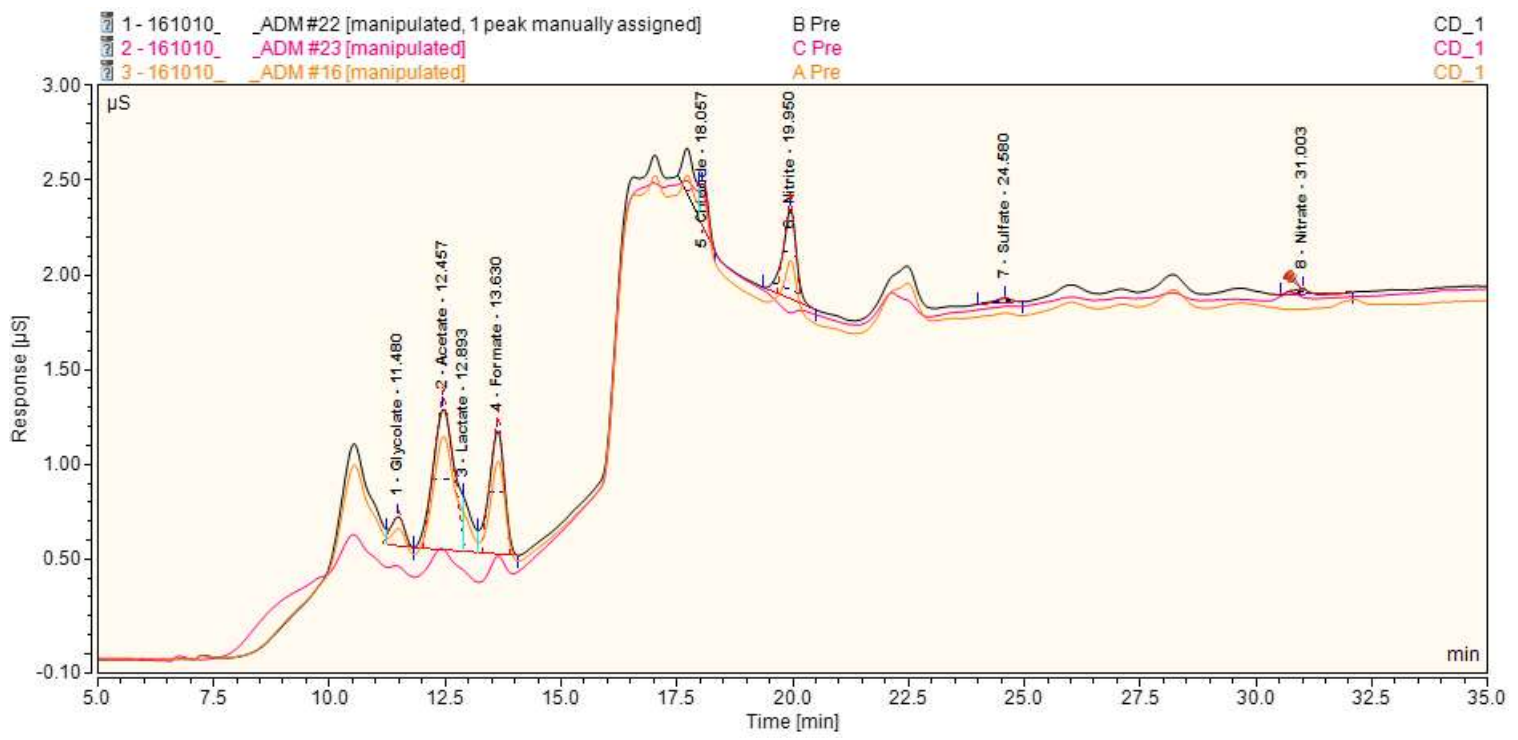

Figure A.5 Anion chromatographs for 1B, pre-titration.

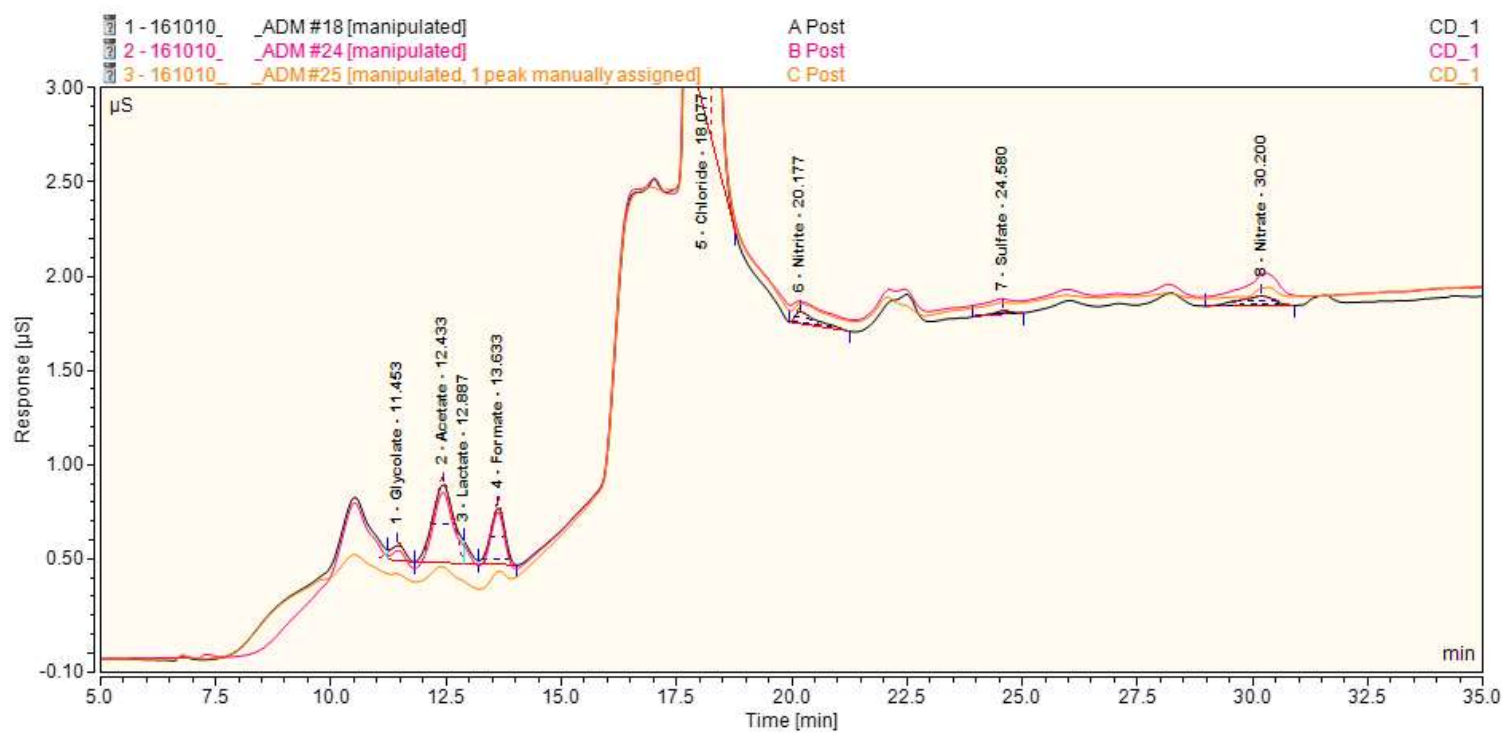

Figure A.6 Anion chromatographs for 1B, post-titration. 


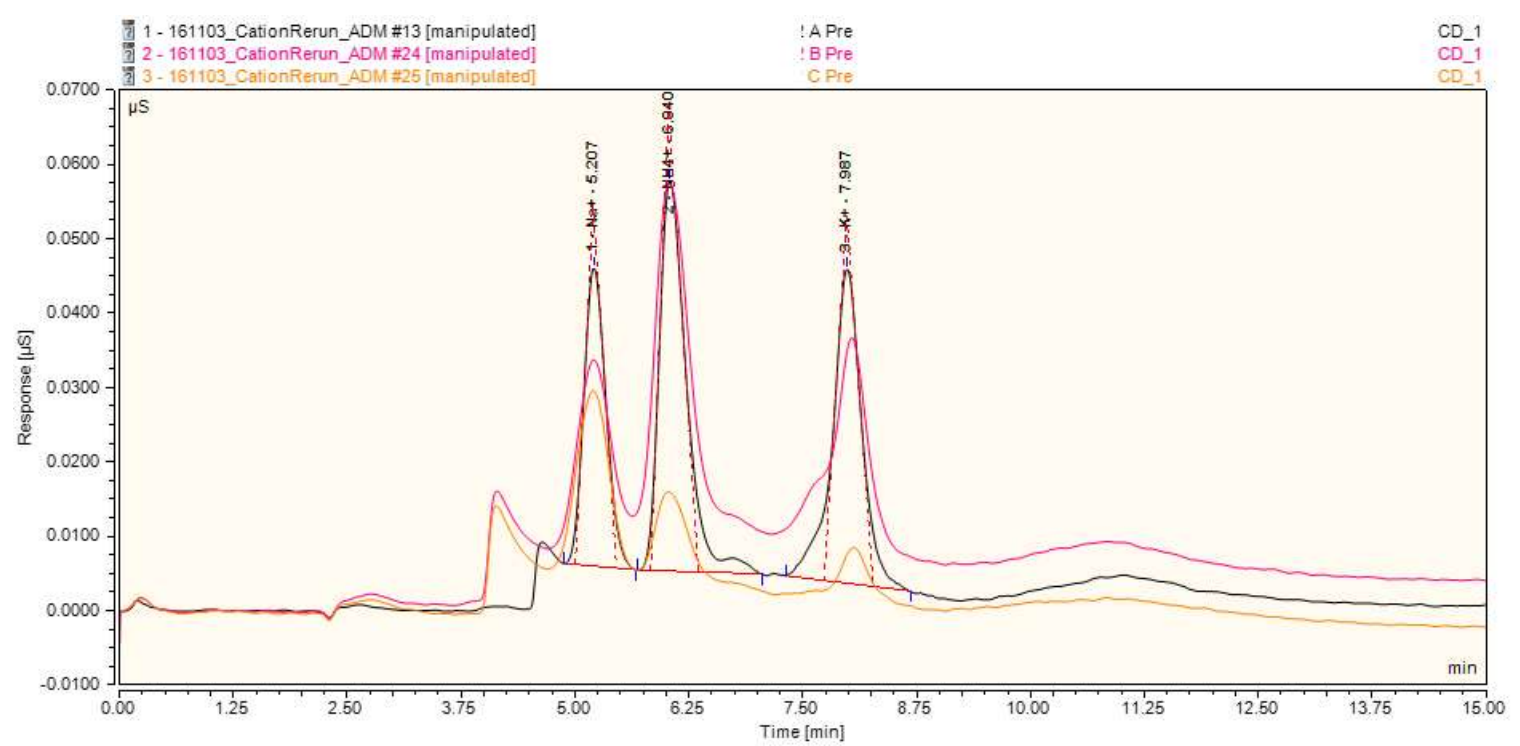

Figure A.7 Cation chromatographs for 1B, pre-titration.

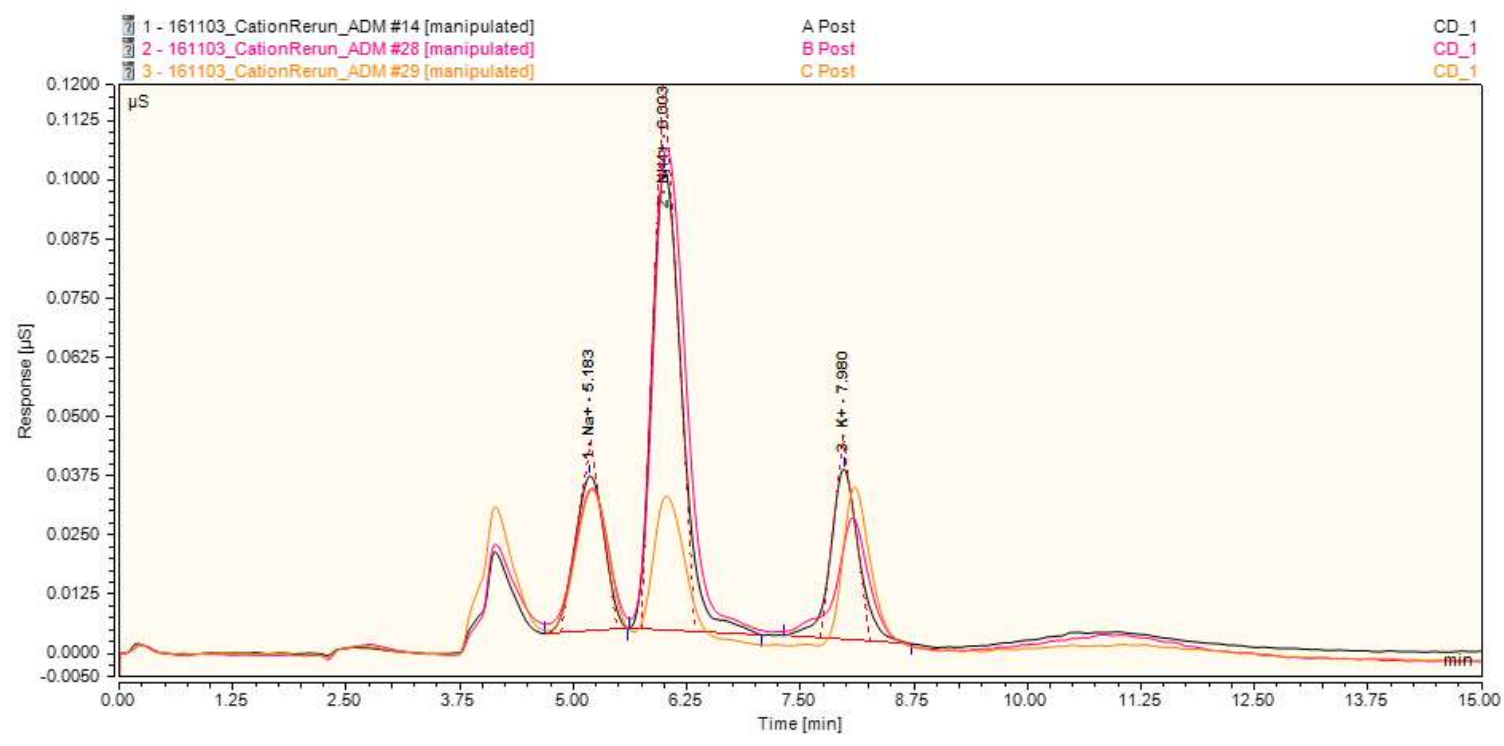

Figure A.8 Cation chromatographs for 1B, post-titration. 


\section{A.1.3 Brand 1, Sampling Code 1C}

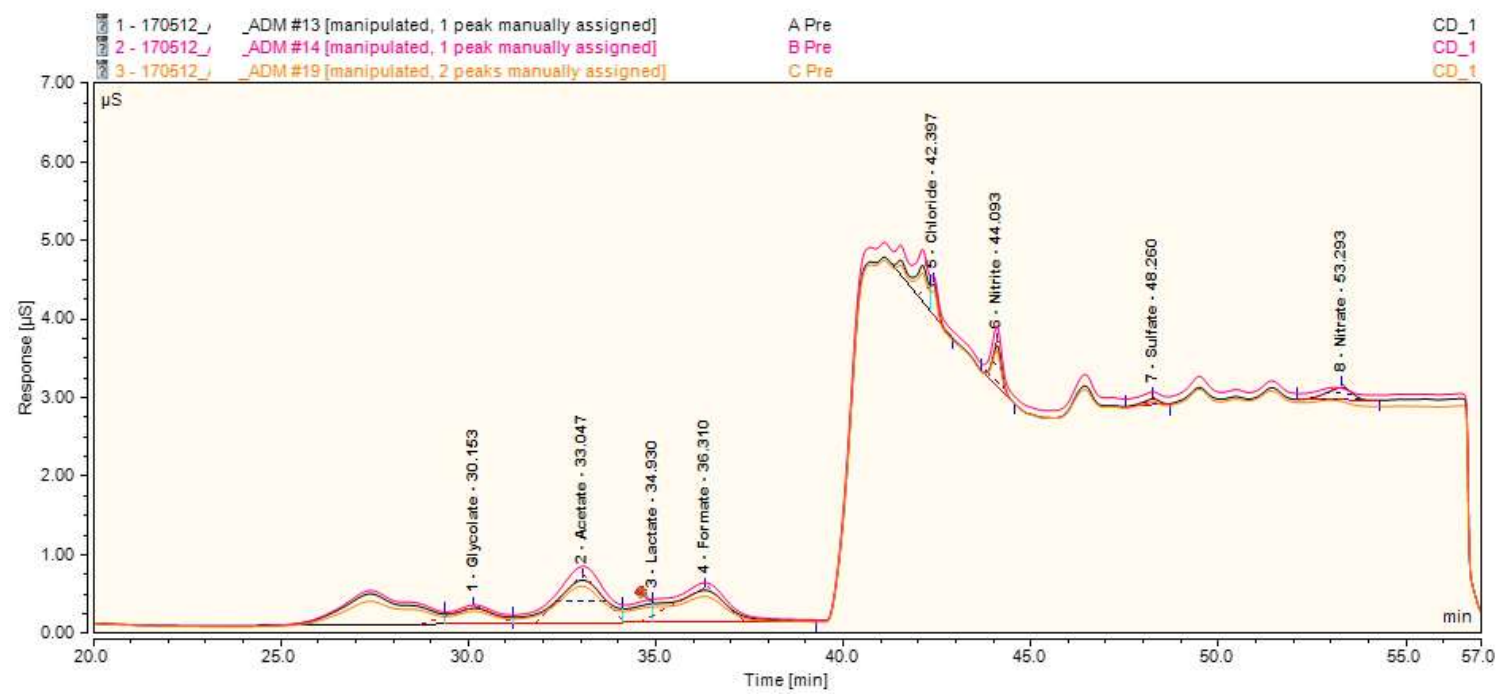

Figure A.9 Anion chromatographs for 1C, pre-titration.

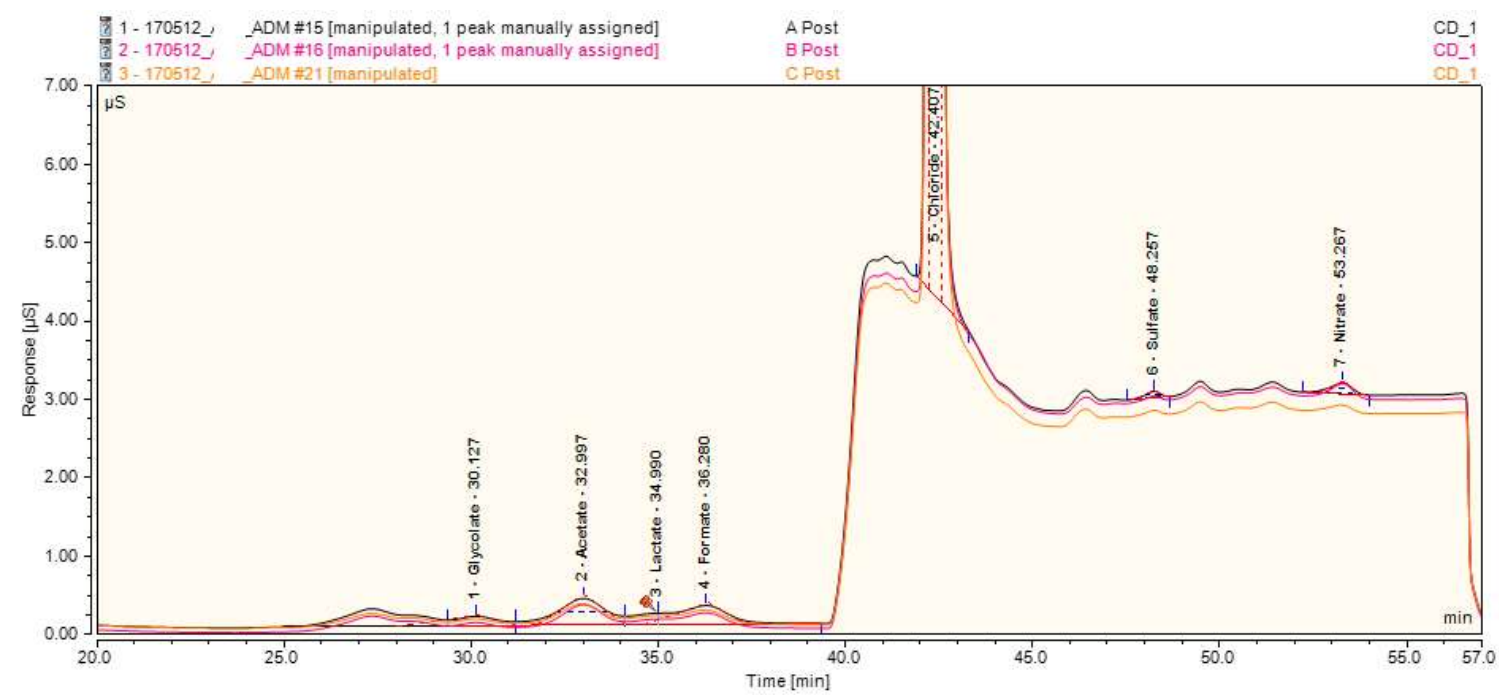

Figure A.10 Anion chromatographs for 1C, post-titration. 


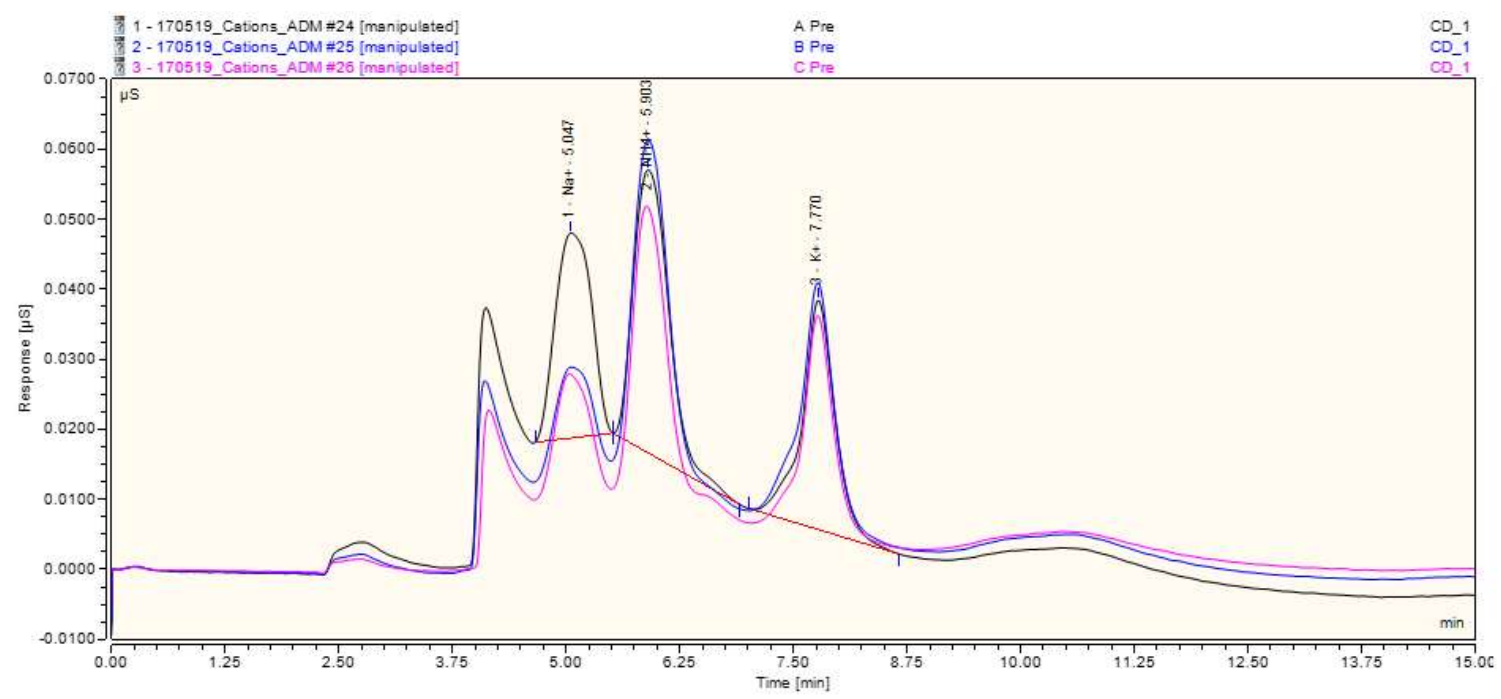

Figure A.11 Cation chromatographs for 1C, pre-titration.

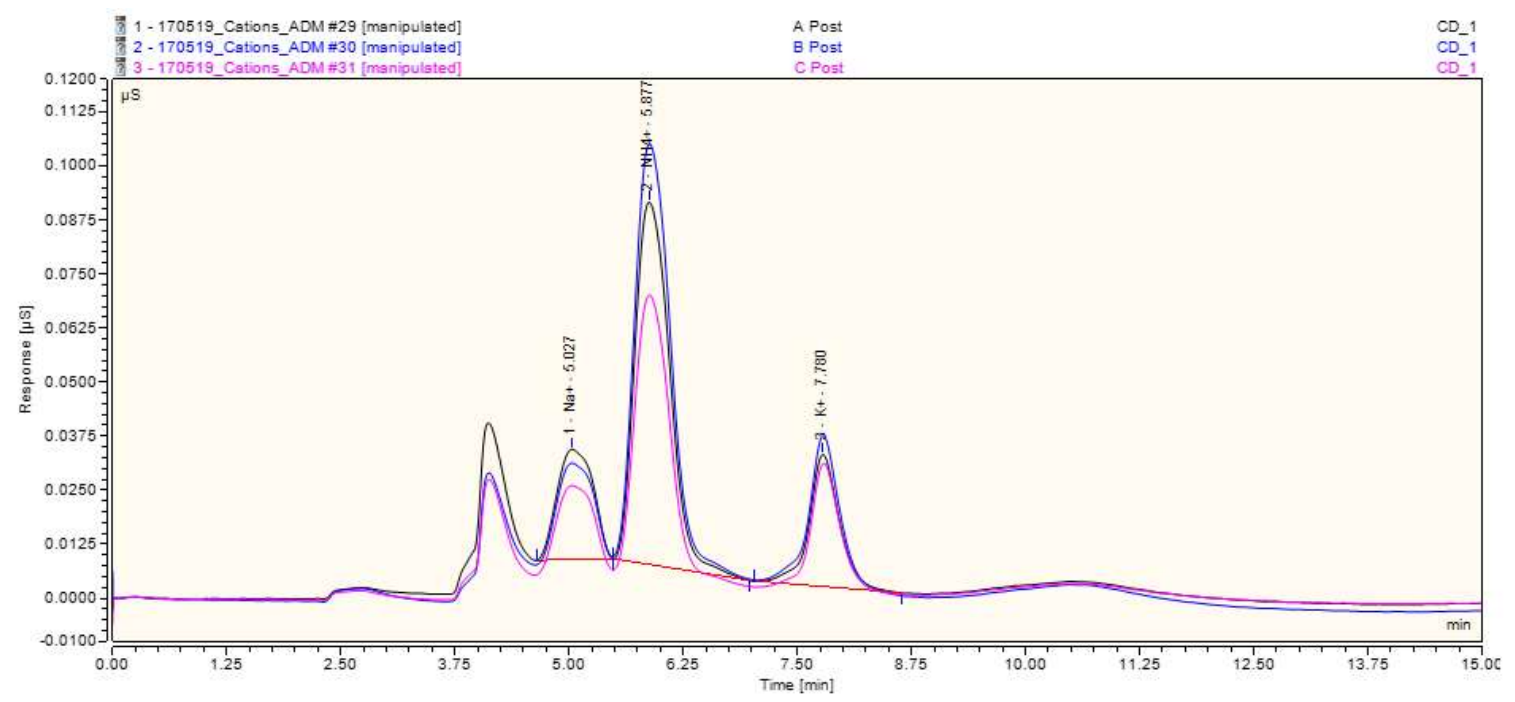

Figure A.12 Cation chromatographs for 1C, post-titration. 


\section{A.1.4 Brand 1, Sampling Code 1Full}

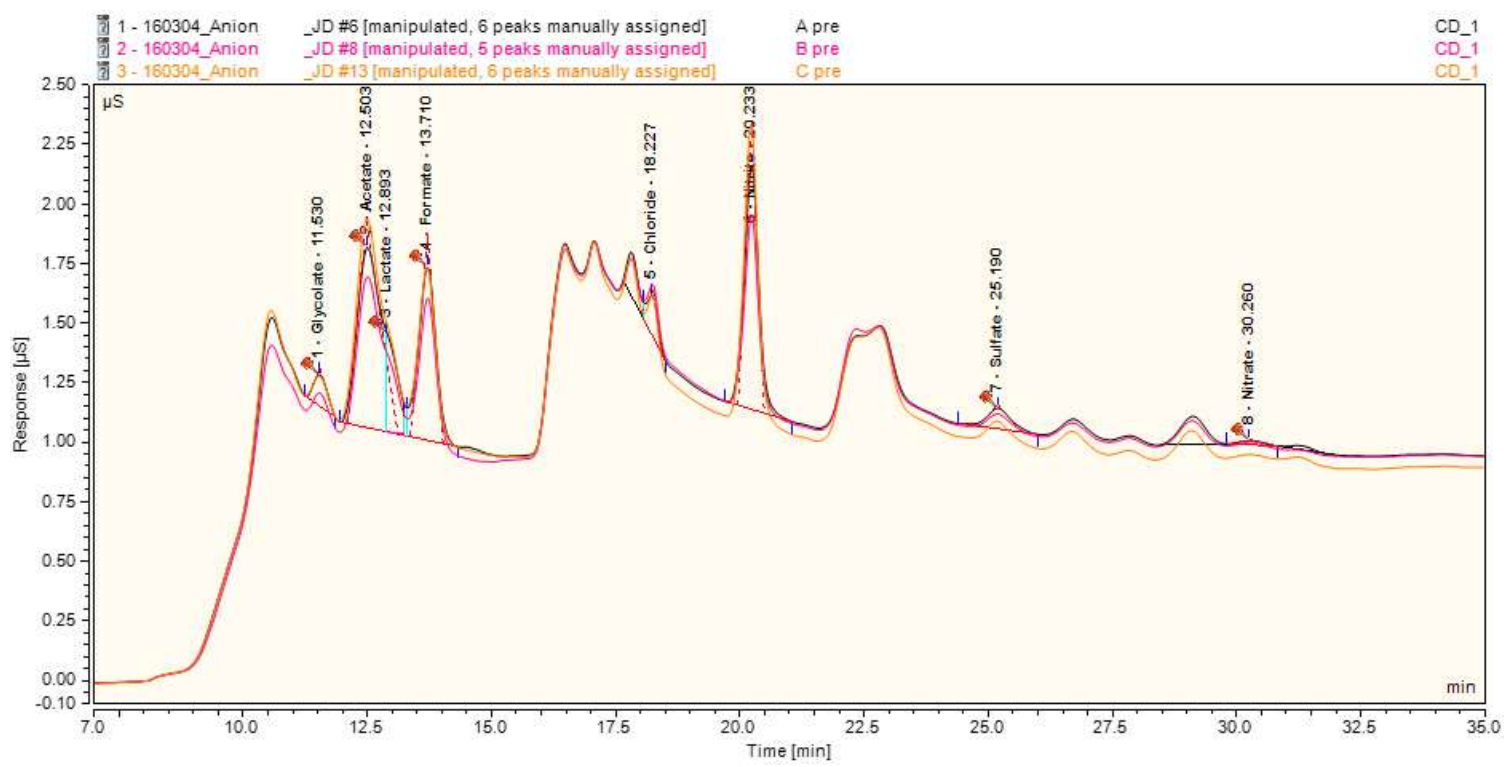

Figure A.13 Anion chromatographs for 1Full, pre-titration.

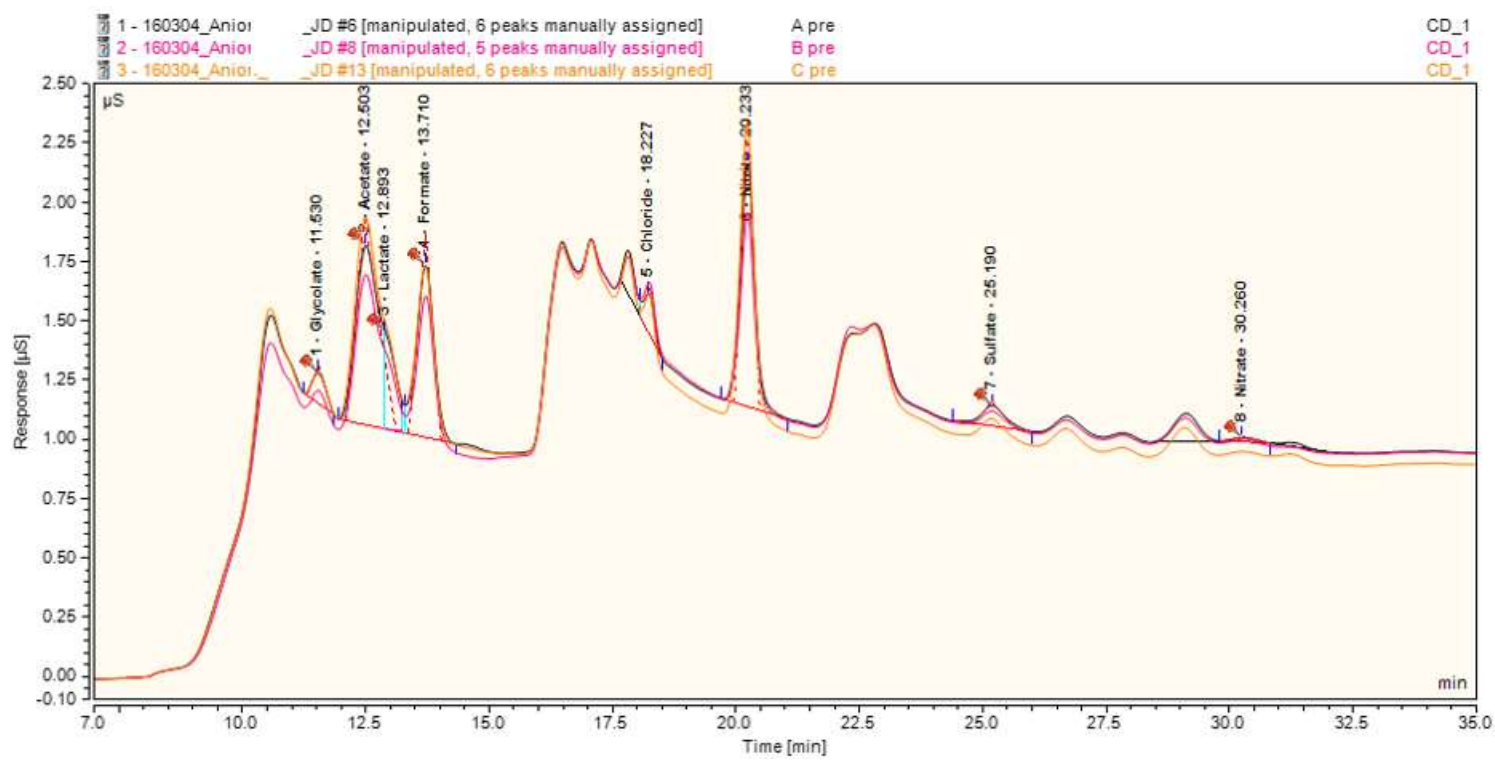

Figure A.14 Anion chromatographs for 1Full, post-titration. 


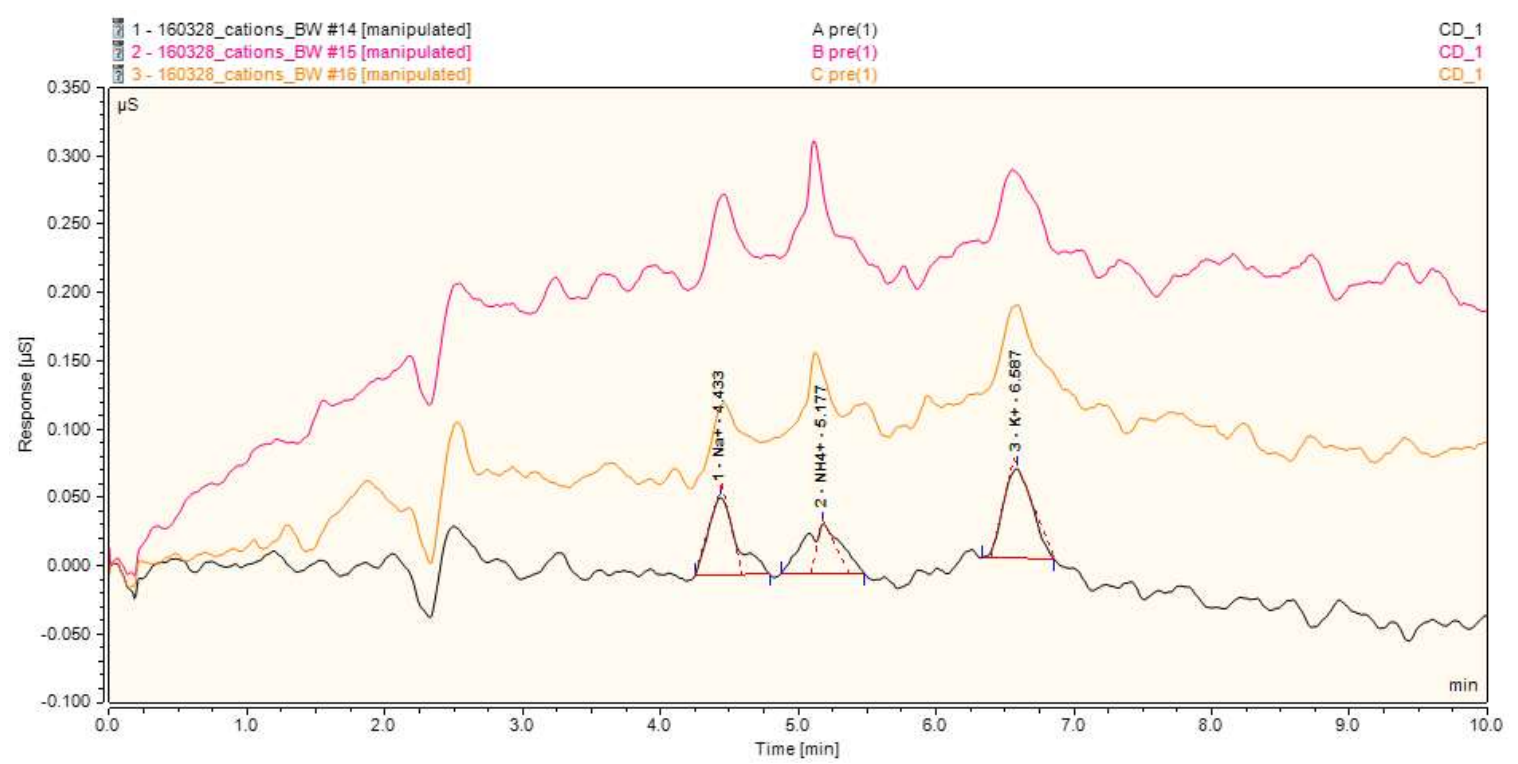

Figure A.15 Cation chromatographs for 1Full, pre-titration.

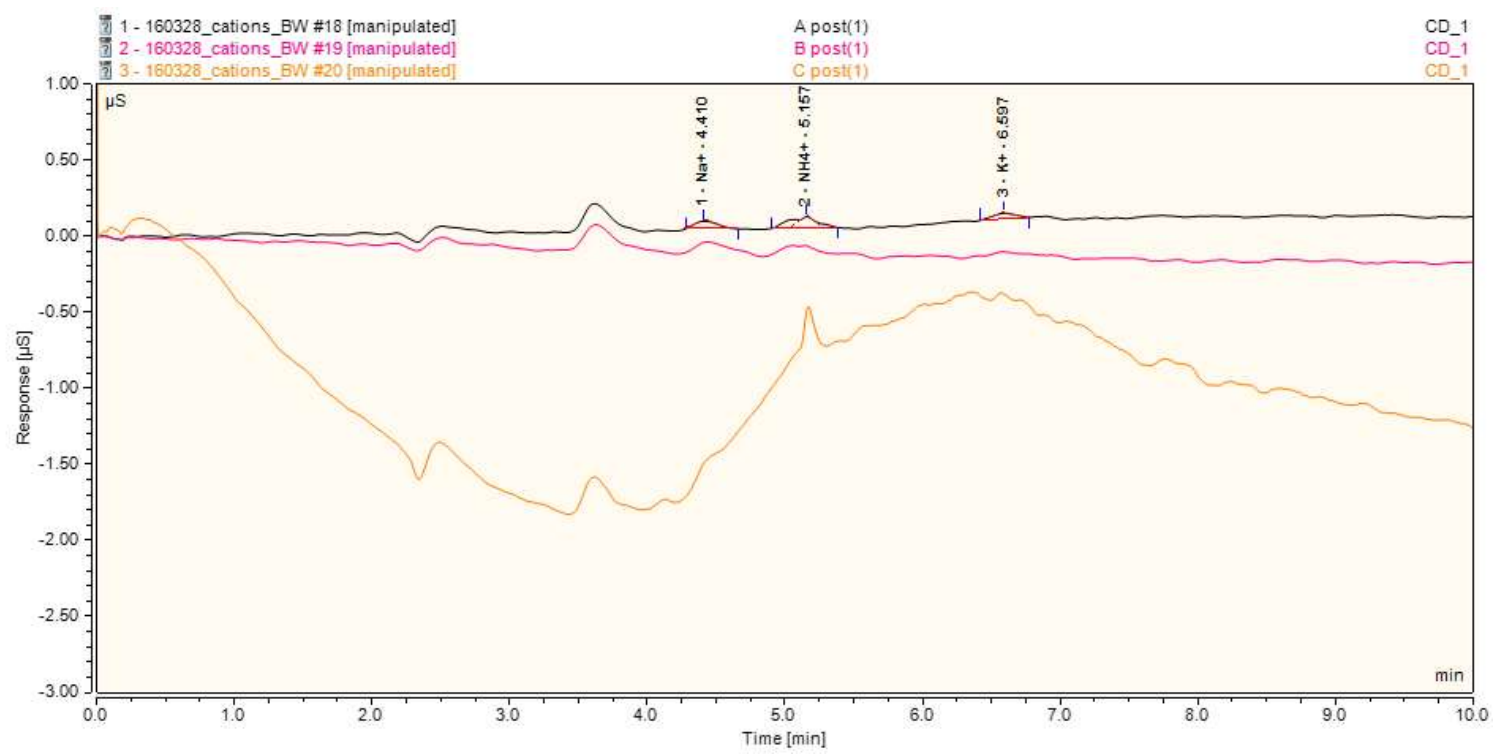

Figure A.16 Cation chromatographs for 1Full, post-titration. 


\section{A.2 Brand 2 Ion Chromatographs}

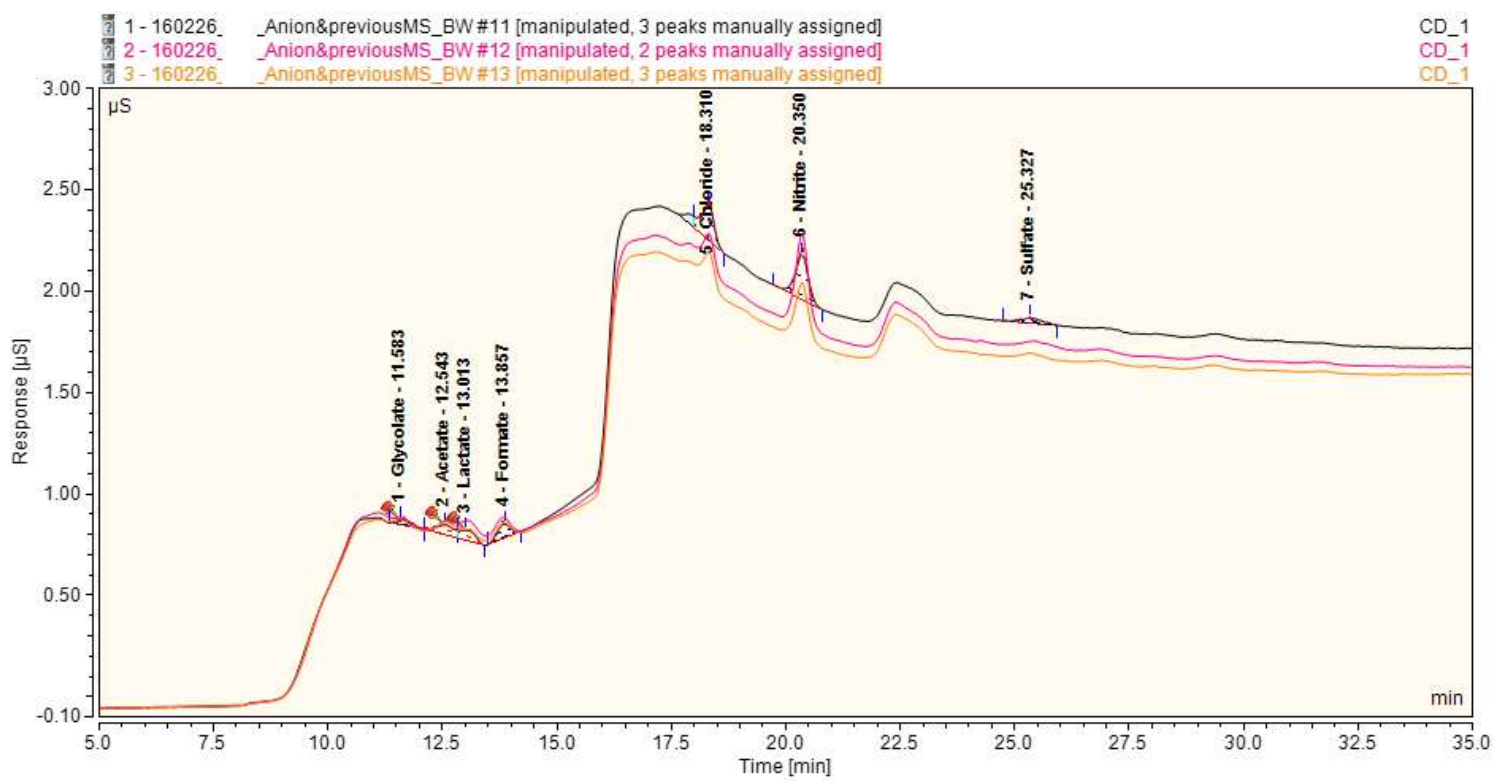

Figure A.17 Anion chromatographs for brand 2, pre-titration.

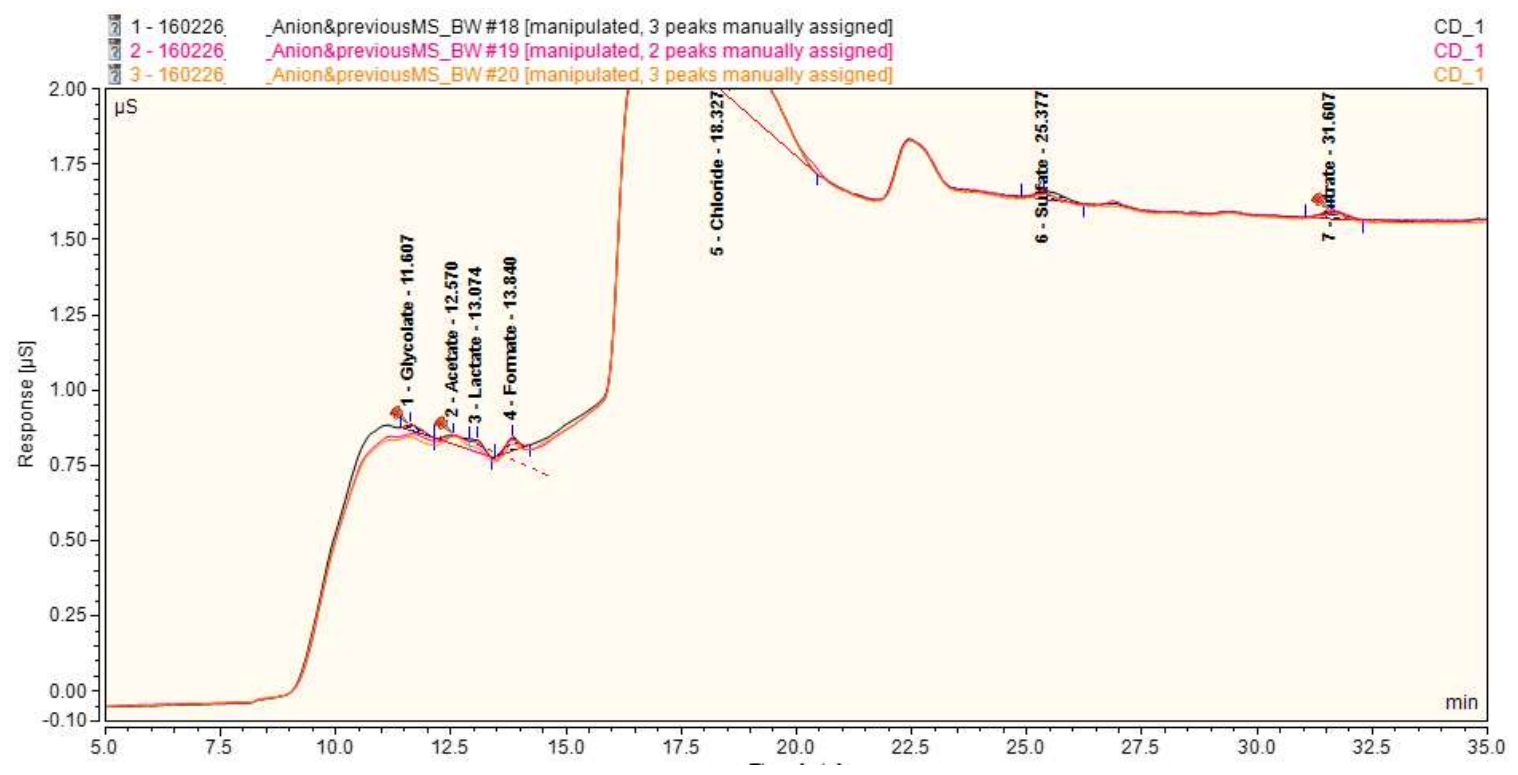

Figure A.18 Anion chromatographs for brand 2, post-titration. 


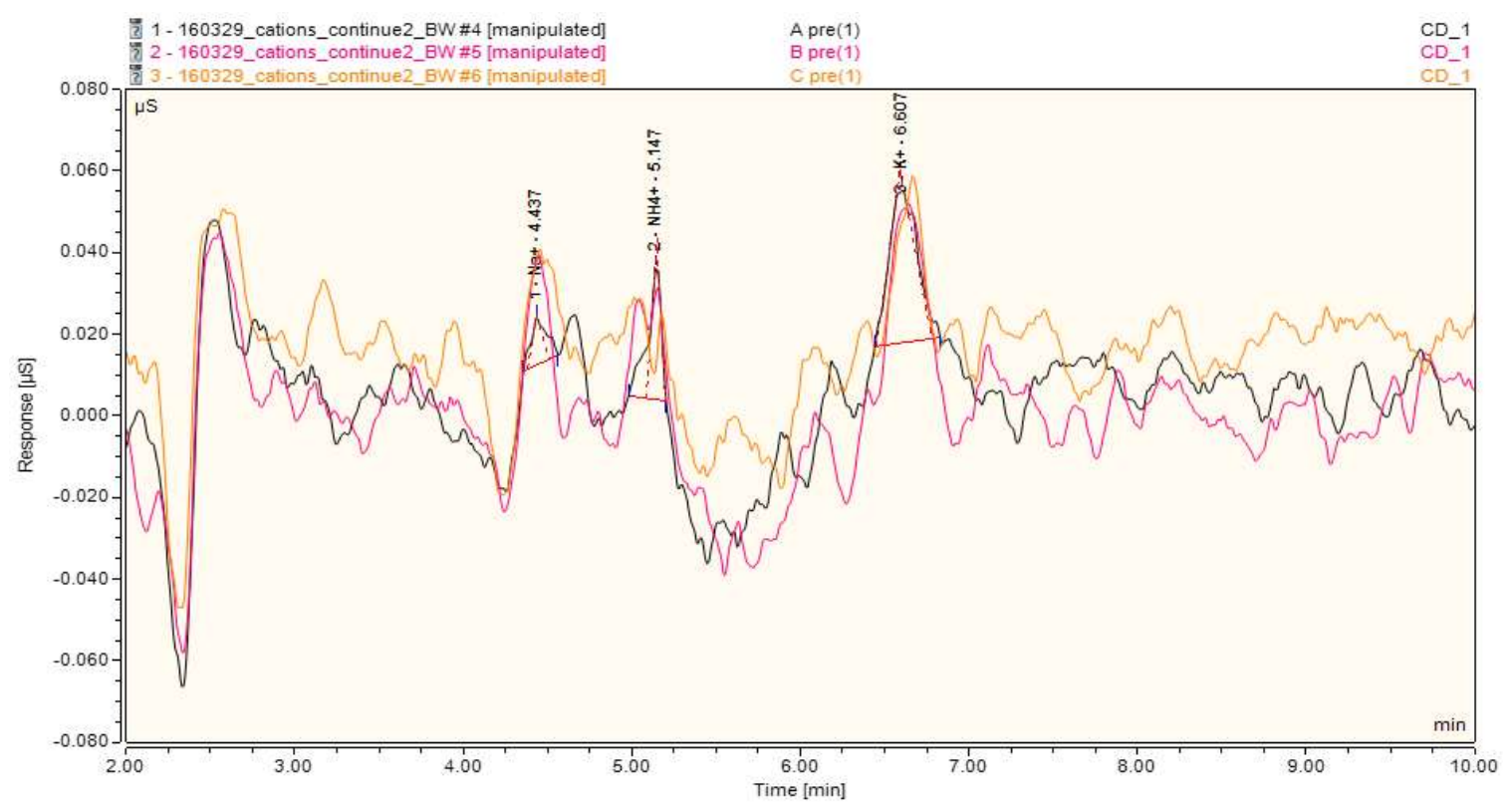

Figure A.19 Cation chromatographs for brand 2, pre-titration.

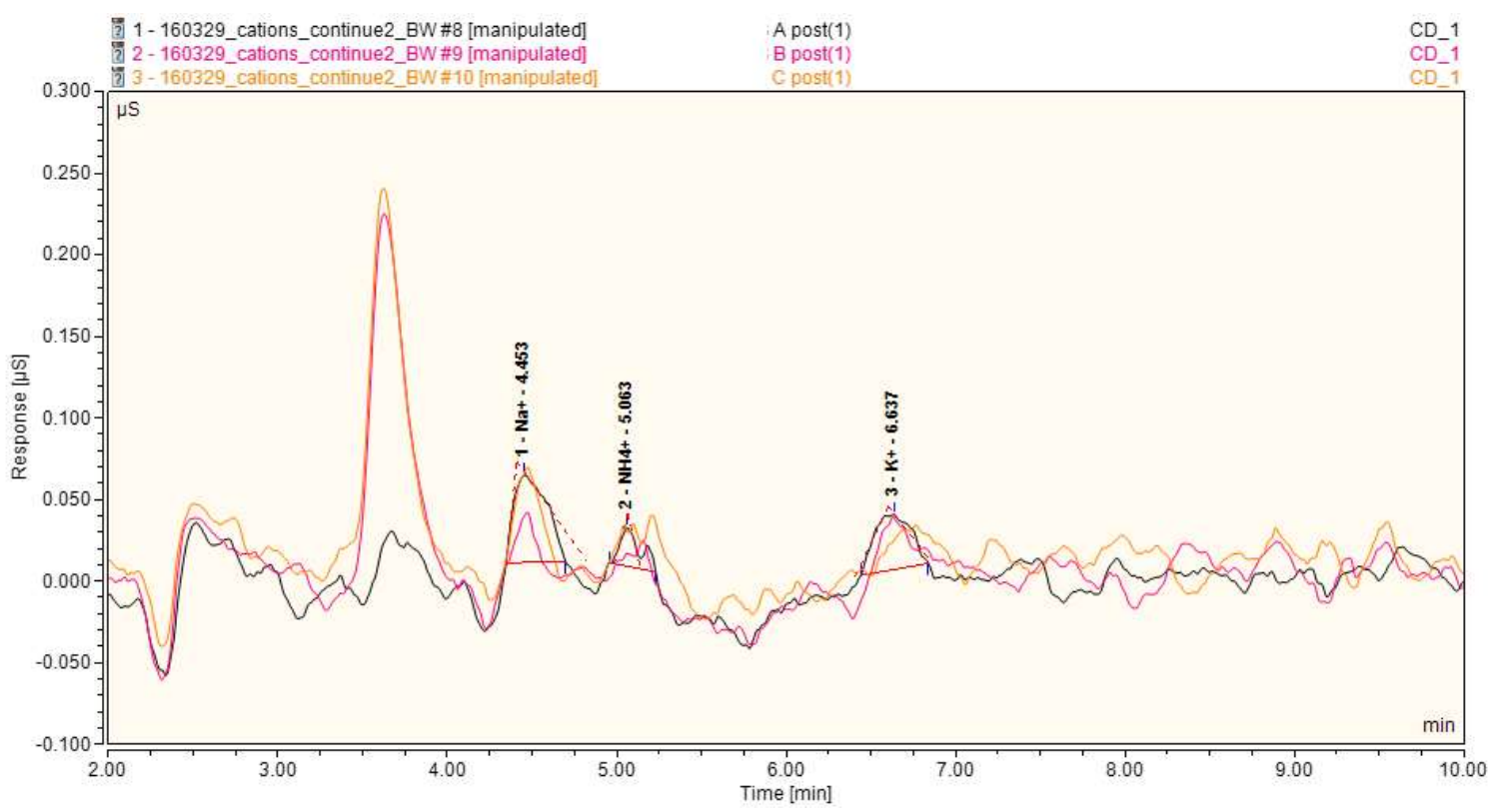

Figure A.20 Cation chromatographs for brand 2, post-titration. 


\section{A.3 Brand 3 Ion Chromatographs}

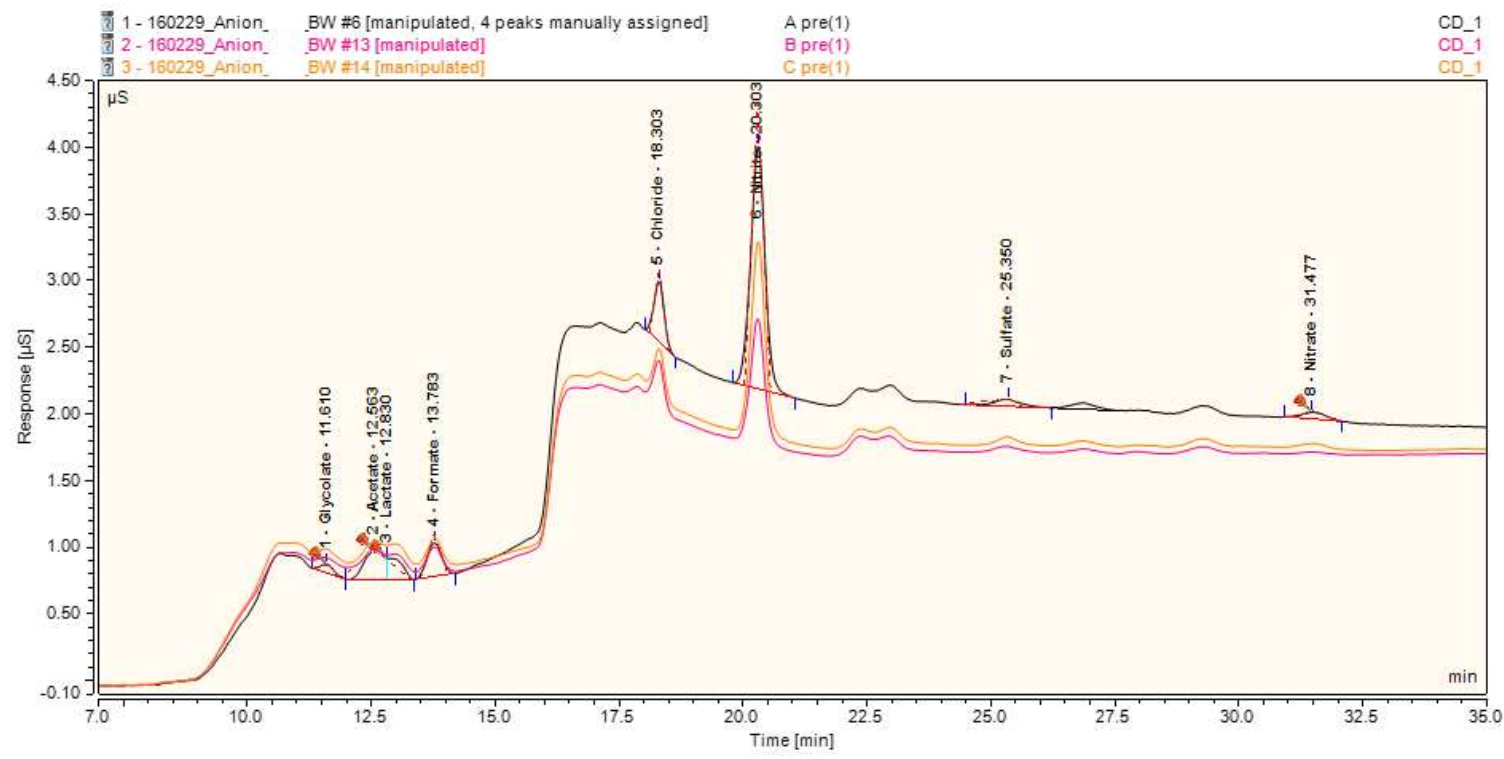

Figure A.21 Anion chromatographs for brand 3, pre-titration.

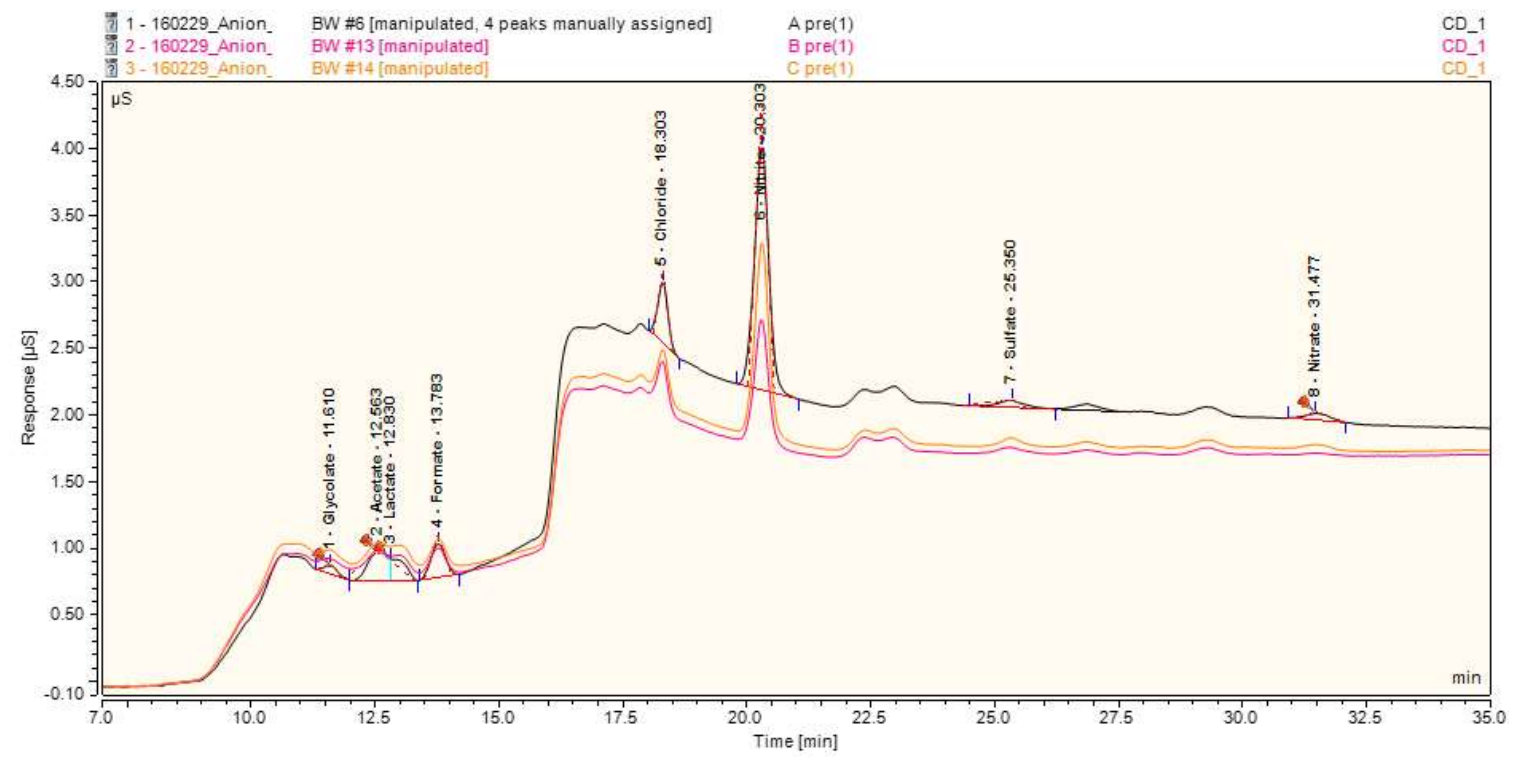

Figure A.22 Anion chromatographs for brand 3, post-titration. 


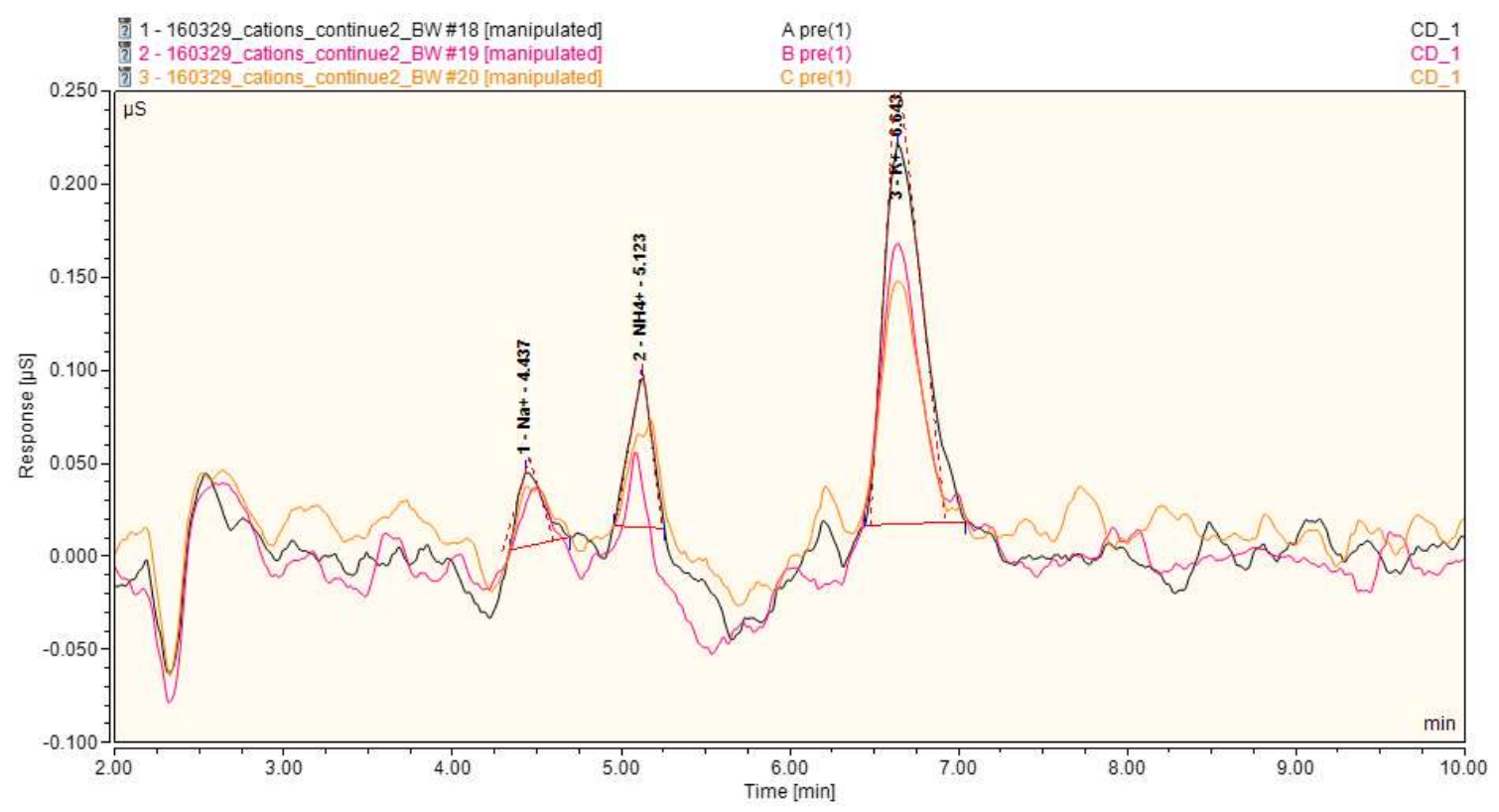

Figure A.23 Cation chromatographs for brand 3, pre-titration.

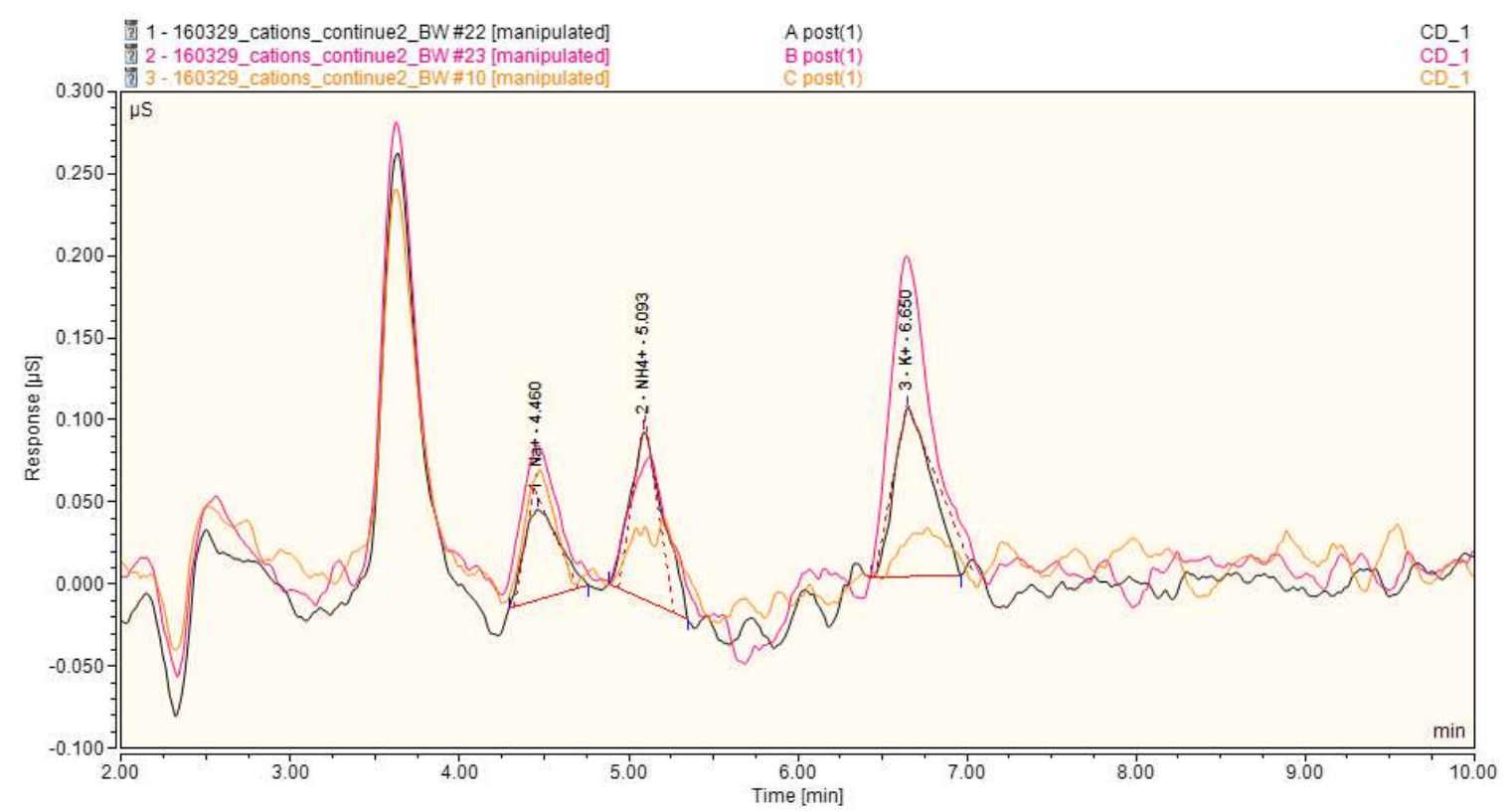

Figure A.24 Cation chromatographs for brand 3, post-titration. 


\section{A.4 Brand 4 Ion Chromatographs}

\section{A.4.1 Brand 4, Sampling Code 4A}

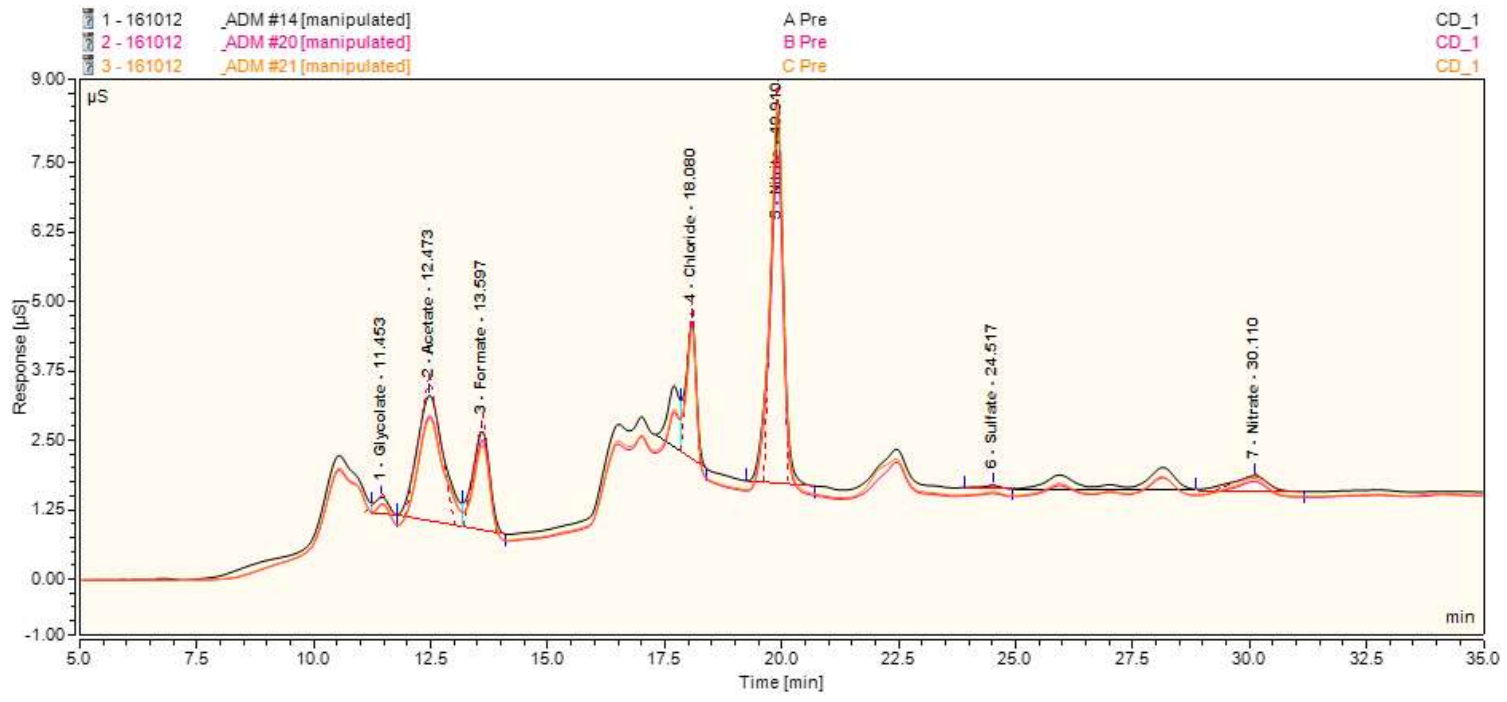

Figure A.25 Anion chromatographs for 4A, pre-titration.

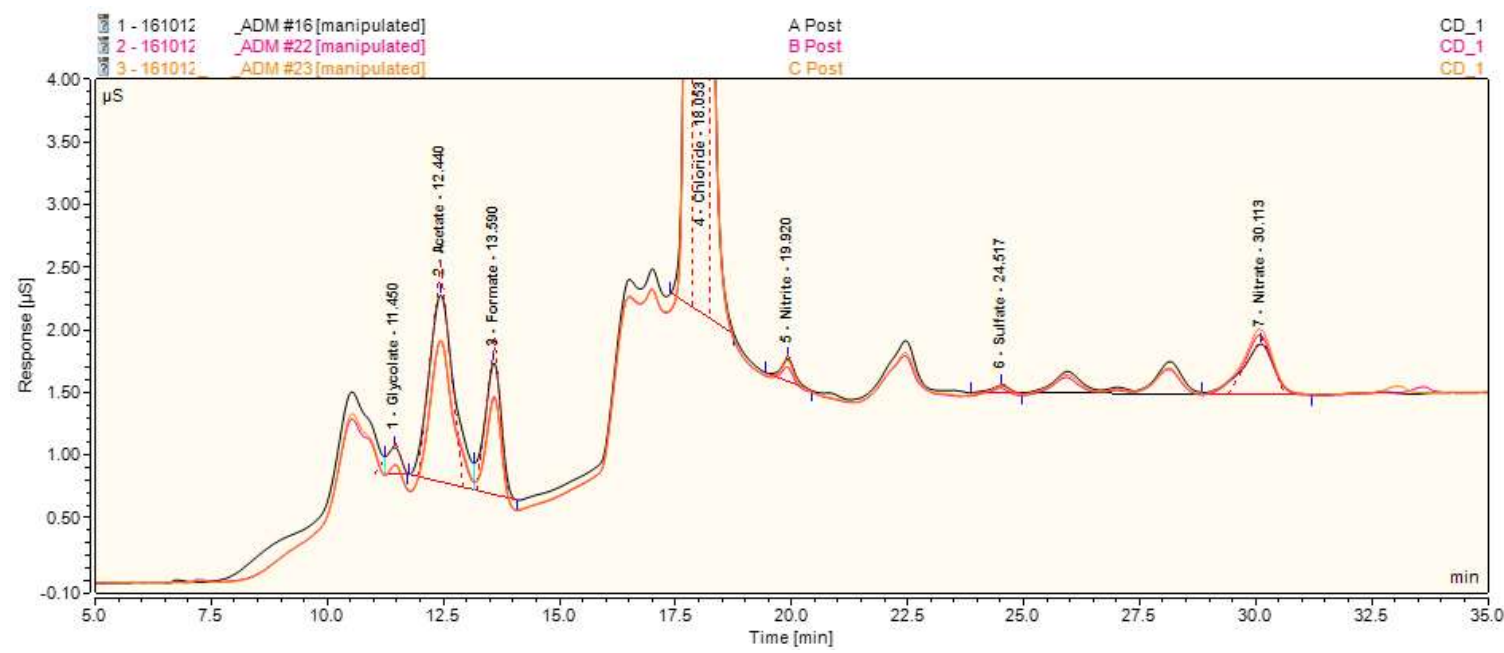

Figure A.26 Anion chromatographs for 4A, post-titration. 


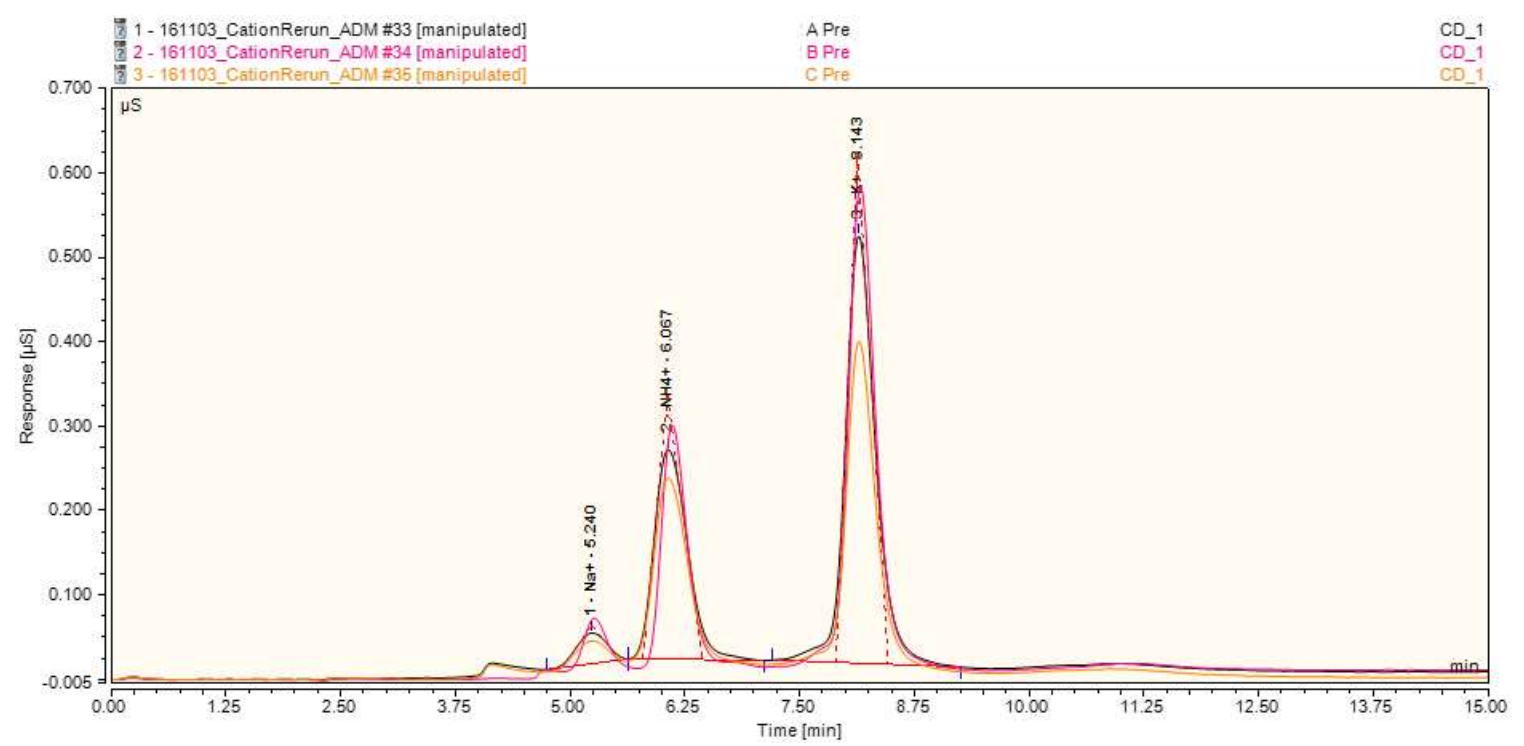

Figure A.27 Cation chromatographs for 4A, pre-titration.

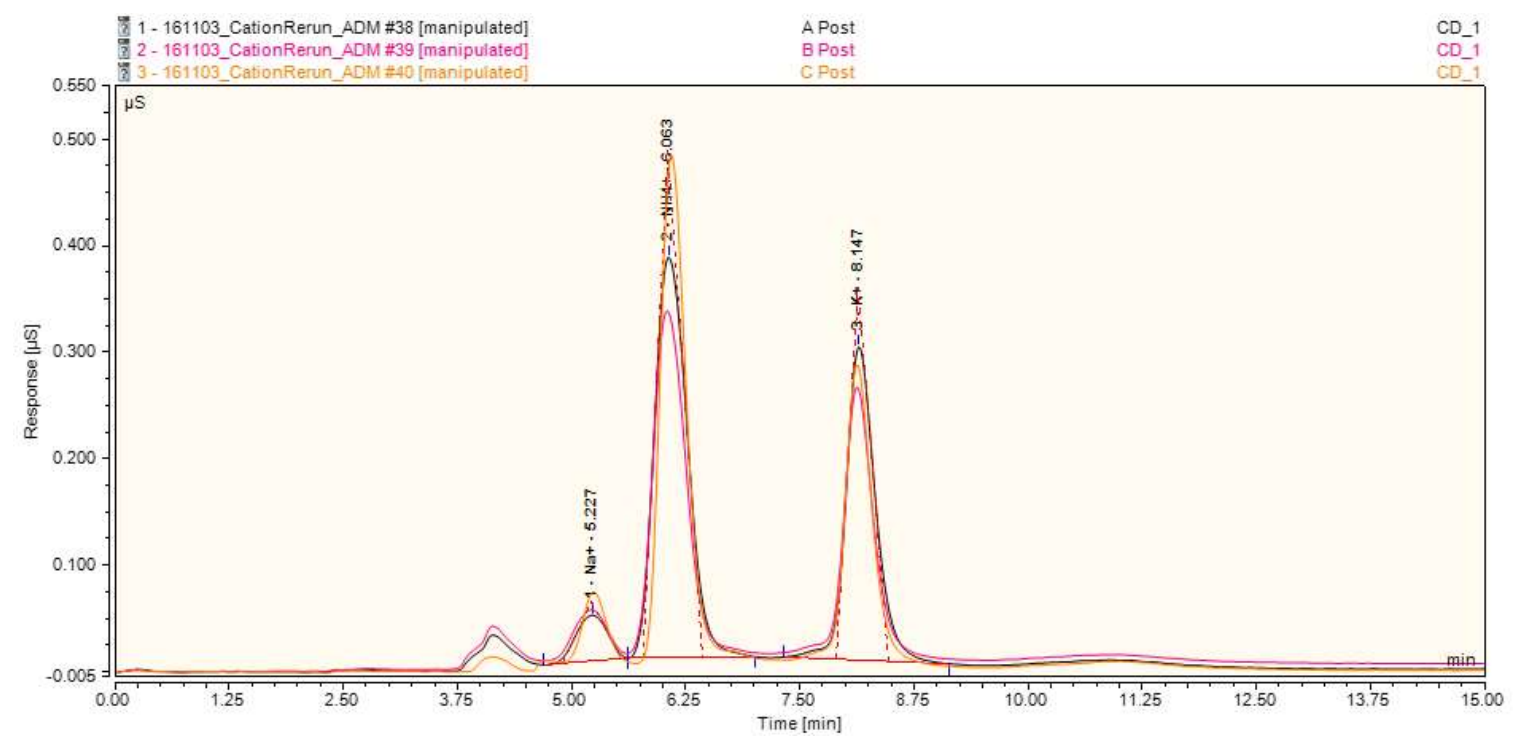

Figure A.28 Cation chromatographs for 4A, post-titration. 


\section{A.4.2 Brand 4, Sampling Code 4B}

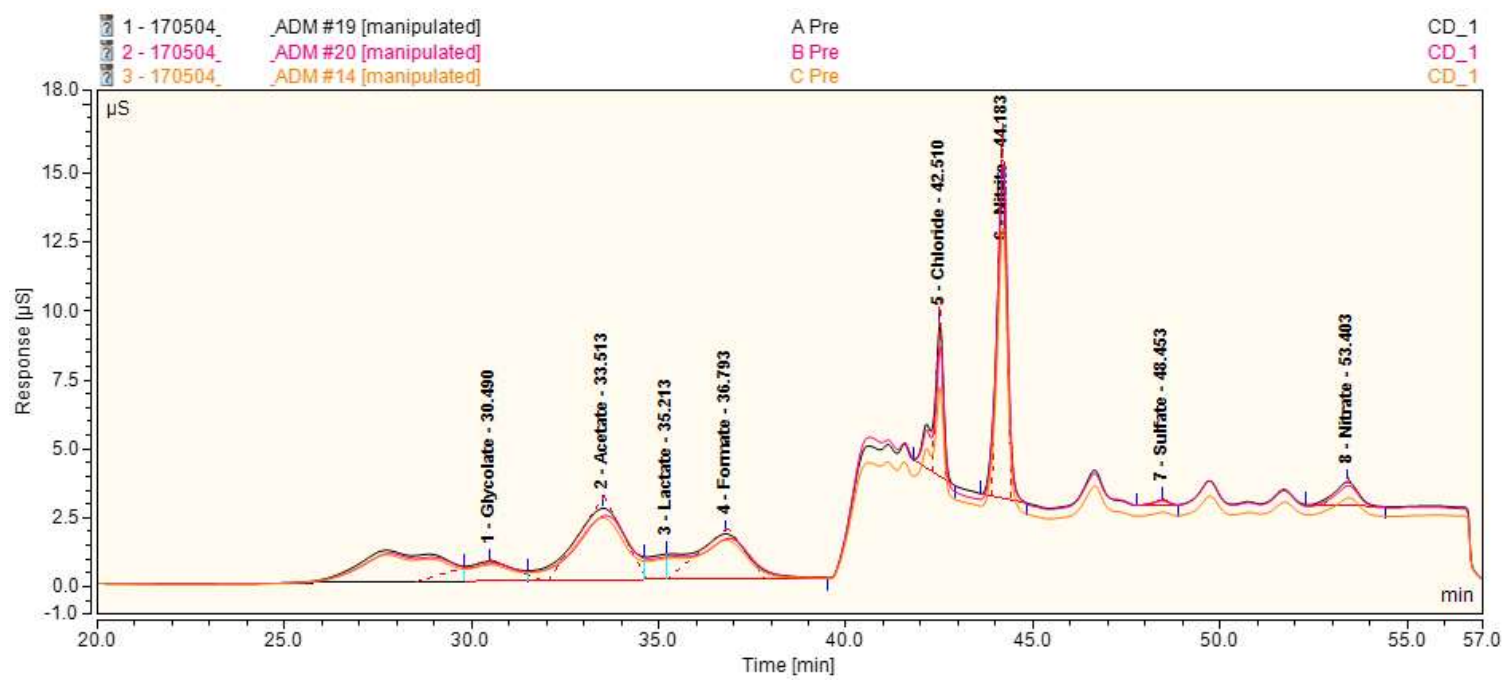

Figure A.29 Anion chromatographs for 4B, pre-titration.

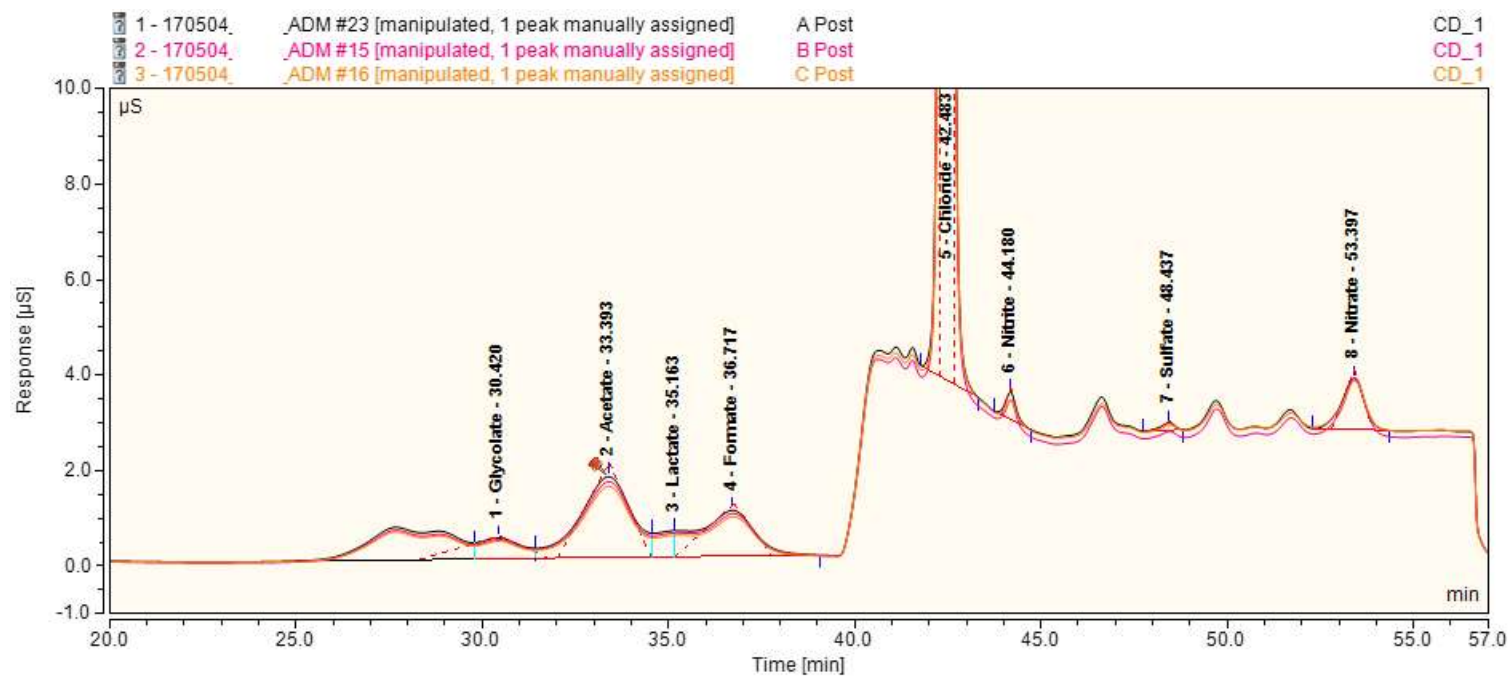

Figure A.30 Anion chromatographs for 4B, post-titration. 


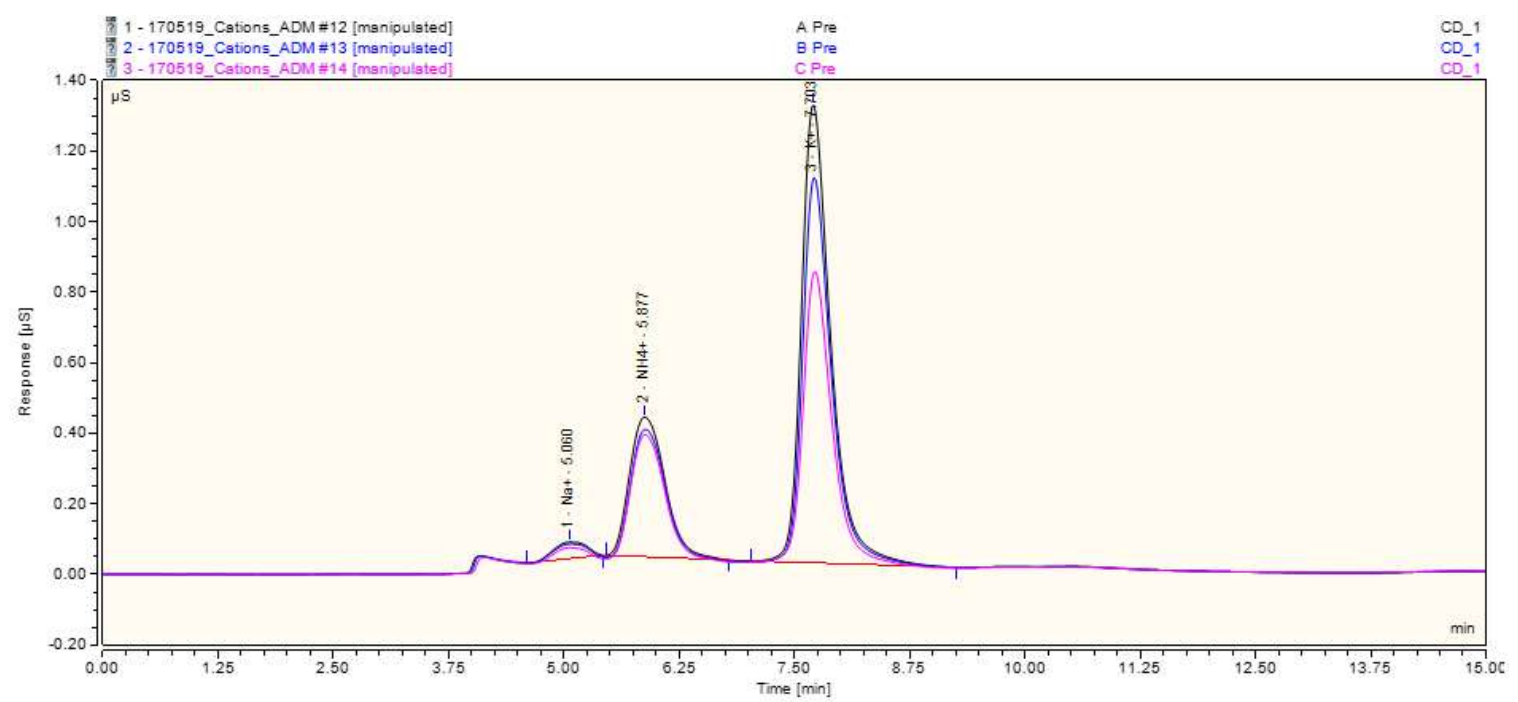

Figure A.31 Cation chromatographs for 4B, pre-titration.

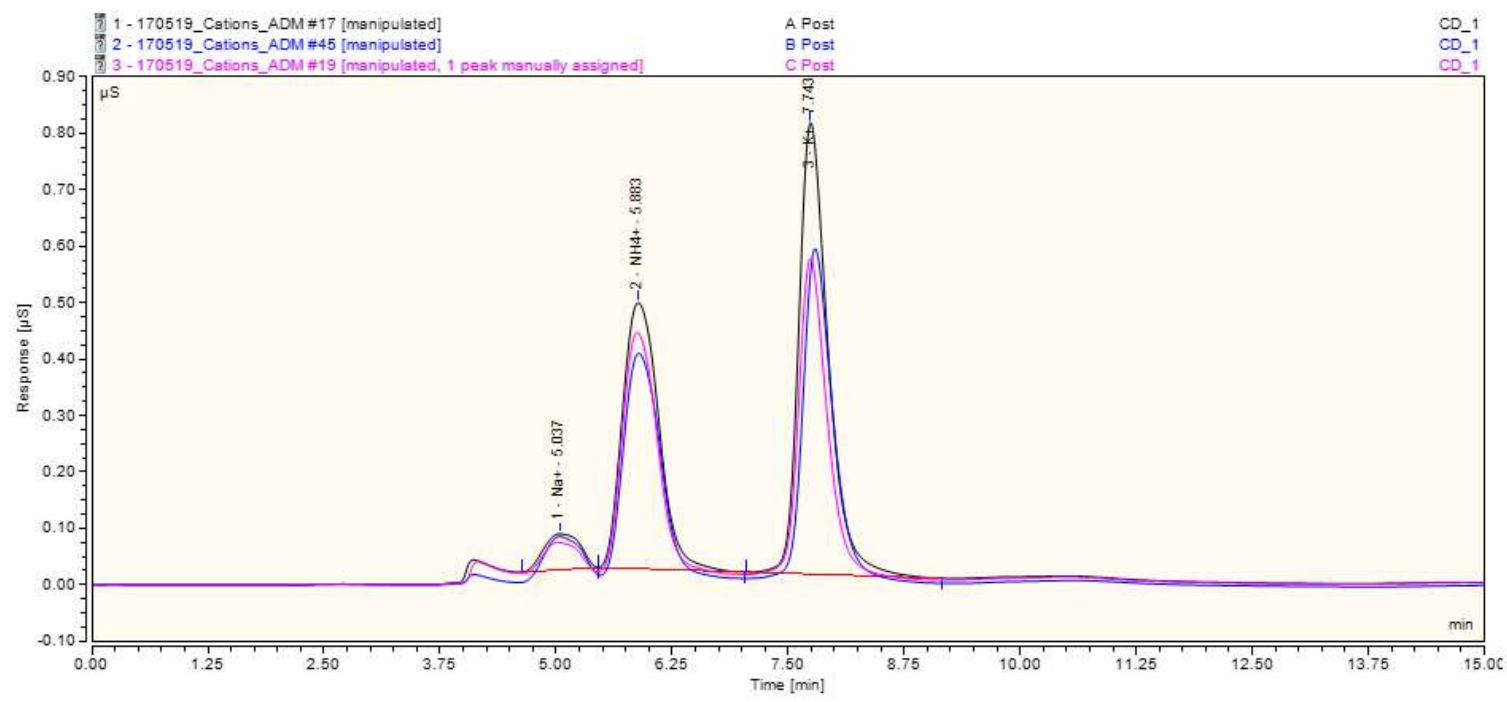

Figure A.32 Cation chromatographs for 4B, post-titration. 


\section{A.4.3 Brand 4, Sampling Code 4Full}

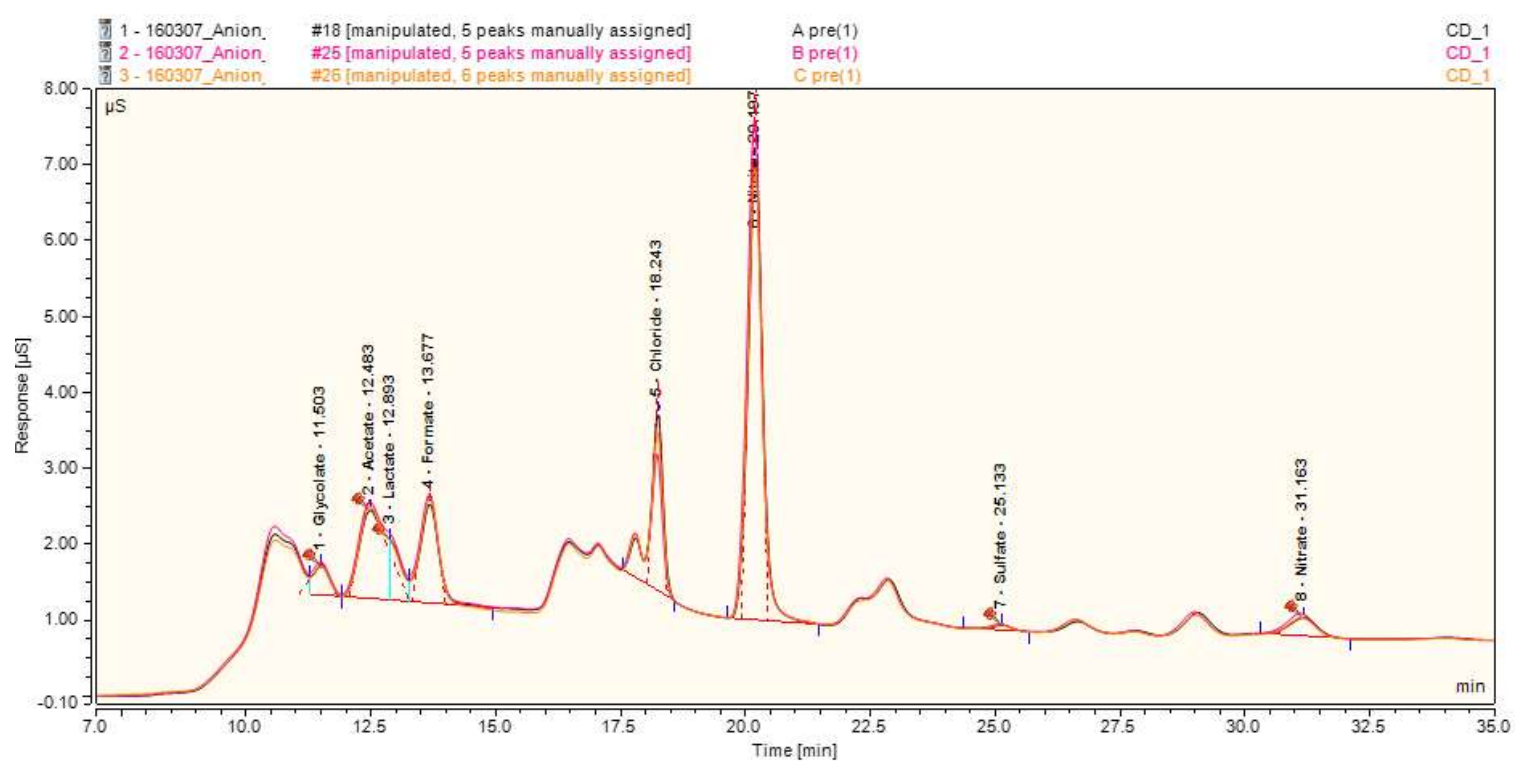

Figure A.33 Anion chromatographs for 4Full, pre-titration.

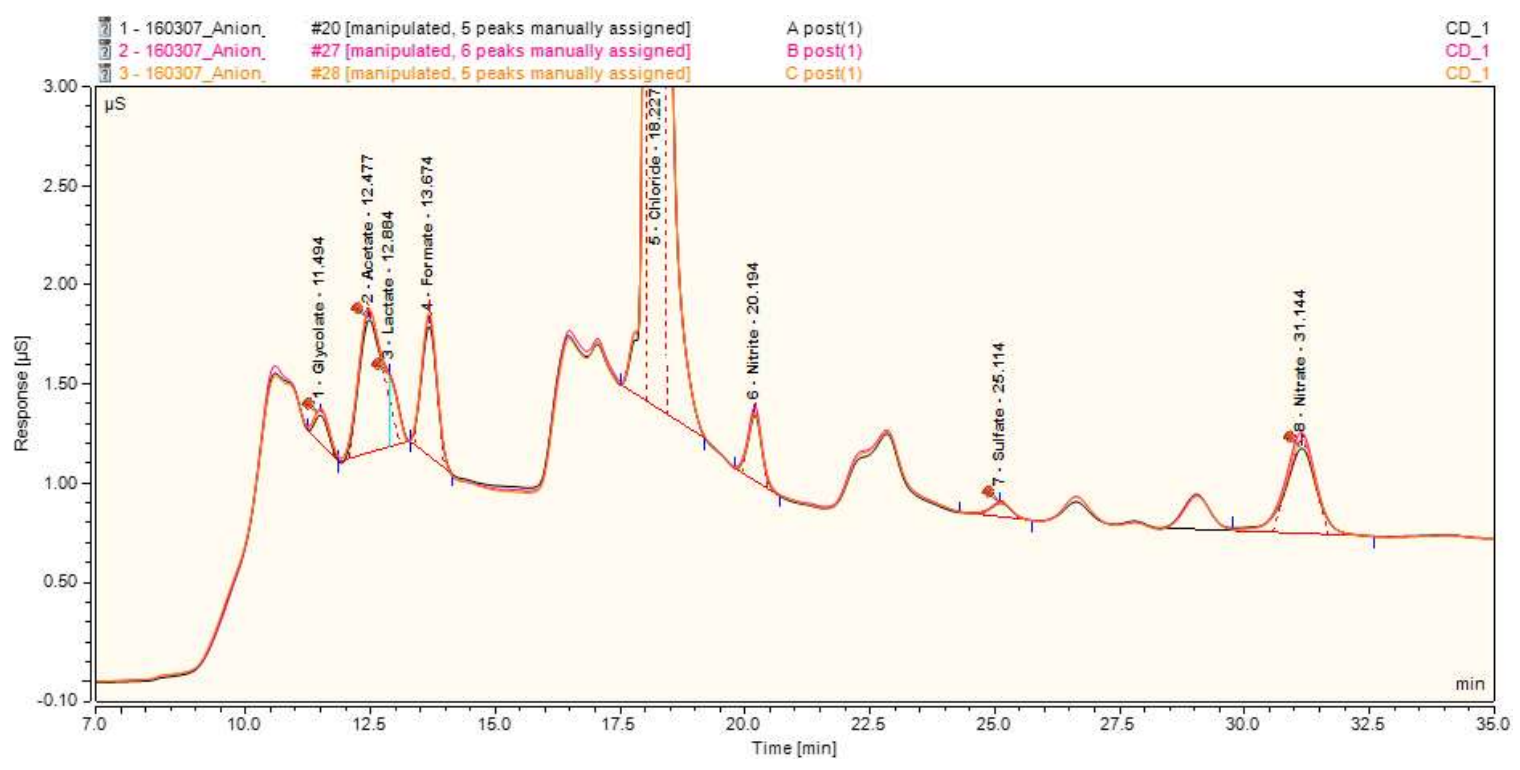

Figure A.34 Anion chromatograph for brand 4Full, post-titration. 


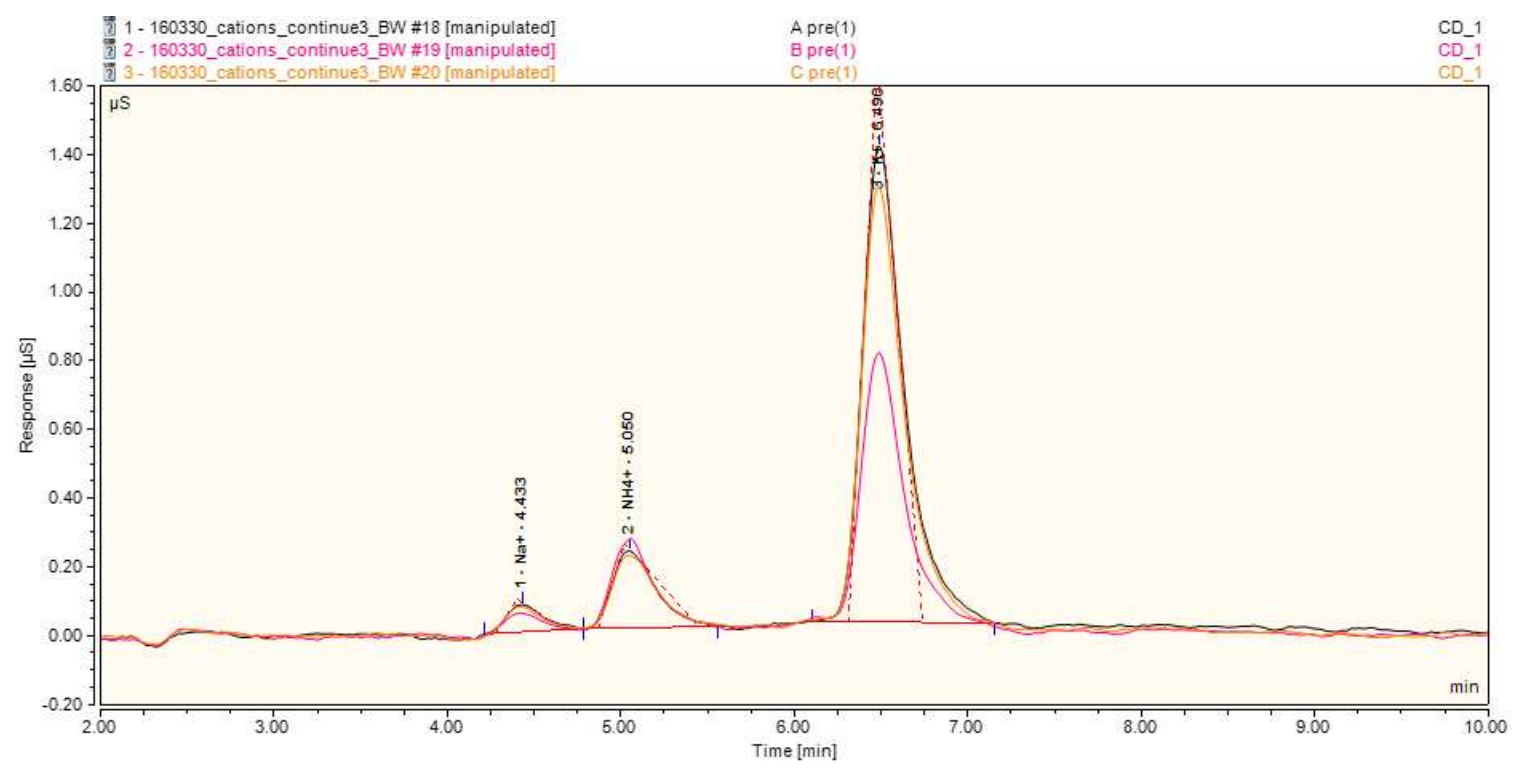

Figure A.35 Cation chromatograph for brand 4Full, pre-titration.

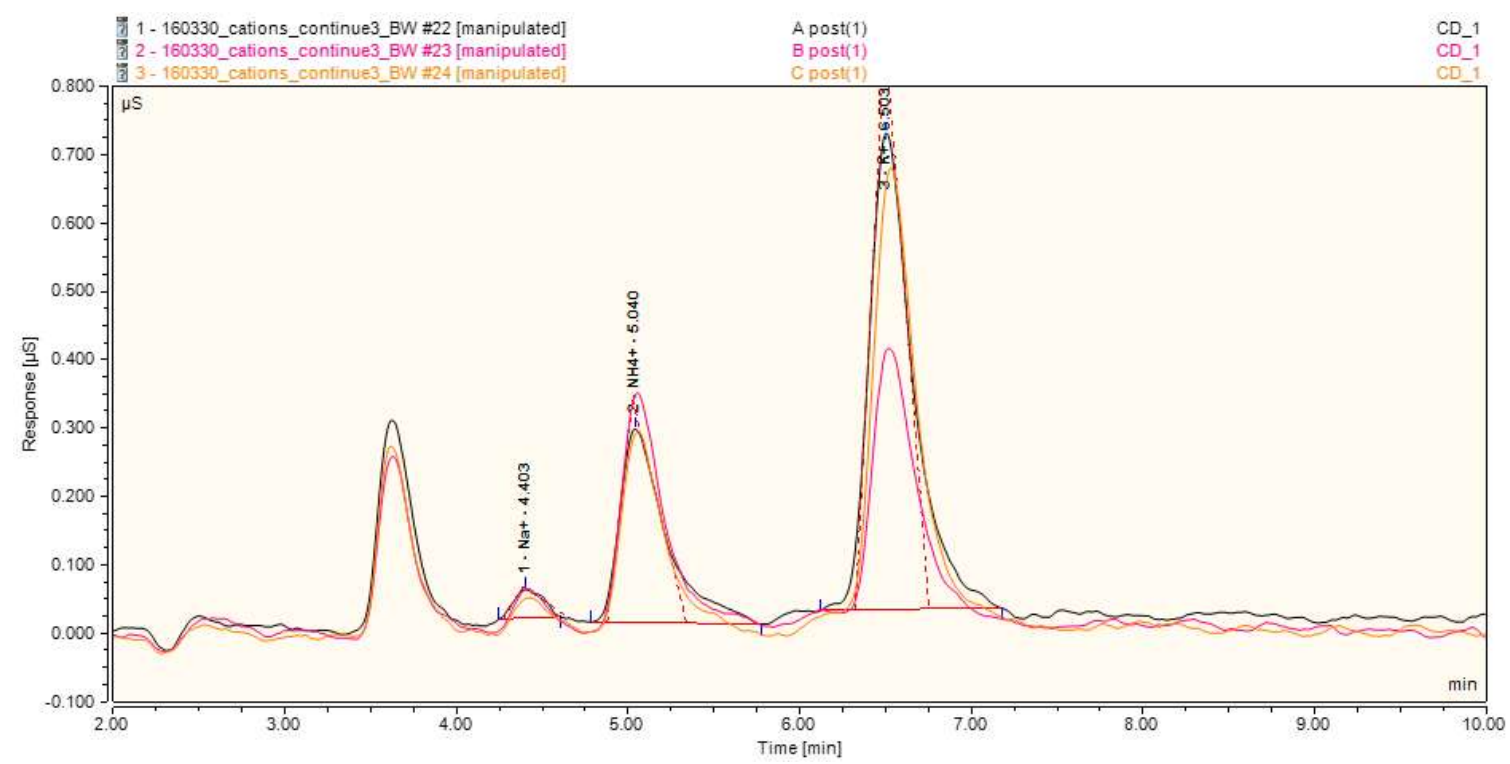

Figure A.36 Cation chromatograph for brand 4Full, post-titration. 


\section{A.5 Brand 5 Ion Chromatographs}

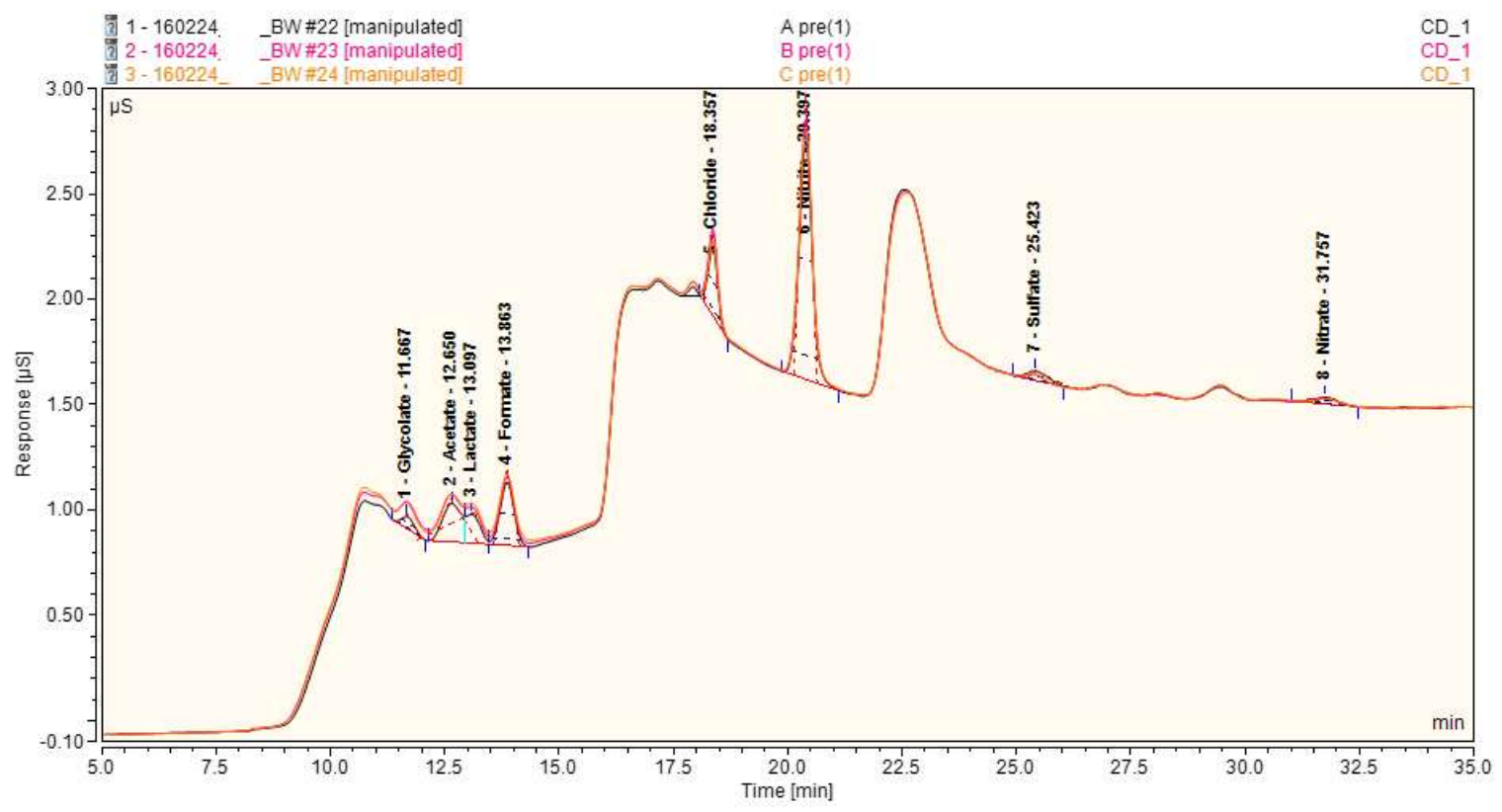

Figure A.37 Anion chromatographs for brand 5, pre-titration.

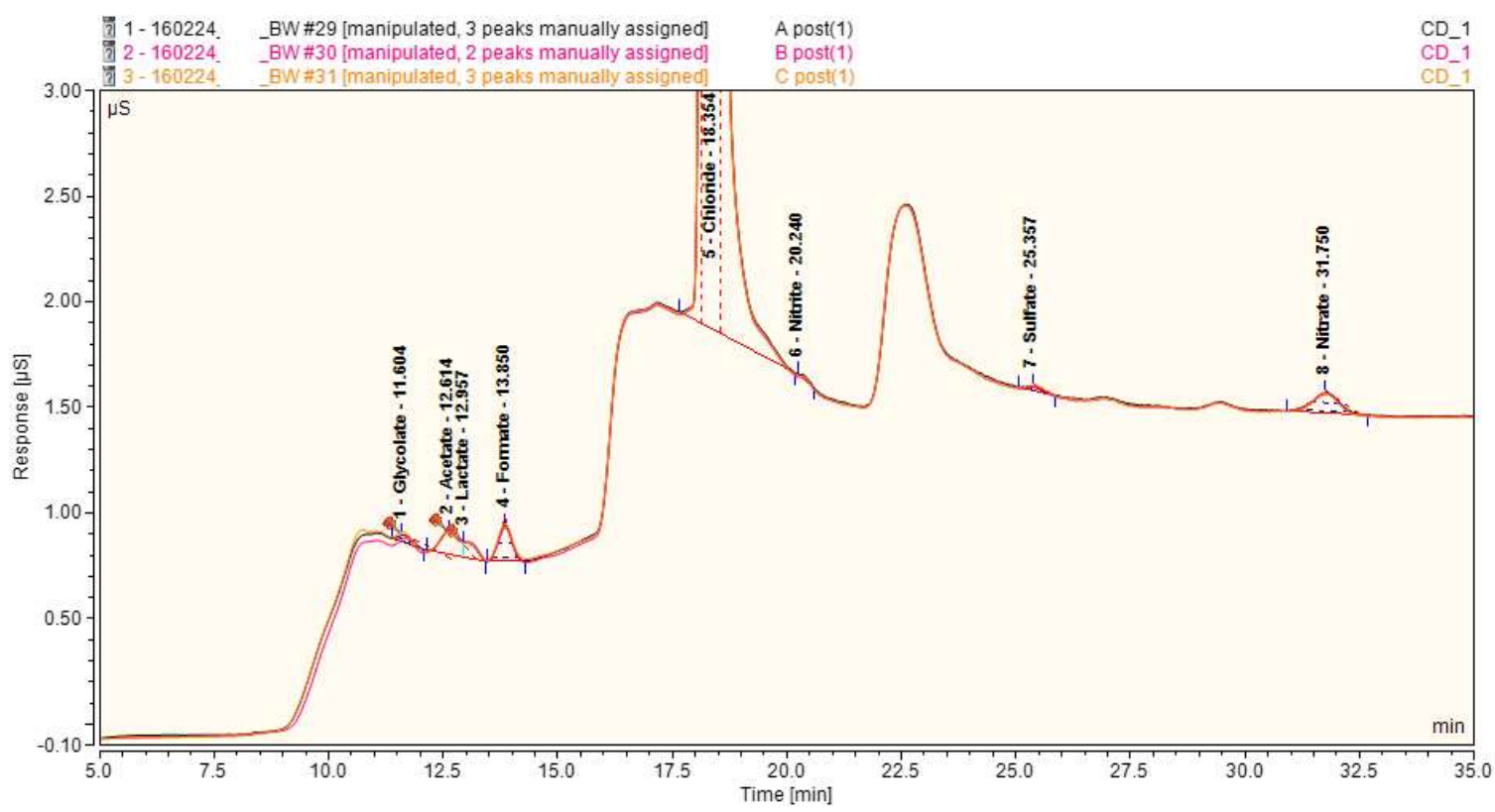

Figure A.38 Anion chromatographs for brand 5, post-titration. 


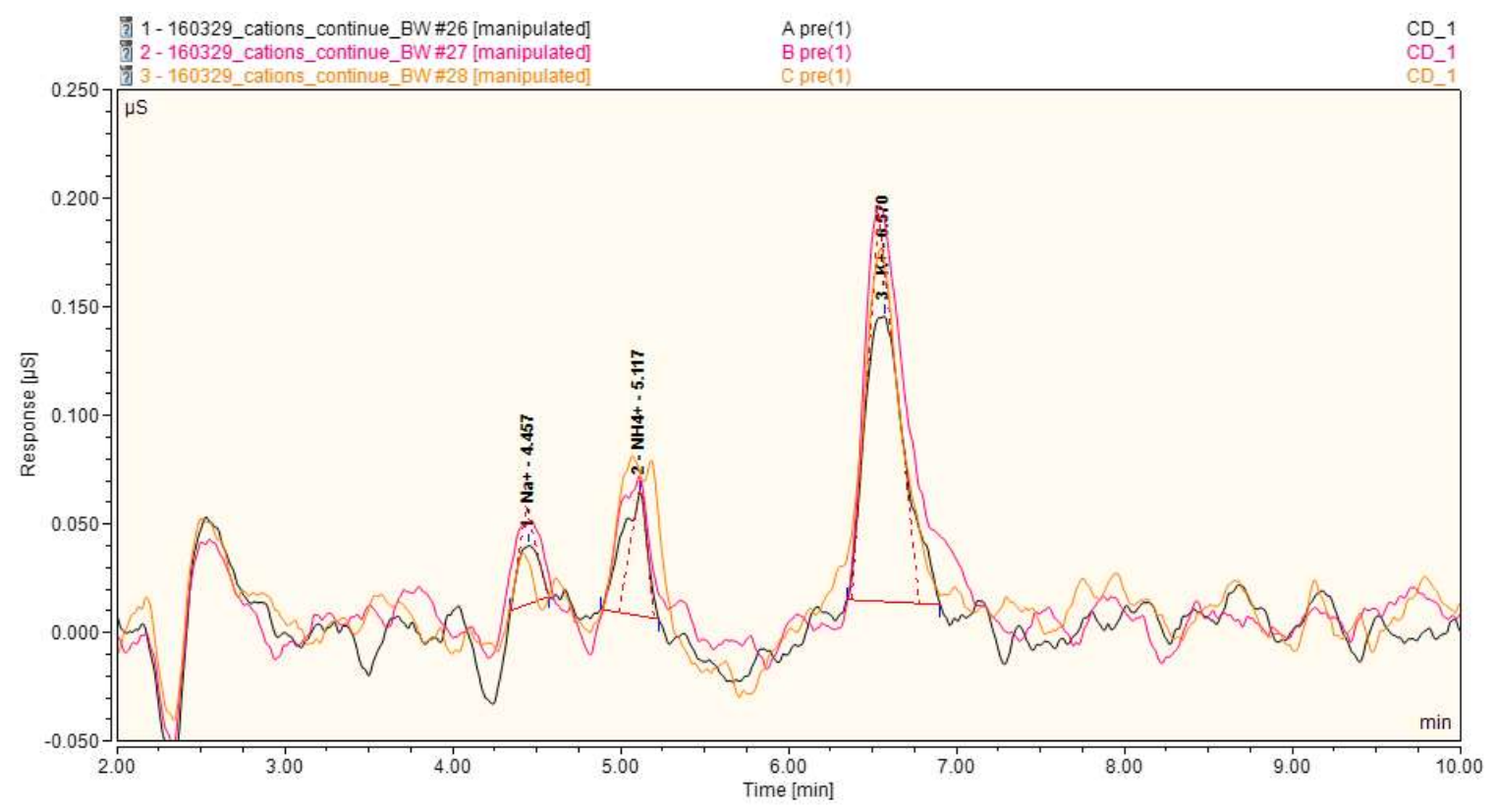

Figure A.39 Cation chromatographs for brand 5, pre-titration.

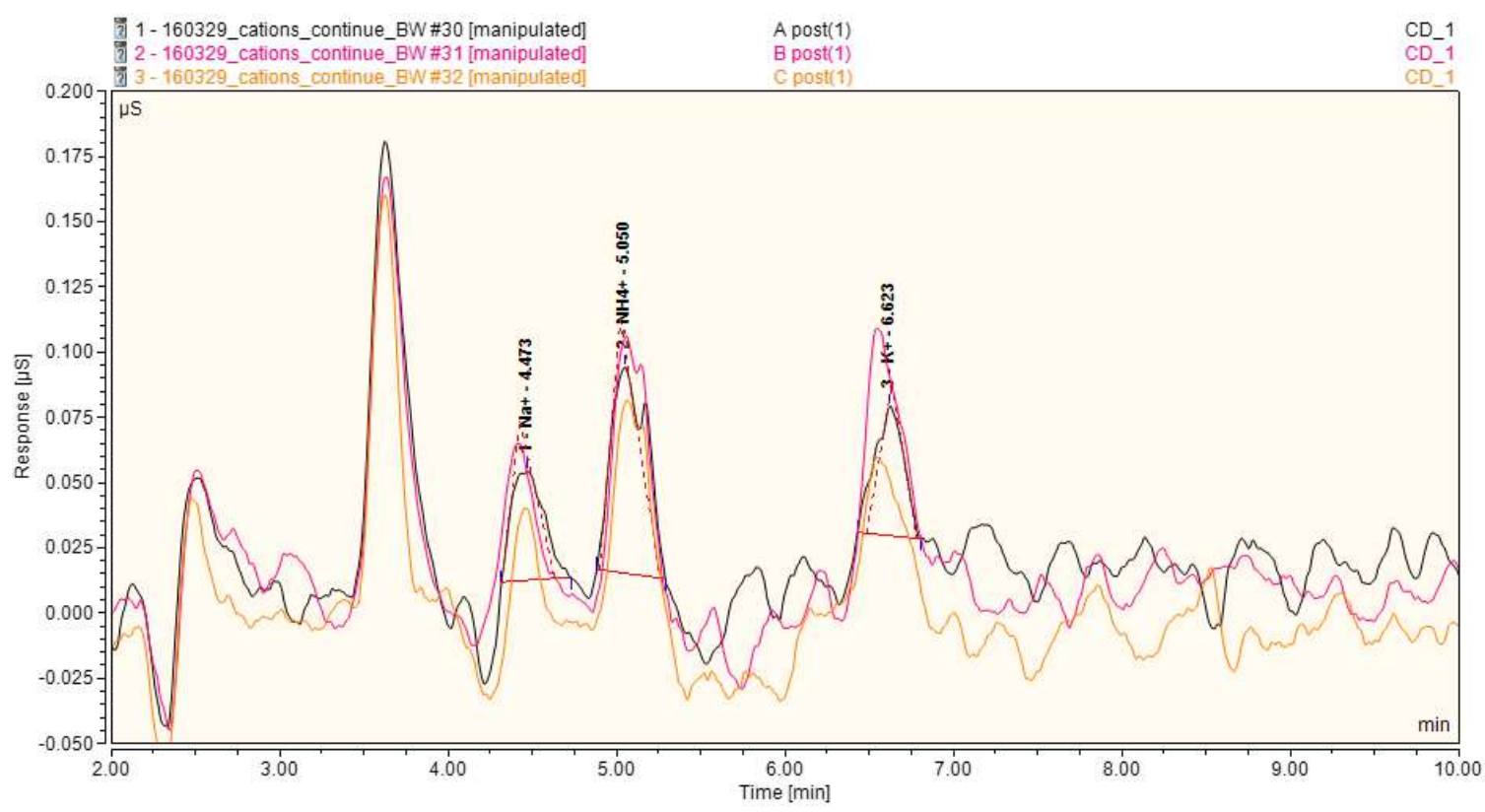

Figure A.40 Cation chromatographs for brand 5, post-titration. 


\section{A.6 Brand 6 Ion Chromatographs}

\section{A.6.1 Brand 6, Sampling Code 6}

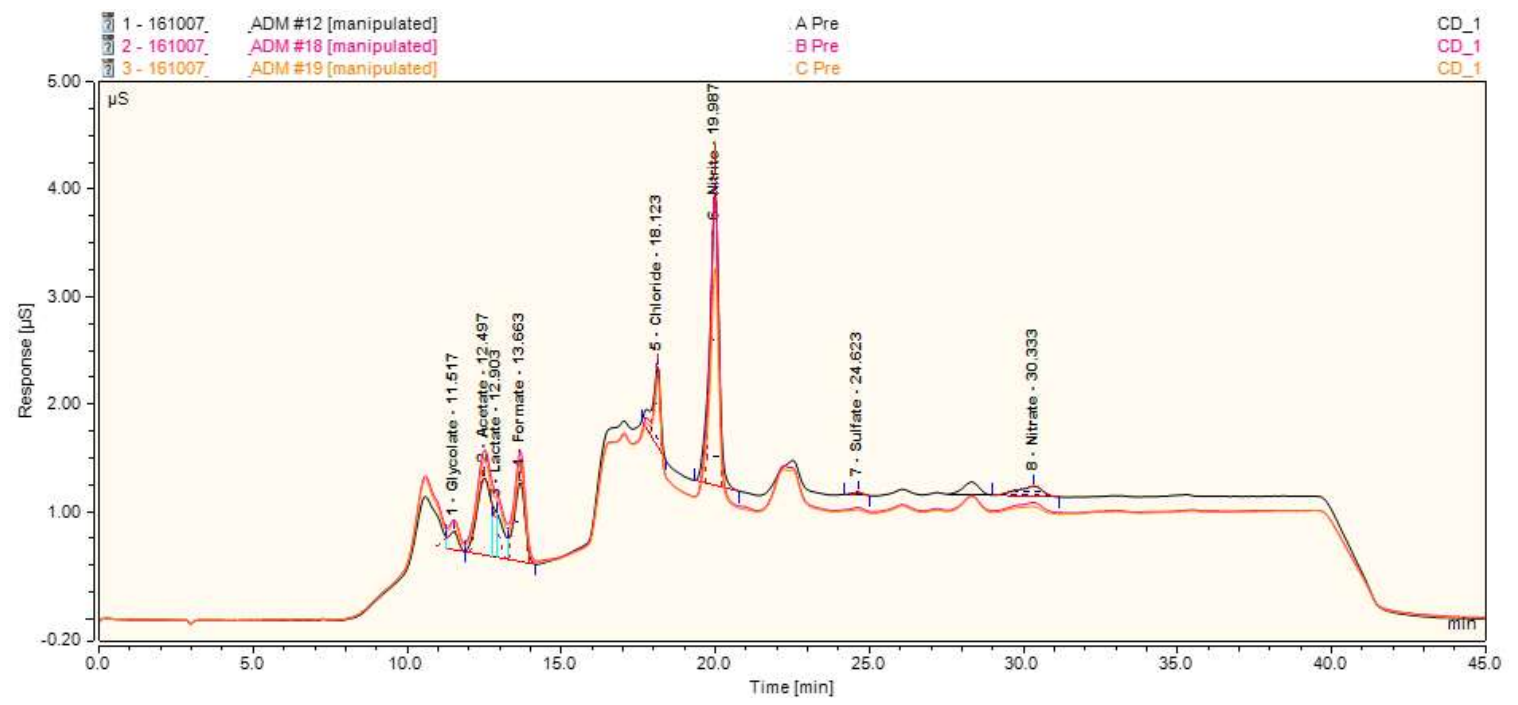

Figure A.41 Anion chromatographs for 6, pre-titration.

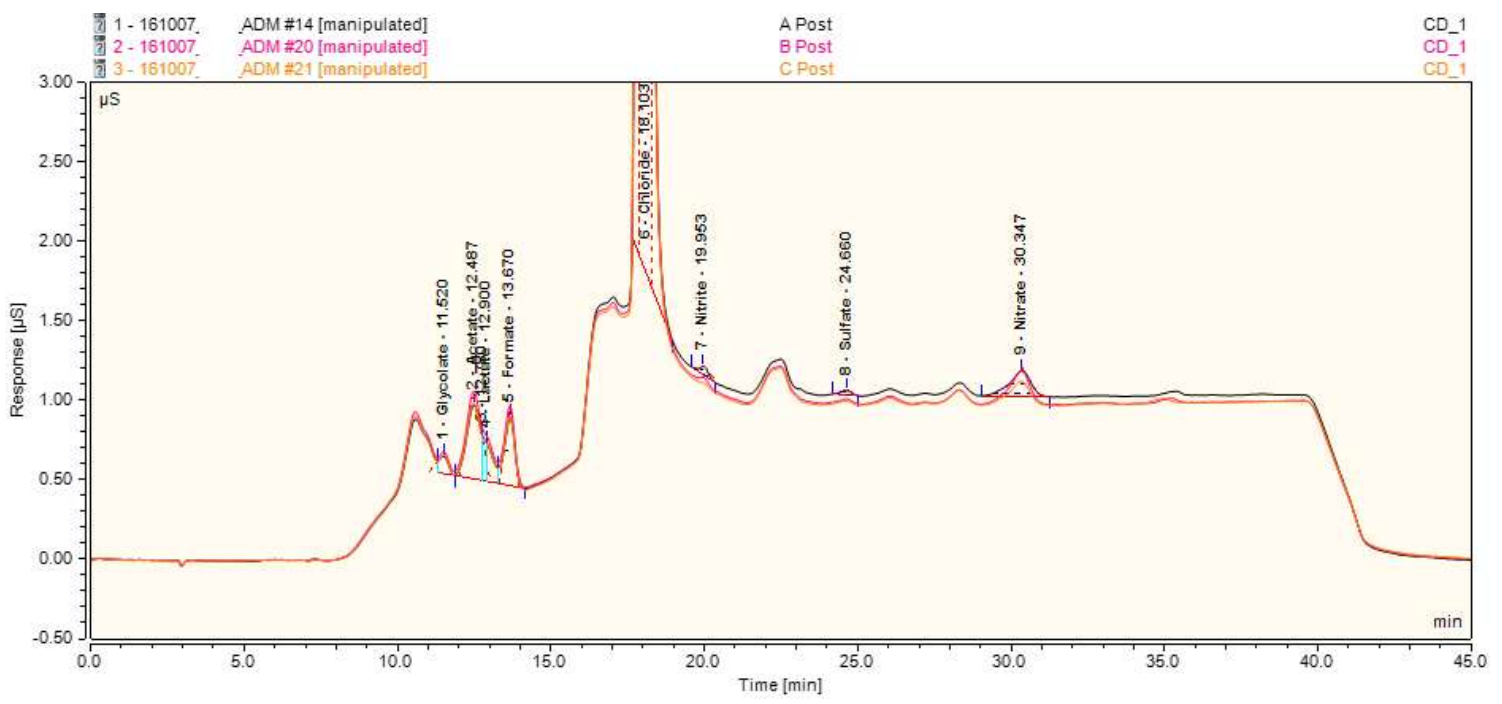

Figure A.42 Anion chromatographs for 6, post-titration. 


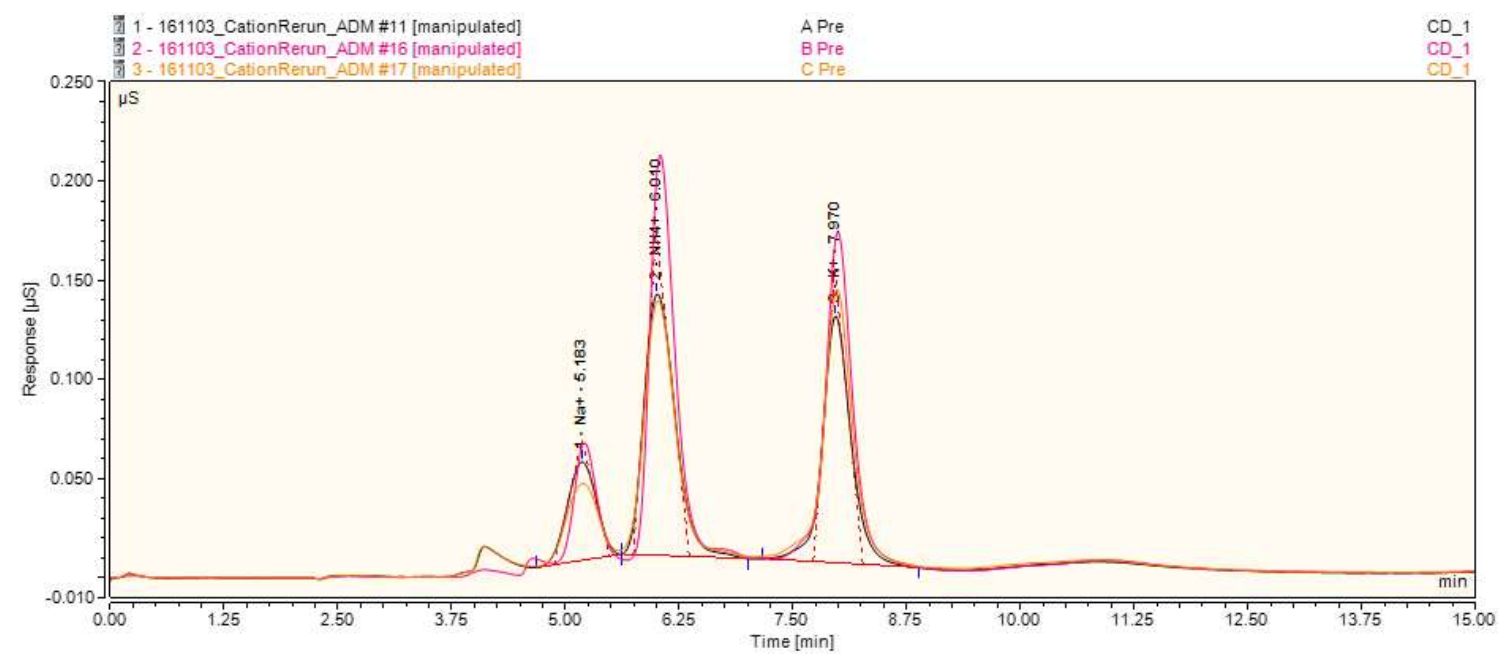

Figure A.43 Cation chromatographs for 6, pre-titration.

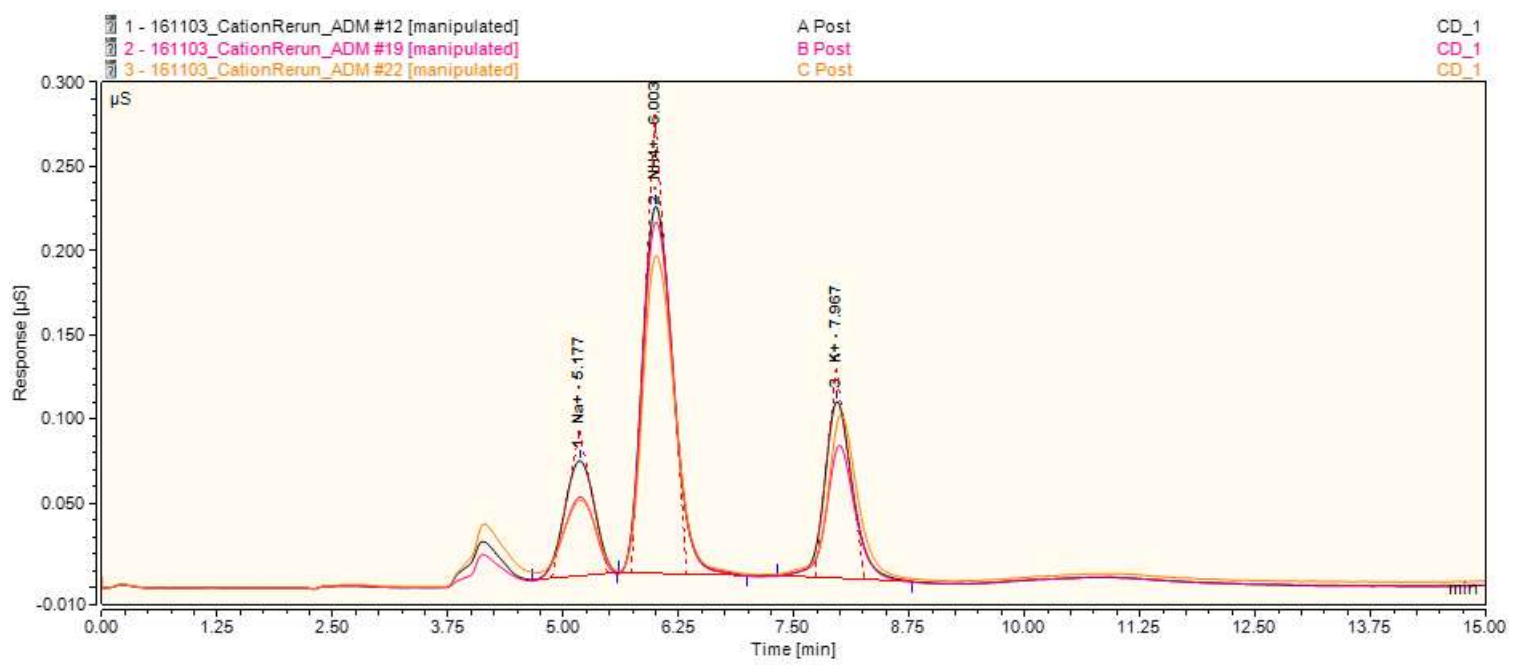

Figure A.44 Cation chromatographs for 6, post-titration. 


\section{A.6.2 Brand 6, Sampling Code 6Full}

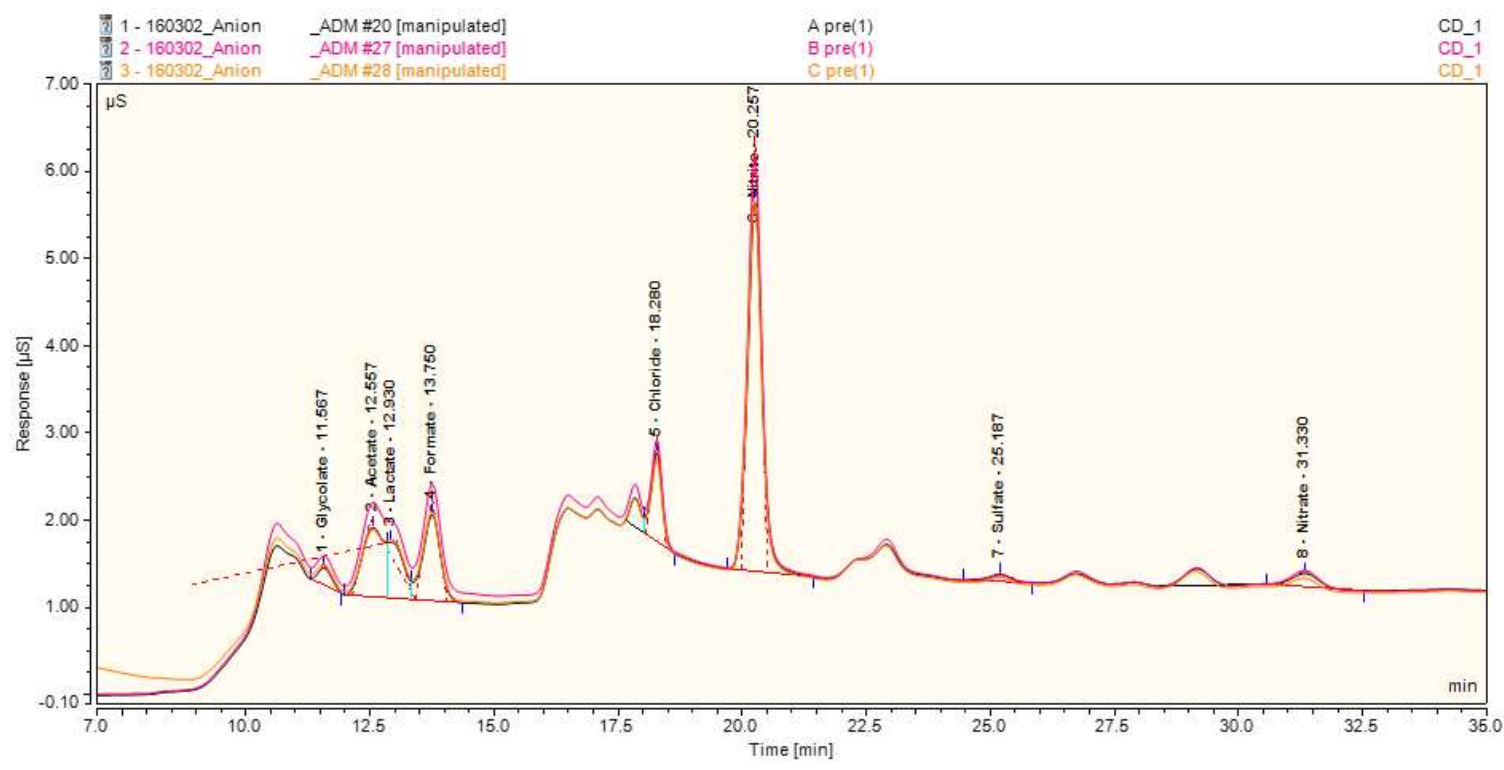

Figure A.45 Anion chromatographs for 6Full, pre-titration.

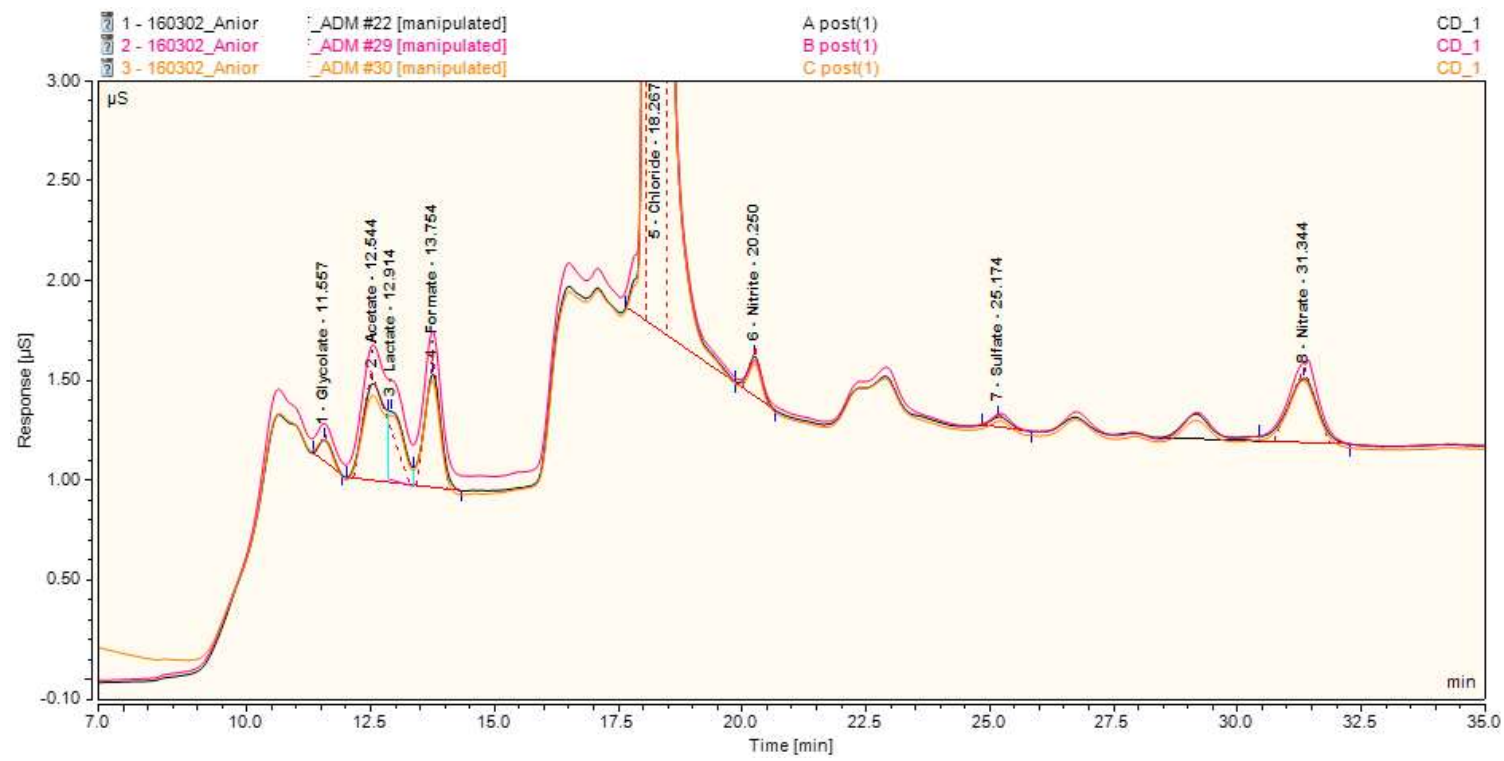

Figure A.46 Anion chromatographs for 6Full, post-titration. 


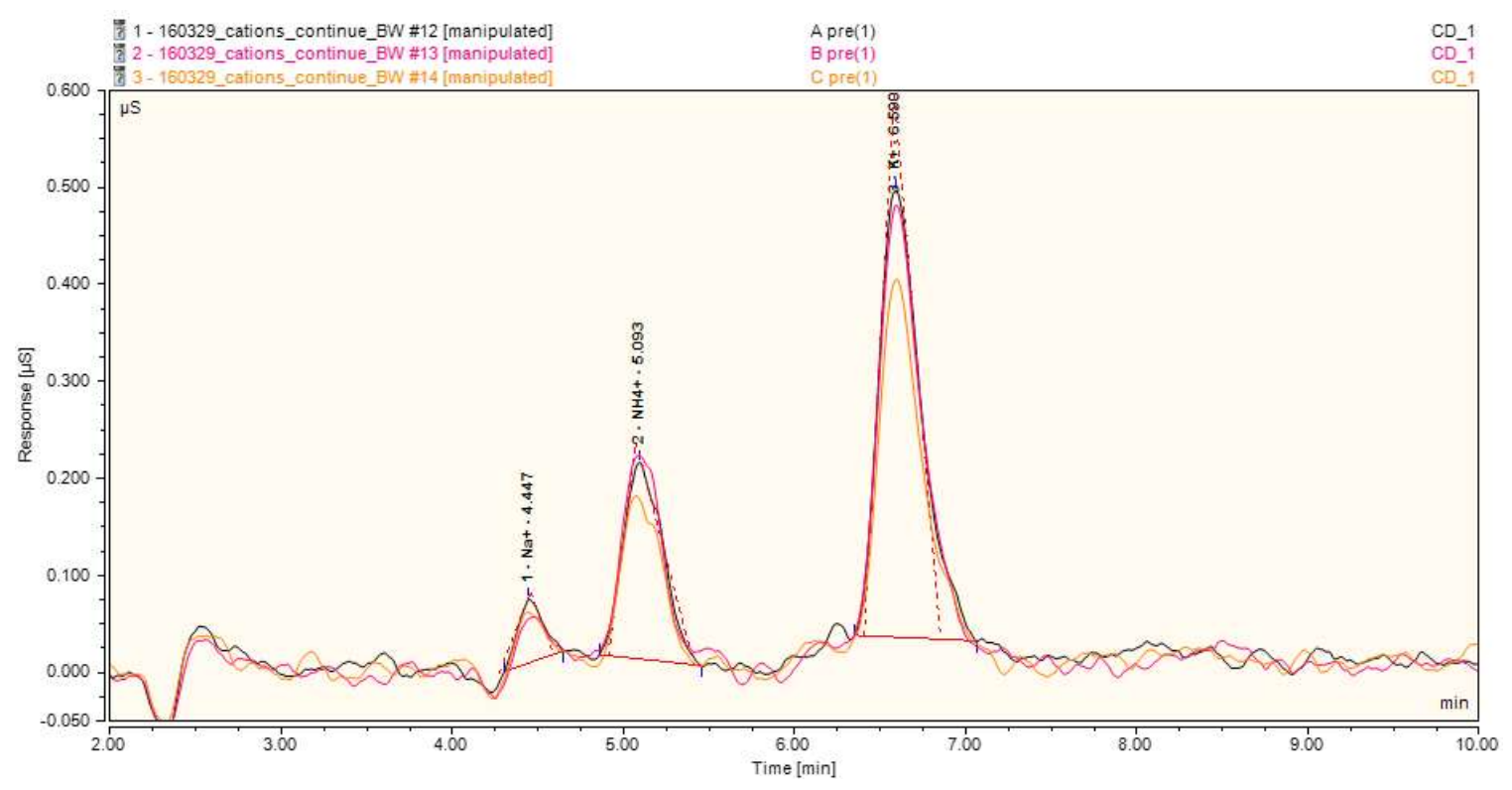

Figure A.47 Cation chromatographs for 6Full, pre-titration.

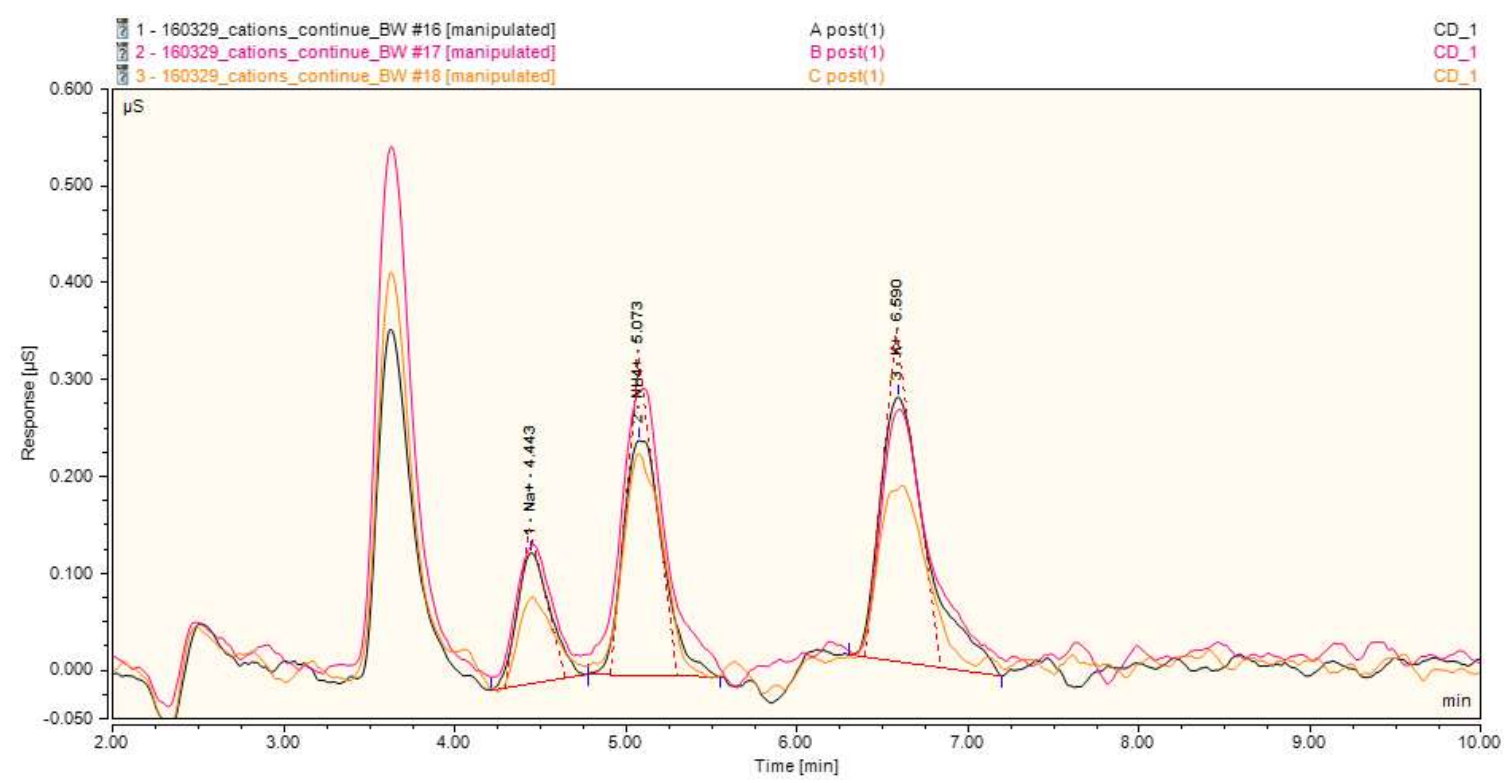

Figure A.48 Cation chromatographs for 6Full, post-titration. 


\section{A.7 Brand 7 Ion Chromatographs}

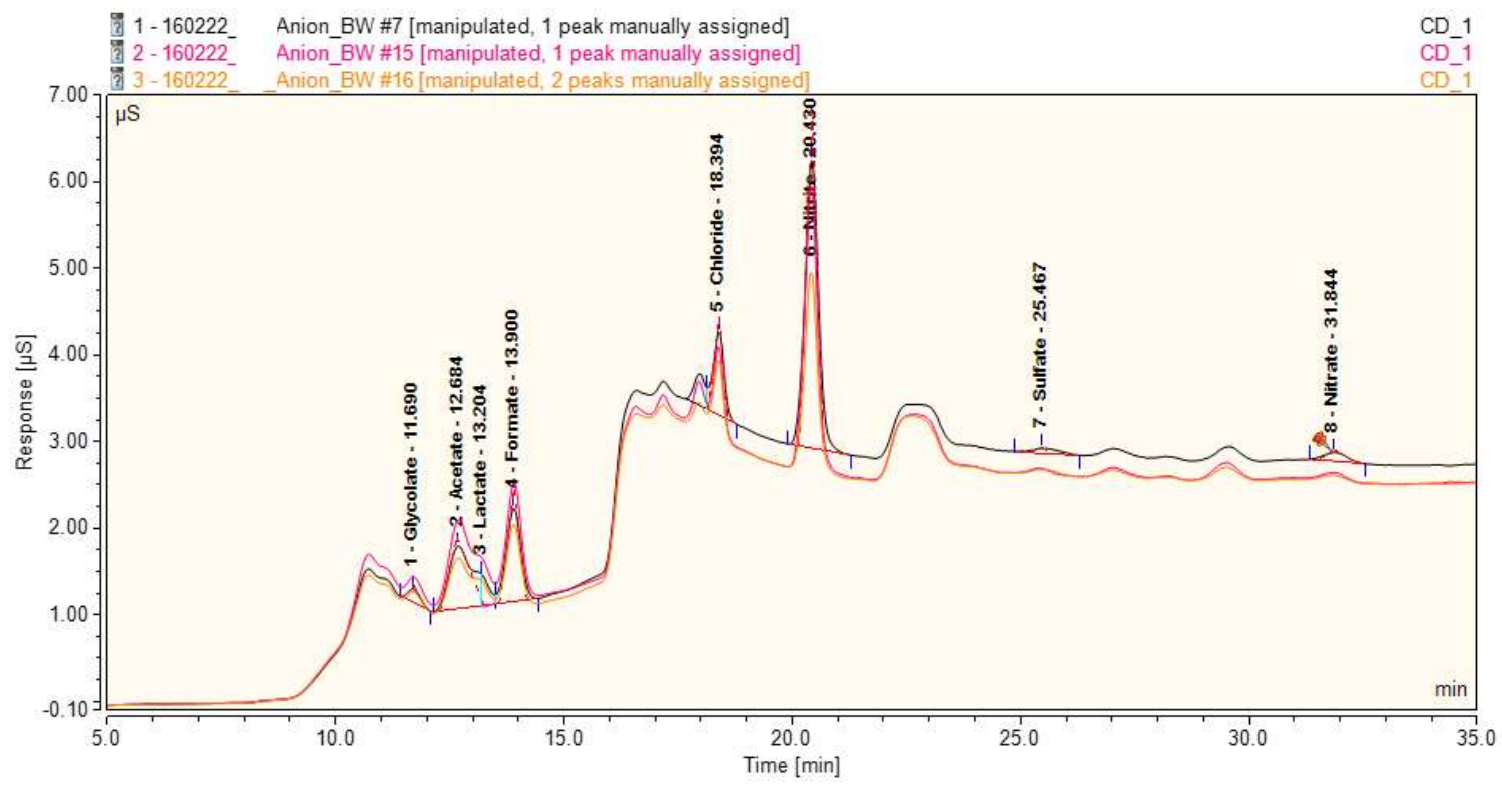

Figure A.49 Anion chromatographs for brand 7, pre-titration.

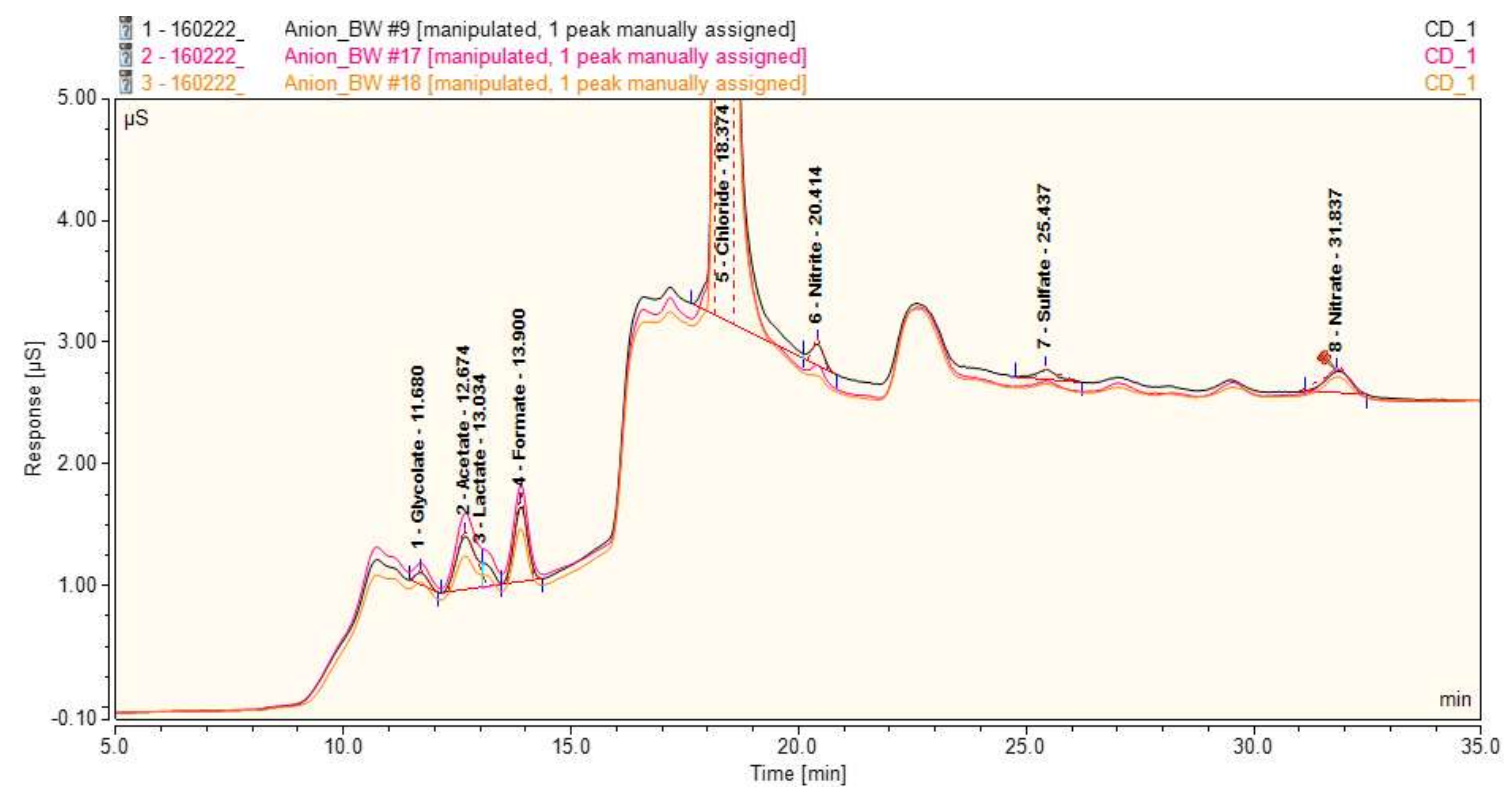

Figure A.50 Anion chromatographs for brand 7, post-titration. 


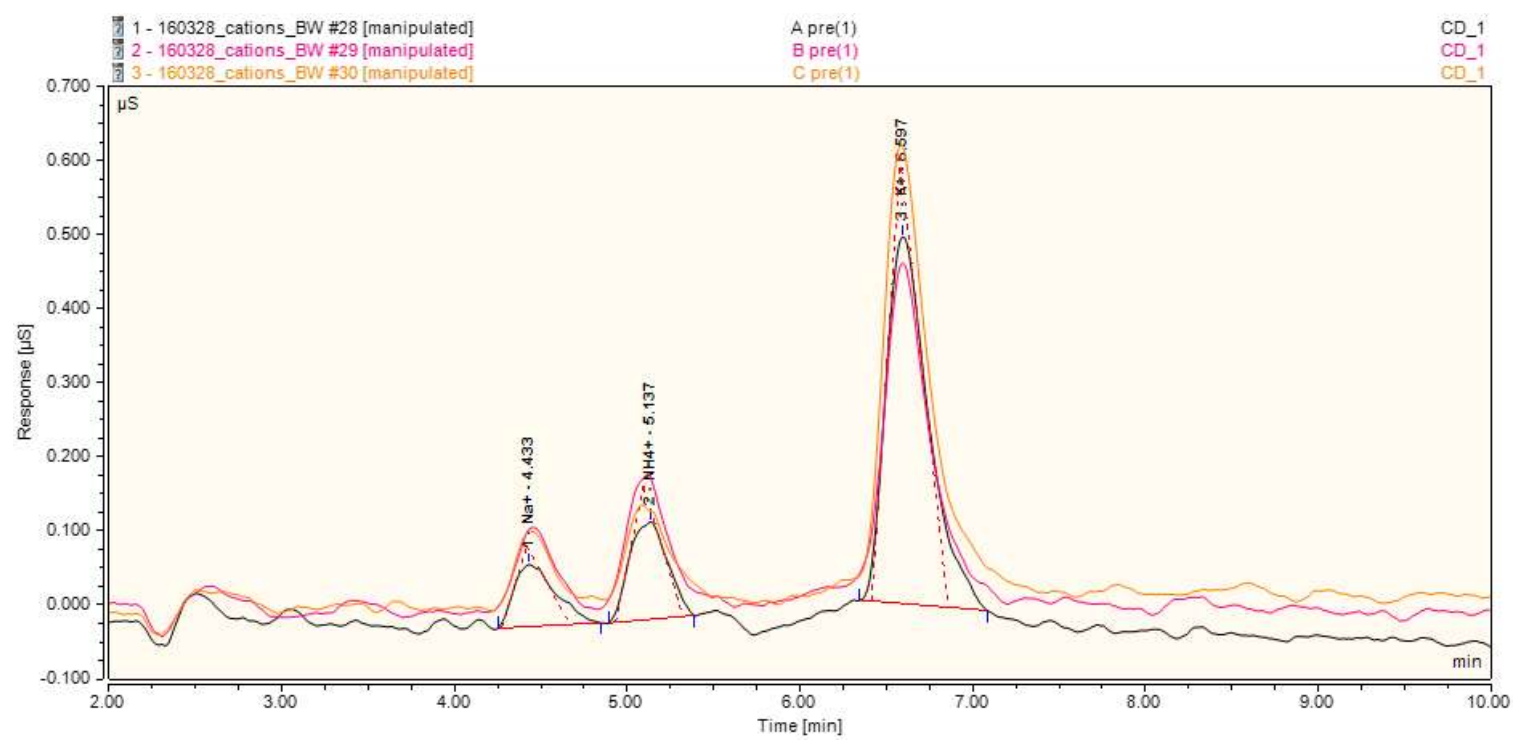

Figure A.51 Cation chromatographs for brand 7, pre-titration.

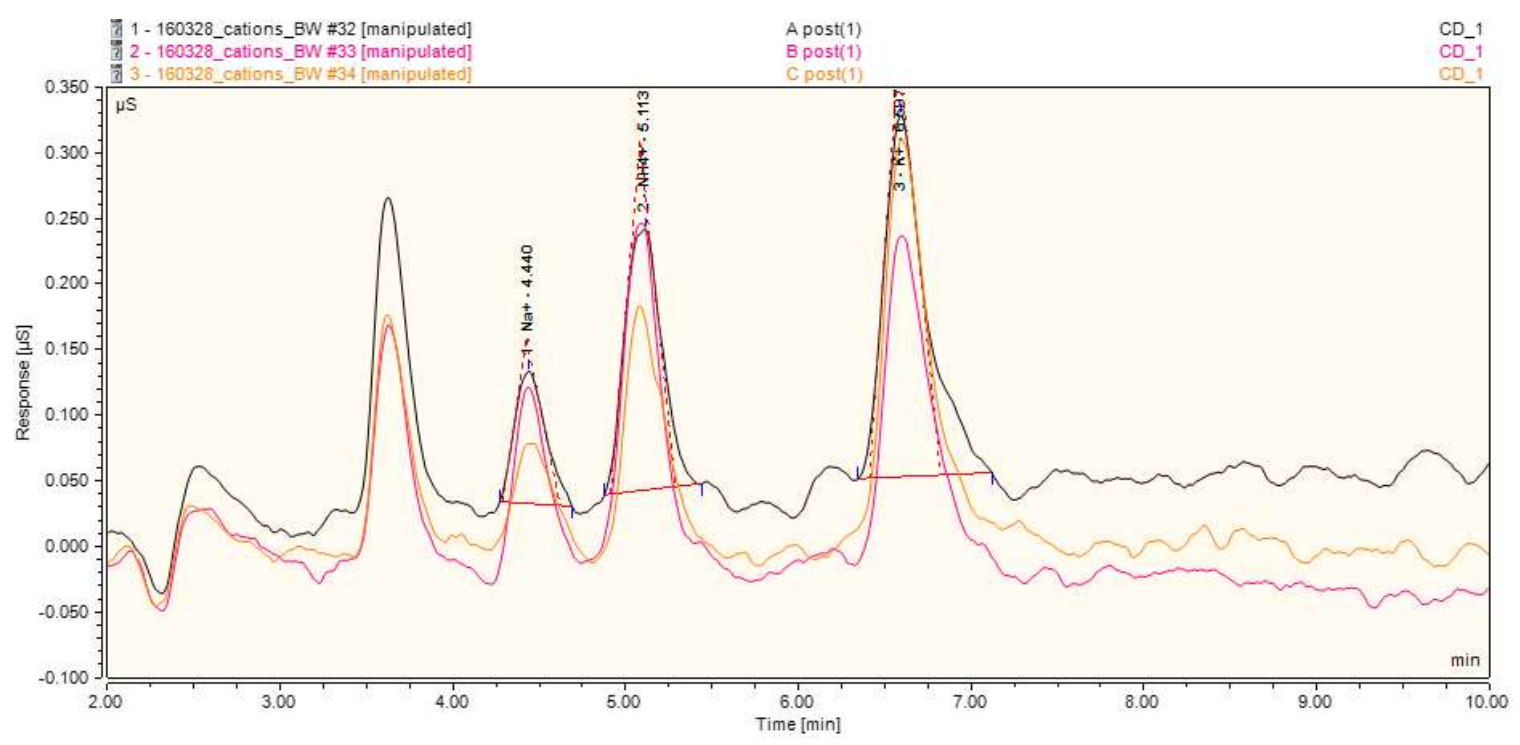

Figure A.52 Cation chromatographs for brand 7, post-titration. 


\section{B. Titration Curves for Tobacco Smoke PM Extracts}

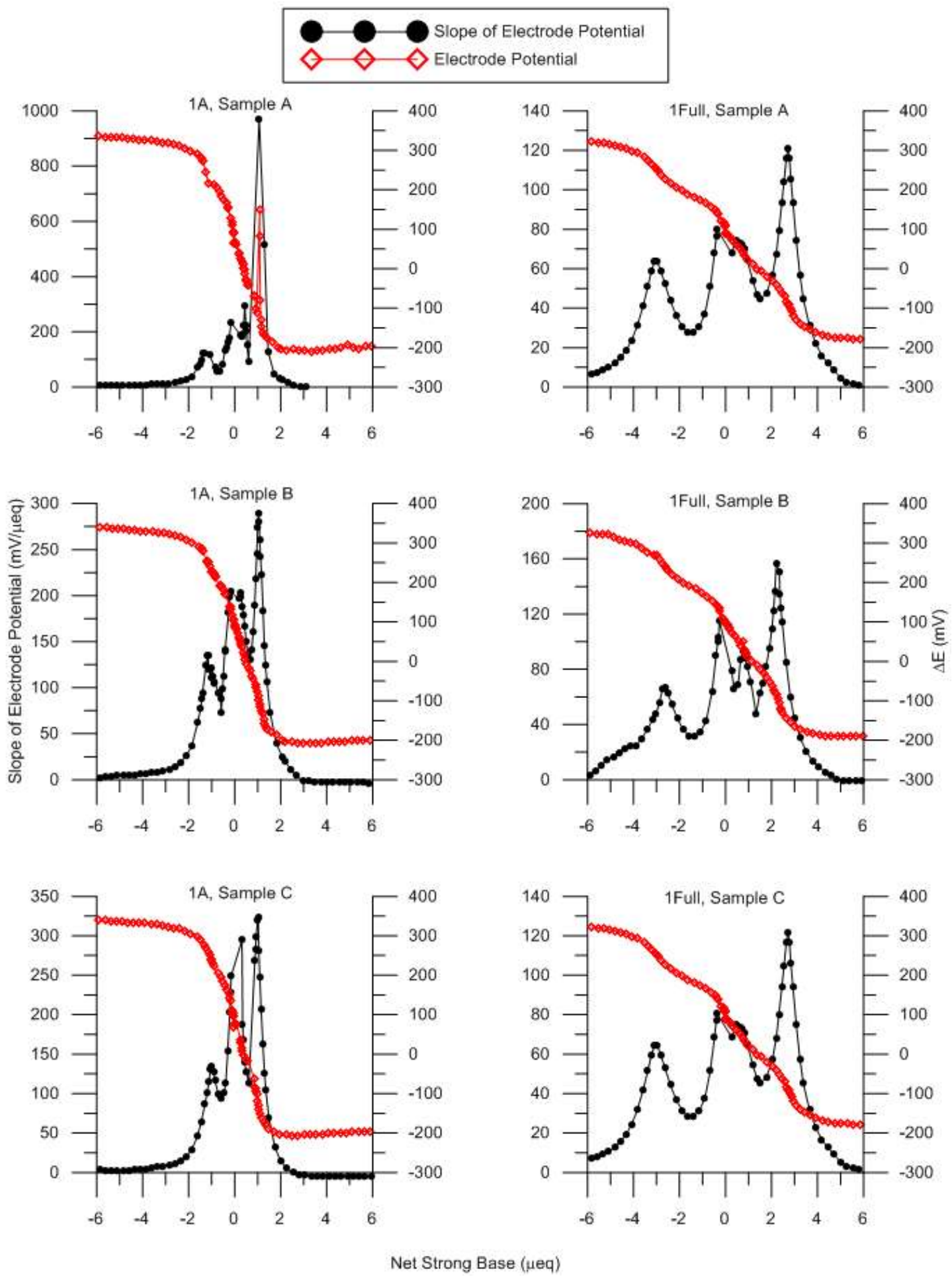

Figure B.1 Titration curves for brand 1. 6-puff sampling from 02/19/2016 (left-hand side) and full-cigarette 03/04/2016 (right-hand side). 

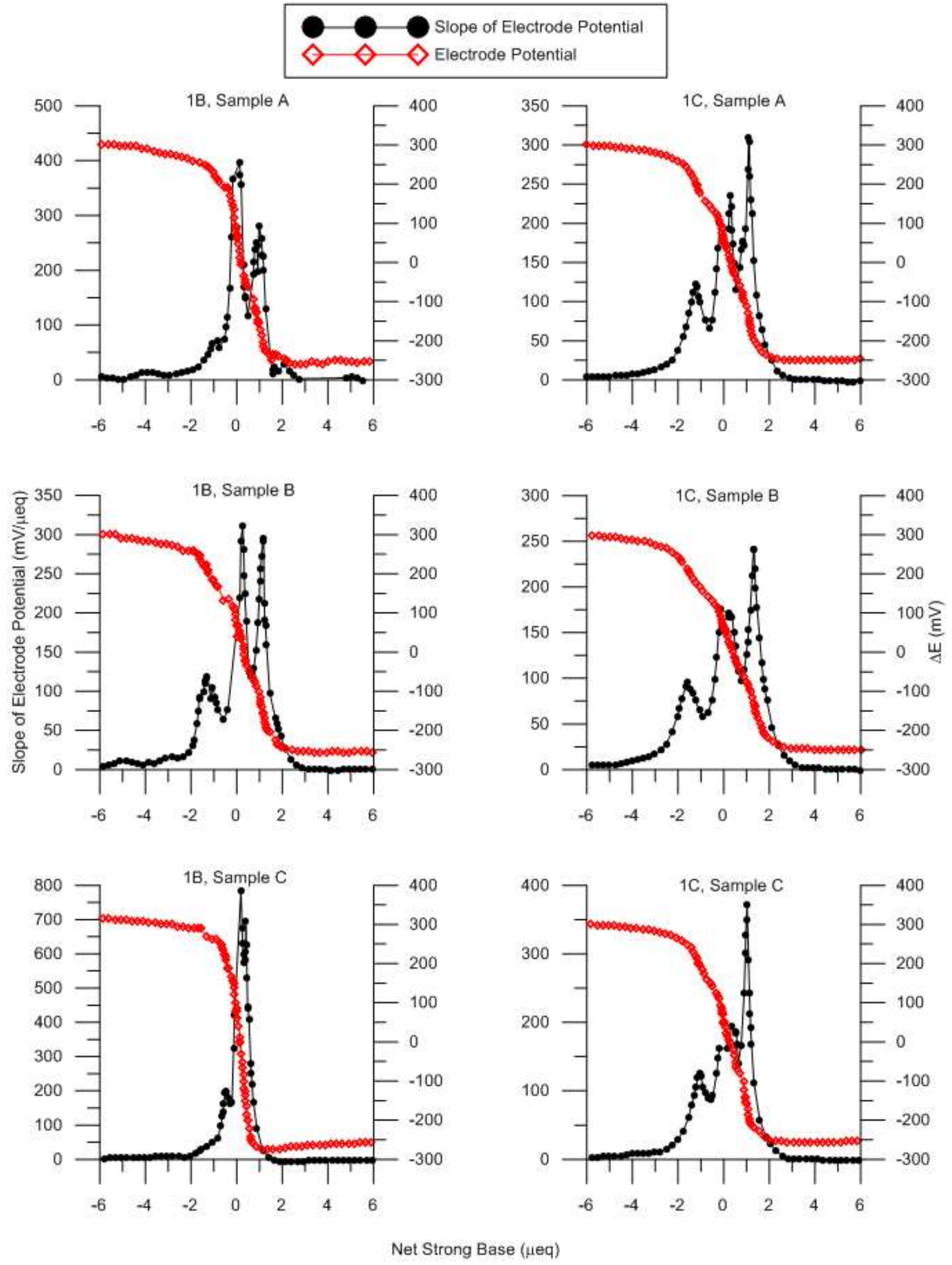

Figure B.2 Titration curves for brand 1. 6-puff sampling from 10/10/2016 (left-hand side) and 05/12/2017 (right-hand side). 

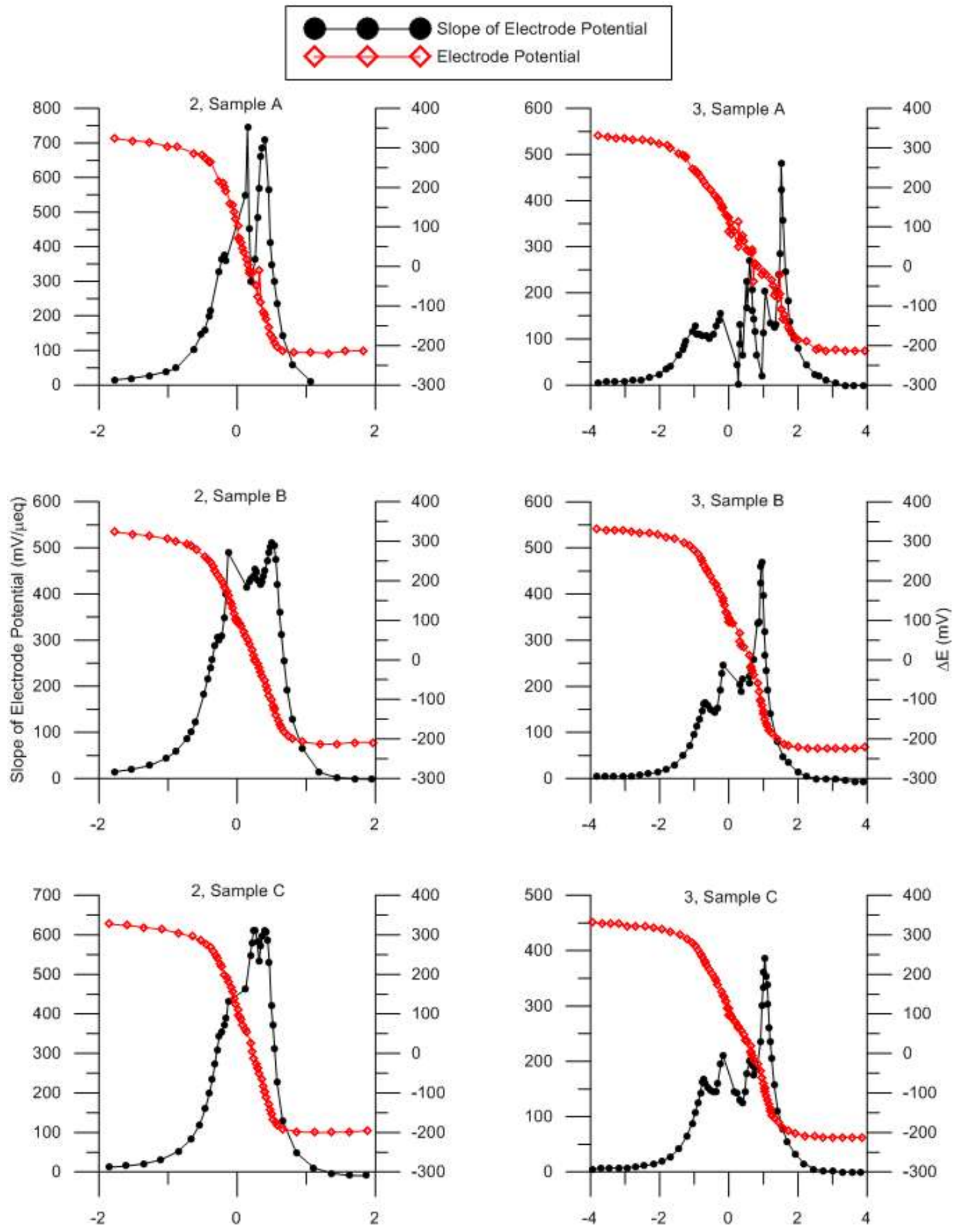

Net Strong Base ( $\mu$ eq)

Figure B.3 Titration curves of 6-puff samples for brands 2 (left-hand side) and 3 (righthand side). 


\section{$\diamond \diamond$ Slope of Electrode Potential}
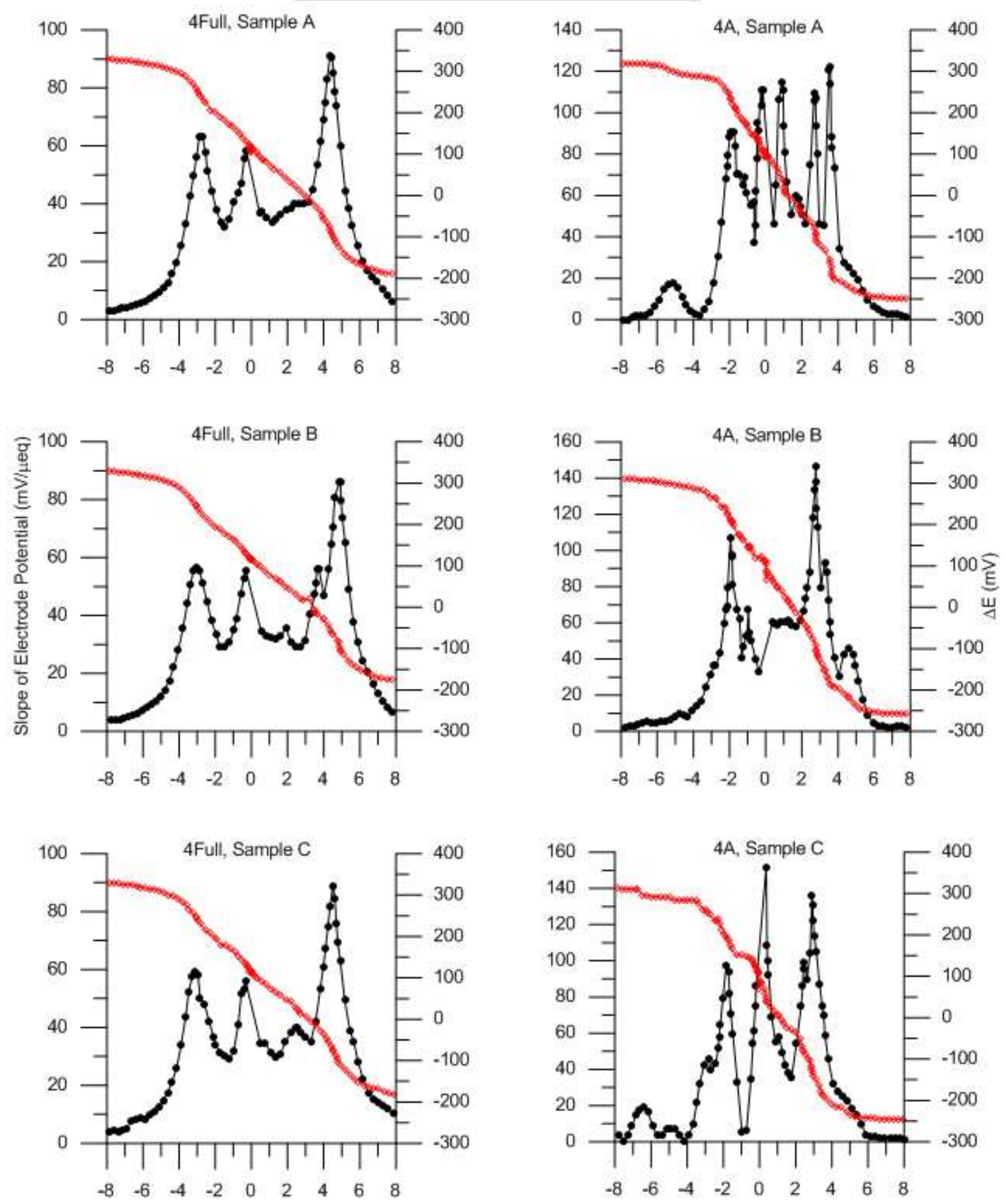

Net Strong Base ( $\mu$ eq)

Figure B.4 Titration curves for brand 4. Full-cigarette sampling from 03/07/2016 (lefthand side) and 6 puff sampling on 10/12/2016 (right-hand side). 

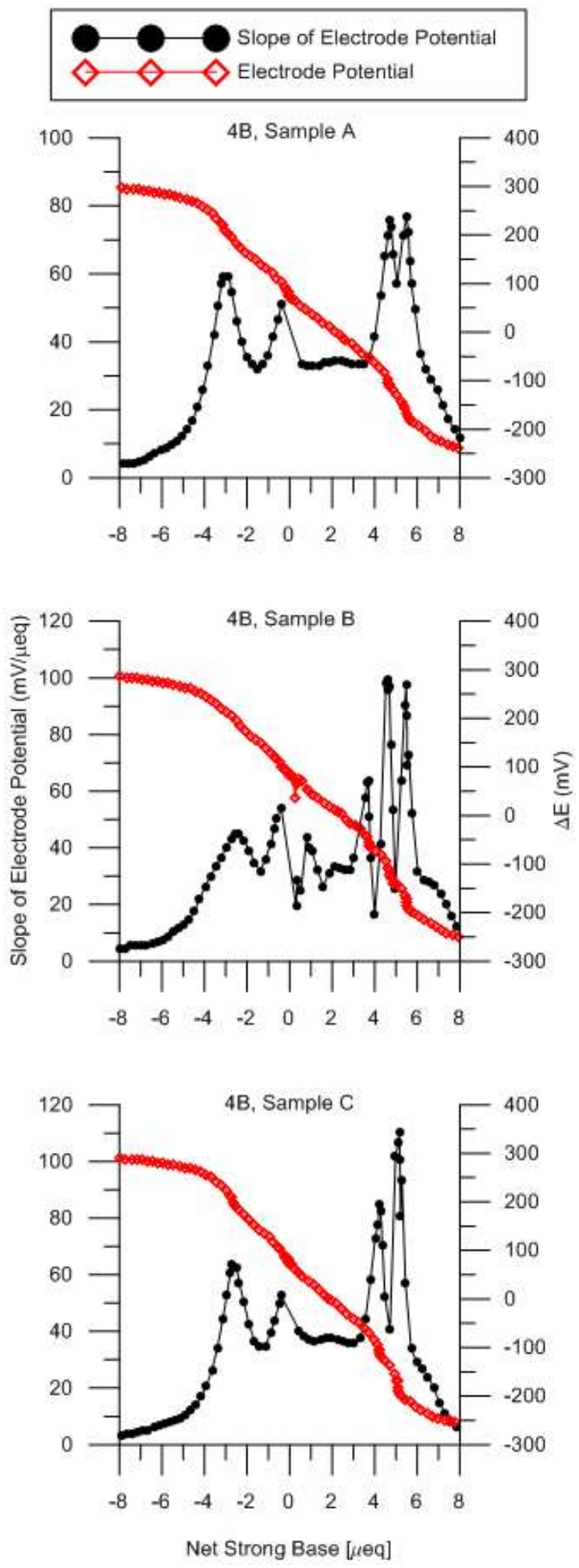

Figure B.5 Titration curves of 6-puff samples for brand 4 on 05/02/2017. 

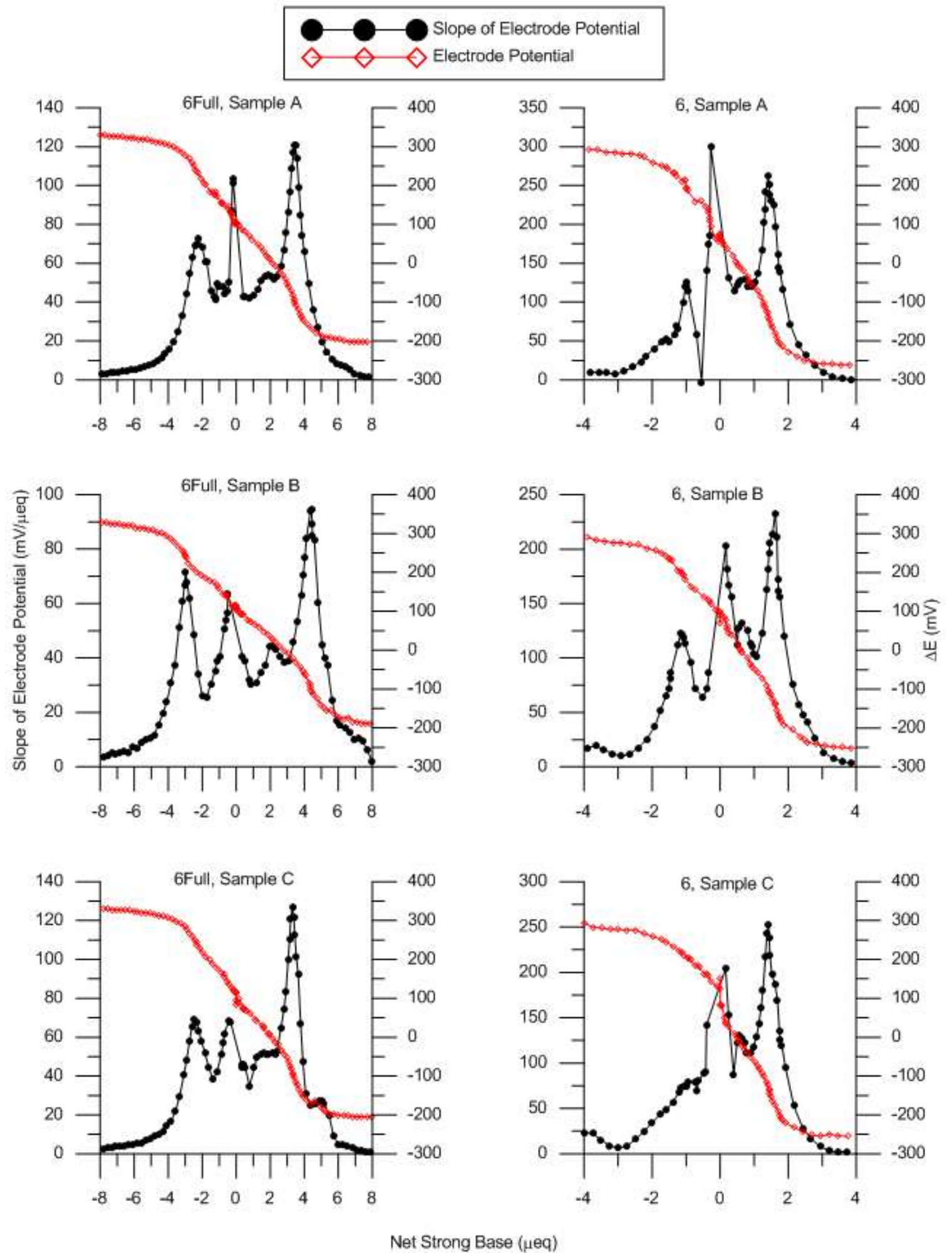

Figure B.6 Titration curves for brand 6. Full-cigarette sampling from 03/02/2016 (lefthand side) and 6-puff sampling on 10/07/2016 (right-hand side). 

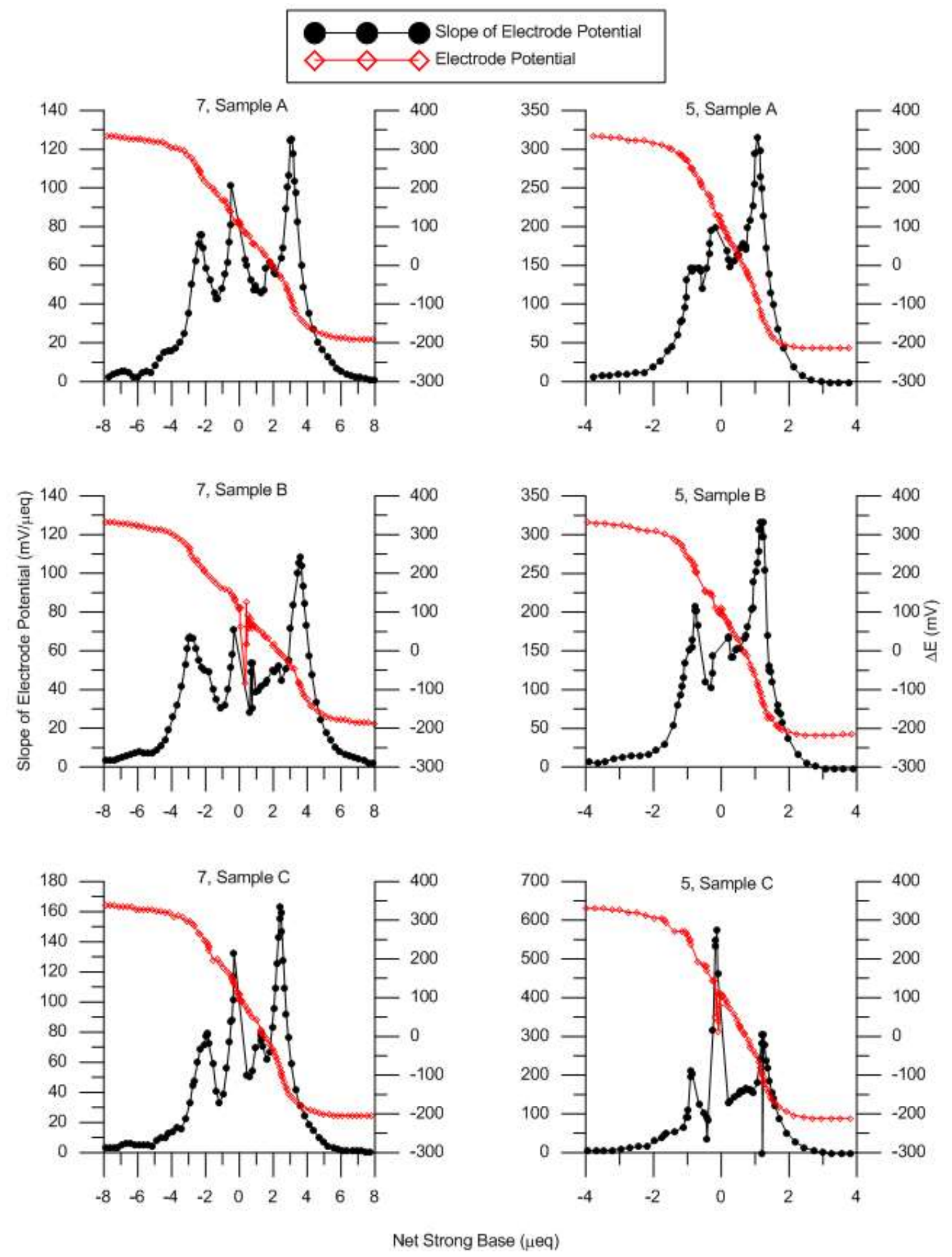

Figure B.7 Titration curves of 6-puff samples for brands 7 (left-hand side) and 5 (righthand side). 


\section{Gas Chromatographs for Water Content Analysis}

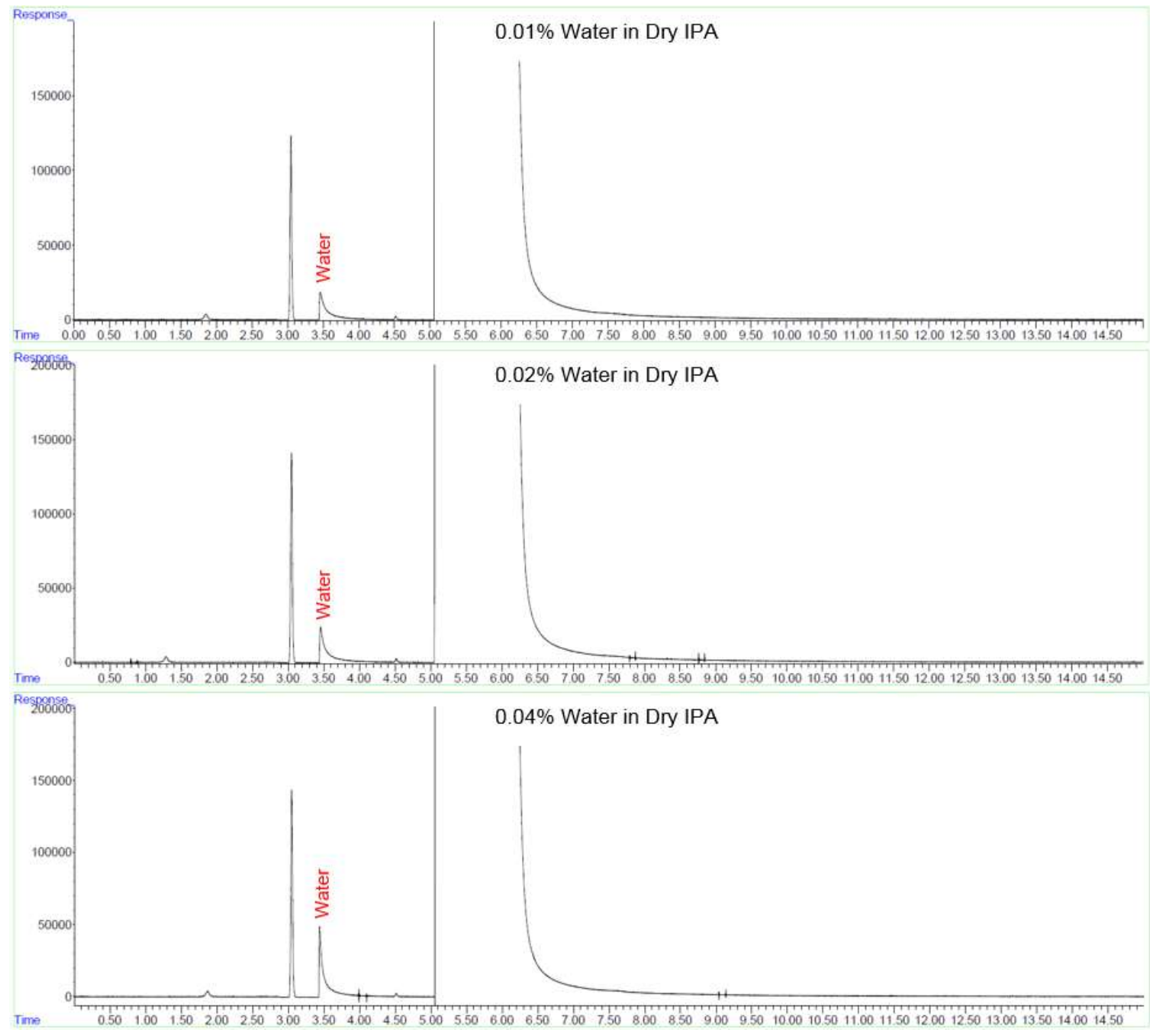

Figure C.1 GC/TCD chromatographs for calibration standards with water contents of $0.01,0.02$, and $0.04 \%$ in dry IPA. 


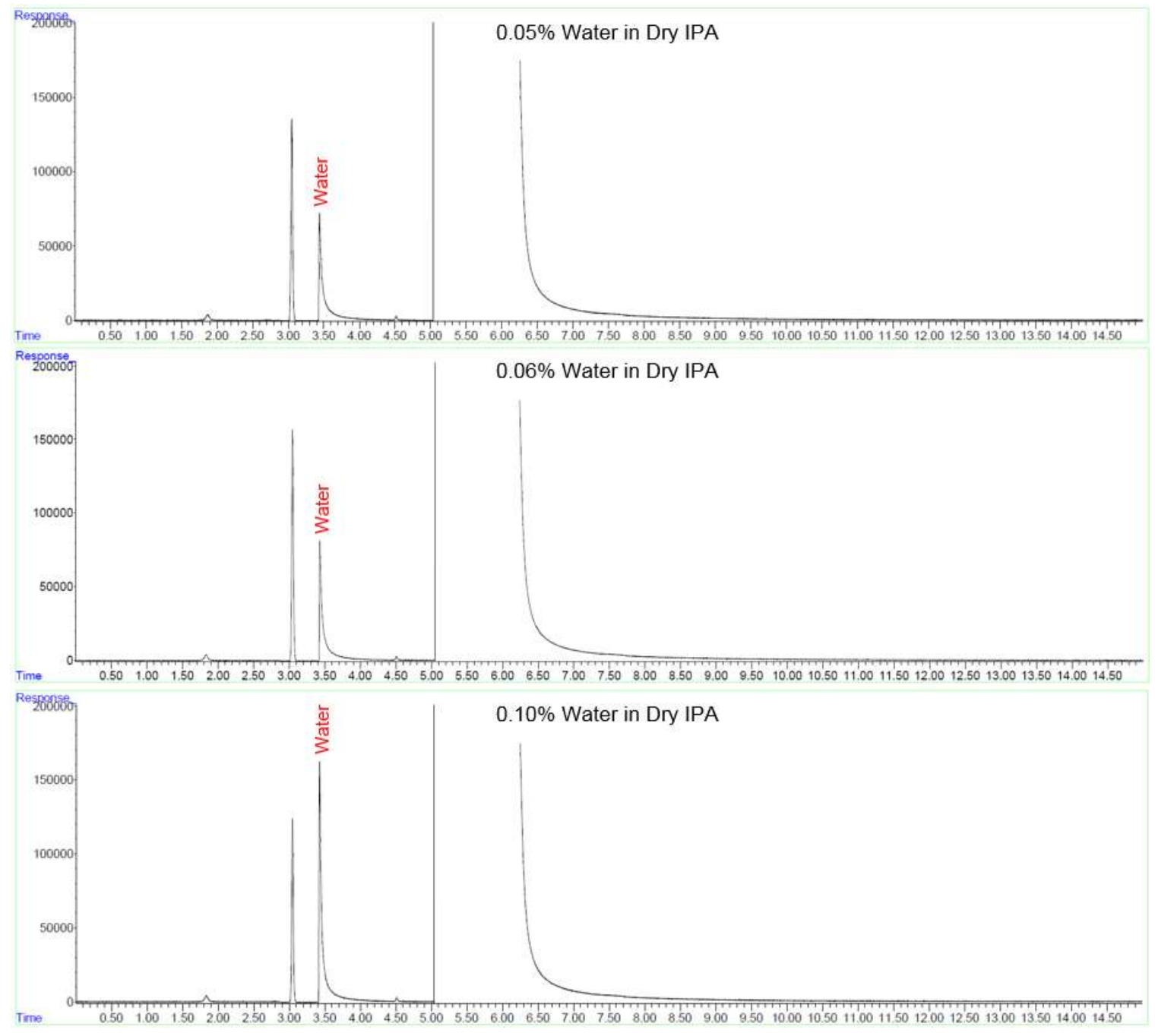

Figure C.2 GC/TCD chromatographs for calibration standards with water contents of $0.05,0.06$, and $0.10 \%$ in dry IPA. 


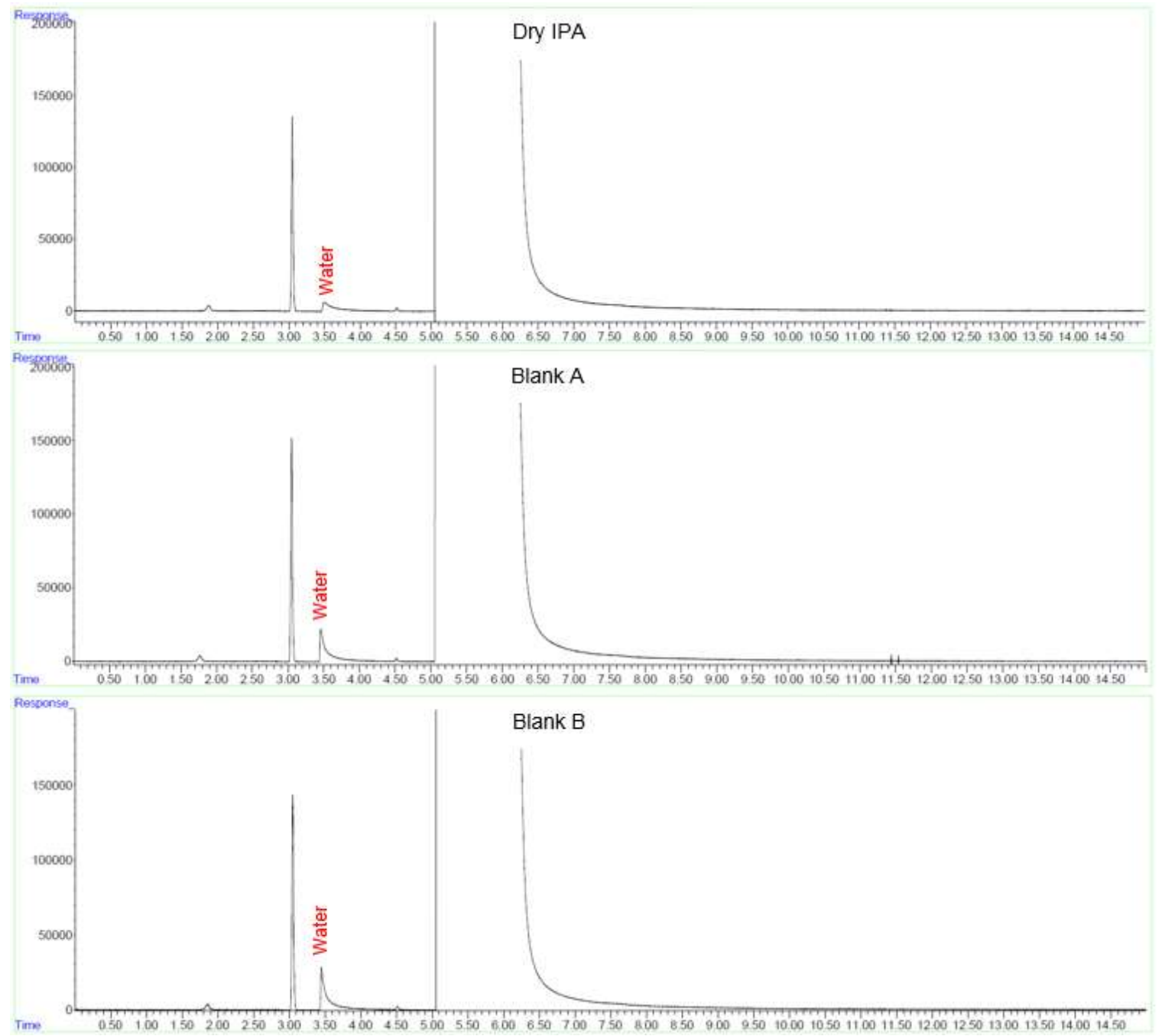

Figure C.3 GC/TCD chromatographs for dry IPA and the two blank samples. 


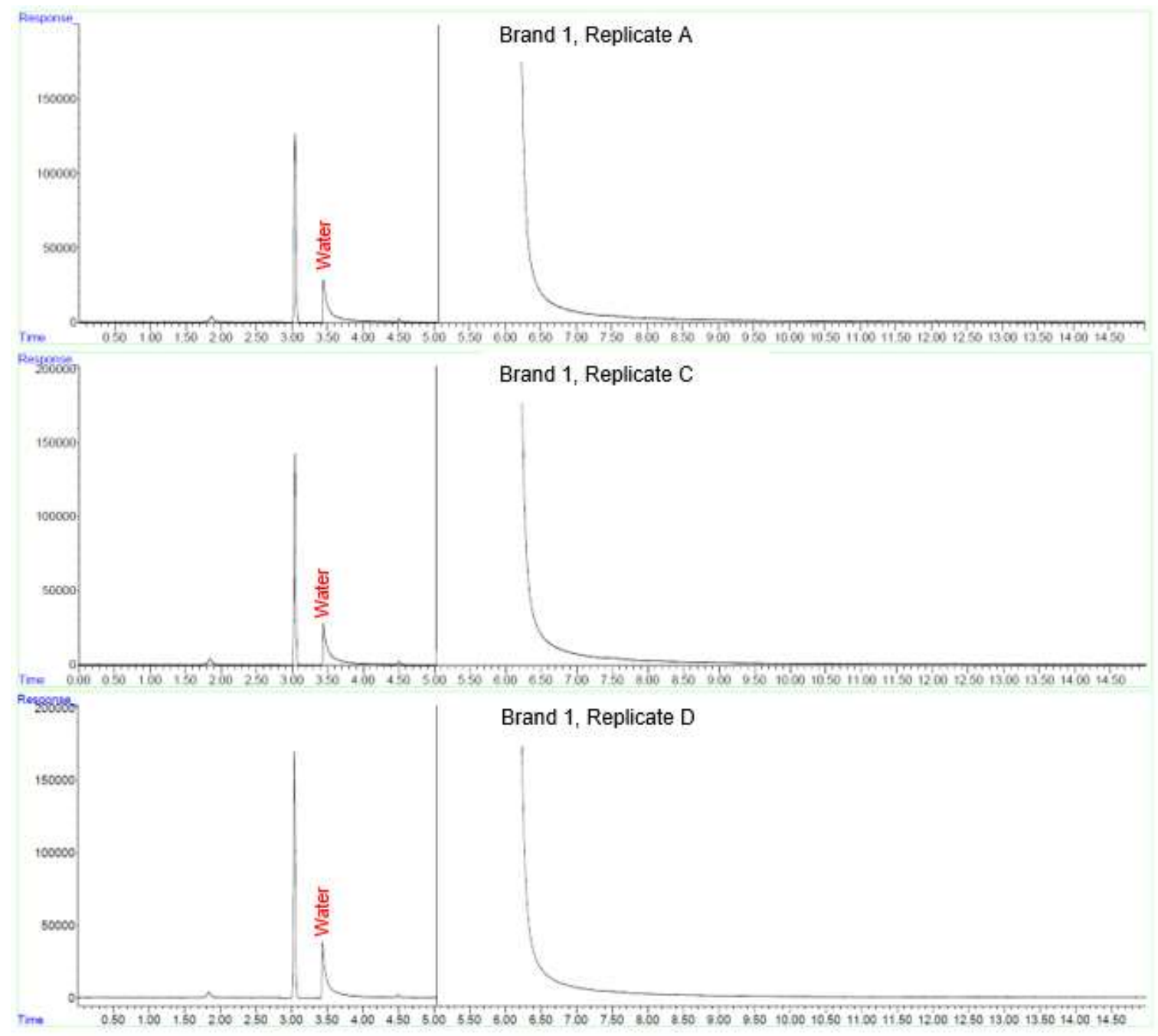

Figure C.4 GC/TCD chromatographs of tobacco smoke PM extracts for brand 1. 


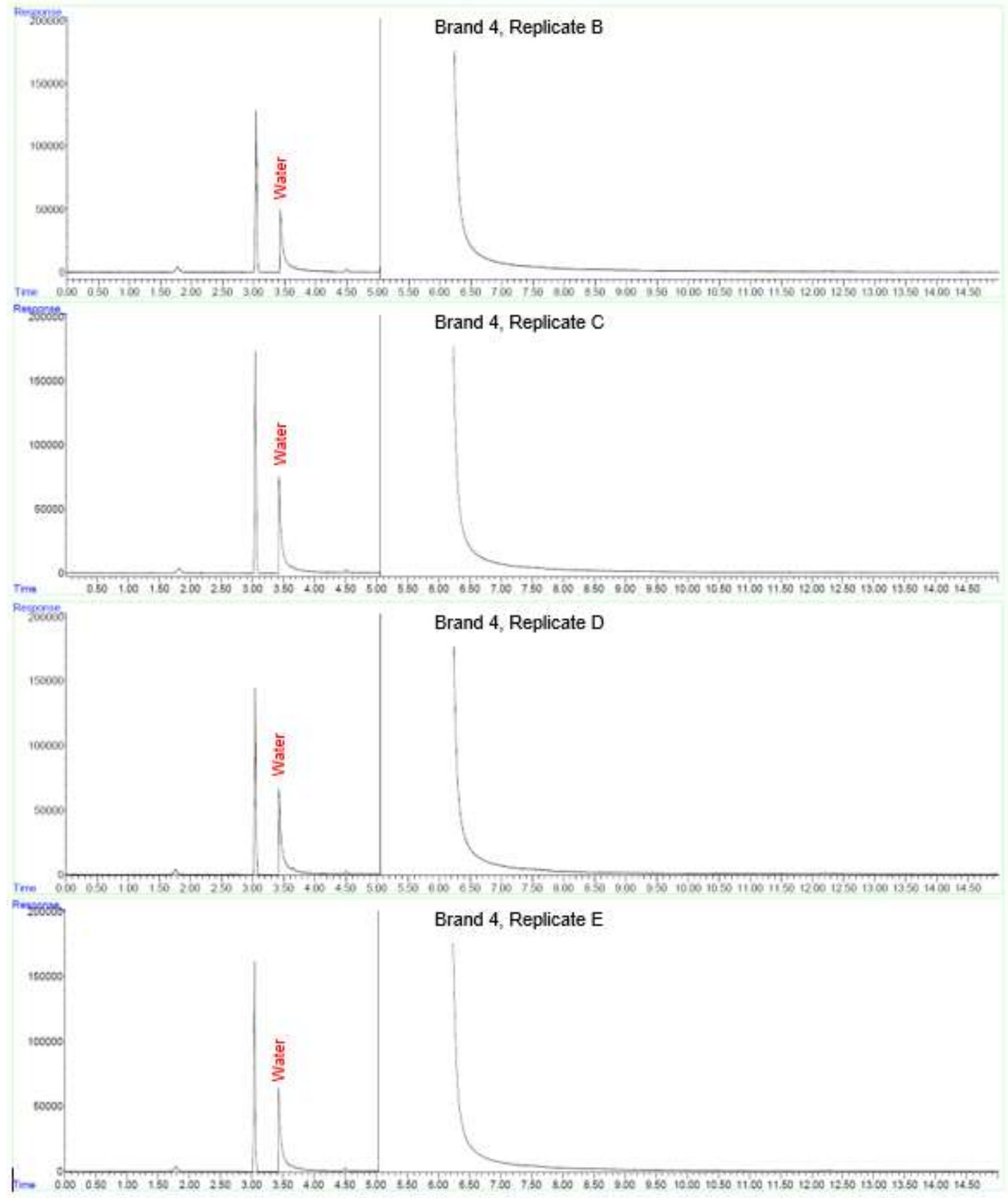

Figure C.5 GC/TCD chromatographs of tobacco smoke PM extracts for brand 4. 